\title{
Ensayos Sobre la Teoría de la Evasión y Elusión de Impuestos Indirectos
}

\author{
por \\ Roberto J. Arias \\ Licenciado en Economía. Facultad de Ciencias Económicas \\ Universidad Nacional de Córdoba (1992) \\ Master of Public Administration. School of International and Public Affairs. \\ Columbia University (2000) \\ Remitido al Departamento de Economía como complimiento parcial de los \\ requisitos para el grado de \\ Doctor en Economía \\ en la \\ UNIVERISDAD NACIONAL DE LA PLATA \\ Agosto 2010 \\ (C) El autor le otorga a la Universidad Nacional de La Plata permiso para \\ reproducir y distribuir copias de este documento, en su totalidad o en parte.
}

Firma del Autor . ........................... Departamento de Economía.

Firma del Director de Tesis. . . . . . . . . . . . . . . . . . . Diego Fernandez Felices

Director 


\section{Índice general}

1. La Economía de la Evasión y la Elusión de Impuestos Indirectos 12

1.1. Introducción . . . . . . . . . . . . . . . . . . . . 12

1.2. Teoría económica de la evasión fiscal . . . . . . . . . . . . . . . 18

1.2.1. Antecedentes . . . . . . . . . . . . . . . . 20

1.2.2. Modelo básico . . . . . . . . . . . . . . 25

1.2.3. Extensiones al modelo básico . . . . . . . . . . . . . 28

1.2.4. Modelos de interacción estratégica . . . . . . . . . . . . . . 48

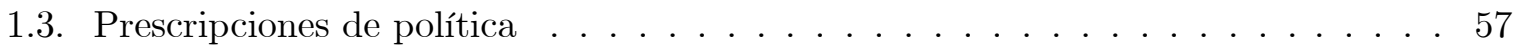

1.3.1. Objetivos de la administración tributaria . . . . . . . . . . 57

1.3.2. Optimización en el modelo básico . . . . . . . . . . . . . . 59

1.3.3. Reglas de auditoría . . . . . . . . . . . . . . . . . . 64

1.3.4. Integridad y calidad de la ley impositiva . . . . . . . . . . . . . 65

1.3.5. Moral tributaria . . . . . . . . . . . . . 66

1.3.6. Moratorias . . . . . . . . . . . . . . 6 6

1.4. Teoría económica de la elusión fiscal . . . . . . . . . . . . . . . . . 69

1.5. Comentarios finales . . . . . . . . . . . . . . . . 73

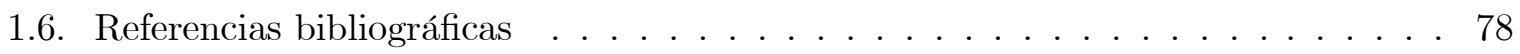

2. Efectos del Impuesto Específico y del Ad Valorem con Evasión 91

2.1. Introducción . . . . . . . . . . . . . . . . . . . . 91

2.2. Antecedentes . . . . . . . . . . . . . . . . . . . 93

2.3. Competencia perfecta . . . . . . . . . . . . . . . 95 
2.3.1. Estática comparativa . . . . . . . . . . . . . . . 98

2.3.2. Actitud frente al riesgo . . . . . . . . . . . . . . . . . 99

2.3.3. Comparación entre funciones impositivas . . . . . . . . . . . . . 103

2.4. Monopolio . . . . . . . . . . . . . . . . . . . 105

2.4.1. Estática comparativa . . . . . . . . . . . . . . . . 108

2.4.2. Comparación entre funciones impositivas . . . . . . . . . . . . . . . 112

2.4.3. Simulación numérica . . . . . . . . . . . . . . . . . . . . . . . 119

2.5. Conclusiones . . . . . . . . . . . . . . . . . . . . 122

2.6. Apéndice . . . . . . . . . . . . . . . . . . . . . . 124

2.6.1. Estática comparativa bajo competencia . . . . . . . . . . . . . . 124

2.6.2. Solución al modelo de aversión al riesgo . . . . . . . . . . . . . . . . . 128

2.6.3. Monopolio . . . . . . . . . . . . . . . . . . . . 133

2.6.4. Gráficos de la simulación numérica . . . . . . . . . . . . . . . 135

2.7. Referencias bibliográficas . . . . . . . . . . . . . . . 140

3. Evasión Fiscal en un Monopolio en Cadena 143

3.1. Introducción . . . . . . . . . . . . . . . . . . . . . 143

3.2. Antecedentes . . . . . . . . . . . . . . . . . . . 145

3.2.1. Coordinación vertical . . . . . . . . . . . . . . 146

3.2.2. Coordinación horizontal . . . . . . . . . . . . . . . . 151

3.2.3. Comentario final sobre los antecedentes . . . . . . . . . . . . . . . . 152

3.3. Modelo con separabilidad . . . . . . . . . . . . . . . 153

3.3.1. Monopolio doble y honestidad . . . . . . . . . . . . . . . . 153

3.3.2. Monopolio doble y evasión . . . . . . . . . . . . . . . 157

3.3.3. Evasión versus honestidad . . . . . . . . . . . . . . . . . . 159

3.3.4. Tarifas en dos partes . . . . . . . . . . . . . . . 161

3.4. Modelo sin separabilidad . . . . . . . . . . . . . . . . . . 163

3.5. Simulación numérica . . . . . . . . . . . . . . . . . 167

3.6. Conclusiones . . . . . . . . . . . . . . . . . . . . 174

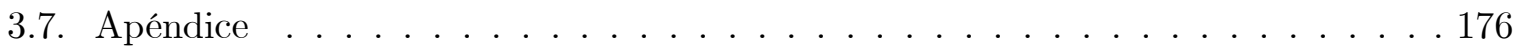

3.7.1. Monopolio y competencia en la etapa final . . . . . . . . . . . . 176 


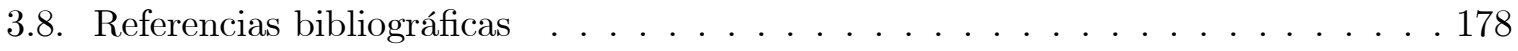

\section{Elusión de Impuestos Indirectos. El Caso del Impuesto sobre los Ingresos $\begin{array}{ll}\text { Brutos } & 181\end{array}$}

4.1. Introducción . . . . . . . . . . . . . . . . . . . . . . . . . 181

4.2. Antecedentes . . . . . . . . . . . . . . . . . . . . 183

4.3. Descripción del Impuesto sobre los Ingresos Brutos ～. . . . . . . . . . . . . . 184

4.4. Modelo básico de elusión . . . . . . . . . . . . . . . . . . . . 188

4.5. Elusión fiscal del IIBB . . . . . . . . . . . . . . . . . . . . . . . 189

4.5.1. Transferencia de base imponible a actividades menos gravadas . . . . . 189

4.5.2. Disminución de base imponible por reducción de etapas . . . . . . . . . 208

4.5.3. Transferencia de base imponible a contribuyentes menos gravados . . . . . 216

4.5.4. Transferencia de base imponible a regiones con menores tasas . . . . . . . 217

4.5.5. Comentario final sobre las posibilidades de elusión . . . . . . . . . . 220

4.5.6. Concurrencia de Base Imponible . . . . . . . . . . . . . . . . . . 221

4.6. Comentarios finales . . . . . . . . . . . . . . . . . . 223

4.7. Apéndice A. Breve historia del Impuesto sobre los Ingresos Brutos . . . . . . . 226

4.7.1. Introducción $\ldots \ldots \ldots \ldots \ldots \ldots$

4.7.2. La colonia . . . . . . . . . . . . . . . . . . . . . 227

4.7.3. Revolución y los gobiernos de Rodriguez y de Rosas . . . . . . . . . . . 230

4.7.4. Organización nacional y creación del Estado de Buenos Aires . . . . . . . 234

4.7.5. Reformas fiscales como consecuencia de crisis económicas: 1890 y 1935 . 236

4.7.6. El Impuesto a las Actividades Lucrativas . . . . . . . . . . . . . . . 238

4.7.7. El Impuesto sobre los Ingresos Brutos . . . . . . . . . . . . . . . . . 241

4.7.8. Comentarios finales . . . . . . . . . . . . . . . . . . . . 242

4.8. Apéndice B. Ejemplos sobre el beneficio de la elusión . . . . . . . . . . . . . . . 243

4.9. Referencias bibliográficas . . . . . . . . . . . . . . . . . 249 


\section{Lista de Tablas}

Tabla 1.1. Modelos de Evasión Fiscal. Supuestos

Tabla 1.2. Modelos de Evasión Fiscal. Resultados

Tabla 1.3. Revisión Literatura Evasión Fiscal de Empresas

Tabla 2.1. Estática Comparativa Impuesto Específico y Ad Valorem en Competencia

Tabla 2.2. Estática Comparativa Impuesto Específico y Ad Valorem en Monopolio (I)

Tabla 2.3. Estática Comparativa Impuesto Específico y Ad Valorem en Monopolio (II)

Tabla 2.4. Simulación Numérica. Parámetros

Tabla 2.5. Simulación Numérica. Valores de Equilibrio

Tabla 3.1. Comparación entre Proposiciones 1 y 3

Tabla 3.2. Simulación Numérica. Parámetros

Tabla 4.1. Ventas en Bloque. Parámetros (Ejemplo 1)

Tabla 4.2. Ventas en Bloque. Valores de Equilibrio (Ejemplo 1)

Tabla 4.3. Ventas en Bloque. Parámetros (Ejemplo 2)

Tabla 4.4. Ventas en Bloque. Valores de Equilibrio (Ejemplo 2)

Tabla 4.5. Ventas en Bloque. Parámetros (Ejemplo 3)

Tabla 4.6. Ventas en Bloque. Valores de Equilibrio (Ejemplo 3)

Tabla 4.7. Política Impositiva Castiga VS (Ejemplo 4)

Tabla 4.8. Política Impositiva y Ordenamiento de las Preferencias (Ejemplo 4)

Tabla 4.9. Política Impositiva Castiga VB (Ejemplo 5)

Tabla 4.10. Política Impositiva y Ordenamiento de las Preferencias (Ejemplo 5)

Tabla 4.1a. Fijación de Precios Canasta. Distribuciónd de Juegos Interactivos

Tabla 4.2a. Fijación de Precios Canasta. Club Social y Deportivo 
Tabla 4.3a. Ventas en Comisión. Supermercado Mayorista

Tabla 4.4a. Transferencia de Ingresos. Clínica Privada

Tabla 4.5a. Mudanza Centro de Costos. Hipermercado Nacional

Tabla 4.6a. Mudanza Centro de Costos. Profesional Independiente (CPN) 


\section{Lista de Gráficos}

Gráfico 2.1. Recaudación Teórica y Esperada, para AV y PU

Gráfico 2.2. Diferencia en Recaudación Esperada

Gráfico 2.3. Diferencia en la Proporción Ocultada

Gráfico 2.4. Recaudación Teórica y Esperada y A

Gráfico 2.5. Recaudación Teórica y Esperada y Phi

Gráfico 2.6. Recaudación Teórica y Esperada y Gamma

Gráfico 2.7. Recaudación Teórica y Esperada y E

Gráfico 2.8. Recaudación Teórica y Esperada y B

Gráfico 2.9. Recaudación Teórica y Esperada y c

Gráfico 2.10. Diferencia en Recaudación Esperada y A

Gráfico 2.11. Diferencia en Recaudación Esperada y Phi

Gráfico 2.12. Diferencia en Recaudación Esperada y Gamma

Gráfico 2.13. Diferencia en Recaudación Esperada y E

Gráfico 2.14. Diferencia en Recaudación Esperada y B

Gráfico 2.16. Diferencia en Recaudación Esperada y c

Gráfico 3.1. Proposición 1

Gráfico 3.2. Proposición 2 (cantidades)

Gráfico 3.3. Proposición 2 (beneficio)

Gráfico 3.4. Proposición 4 (I)

Gráfico 3.5. Proposición 4 (II)

Gráfico 3.6. Proposición 5

Gráfico 3.7. Proposición 6 
Gráfico 3.8. Proposición 7

Gráfico 3.9. Proposición 4B. Sin Separabilidad

Gráfico 4.1. Venta Separada (Ejemplo 1)

Gráfico 4.2. Venta en Bloque (Ejemplo 1)

Gráfico 4.3. Venta Separada (Ejemplo 2)

Gráfico 4.4. Venta en Bloque (Ejemplo 2)

Gráfico 4.5. Venta en Bloque Mixta (Ejemplo 2)

Gráfico 4.6. Venta Separada (Ejemplo 3)

Gráfico 4.7. Venta en Bloque (Ejemplo 3)

Gráfico 4.8. Venta en Bloque Mixta (Ejemplo 3)

Gráfico 4.9. Venta en Comisión

Gráfico 4.10. Monopolio en Cadena

Gráfico 4.11. Integración Vertical

Gráfico 4.12. Monopolio en Cadena

Gráfico 4.13. Monopolio Integrado 


\section{Resumen}

La evasión y la elusión de impuestos pueden considerarse comportamientos llevados a cabo por los contribuyentes que tienen motivaciones similares. Sin embargo, las teorías económicas que abordan tales comportamientos han tomado carriles disímiles. La evasión fiscal se considera una actividad oculta que las administraciones tributarias combaten mediante auditorias y penalidades económicas, las cuales no abarcan a la totalidad de los contribuyentes. Por lo tanto, la evaluación del riesgo es un componente central en la determinación de los costos y beneficios de tal actividad. Por el contrario, la elusión fiscal es una actividad abierta donde la administración tributaria no tiene intervención. El análisis económico en este caso considera únicamente las oportunidades que presenta la política tributaria para tal actividad, entendiendo por política tributaria a la definición del hecho imponible y la base imponible, la estructura de tasas impositivas y las exenciones y deducciones permitidas.

Aquí se presentan tres ensayos que incluyen contribuciones originales al análisis teórico de la evasión y la elusión fiscal de impuestos indirectos. Se inicia la tesis con una revisión de la literatura sobre la teoría económica de la evasión y la elusión donde se identifican temas no tratados hasta ahora que se consideran de interés para el investigador (Capítulo 1).

El Capítulo 2 presenta un análisis de la incidencia de impuestos especificos y ad valorem que pueden ser evadidos en entornos competitivos y bajo monopolio. Se demuestra que bajo competencia los efectos de ambos impuestos son similares: la decisión de evasión es separable de la decisión de producción, el nivel de evasión óptimo es el mismo, los resultados de estática comparativa son similares y las consecuencias en términos de bienestar son idénticas. Bajo monopolio, la separabilidad se mantiene en el modelo presentado sólo para el impuesto específico y los resultados de estática comparativa son esencialmente similares para ambos impuestos, salvo aquellos afectados por la ausencia de separabilidad presente para el impuesto ad valorem. Respecto a la superioridad en términos de bienestar de un impuesto ad valorem aplicado a las ventas de un monopolista, se demuestra que la misma se mantiene cuando existe la posibilidad de evasión pero bajo condiciones especiales. El impuesto ad valorem domina al específico en términos de recaudación esperada y de bienestar, en la medida en que exista una relación positiva entre tasas impositivas y recaudación esperada. 
En el Capítulo 3 se analiza la evasión fiscal dentro de una estructura vertical. En particular, se analiza el efecto de la posibilidad de evasión de un impuesto específico que grava la venta final de un monopolio en cadena, respecto al beneficio de toda la cadena y en la distribución de tal beneficio entre productor y minorista. Se demuestra que si la separabilidad está presente, la ganancia para toda la cadena proveniente de la integración es la misma con o sin evasión, aunque la ganancia para el productor (y por lo tanto el incentivo a integrarse) es mayor cuando existe la posibilidad de evasión. Bajo el supuesto de información perfecta, una tarifa en dos partes resuelve la externalidad generada por el monopolio en cadena y le permite al productor apropiarse del beneficio que surge de la actividad de evasión de impuestos. Si no hay separabilidad, la ganancia tanto para toda la cadena y para el productor pueden ser mayor o menor cuando hay evasión respecto al caso de honestidad.

Como la elusión se relaciona con las características específicas que tiene una determinada legislación tributaria, en el análisis que se presenta en el Capítulo 4 respecto a la elusión fiscal de impuestos indirectos se toma como referencia el Impuesto sobre los Ingresos Brutos (IIBB) de la Provincia de Buenos Aires. Se argumenta en tal capítulo que un elemento central en las posibilidades de elusión del IIBB es la diferencia de alícuotas entre sectores económicos, regiones y contribuyentes. Cuando existen posibilidades de transferencia de ingresos entre sectores económicos, regiones o contribuyentes, tales diferencias de alícuotas generan incentivos a eludir el impuesto, lo que puede darse a través de diferentes mecanismos identificados. Unificar las alícuotas a través de los sectores económicos, si bien reduce el incentivo de transferencia de ingresos, agrava el problema vinculado con la imposición en varias etapas y las posibilidades de elusión que se generan eliminando etapas de producción y comercialización. La diferencia de alícuotas entre regiones también es una fuente de elusión, pero es un problema más complejo de resolver, ya que implica coordinación interjurisdiccional. Un elemento a considerar respecto a la diferencia de alícuotas entre contribuyentes es la significativa concurrencia de bases imponibles con el nivel nacional. Las exenciones subjetivas son similares a las de impuestos nacionales (Ganancias e IVA) y, por lo tanto, será limitado el alcance que puedan tener las medidas tomadas por un fisco subnacional. 


\section{Capítulo 1}

\section{La Economía de la Evasión y la Elusión de Impuestos Indirectos}

\subsection{Introducción}

Los impuestos forman parte de la vida económica de todas las sociedades modernas. No es de sorprender, entonces, la atención que han obtenido en la teoría económica. Los análisis abarcan desde cuestiones generales, como el impacto de la imposición en la eficiencia económica y el bienestar general, como otros aspectos mucho más específicos que hacen a los diversos efectos de impuestos con características diferentes. Dentro de este amplio campo de estudio, en este capítulo se revisa la literatura sobre la teoría económica de la evasión y la elusión fiscal de impuestos indirectos. En los tres capítulos siguientes, se analizan aspectos puntuales respecto a los cuales se realizan contribuciones originales a la teoría económica.

Antes de avanzar, es necesario determinar el alcance de esta revisión, definiendo impuesto indirecto, evasión fiscal y elusión fiscal. La definición de impuesto indirecto, no ofrece duda. La principal clasificación, de todas las posibles, respecto a los diversos tipos de impuestos existentes es la siguiente:

"Los impuestos pueden dividirse en dos grandes clases: los impuestos directos sobre las personas físicas y sobre las sociedades y los impuestos indirectos sobre una amplia variedad de bienes y servicios" [Stiglitz (2000), p. 477, cursiva en el original]. 
Es claro entonces, que la definición de impuesto indirecto no hace referencia al sujeto del impuesto, sino al objeto. Las empresas pagan impuestos directos (como el impuesto a las ganancias) y también impuestos indirectos (como el impuesto a las ventas, el impuesto al valor agregado o el impuesto sobre los ingresos brutos). En este documento se focaliza el análisis en impuestos indirectos, utilizando la definición de Stiglitz (2000).

Por otro lado, las definiciones de evasión fiscal y elusión fiscal requieren mayor detenimiento. Una de las principales características de los impuestos es que modifican el comportamiento de los agentes económicos, respecto a una situación en la cual los mismos no existieran, lo cual tiene consecuencias de todo tipo. ${ }^{1}$ De acuerdo al tipo de comportamiento que promueva o restringa, serán los efectos económicos de determinado impuesto. La implicancia más obvia de un impuesto indirecto es que modificará el precio relativo del bien que grava y por lo tanto afectará el nivel de producción y consumo del mismo. Este efecto se denomina en la literatura especializada "respuesta de sustitución reales": expresan, en términos microeconómicos, tanto el efecto sustitución como el efecto ingreso provocado por la variación del precio relativo de un bien (o efecto precio) generado por la presencia de un impuesto indirecto. ${ }^{2}$

Ahora bien, los sistemas impositivos (incluyendo en este concepto la estructura de tasas, los mecanismos de control y las penalidades vigentes por falta de cumplimiento) otorgan a los contribuyentes diversas posibilidades para reducir su carga tributaria, adicionales a simplemente dejar de consumir el bien que esté gravado (la respuesta de sustitución real). Los contribuyentes pueden decidir no cumplir con la ley, lo cual en este contexto se denomina evasión fiscal. Por los problemas de información que existen en la imposición, esta alternativa puede incluso no ser detectada por el Estado, aunque si lo fuese se puede presumir que existirá un castigo. Deste este punto de vista, la evasión es claramente una conducta ilegal y de hecho los primeros análisis económicos de la misma se realizaron utilizando el instrumental del análisis económico del crimen. ${ }^{3}$ Sin embargo, hay otro conjunto de comportamientos, denominados elusión fiscal, que no serán vistos por parte del contribuyente como incumplimiento de la ley pero que implican

\footnotetext{
${ }^{1}$ Kaplow (2006) presenta una revisión reciente de la teoría de la imposición, donde estos efectos se estudian en detalle.

${ }^{2}$ Slemrod y Yitzhaki (2000), p.4.

${ }^{3}$ El trabajo seminal de Allingnam and Sandmo (1972) sobre teoría económica de la evasión impositiva aplicó instrumental reciente, en esa época, sobre decisiones bajo incertidumbre y sobre la economía del crimen a la evasión fiscal de un impuesto directo pagado por individuos.
} 
claramente una reducción de la carga impositiva legal. Una definición precisa de elusión en uso hoy por la academa es: "reducción de la obligaciones impositivas mediante manipulaciones permitidas por la ley". ${ }^{4}$ En definitiva, esta visión, atribuida a un juez norteamericano de principios del siglo XX, Oliver Wendell Holmes, divide la respuesta a la imposición por parte de los contribuyentes en aquella que utiliza las herramientas legales vigentes (elusión) de aquella que queda del otro lado de la línea trazada por el "plexo normativo" (evasión). ${ }^{5}$

Sin embargo, hay varias cuestiones que deben ser señaladas, respecto a esta definición de evasión y elusión. En primer lugar, es claro que la línea es difusa, como muchas lineas que surjen de una ley. El derecho tributario es uno de los más complejos y los intereses en juego dificultan que se establezca una jurisprudencia clara, incluso en temas relativamente simples. Por lo tanto, hay que considerar que la definición adoptada implica una simplificación de la realidad que en infinidad de casos concretos no es aplicable en absoluto. En segundo lugar, algunas administraciones tributarias modernas (Canada y Australia, por ejemplo) han adoptado leyes anti-elusión que, además de hacer aún más difusa la línea de lo legal, intentan desde la regulación eliminar las conductas estudiadas por los modelos de elusión fiscal. Otras administraciones tributarias modernas rechazan este tipo de medidas, como ser Estados Unidaos de América, aunque tienen esquemas de previa disclousure de las operaciones más controvertidas que también funcionan como esquemas anti-elusión. Hasta ahora esta regulación anti-elusión ataca las operaciones de elusión fiscal más bien extremas, pero no las más comunes y arraigadas. ${ }^{6}$

Por otro lado, en la literatura contable se diferencia entre elusión fiscal (tax avoidance) y planificación fiscal (tax planning). El objetivo de la elusión fiscal es minimizar el impuesto a pagar dentro del marco legal vigente, mientras que la planificación fiscal tiene por objetivo minimizar el costo del cumplimiento tributario. La diferencia radica en que algunas actividades que implican elusión pueden tener costos indirectos para la empresa, que deben considerarse.

\footnotetext{
${ }^{4}$ Kaplow (2006), p. 71, traducción propia.

${ }^{5}$ Más allá del conjunto de consideraciones que se realizan más adelante, los principales estudiosos del tema adoptan esta definición [Cowell (1990, 1995), Alm (1999), Franzoni (1999), Slemrod y Yitzhaki (2000), Sandmo (2005) y Kaplow (2006)]. Una definición alternativa pasa por discriminar entre consecuencias deseadas o no por parte del legislador, aunque discutir intenciones puede incluso ser mas complejo que lo que puede implicar traza una línea de acuerdo a un plexo normativo.

${ }^{6}$ La posición de los diversos países para los casos más extremos de elusión fiscal está en permanente revisión, ya que es una preocupación de política permanente [ver, por ejemplo, Finantial Times (18 de marzo 2004$)$, p.4. y The Economist (20 de marzo de 2004)].
} 
En definitiva, la planificación fiscal debe considerar: (1) las implicaciones impositivas de la transacción propuesta, para todas las partes y (2) el costo no impositivo de implementar las estrategias de planificación fiscal. Elusión y planificación fiscal serán similares si se incorpora dentro de la decisión del empresario el costo directo asociado a la elusión. El arbitraje fiscal (tax arbitrage) es un caso especial de elusión fiscal. La palabra arbitraje hace referencia a operaciones de compra venta de activos a fin de obtener una ganancia originada en diferentes precios entre mercados. El arbitraje fiscal se refiere a operaciones de compra venta de activos pero a fin de obtener una ganancia que surja de diferentes tasas o sistemas impositivos. Por este motivo, la literatura sobre arbitraje fiscal se refiere casi exclusivamente a la compra venta de activos financieros a fin de obtener beneficios impositivos. ${ }^{7}$

Otro problema adicional de la separación entre evasión y elusión basada en la legislación tributaria, es que aplicando en forma rigurosa el concepto de elusión, las respuestas de sustitución reales entran en tal definición, ya que son respuestas a la imposición tomadas dentro del marco legal vigente y que, si bien se realizan con el objetivo de maximización del bienestar, implican una menor carga tributaria. Sin embargo, cualquier análisis del sistema impositivo considerará las respuestas de sustitución reales como parte del modelo, aunque no necesariamente a la elusión. Por este motivo, Slemrod y Yitzhaki (2000) califican como elusión, exclusivamente, las conductas realizadas dentro del marco legal vigente, que logran disminuir la carga impositiva sin modificar la canasta de consumo, o sea que dejan fuera a las respuestas de sustitución reales.

Asimilando el mismo caso a un impuesto indirecto, lo que se puede afirmar es que la elusión fiscal son conductas llevadas a cabo por parte de las empresas dentro del marco legal vigente que logran reducir la carga impositiva sin modificar las decisiones de producción de bienes y servicios. En este trabajo se utilizará tal definición.

Tal cual lo plantea Cowell (1995, p. 17-18) lo relevante de la distinción entre elusión y evasión fiscal, sobretodo dentro de comportamientos fronterizos, pasa por considerar las conductas de los agentes en cada caso desde un punto de vista económico. Cuando hay evasión fiscal, los contribuyentes perciben que están tomando una decisión que tiene un beneficio inmediato (no pagan el impuesto) pero enfrentan un costo potencial (incierto) que puede ser inclusive mayor que el beneficio. Con la elusión fiscal, el contribuyente tiene la certeza que su comportamiento

\footnotetext{
${ }^{7}$ Ver, entre otros, Agell y Persons (1998) y Erickson, Goolsbee y Maydew (2003).
} 
es legal, y posiblemente el deseado por el legislador, y las consideraciones de costo y beneficio son dentro de un contexto de certidumbre. El planteo económico de la evasión y la elusión, por lo tanto, será sustancialmente diferentes. Como se verá más adelante, con este enfoque, no hay espacio para situaciones dudosas desde el punto de vista de la conducta de los agentes. La clasificación de una conducta en particular, sí podrá estar sujeta a intepretaciones, donde incluso jugará un papel las intenciones del legislador para considerar si una determinada maniobra está permitida o no por la ley. ${ }^{8}$

Ahora bien, si bien la economía de la evasión y de la elusión son diferentes, ya que el problema económico que enfrentan los actores son distintos, tienen un punto de partida y una consecuencia final similares. Ambas representan un comportamiento de los contribuyentes que tienen como objeto reducir su carga impostiva. Y ambas tienen como consecuencia final una menor recaudación tributaria que representa una diferencia entre las tasas legisladas y las tasas efectivas.

En la literatura económica sobre tributación, se reconoce que la diferencia entre los impuestos legislados y los efectivos puede ser significativa. Se entiende que los contribuyentes responden de diferentes maneras a los impuestos y que tales respuestas generan efectos que pueden implicar diferencias sustanciales entre el estado de situación imaginado por el legislador y el real. Un buen resumen de estas enseñanzas es la siguiente:

"Reconocer la variedad de respuestas conductuales a la imposición enriquece en forma importante el análisis normativo de los impuestos. Modifica las respuestas a temas de análisis tales como la incidencia, la progresividad óptima, la imposición óptima sobre los bienes y la combinación óptima de impuestos a los ingresos y a los bienes. Genera un conjunto totalmente nuevo de preguntas de políticas públicas, tales como el nivel apropiado de recursos aplicados a la administración y el control de cumplimiento, y cómo tales recursos deben ser aplicados". ${ }^{9}$

\footnotetext{
${ }^{8}$ Sandmo (2005) nota que desde el punto de vista moral la consideración de la elusión y la evasión puede ser dudosa ¿Es más cuestionable una persona pobre que tiene parte de sus ingresos en negro o una persona rica que contrata un abogado costoso para pagar menos impuestos en forma "legal"? Por otro lado, se ha encontrado que en la opinión pública la consideración de la evasión es negativa (moralmente reprochable), pero no en el caso de la elusión fiscal [Kirchler, Maciejovsky y Schneider (2003)].

${ }^{9}$ Slemrod y Yitzhaki (traducción propia, 2000).
} 
Dentro de las respuestas a la imposición se encuentran la evasión fiscal y la elusión. Ambas respuestas afectan los costos del cumplimiento, la incidencia del sistema impositivo (la distribución de la carga tributaria) y la recaudación fiscal. ${ }^{10}$

Si bien la evasión fiscal tiene puntos de contacto importantes con la elusión, esta última presenta características específicas que merecen un tratamiento detallado. ${ }^{11}$ La diferencia sustancial es que en presencia de elusión no hay riesgo: la auditoría que puede recaer sobre las declaraciones juradas no tiene efecto, ya que se supone que las decisiones tomadas son legales, mientras que la evaluación del riesgo en los modelos de evasión es un componente central. ${ }^{12}$ Otro aspecto relevante es que pueden existir contribuyentes que no quieran evadir por razones morales, pero no tengan problemas para eludir.

El juego de la elusión es sustancialmente distinto al de la evasión también desde el punto de vista del Estado, ya que las herramientas de política son muy diferentes: en el caso de elusión es la política tributaria y en el caso de la evasión la política de fiscalización.

En definitiva, tal cual afirma Slemrod y Yitzhaki (2000), la elusión y la evasión son parte del mismo problema económico: el gobierno intenta recaudar impuestos pero a la vez brinda oportunidades para que los contrribuyentes reduzcan su carga impositiva esperada. Tales oportunidades tienen un costo, en el caso de la elusión tal costo tiene certeza, pero en la evasión es un costo esperado. En ambos casos, el costo dependerá, al menos en parte, de las propias acciones del gobierno (del sistema impositivo y de las herramientas de control). El análisis económico dependerá entonces de la características que tengan las diversas partes de este problema, como ser el sistema impositivo, las funciones objetivos de los actores, las funciones de costos y las herramientas de política. La literatura económica sin embargo, ha tendido a analizar ambos

\footnotetext{
${ }^{10}$ En el caso de la elusión fiscal, el efecto en la recaudación no será necesariamente directo, ya que frecuentemente el impuesto que un contribuyente deja de pagar es transferido a otros. También puede suceder que la recaudación que un fisco deje de percibir, sea transferida a otro fisco.

${ }^{11}$ Cowell (1990) presenta el primer modelo que incluye ambos comportamientos y demuestra, para un impuesto directo y contribuyentes aversos al riesgo, que los contribuyentes de mayores ingresos serán más propensos a eludir el impuesto, mientras que los pobres evadirán y terminarán pagando la multa (si son detectados). Slemrod y Yitzhaki (2000, p. 16 y ss.) presentan un modelo de respuesta a la imposición donde los individuos puede aplicar distinto esfuerzo a la reducción del impuesto esperado, sea mediante elusión o evasión. Waud (1986), por otro lado, estudia la complementariedad versus sustitución de las respuestas, como puede darse si al fortalecer la fiscalización para reducir la evasión aumenta la elusión. Lee (2001) presenta un modelo de reducción de la carga tributaria mediante un autoseguro, el cual puede representar tanto evasión o como elusión.

${ }^{12}$ En el modelo de Slemrod (1998) el riesgo de la auditoría cuando hay evasión fiscal implica un costo que puede asimilarse al costo directo de la elusión, el cual es efectado por la política tributaria.
} 
problemas en forma separada. ${ }^{13}$

En este capitulo, se sigue el mismo camino y se organiza la revisión del siguiente modo. En la próxima sección se presenta la teoría económica de la evasión fiscal. En la sección tres, se presentan las consecuencias en términos de política pública de tal literatura. En la sección cuatro se analiza la literatura sobre teoría de la elusión fiscal. Por último, en la sección cinco se presentan comentarios generales y se vincula la revisión que se realiza en este capítulo con el contenido del resto de los capítulos.

\subsection{Teoría económica de la evasión fiscal}

La teoría vigente de la evasión fiscal aparece a principios de la década del 70' del siglo pasado, como una aplicación específica de la teoría económica del crimen desarrollada por Gary Becker a fines de los 60'. ${ }^{14} \mathrm{El}$ trabajo que se considera el origen de los desarrollos posteriores sobre evasión [Allingham y Sandmo (1972)] presenta un modelo en el cual la evasión es el resultado de la decisión tomada por el individuo maximizador de utilidad, decisión que dependerá de la estimación de los costos y beneficios esperados de evadir. Lo relevante es que pagar impuestos se analiza como un proceso de toma de decisiones bajo incertidumbre, lo que implica un ejercicio de evaluación de los riesgos involucrados. La incertidumbre está relacionada con los costos de evadir, ya que al momento de declarar los impuestos, el individuo no sabe si será auditado o no. Así, los costos son el impuesto evadido (el cual deberá ser pagado en el caso de ser detectado) más las penalidades, multiplicados por la probabilidad de auditoria, y el beneficio es el monto del impuesto evadido.

Las revisiones de la literatura muestran que éste ha sido un campo de investigación muy

\footnotetext{
${ }^{13}$ Los estudios empíricos de la evasión y de la elusión también han seguido caminos separados. La elusión es en principio realizada abiertamente y no en forma oculta como la evasión, por lo cual puede ser observada en forma directa. Por ejemplo, con el impuesto a las ganancias es posible comparar la tasa de ganancia según los balances versus el impuesto efectivo pagado, obteniendo una tasa efectiva cuya variación es consecuencia a las maniobras de elusión fiscal, ya que obviamente si fuese evasión no estarían registardas las operaciones en el balance. Para estudios que siguen este camino ver Plesko (2003), Mills, Newberry y Trautman (2002), Dyreng, Hanlon y Maydew (2007), entre otros.

${ }^{14}$ Becker (1968) analiza en términos económicos todo tipo de incumplimiento de una regulación la cual es controlada por el Estado. La principal característica de su análisis es que el individuo se embarca en una actividad ilegal en la medida en que el beneficio esperado de tal acción sea positivo. La aplicación del esquema a la evasión impositiva, además de estar mencionada como una posibilidad por el mismo Becker (1968, p. 170) se puede considerar incluso más razonable que a otras actividades ilegales debido a su naturaleza económica.
} 
enérgico en el cual el modelo básico se fue ampliado y perfeccionado en varias direcciones. ${ }^{15}$ De este modo, la literatura especializada hoy sobre la economía de la evasión impositiva es muy voluminosa. Tanto el modelo original, como la gran mayoría de las extensiones, estuvieron focalizados en impuestos directos a los ingresos. Por otro lado, los estudios empíricos vinculados con la misma temática fueron realizados, también en su inmensa mayoría, en países desarrollados.

Sin embargo, las estructuras tributarias de los países desarrollados son bastante diferentes a aquellas de los países en desarrollo. Son más importantes en los países en desarrollo los impuestos indirectos, tanto los impuestos específicos (especialmente a materias primas, como minerales y combustibles) y los impuestos al consumo, que son más fáciles de cobrar. Por el contrario, el impuesto a los ingresos es la principal fuente de recursos del Estado sólo en países industrializados. ${ }^{16}$ Este puede ser uno de los motivos por los cuales la teoría económica de la evasión, desarrollada en países industrializados, se ha focalizado en el impuesto a los ingresos.

Otro elemento que difiere significativamente entre los países en desarrollo y los desarrollados, es el alcance de la evasión. Mientras que las distintas estimaciones del grado de evasión en Estados Unidos y en países europeos, normalmente ubican las cifras entre el 10 y el $20 \%$, la evasión en América Latina puede llegar al 50 o 70 \%, especialmente en el impuestos a los ingresos, aunque también en impuestos indirectos, como el Impuesto al Valor Agregado (IVA). ${ }^{17}$ Con tan altos niveles de evasión, especialmente en los países en desarrollo, los estudios del sistema impositivo deben considerar la existencia de la evasión. Esto es así debido a que la evasión fiscal afecta: i) la equidad de los tributos, ya que es probable que contribuyentes de distinto nivel de ingresos evadan proporciones diversas, con lo cual las tasas efectivas puede ser mas regresivas o progresivas que las legisladas; ii) la eficiencia, la carga excedente generada por los tributos puede ser mayor al existir evasión fiscal y control de su cumplimiento, el cual es costoso; iii) la incidencia: las mediciones de quien soporta la carga tributaria deben considerar la evasión, al ser ésta muy diferente por tipo de contribuyente y también por tipo de impuesto, debido a que

\footnotetext{
${ }^{15}$ Algunas revisiones de la literatura son Cowell (1995), Myles (1995, capítulo 12), Andreoni, Erard y Feistein (1998), Alm (1999), Franzoni (1999), Slemrod y Yitzhaki (2000), Sandmo (2005) y Slemrod (2007).

${ }^{16}$ Tanzi y Zee (2000) y Shome (1999).

${ }^{17}$ La estimación oficial del IRS (Internal Revenue Service de los Estados Unidos) sobre la evasión del impuesto al ingreso en ese país la ubica en el 17\% [Slemrod y Yitzhaki (2000)], otras estimaciones ubicaban la evasión del mismo impuesto en el Reino Unido en el orden del 15\% [Myles (1995)]. En el caso del impuesto a las ventas (estatal), la evasión se estima en el $5 \%$ en Estados Unidos [Murray (1995)]. Para los países en desarrollo ver Fjeldstad y Semboja (2001) y Tanzi y Tsibouris (2000).
} 
algunos impuestos son mucho más fáciles de evadir que otros. Una preguntas usual al respecto es hasta que punto, ante la presencia de evasión impositiva, un incremento de la tasa impositiva implica mayor recaudación. Si bien la pregunta es simple, como se analiza en esta revisión su respuesta varía acorde a una importante cantidad de factores.

En esta sección se revisan los principales desarrollos teóricos vinculados a la evasión fiscal. Si bien esta es una revisión amplia, no focalizada exclusivamente en un determinado impuesto, se le prestará mayor atención a los estudios referidos a la evasión en impuestos indirectos. ${ }^{18}$

\subsubsection{Antecedentes}

Los estudios teóricos sobre la evasión realizados durante los primeros años posteriores al trabajo de Allingham y Sandmo (1972) estuvieron casi exclusivamente focalizados en impuestos directos (puntualmente el impueso a los ingresos pagados por personas). Recién en el año 1984 aparece el primer estudio sobre evasión de impuestos indrectos, en el cual Marelli (1984) presenta un modelo que permite analizar las principales herramientas de política impositiva dentro de un modelo de equilibrio parcial y evasión de un impuesto indirecto ad valorem. El modelo es similar al de Allingham y Sandmo (1972) al asumir contribuyentes con aversión al riesgo. La diferencia sustancial es, sin embargo, que ahora el ingreso no es exógeno sino que está determinado por el nivel de ventas de equilibrio de un monopolista maximizador de beneficios que enfrenta una demanda con pendiente negativa. Esta es la principal diferencia entre todos los modelos de evasión referidos a impuestos directos y a impuestos indirectos. ${ }^{19}$

Otras diferencias sustanciales entre evasión de personas y de empresas es que es de esperar que las compañías relativamente grandes se comporten como neutrales al riesgo, mientra que la aversión al riesgo es el supuesto usual respecto a evasión fiscal de individuos. Además cuando el contribuyente es una empresa aquellos que preparan y presentan las declaraciones de impuestos a la administración tributaria no serán los dueños, sino gerentes con incentivos no necesartiamente

\footnotetext{
${ }^{18}$ No se incluye en esta revisión la literatura sobre economía subterránea, que está muy relacionada con la evasión especialmente de impuestos al consumo [ver al respecto Loayza (1996) y Wigger (2002)].

${ }^{19}$ Hay también una importante bibliografía, iniciada por Andersen (1977), referida a evasión de impuestos directos en la cual el ingreso del individuo es endógeno, dependiendo de una decisión entre trabajo y ocio. Aún así, el modelo de un productor de bienes es sustancialmente diferente al de un trabajador que recibe un ingreso de acuerdo a la cantidad de horas trabajadas.
} 
alineados con los de los accionistas. ${ }^{20}$

El trabajo de Marrelli (1984) debe considerarse como la investigación que abrió paso a un nuevo campo de estudio, al construir la primer aplicación de la economía de la incertidumbre a la evasión fiscal de un impuesto indirecto. El objetivo del trabajo fue estudiar la decisión del empresario respecto a si evadir impuestos, y en que medida hacerlo, a través de la subdeclaración de las ventas, limitando el análisis a una firma monopolista, y utilizando dos impuestos: ad valorem y sobre los beneficios. En particular, un mercado con monopolio permite estudiar la interpendencia entre las decisiones de trasladar la carga impositiva (tax shifting) a través de mayores precios (y menores cantidades) y de evasión fiscal, para empresarios aversos al riesgo. La principal conclusión es que, si la probabilidad de auditoria es constante, la decisión de evasión impositiva no tiene influencia en la de trasladar la carga impositiva, en equilibrios interiores. Esto es, las condiciones de maximización de beneficios después de impuestos son similares con o sin la posibilidad de evasión: las decisiones de cantidades producidas y evasión fiscal son separables.

Marrelli (1984) examina también dos reglas alternativas bajo las cuales la probabilidad de auditoria es función de la base imponible declarada (función creciente y decreciente) y encuentra que en este caso las decisiones de producción y evasión ya no son separables: las cantidades de equilibrio dependerán de la tasa óptima de declaración, y viceversa. En el mismo documento, se compara un impuesto a las ventas (ad valorem) con el impuesto sobre los beneficios y se demuestra que un impuesto ad valorem presenta un nivel de cumplimiento mayor que uno sobre los beneficios de igual recaudación teórica.

Los mismos temas son analizados para competencia imperfecta (duopolio que fija cantidades) en Marrelli y Martina (1988). En este caso se utilizan tres impuestos (beneficios, ad valorem y específico) para estudiar el impacto de la colusión en la evasión fiscal. El modelo es construye para empresarios aversos al riesgo que deben decidir la cantidad a subdeclarar. Los resultados respecto a separabilidad son aún más fuertes que en el caso de monopolio, ya que se mantiene inclusive para soluciones de esquina. Sin embargo, el origen de este resultado no es debido a la configuración del mercado sino a la forma en la cual está modelada la evasión (en el modelo bajo monopolio a evasión es una cantidad, mientras que en el de oligopolio es un porcentaje del

\footnotetext{
${ }^{20}$ Ver Slemrod $(2004,2007)$.
} 
impuesto legislado). Si bien se modelan ambos impuestos indirectos, no se vincula el problema de la evasión fiscal con el del impacto diferencial en el bienestar de un impuesto ad valorem y uno específico. Los resultados que se buscan se refieren al impacto del grado de colusión fiscal en la evasión impositiva y a los efectos de los parámetros de política (probabilidad de auditoría, penalidad y tasa impositiva) sobre el grado de cumplimiento, para los tres impuestos analizados.

Wang y Conant (1988) presentan un modelo de aversión al riesgo donde el monopolista evade impuestos a las ganancias mediante la sobredeclaración de costos. Se muestra que la tasa del impuesto y la penalidad no afectan el nivel de producción de maximización de beneficios (se mantiene la separabilidad). Un incremento en la tasa impositiva o en la probabilidad de auditoría reduce el nivel de evasión de equilibrio. La diferencia con Marelli (1984) es en la forma de evadir impuestos que tiene el contribuyente, pero los supuestos y los resultados son los mismos.

Virmani (1989) incorpora la evasión de un impuesto ad valorem al modelo estándar de equilibrio parcial en un mercado competitivo, con libre entrada, empresarios neutrales frente al riesgo y curvas de costos medios en forma de U. El modelo tiene dos características importantes: i) asume que la probabilidad de auditoria se incrementa con el nivel de producción y ii) incluye una función de costos directos de la evasión fiscal, la cual depende de la proporción del nivel de producción ocultado. Estos dos nuevos componentes, hacen la estática comparativa diferente a la de los modelos previos: la evasión está asociada a ineficiencia en la producción (no se mantiene la separabilidad), la evasión puede incrementarse con aumentos en las multas y estará positiva y negativamente relacionada con la tasas impositivas (curva de Laffer). Algunos trabajos posteriores a Virmani (1989) incluyeron las funciones de costos directos de la evasión, y de hecho, con empresas neutrales al riesgo, tales funciones son necesarias para obtener soluciones interiores. $^{21}$ La separabilidad no se mantiene debido a que el nivel de producción afecta la probabilidad de detección, y por lo tanto el costo-beneficio de la evasión fiscal. Si bien las probabilidades de auditoria crecientes son parte de las estrategias de auditorias reales, al ser una estrategia dominada por otras, no son muy comunes en la literatura.

Cremer y Gahvari (1993) presenta un modelo de evasión fiscal de impuestos específicos,

\footnotetext{
${ }^{21}$ Algunos trabajos recientes, como Crocker y Slemrod (2004), Eichhorn (2005) y Bayer y Cowell (2009) presentan una función de costos de la evasión que depende de la base imponible ocultada (y no del nivel de producción ocultado). Sólo en el caso de un impuestos específico ambas funciones son idénticas.
} 
pero a fin de estudiar el tema más general de imposición óptima bajo evasión fiscal. El objetivo es incorporar la evasión fiscal en la formulación de Ramsey acerca de la estructura de alícuotas impositivas óptimas. La idea es que cualquier tasa impositiva efectiva puede ser alcanzada modificando las tasas legisladas, pero también utilizando otras herramientas de política (como la probabilidad de auditoria). Si bien el objetivo principal no es la evasión fiscal el tema es tratado detalladamente. Los mercados son competitivos y, siguiendo a Virmani (1989), incorpora una función de costos de la evasión. Debido a que tal función es proporcional a la producción y la probabilidad de auditoria es constante, la separabilidad se mantiene.

Yaniv (1995) presenta un modelo general de evasión fiscal aplicable a cualquier tipo de impuesto que pueda ser evadido por una empresa, sea subdeclarando su base imponible o sobredeclarando las deducciones permitidas. Es general en términos de que su configuración permite estudiar cualquier tipo de impuestos proporcional a cierta base imponible y cualquier forma de evasión, no solo la subdeclaración de ventas. Un incremento en la tasa de impuestos siempre disminuirá la evasión, aunque para ello es necesario asumir aversión al riesgo absoluta decreciente. Al igual que en Marrelli y Martina (1988), la decisión respecto a la actividad es independiente de los intentos de la firma de evadir impuestos, incluso para soluciones de esquina, debido a la forma en que sucede la evasión: el empresario debe decidir un monto (y no una proporción de su base imponible) por el cual no pagará impuestos.

Recientemente, se ha analizado la evasión por parte de empresas con mayor profundidad. Se ha incorporado la teoría de la agencia en la medida en que aquellos que preparan y presentan las declaraciones de impuestos a la administración tributaria no serán los dueños, sino gerentes con incentivos no necesariamente alineados con los de los accionistas. ${ }^{22}$ También se ha analizado la evasión fiscal cuando existe interacción estratégica entre las firmas y en modelos de oligopolio con diferenciación de productos. ${ }^{23}$

Para cerrar esta introducción, se presenta en la Tabla 1.1 un resumen de la forma en que están armados los modelos principales de evasión impositiva, mientras que en la Tabla 1.2 se presentan los resultados obtenidos.

\footnotetext{
${ }^{22}$ Chen y Chu (2005) y Crocker y Slemrod (2004).

${ }^{23}$ Goerke y Runkel (2006), Bayer y Cowell (2009) y Eichhorn (2006).
} 
Tabla 1.1. Modelos de evasión fiscal. Supuestos

\begin{tabular}{|c|c|c|c|c|c|c|}
\hline & Impuesto & $\begin{array}{c}\text { Probabilidad } \\
\text { de auditoria }\end{array}$ & Mercado & Riesgo & $\begin{array}{l}\text { Costos de } \\
\text { Evasión }\end{array}$ & Evasión \\
\hline $\begin{array}{l}\text { Marrelli } \\
\text { (1984) }\end{array}$ & $\begin{array}{l}\text { Ad Valorem } \\
\text { Beneficio }\end{array}$ & $\begin{array}{c}\text { Fija } \\
\text { Variable }\end{array}$ & Monopolio & Aversión & No & Proporcional \\
\hline $\begin{array}{l}\text { Wang y } \\
\text { Conant } \\
\text { (1988) }\end{array}$ & Beneficio & Fija & Monopolio & Aversión & No & Proporcional \\
\hline $\begin{array}{l}\text { Marelli y } \\
\text { Martina } \\
\text { (1988) }\end{array}$ & $\begin{array}{c}\text { Beneficio } \\
\text { Ad Valorem } \\
\text { Específico }\end{array}$ & $\begin{array}{c}\text { Fija } \\
\text { Variable }\end{array}$ & Duopolio & Aversión & No & Cantidad \\
\hline $\begin{array}{l}\text { Yaniv } \\
\text { (1988) }\end{array}$ & $\begin{array}{c}\text { Beneficio } \\
\text { Retenciones }\end{array}$ & Fija & Monopolio & Aversión & No & Proporcional \\
\hline $\begin{array}{l}\text { Virmani } \\
\text { (1989) }\end{array}$ & Ad Valorem & Variable & Competitivo & Neutral & $\mathrm{Si}$ & Proporcional \\
\hline $\begin{array}{l}\text { Cremer y } \\
\text { Ghavari } \\
(1993)\end{array}$ & Específico & Fija & Competitivo & Neutral & $\mathrm{Si}$ & Proporcional \\
\hline $\begin{array}{l}\text { Yaniv } \\
(1995)\end{array}$ & $\begin{array}{c}\text { Proporcional } \\
\text { (general) }\end{array}$ & Fija & Monopolio & Aversión & No & Cantidad \\
\hline
\end{tabular}


Tabla 1.2. Modelos de evasión fiscal. Resultados

\begin{tabular}{|c|c|c|c|c|c|c|}
\hline & \multirow[t]{2}{*}{ Separabilidad } & \multicolumn{5}{|c|}{ Estática Comparativa } \\
\hline & & $\begin{array}{c}\text { Evasión / } \\
\text { Tasa } \\
\text { Impositiva }\end{array}$ & $\begin{array}{c}\text { Evasión / } \\
\text { Probabilid } \\
\text { ad de } \\
\text { Auditoria } \\
\end{array}$ & $\begin{array}{l}\text { Evasión } \\
\text { / Multas }\end{array}$ & $\begin{array}{c}\text { Impuesto } \\
\text { Esperado / } \\
\text { Tasa } \\
\text { Impositiva } \\
\end{array}$ & $\begin{array}{l}\text { Precios } \\
\text { / Tasa } \\
\text { Impositiva }\end{array}$ \\
\hline $\begin{array}{l}\text { Marrelli } \\
\text { (1984) }\end{array}$ & $\begin{array}{l}\mathrm{Si}^{*}, \text { con } \\
\text { probabilidad } \\
\text { de auditoria } \\
\text { constante }\end{array}$ & $<0 ;>0$ & $<0$ & $<0$ & $\ldots$ & $\cdots$ \\
\hline $\begin{array}{l}\text { Wang y } \\
\text { Conant } \\
(1988)\end{array}$ & $\mathrm{Si}^{*}$ & $<0$ & $<0$ & $<0$ & $\ldots$ & $\ldots$ \\
\hline $\begin{array}{l}\text { Marelli and } \\
\text { Martina } \\
(1988)\end{array}$ & $\begin{array}{c}\mathrm{Si}^{*}, \text { con } \\
\text { probabilidad } \\
\text { de auditoria } \\
\text { constante }\end{array}$ & $\underset{0^{\#}}{<0 ;}=0 ;>$ & $<0$ & $<0$ & $\ldots$ & $\cdots$ \\
\hline $\begin{array}{l}\text { Virmani } \\
(1989)\end{array}$ & No & $>0$ & $\cdots$ & $<0 ;>0$ & $<0 ;>0$ & $\cdots$ \\
\hline $\begin{array}{l}\text { Cremer y } \\
\text { Ghavari } \\
(1993)\end{array}$ & $\mathrm{Si}$ & $<0$ & $<0$ & $\cdots$ & $<0 ;>0$ & $>0$ \\
\hline $\begin{array}{l}\text { Yaniv } \\
(1995)\end{array}$ & $\mathrm{Si}$ & $<0$ & $<0$ & $<0$ & $\cdots$ & $\cdots$ \\
\hline
\end{tabular}

* Sólo en solución interior.

${ }^{\dagger}$ El signo dependerá de la función de penalidades.

\# El signo dependerá del tipo de impuesto (menor específico, igual beneficio, mayor ad valorem).

En la siguiente sección, se analizarán los principales modelos, el modelo de Marelli (1984), el de Cremer y Gahvari (1993) y los modelos de interacción estratégica.

\subsubsection{Modelo básico}

\section{a. Modelos con aversión al riesgo}

El modelo de Marrelli (1984) se supone que los contribuyentes son monopolistas aversos al riesgo que tienen una función de utilidad cuyo único argumento es el ingreso disponible. El ingreso no es conocido por la administración tributaria, con lo cual tienen la opción de declarar una porción del ingreso real y así pagar menos impuestos. La administración tributaria auditará una proporción de las declaraciones ingresadas y si detecta que el ingreso real es mayor que 
el declarado aplica una multa sobre la diferencia. Se asume que las auditorías son totalmente efectivas, o sea que detectan toda la evasión existente. ${ }^{24}$

En este modelo, el nivel de actividad es independiente del nivel de evasión. Esta condición, se la ha denominado de "separabilidad" entre las decisiones de producción y evasión, y es un tema recurrente en la litaratura sobre evasión de impuestos indirectos. ${ }^{25}$

En la estática comparativa, aparece como un elemento central la forma de la función de utilidad y en varios casos no es posible obtener resultados claros. La tasa impositiva tiene un efecto ambiguo sobre la proporción de ventas ocultadas. Por otro lado, un aumento de la penalidad o de la probabilidad de auditoría reduce el nivel de evasión.

\section{b. Modelos con neutralidad frente al riesgo}

Un esquema diferente es el propuesto por Cremer y Gahvari (1993), que plantean un modelo que asume firmas con tecnologías de producción lineales (costos medios y marginales fijos) para producir un único output que se comercializa en un mercado competitivo y el cual está sujeto a una tasa impositiva $t$. La evasión toma la forma de ocultamiento de parte de las ventas por parte de las empresas a la administración tributaria, tal proporción es $(1-\alpha)$. Además, existe una probabilidad $\phi$ de que la evasión será descubierta y castigada a través de una auditoria fiscal. Las ventas evadidas y descubiertas durante una auditoria deberán pagar en concepto de penalidad, además del impuesto, una sobretasa $f$. El empresario es neutral frente al riesgo. Evadir impuestos tiene un costo administrativo directo (el ocultamiento de ventas implica una doble contabilidad o algo parecido). A tal fin, se utiliza una función de costo promedio de evasión por unidad de output $g$, la cual es una función de la evasión llevada a cabo, esto es: $g(1-\alpha){ }^{26}$

La firma tiene dos decisiones a tomar: la cantidad de output a producir y el nivel de ocul-

\footnotetext{
${ }^{24}$ Escobari (2006) propone un modelo con detección imperfecta de la evasión, basada en fiscalizadores corruptos. Encuentra que también aquí los efectos de la probabilidad de auditoría y las multas son similares, pero de menor magnitud, que cuando la detección es perfecta.

${ }^{25}$ Además de Marrelli (1984), se concentran en este tema Virmani (1989) y Lee (1998), entre otros. Sandmo (2005) afirma que una consecuencia central de la separabilidad es que la tasa impositiva óptima que se fija con determinado objetivo de política pública (por ejemplo, reducir el consumo de un determinado bien con externalidades negativas) no se ve modificada por la evasión. El problema de fijación de esa tasa óptima y el control de la evasión son problemas separables.

${ }^{26}$ Esta función fue introducida en la literatura de evasión impositiva por Virmani (1989).
} 
tamiento del mismo a fin de pagar menos impuestos. Algunos conceptos adicionales son los siguientes:

- La tasa de retorno $r$ por peso evadido de impuestos toma el valor $-f$ con probabilidad $\phi$ y el valor 1 con probabilidad $1-\phi$.

- La tasa esperada de retorno $r_{e}$ por peso evadido es entonces $r_{e}=1-\phi-\phi f$

- La tasa esperada del impuesto $t_{e}$ esta dada por la tasa nominal $t$ multiplicada por un factor de 1 menos la proporción de output evadido por $r_{e}$. Esto es: $t_{e}=t\left(1-\alpha r_{e}\right)$

A partir de este modelo, algunas conclusiones relevantes que encuentra Cremer y Gahvari son las siguientes:

i) Si la firma evade lo hará hasta el punto en el cual el costo marginal de ocultar se iguala con la reducción marginal en la tasa esperada de impuestos.

ii) La firma siempre evadirá algo en la medida en que $t_{e}$ sea menor a $t$, esto es que la tasa esperada de retorno sea positiva.

iii) Las decisiones acerca del nivel de output y del grado de evasión son "separables", son decisiones independientes.

iv) Los cambios en $\phi$ y en $t$ en un sector no afectan los valores del impuesto esperado $\left(t_{e}\right)$, de $p$ ni de $\alpha$ para firmas de otros sectores.

v) Un incremento en la tasa impositiva en un determinado sector $(t)$ tiene un impacto positivo en el nivel de evasión $(1-\alpha)$, indeterminado en el impuesto esperado $t_{e}$, positivo en el precio del bien $p$ e indeterminado en la recaudación del gobierno $R=\Sigma t_{e} Q$ (donde $Q$ es el output de toda la industria).

vi) Un incremento en la probabilidad de auditoria de un determinado sector $\phi$, tiene un impacto negativo en $\alpha$ (una mayor probabilidad de auditoria disminuye la evasión), positivo en $t_{e}$ (aumenta el impuesto pagado por las empresas de ese sector), positivo en $p$ (aumenta los precios en el sector) e indeterminado en la recaudación $R$.

Estos resultados no son especiales para el caso competitivo. Asumiendo neutralidad frente al riesgo, se mantiene la separabilidad y el resto de las conclusiones en mercados monopólicos. 


\subsubsection{Extensiones al modelo básico}

Se ha criticado que los modelos hasta aquí presentados no resisten un cálculo grosero en relación al nivel de evasión, las probabilidades de auditoria y las penalidades, al menos en países desarrollados. ${ }^{27} \mathrm{El}$ nivel de evasión real no corresponde con un cálculo de utilidad esperada. Como nota Alm (1999), usando una aproximación lineal de la utilidad esperada (neutralidad frente al riesgo), existirá evasión siempre y cuando $\phi f$ sea menor que $t$ : para el empresario (o el individuo) no será negocio evadir si la penalidad esperada es mayor que el impuesto. ${ }^{28}$ Incluso con penas muy altas (de 2 o 3 veces el impuesto a pagar), las probabilidades de auditoria usuales implicarían que nadie pagaría el impuesto. Los niveles reales de evasión implica una excesivo grado de aversión al riesgo, poco realistas. ${ }^{29}$

Como afirma Slemrod y Yitzhaki (2000, traducción propia, p. 9):

"La pregunta intrigante es porque que la gente paga impuestos, y no porque evade".

Sin embargo, estos cálculos generales efectivamente inducen a pensar que el modelo no da buenas predicciones del nivel de evasión, aunque la respuesta de la evasión a los cambios en las diversas variables de política predichos por el modelo se han verificado ampliamente en estudios empíricos, así como en experimentos [Alm (1999)].

Otra situación contra fáctica del modelo básico es que tal como está presentado, implica una política de combate a la evasión muy simple: altas penas y muy baja cobertura de la auditoria. Esto es así debido a que $\phi$ tiene un costo, mientras que $f$ no lo tiene, es una transferencia de recursos. Sin embargo, esta prescripción, que es por otro lado común a los modelos económicos del crimen, es poco realista debido a que es altamente inequitativa y además incrementa el riesgo de corrupción y el costo de los errores. ${ }^{30}$

\footnotetext{
${ }^{27}$ Ver Alm (1999) y Slemrod y Yitzhaki (2000).

${ }^{28} \mathrm{El}$ caso simple que presenta Alm (1999, p 9) plantea una aproximación lineal de la función de utilidad y evasión sin costo directo. La utilidad esperada si evade todo su ingreso es $U_{e}=(1-\phi) U\left(\Pi^{n d}\right)+\phi U\left(\Pi^{d}\right)$; la utilidad que tendría con certidumbre en el caso de no evadir será $U_{n e}=U(\Pi)$, donde $\Pi^{\text {nd }}=Y ; \Pi^{d}=Y-f$ y $\Pi=Y(1-t)$. Haciendo $U_{e}=U_{n e}$ se obtiene la máxima cantidad de impuestos que el contribuyente está dispuesto a pagar, que es cuando $\phi f=t$.

${ }^{29}$ Se han plenteado todo tipo de explicaciones alterntativas a este puzzle teórico, varias de las cuales se revisan mas adelante. Una de ellas es apartarse de los modelos de utilidad esperada [Bernasconi (1997)].

${ }^{30} \mathrm{El}$ caso extremo sería la pena de muerte al evasor, el problema es que los que son encontrados evadiendo
} 
Es evidente entonces que el modelo debe ser ampliado para obtener respuestas más acordes con la realidad, y de hecho hay una importante literatura en esta dirección. Las ampliaciones del modelo básico han sido variadas, a esta sección se presentan las principales que son de aplicación a impuestos indirectos. Una limitación general de estas ampliaciones es que los modelos teóricos pueden incorporar muy pocos agregados a la vez, ya que en la medida que incorporan más factores se hace mucho más complejo obtener conclusiones analíticas no ambiguas.

\section{a. Probabilidad de auditoría variable}

Las reglas que utilizan las administraciones tributarias modernas para seleccionar los contribuyentes a ser auditados son bastante complejas y consideran un conjunto de información amplia, lo que difiere sustancialmente de un $\phi$ fijo (misma probabilidad de auditoría para todos los contribuyentes, o sea una regla aleatoria simple). Así, varios autores han reemplazado en los modelos de evasión la probabilidad constante $\phi$ por una función $\phi(\cdot)$, lo que genera un conjunto interesante de cuestiones. Claro que la información a incluir como argumentos en una función $\phi(\cdot)$ puede ser bastante diversa. La mayor limitación es que la función debe contener como argumentos a variables conocidas por la administración tributaria, y en los modelos más simples la única relevante es el ingreso (o las ventas en nuestro caso) declarados por el contribuyente.

Allingham y Sandmo (1972) plantean como alternativa al modelo básico una función $\phi(X)$, donde $X$ es el ingreso declarado por el contribuyente. El interrogante que se plantean es que signo debería tener $\phi^{\prime}(X)$. A favor de $\phi^{\prime}(X)<0$, presentan el argumento que, estadísticamente, es mas probable que los contribuyentes que declaran menos hayan evadido. A favor de $\phi^{\prime}(X)>0$, presentan un argumento menos sólido: "los ricos evaden más". Allingham y Sandmo (1972) eligen la primer opción, aunque sobre esto las opiniones distan de ser unanimes. Ante este caso, los resultados de estática comparativa no difieren sustancialmente. Un aumento en la penalidad disminuye la evasión. Si bien en este caso $\partial S / \partial \phi$ no tiene mayor sentido (donde $S$ es el ingreso ocultado), demuestran que un traslado hacia la derecha de la función $\phi(X)$ disminuirá la evasión.

Por otro lado, Marrelli (1984) no decide cual de las dos podría ser más plausible y concluye que cuando la probabilidad de auditoría depende de la cantidad declarada, la separabilidad entre

estarían dispuestos a sobornar al inspector con todos sus activos. Además, un error con esta pena es muy costoso y además irreversible. 
decisiones de producción y de evasión ya no se mantiene. Otro resultado interesante de Marrelli (1984) es que encuentra que la tasa óptima de declaración será mayor, ceteris paribus, que la correspondiente al caso de probabilidad fija de auditoría cuando $\phi^{\prime}(X)<0$, y viceversa. Desde el punto de vista de la administración tributaria las funciones de tipo $\phi^{\prime}(X)<0$ dominarán a aquellas donde $\phi^{\prime}(X)>0$.

Hacer depender las probabilidades de auditoría de los ingresos declarados no deja de ser un esquema demasiado simple e incluso, si se puede usar la expresión, inocente. En general, las administraciones tributarias tienen una enorme cantidad de información acerca de los contribuyentes, la cual usarán en forma intensiva para mejorar la eficacia de las auditorías. Una aproximación que intenta reflejar esta realiadad es la de Virmani (1989) que utiliza una función de probabilidad de auditoría $\phi=\phi(q), \phi^{\prime}(q)>0$ y $\phi^{\prime \prime}(q)>0$, donde $q$ es el nivel de producción de la firma. Argumenta que si bien las ventas no son un dato conocido para la Administración Tributaria (de nuevo, esto no solo es real sino que es un supuesto critico del modelo: si las ventas fuesen conocidas no sería necesario hacer ningún tipo de auditoría), el gobierno tiene varios indicadores que le permiten conocer, quizás no el nivel de producción en un periodo determinado, pero si la capacidad productiva instalada. El supuesto $\phi^{\prime}(q)>0$, basado en "evidencia empírica casual" tiene consecuencias importantes en el modelo de Virmani (1989): curiosamente, se aleja de las prescripciones que surgen de los modelos teóricos y a la vez refleja mejor el comportamiento real de las administraciones tributarias.

La idea más general es que el gobierno podría conocer el comportamiento de alguna variable que esté relacionada en forma monotónica con el nivel de producción, y de esa forma vincularía la probabilidad de auditoría con $q$. Este argumento se ha ido afianzando en la literatura y hay diversos estudios que plantean que la probabilidad de auditoría debe depender, no de las ventas declaradas ni de las ventas reales, sino de indicadores que permitan evaluar el riesgo de evasión del contribuyente en función de la categorización que haya realizado la administración tributaria. ${ }^{31}$

\footnotetext{
${ }^{31}$ De hecho, esto se parece bastante a la determinación de la probabilidad de auditoría que hacen las administraciones tributarias en la realidad. En CIAT (2003) se observa, por ejemplo, lo que podría considerarse el estándar internacional al respecto. Algunos estudios teóricos que fundamentan esta aproximación a la temática son Scotchmer (1987), Macho-Stadler y Pérez-Castrillo (2002b, 2005) y Marhuenda, Vasin y Vasina (2002) y Lee (1998).
} 


\section{b. Percepción de probabilidades}

El cuestionamiento al modelo básico acerca que predice una mayor evasión que la existente en la realidad es común a modelos que utilizan la utilidad esperada. Una respuesta que se le ha dado a este tipo de cuestionamiento [ver las referencias dadas por Alm (1999)], principalmente desde la sicología, es que la gente tiende a sobreestimar probabilidades pequeñas. También el comportamiento tiende a ser "irracional" para otras situaciones en las que se dan costos muy altos pero con probabilidades mínimas, como desastres naturales. Si la gente efectivamente tiene una percepción mayor a la real sobre la posibilidad de ser auditado, el cálculo cambiaría drásticamente. Esto implica que aparece una nueva herramienta de la administración tributaria, la percepción del riesgo de ser auditado, que podría tener determinantes diferentes al riesgo real. ${ }^{32}$

Es interesante notar que la gente que es más "honesta" (evade menos) es la que más sobreestima la posibilidad de ser atrapado. ${ }^{33}$ Esto explicaría un motivo por el cual determinadas personas, con costos y beneficios similares a personas que evaden, no incurren en tal actividad. Si bien esto se ha intentado explicar desde la moral y las normas sociales, otra interpretación es que esta sería una decisión coherente con el cálculo de la utilidad esperada en el caso de que exista una percepción más alta de $\phi$. Las personas que se consideran son más "honestas" en realidad actuarían de ese modo por tener una errada percepción del riesgo.

\section{c. Normas sociales}

En diversos estudiosse intenta explicar el cumplimiento de la ley tributaria a través de las normas sociales o la "moral tributaria" existente en la población. ${ }^{34}$ Las normas sociales ayudan a definir la conducta de los miembros de la sociedad estableciendo que está "bien" y que está "mal", más allá de lo que está prescripto en la constitución y las leyes. Estas normas tienen validez en la medida en que las personas consideren que determinado comportamiento es visto

\footnotetext{
${ }^{32}$ Alm, Jackson y Beck (2004), a través de un metodo experimental, demuestran que la percepción de la probabilidad está más afectada por una comunicación "extraoficial" (información de otros contribuyentes), que por una comunicación oficial (el gobierno afirmando cual es la probabilidad de auditoría real). Erard y Feinstein (1994a) presentan un modelo donde la percepción de las probabilidades varía respecto a las probabilidades de auditoría reales, aunque tal variación surge de parámetros exógenos.

${ }^{33}$ Andreoni, Erard y Feinstein (1998).

${ }^{34}$ Ver Myles y Naylor (1995), Myles (1995), Falkinger (1995) y Torgler (2003).
} 
como positivo (o negativo) también por el resto de la sociedad [Alm (1999)]. Eso es así porque los contribuyentes no son personas aisladas que realizan un cálculo individual acerca de evadir o no, sino que se encuentran en un determinado contexto social y las normas que rigen ese contexto afectan el cumplimiento tributario.

En el estudio de la evasión, tales incentivos [sintetizados por Andreoni, Erard y Feinsten (1998) como "shame and guilty"] existen si el contribuyente tiene culpa por evadir incluso si no es atrapado y si al ser descubierta la evasión por un auditor sentirá vergüenza. Esto sucederá si en esa sociedad la evasión es vista como algo reprochable. Según esta visión del rol de las normas sociales, en la medida en que en la sociedad la evasión sea peor vista, será más alto el cumplimiento tributario, independientemente de la utilidad esperada de la evasión.

Se ha encontrado que las personas que evaden conocen más personas que también evaden, que aquellas que no evaden [Myles (1995)], lo que avala el carácter social de estas normas. Otro hecho a favor de esta teoría es que existe una gran diversidad del nivel del cumplimiento tributario entre países, que no son fácilmente explicados por la utilidad esperada, ya que tienen tasas impositivas, probabilidad de auditoria y multas no tan disímiles. Tampoco es fácil explicar usando exclusivamente la teoría de la utilidad esperada el hecho de que normalmente se encuentran personas y firmas que no evaden ni un centavo, independientemente del beneficio esperado de la evasión. ${ }^{35}$

Se han desarrollado modelos que incorporan el concepto de "preferencia por la honestidad" dentro de la función de utilidad y a partir de ahí reconstruyen las conclusiones analíticas correspondientes, las que no difieren significativamente del modelo básico, aunque si permitirían justificar un nivel de evasión menor al predicho por un modelo que no incorpora estas preferencias por la honestidad [Myles (1995)]. ${ }^{36}$

Existe también la posibilidad de incluir las normas sociales como un parámetro dentro del modelo básico. De hecho, en el propio trabajo seminal de Allingham y Sandmo (1972) se presenta un modelo ampliado en el cual se incorpora un costo en términos de culpa por evadir

\footnotetext{
${ }^{35}$ Se requiere un nivel muy alto de aversión al riesgo o de costos directos de evasión en modelos de neutralidad frente al riesgo para justificar un comporamiento de cumplimiento total.

${ }^{36}$ El problema de incorporar las normas sociales (y de algún modo determinadas preferencias "sicológicas" por algún comportamiento particular) en los modelos económicos de la evasión es que las mismas no son directamente observables, por lo cual a través de ese procedimiento se podrían justificar demasiadas diferencias entre la teoría y los estudios empíricos.
} 
$\left(Z_{0}\right)$, así como la reputación afectada $\left(Z_{1}\right)$ si la evasión es detectada dentro de la función de utilidad del individuo. En tal caso, el contribuyente individual maximiza:

$$
\operatorname{Max}_{S} E(U)=(1-\phi) U\left(\Pi^{n d}, Z_{0}\right)+\phi U\left(\Pi^{d}, Z_{1}\right)
$$

Asumiento que $U\left(\Pi, Z_{0}\right)>U\left(\Pi, Z_{1}\right)$. el nivel de ingreso y la reputación se convierten es sustitutos respecto a la conveniencia de evadir. Las condiciones bajo las cuales la evasión es conveniente son mas fuertes con una reputación alta. Estos parámetros permiten que individuos con niveles de ingreso similares y bajo el mismo conjunto de parámetros, tengan comportamientos muy diferentes respecto a la evasión, debido fundamentalmente a la diversidad de valores respecto a los parámetros $Z_{0} \quad$ y $\quad Z_{1}$

Una alternativa muy intuitiva para considerar las normas sociales dentro de un modelo de utilidad esperada es hacer depender el grado de aversión al riesgo de cada contribuyente de su moral tributaria. Falkinger (1995) presenta un modelo en el cual la percepción de equidad como norma social, afecta el grado de aversión al riesgo.

Otra alternativa de modelar las normas sociales, que se ha usando bastante tanto en modelos teóricos como en estimaciones econométricas, es trabajar con dos grupos de contribuyentes, los honestos y los que se suman al juego de la evasión fiscal. Erard y Feinstein (1994b) presentan el caso formalmente. En general, la inclusión de un grupo de contribuyentes que no evaden aún cuando el beneficio esperado es positivo, mejora notablemente el ajuste del modelo al comportamiento real de los contribuyentes.

En general las normas sociales fueron tratadas como una variable exógena de la cual se sabía poco y nada acerca de sus determinantes. Sin embargo, algunos estudios recientes tratan la "moral tributaria" como una variable de política pública. Feld y Frey (2002), a partir de un análisis del cumplimiento tributario en los 26 cantones Suizos, presentan un modelo en el cual la variable dependiente es la "moral tributaria" y aparecen como variables que la afectan significativamente al grado de participación en el gobierno del canton y especialmente en la elección de los bienes públicos, así como la forma en que son tratados los contribuyentes.

Torgler (2003) realiza un estudio similar utilizando datos de la World Values Survey para Canadá del año 1990. La variable dependiente es "moral tributaria", y los factores determinantes 
son confianza en el gobierno, orgullo (en este caso, de ser canadiense) y religiosidad. Torgler (2003) encuentra que una mayor confianza en el gobierno y un mayor orgullo se relaciona con una mayor moral tributaria. Con relación a la religiosidad encuentra que si bien la práctica religiosa tiende a estar correlacionada con una menor evasión tributaria, no hay diferencias significativas según la religión particular practicada.

Como consecuencia de este tipo de aproximaciones a la temátiva, hoy bastante usuales, la literatura actual tiende a separar las explicaciones "económicas" de la evasión, basadas en la teoría de la utilidad esperada de las "no económicas", de las cuales son un elemento central las normas sociales. ${ }^{37}$

\section{d. Modelos dinámicos}

El gobierno es permanente, con lo cual la fuente de financiamiento (los impuestos) también lo será. Esto hace que la evasión fiscal tenga una característica dinámica particular que ha sido incorporada en diversos estudios [Engel y Hines (1999) y Lipatov (2003)]. Aquí, también Allingham y Sandmo (1972) son los precursores al presentar una versión dinámica del modelo básico de evasión. La pregunta que se hacen es si bajo un esquema repetitivo, dados valores fijos de los parámetros, ¿la evasión aumentará o disminuirá a lo largo del tiempo? En general, está claro que el individuo "miope" (no considera las consecuencias intertemporales) evadirá siempre más que el individuo consistente. Además, si el individuo conoce que si es detectado en algun momento del futuro todos los impuestos pasados evadidos serán cobrados más una penalidad, la evasión teóricamente desaparece. ${ }^{38}$ Por supuesto que en este caso tanto los supuestos como las conclusiones son erróneas: siempre hay un período de prescripción de impuestos $(2,5$ o hasta 10 años), más atrás de ese periodo no se audita, y la evasión existe. De todos modos, es interesante notar como la incorporación de más periodos aumenta sustancialmente el costo de la evasión y por lo tanto disminuye su nivel, yendo también en la dirección de fundamentar un nivel de evasión óptimo para el contribuyente menor que al del modelo básico.

Un modelo dinámico de la evasión fiscal en su presentación más simple establece lo siguiente [Engel y Hines (1999)]: en un período 0 el contribuyente genera sus ventas y a la vez decide

\footnotetext{
${ }^{37}$ Ver por ejemplo Slemrod (2007). Molero y Pujol (2005) presentan un modelo econométrico donde están los factores económicos y los no económicos (psicológicos) dentro de las variables independientes.

${ }^{38}$ Siempre que la penalidad considere el paso del tiempo compensando la tasa de descuento del contribuyente.
} 
que porcentaje de la base imponible declarar a la administración tributaria. En el período 1, la administración tributaria decide cuales declaraciones auditar, realiza las auditorias y aplica las penalidades. La imposición es permanente, con lo cual en los periodos subsiguientes la misma dinámica se repite. La administración tributaria puede intentar (si lo considera deseable) disminuir la brecha temporal entre el momento en el cual se produce el hecho imponible y la auditoria, aunque la cuestión distintiva de que una cosa viene después de la otra siempre se mantiene. Si la administración tributaria decide auditar, y encuentra evasión, el impuesto omitido más la penalidad, será pagada en un período posterior que el resto del impuesto. Además, las reglas de auditoria de la administración tributaria también pueden ser impactadas significativamente al considerar varios períodos y no solo uno. En todos los países, existe un periodo de prescripción de las obligaciones tributarias mayor a un año, con lo cual la administración tributaria mantiene el derecho de reclamar por el impuesto omitido en varios periodos anteriores al actual.

Todo esto implica modificaciones en el cálculo de la utilidad esperada del contribuyente y además provee alternativas a la administración tributaria para aplicar las reglas de auditoria. Engel y Hines (1999) establecen que si la administración tributaria una vez seleccionado el contribuyente le audita más de un periodo, el costo de una auditoria para el contribuyente puede ser significativamente mayor al considerado en el modelo básico, en el cual el mismo estaba dado por el impuesto evadido en un período multiplicado por la penalidad correspondiente.

Si esto fuese así, además, el nivel de evasión por parte de una empresa dependerá de cuanto evadió en los períodos pasados. Engel y Hines (1999) encuentran que la evasión en un determinado período es mayor cuando la evasión en períodos anteriores es menor, relativa a la base imponible y el impuesto determinado en el período actual.

Estos aspectos también están muy relacionados con el efecto de las moratorias o amnistías tributarias, tema que se revisa más adelante. Según Alm (1999), el aspecto intertemporal de la evasión es un elemento importante aunque bastante descuidado dentro de la literatura.

\section{e. Mercados de capitales imperfectos}

Relacionado con el aspecto dinámico de la evasión, se encuentra el hecho de que la teoría económica de la evasión supone un mercado de capitales perfecto y cuando se levanta este 
supuesto aparecen elementos nuevos que deben tomarse en cuenta. Esto es analizado por Andreoni (1992) que presenta un modelo de evasión con restricciones al crédito para el impuesto a los ingresos. El argumento general es que cuando un contribuyente decide evadir incrementa su consumo en el período actual, mientras que, en el caso de ser auditado y pagar la multa, eso se realiza en el futuro. Inclusive, esto abre una posibilidad que carece de sentido con un mercado de capitales perfecto: evadir el impuesto en el período actual y, sin ser auditado, pagar lo que corresponde en un período futuro, eliminando la penalidad adicional que pudiese significar ser atrapado evadiendo, utilizando de este modo al fisco como una fuente de financiamiento.

De aquí surge una de las conclusiones centrales del modelo de Andreoni (1992): si los contribuyentes utilizan la administración tributaria como una fuente de financiamiento, no será eficiente una política que implique el cumplimiento total, ya que la misma es costosa y de todos modos una parte de los evasores pagarán en el futuro, independientemente de si son auditados o no (devolverán los fondos que tomaron prestados). Otra conclusión importante es que si las personas (o empresas) tienen restricciones de liquidez estarán dispuestas a participar de un juego "injusto" (evadir por más que tenga una utilidad esperada negativa) a fin de transferir recursos del futuro al presente.

El análisis de Andreoni (1992) se concentra en aquel segmento de contribuyentes que tienen el crédito restringido, por determinados motivos, y que por lo tanto deben acceder a mercados secundarios (e ilegales), donde el crédito es mucho más caro y riesgoso (tales préstamos se denominan "loan shark", el colateral puede ser la vida humana). En este contexto, la administración tributaria es una fuente de financiamiento alternativa de "alto riesgo". Sin embargo, el mismo análisis podría generalizarse para países en desarrollo en las cuales las restricciones crediticias son más comunes, debido a problemas institucionales que generan imperfecciones en el mercado de capitales.

Otro tema vinculado con las restricciones de financiamiento, que no ofrece complejidad analítica pero muy relevante para las administraciones tributarias en contextos macroeconómicos inestables es la tasa de interés vigente. Si la misma tiene variaciones importantes, la administración podría cobrar intereses menores a la tasa pasiva en el mercado por los impuestos pagados fuera de término. Si ese es el caso, existe un beneficio de evadir en el período actual y pagar lo que corresponda en el futuro una vez que bajen las tasas de interés, por más que la 
evasión tenga una utilidad esperada negativa (calculada según el modelo básico).

\section{f. Costos asociados al cumplimiento}

Otra extensión que ha tenido el modelo básico se refiere los costos directos asociados al cumplimiento de la ley tributaria, y en particular, a la complejidad de la ley impositiva [Kaplow (1994 y 1995) y Das-Gupta (2004)]. Por complejidad se incorporan dos elementos, la incertidumbre sobre la correcta aplicación de la ley impositiva y el costo asociado a disminuir la incertidumbre el mínimo posible. El problema planteado por Kaplow (1994 y 1995) es que, en la medida en que los sistemas tributarios intentan considerar muchas situaciones prácticas distintas, las leyes impositivas tienden a ser complejas y es costoso conocer exactamente el impuesto determinado. Como consecuencia, el contribuyente puede no conocer exactamente que va a pasar si es auditado efectivamente: incluso en el caso de haberse comportado en forma honesta, es posible ser castigado por haber evadido, ya que los auditores no considerarán las intenciones del contribuyente, sino únicamente si ha pagado lo que corresponde a la ley impositiva, la cual conocen mejor que el contribuyente. También puede darse el caso de que la auditoria determine que pagó mas de lo que debía.

En definitiva, el contribuyente enfrenta una distribución de probabilidades del impuesto determinado, centrada en el valor conocido por los contribuyentes como el impuesto a pagar, en lugar de un monto certero.

Una conclusión frecuente al respecto es que la complejidad genera mayor recaudación que una ley tributaria con las mismas tasas promedio pero más simple y clara, o sea con menor complejidad [Scotchmer y Slemrod (1988)]. La intuición detrás de este resultado es la siguiente: si un contribuyente es auditado y pagó de menos implica pagar lo restante más la penalidad, mientras que si pagó de más le devolverán el sobrante, pero en general no le dan ningún premio. Por este motivo, ceteris paribus, al maximimzar la utilidad esperada de la evasión es óptimo para los contribuyentes declarar en promedio más de lo que pagarían con certeza.

Además, la presencia de incertidumbre implica que algunos contribuyentes (con alta aversión al riesgo, o totalmente honestos) pagarán más de lo que corresponde, con lo cual las medidas agregadas de la evasión (impuesto teórico menos recaudación total) subestiman la evasión calculada como la suma de los montos evadidos por cada contribuyente. 
Por último, los modelos teóricos consideran que la evasión es siempre deliberada, pero la realidad es que las auditorías pueden encontrar evasión deliberada y otra que no lo es, lo cual dependerá de la complejidad de la ley impositiva. Esto es estudiado en forma empirica por Erard (1997).

\section{g. Formas de evasión y oportunidades de evadir}

Un supuesto simplificador del modelo básico de evasión fiscal por parte de empresas es que la única forma de evasión es el ocultamiento de ingresos. Sin embargo, la evasión toma muchas otras formas, siendo algunas de las más importantes la sobredeclaración de deducciones (retenciones y percepciones sufridas) y la incorrecta declaración de la actividad (en los casos en que cada actividad tiene alícuotas diferentes). El proceso a través del cual una empresa determina el monto que debe pagar a la administración tributaria tiene seis pasos y en cada uno de los cuales puede haber falseamiento de información o incumplimiento de obligaciones con el objeto de pagar menos impuesto:

a) Inscripción en la administración tributaria. La falta de registración es un problema vinculado con la economía informal, y es mucho más usual en países en desarrollo que en aquellos desarrolados.

b) Determinar la base imponible. Esto es, calcular el monto que corresponde a todas las ventas realizadas en el período correspondiente. La forma de evasión en este caso es el ocultamiento de ingresos, que es el único supuesto de evasión de los modelos tradicionales [Marrelli (1984), Virmani (1989) y Cremer y Gahvari (1993)].

c) Calcular el impuesto determinado. Esto implica definir que alícuota corresponde a la base imponible ya calculada, según la legislación fiscal vigente. En general, los impuestos al consumo tienen diferentes alícuotas según el producto o servicio que se comercialice. La evasión en este caso toma la forma de incorrecto encuadramiento de la actividad realizada. En un caso extremo, una empresa podría declarar determinadas ventas como que corresponden a una actividad exenta (alícuota igual a cero), cuando no lo es.

d) Calcular el impuesto a pagar. Una vez calculado el impuesto determinado, se deben deducir todas las retenciones o percepciones sufridas, cálculo del cual surge el impuesto a pagar. 
La forma obvia de falsear la declaración jurada es inventar deducciones o sobreestimar deducciones efectivamente realizadas.

e) Presentar oportunamente la declaración jurada con el impuesto a pagar. La evasión también toma la forma de no presentación de la declaración jurada (omisión), el cual plantea cuestiones bastante particulares al planteo del problema. La omisión está más vinculada con la falta de inscripción, aunque son conceptos diferentes.

f) Pagar el impuesto. Si bien tomando una definición amplia de evasión esta conducta entra dentro del concepto, desde el punto de vista de la administración tributaria el problema es totalmente diferente. No es problema de auditoria, sino más bien de ejecución en sede judicial de la deuda informada por el contribuyente.

Desde el punto de vista del análisis económico, la evasión a través de la falta de inscripción y de la omisión plantea problemas muy diferentes al resto, los que se analizarán por separado más adelante. La falta de pago no plantea problema analítico alguno. El resto de las formas de evasión han sido poco consideradas en la literatura, aunque es probable que en la medida en que modifiquen el impuesto esperado puedan tener un tratamiento similar al ocultamiento de ventas. De hecho, Yaniv (1995) presenta un modelo en el cual la evasión puede tomar cualquier forma (ya que la variable de elección del contribuyente es un impuesto pagado menor que el que corresponde y no el nivel de ingresos a declarar) y las conclusiones son similares a los modelos tradicionales.

Sin embargo, el análisis de la retenciones en la fuente merece un análisis un poco diferente. Cuando existen retenciones (o percepciones) aparecen dos agentes que son responsables por el mismo impuesto, en forma solidaria. Además, salvo casos extremos (por ejemplo, el impuesto a las ganancias de trabajadores en relación de dependencia), el impuesto determinado no es retenido en su totalidad por el agente. Esto implica que, en primer lugar el agente retiene, luego deposita a la administración tributaria y luego el contribuyente determina el impuesto y paga la diferencia (entre lo determinado y lo retenido), a su vez, a la administración tributaria El primer problema es que aparecen al menos dos posibles evasores respecto al mismo impuesto: el agente de retención puede no depositar montos retenidos y el contribuyente puede no pagar la diferencia cuando no ha sido retenido el $100 \%$ del impuesto determinado (lo cual es usual). 
Yaniv (1988) analiza el problema agregando una complejidad adicional: la empresa paga el impuesto a las ganancias corporativas y es además agente de retención del impuesto a las ganancias que pagan sus trabajadores.

Aquí las herramientas de política se multiplican: hay dos tasas impositivas (la que paga la empresa y la que pagan los trabajadores), está la tasa de retención (el porcentaje del impuesto que pagan los trabajadores que es retenido), hay tres penalidades (por no pagar la empresa, por no depositar impuestos retenidos y por no pagar el trabajador) y al menos dos probabilidades de auditoría (la de la empresa y la del trabajador). Lógicamente, los resultados de estática comparativa son bastante ambiguos.

El mecanismo que adopta la evasión depende en forma crucial de la característica de la empresa. Las empresas grandes, por cuestiones de control interno, registran en su sistema contable toda su operatoria comercial, con lo cual es muy difícil que puedan ocultar ventas a la administración tributaria. Chen y Chi (2002) plantea un modelo de evasión del impuesto a los ingresos por parte de las empresas en el cual incorporan los mayores costos generados por la evasión en términos de menor control interno y dificultad de alinear incentivos entre el principal (dueño) y el agente (gerente). El mencionado trabajo, sin embargo, sigue asumiendo que la evasión pasa, en el caso de impuesto a los ingresos, por declarar menos ventas o más costos deducibles que los reales, cuando en realidad otras formas de evasión más usuales por parte de las empresas generan un costo mucho menor (como es el caso del incorrecto encuadramiento de la actividad). Otro elemento central no mencionado en el trabajo de Chen y Chu (2005) es el tamaño de la empresa: las perdidas generadas por un menor control interno puede ser significativas o no según el tamaño y complejidad de la empresa. De hecho, en el caso extremo de una empresa pequeña cuyas ventas son supervisadas en forma directa por su dueño, el problema no existe.

En definitiva, la posibilidad de ocultar ventas existe sólo para pequeñas y medianas empresas, con lo cual todo el esquema de evasión fiscal del modelo básico, así como los modelos de interacción estratégica que se presentarán más adelante, son válidos sólo bajo ese supuesto. ${ }^{39}$

La función $g(1-\alpha)$ del modelo Cremer y Gahvari (costo de la evasión) intenta reflejar las posibilidades económicas y tecnológicas de evadir. Varias particularidades de cada empresa,

\footnotetext{
${ }^{39}$ Esto implica que la regla de selección de montos mínimos, que se discute más adelante, carece de sentido en el caso de los grandes contribuyentes, para los cuales deberá adoptarse otro mecanismo de selección.
} 
además del tamaño, pueden afectar el costo de la evasión. ${ }^{40} \mathrm{Si}$ bien no hay modelos formales ni mucho menos estudios empíricos sobre la forma que podría tomar la función $g(1-\alpha)$, es un tema de análisis permanente por parte de las administraciones tributarias. Cowell (2004), a modo de ejemplo, plantea los siguientes determinantes de esa función: a) la naturaleza del producto, b) el tamaño y la estructura organizativa de la empresa, c) el rol de la reputación en el sector, y d) el grado de concentración de la industria.

Un problema relacionado que tienen las empresas grandes es el de control interno de los profesionales que completan las declaraciones juradas de impuestos. Si se utiliza un mecanismo de incentivo vinculado con el impuesto efectivo que se paga (algo usual en el impuesto a las ganancias en EEUU), existe el riesgo de que el profesional asuma un riesgo exesivo e, inclusive, llegue a la evasión fiscal aun sin acuerdo de la empresa. Es interesante notar que, ante esta situación, las penalidades a los propietarios de la empresa, de detectarse la evasión, no tienen un efecto tan claro como las posibles penas que castiguen el comportamiento del profesional. Este tema es estudiado formalmente por Crocker y Slemrod (2005).

Otra forma de modelizar estas distintas alternativas es a través de una función (o parámetro) de habilidad de evadir. Según el impuesto que se esté considerando, los esquemas de retención vigente, así como otros factores como ser la utilización de dinero bancario, la habilidad de evadir varía sustancialmente de sector a sector, e inclusive de contribuyente a contribuyente. Jones (2001) demuestra a través de un modelo que aplica la teoría de los juegos que aquellos contribuyentes con mayor habilidad para evadir, recibirán una probabilidad de auditoría mayor, y aún así tendrán un impuesto esperado menor. ${ }^{41}$ Un esquema similar utilizan Macho-Stadler y Perez-Castrillo (1997) que plantean diversas fuentes de ingreso con diversa capacidad de ocultamiento (por ejemplo, salarios en relación de dependencia e ingresos por cuenta propia).

Lo relevante es que la evasión no depende exclusivamente de su beneficio esperado, sino también de las oportunidades de evadir. Hay determinados sistemas como es el caso de la retención en la fuente o los anticipos a cuenta que tienen un impacto en el nivel de evasión, si

\footnotetext{
${ }^{40}$ Virmani (1989) demuestra que si los costos directos de evasión son lineales, las empresas chicas evaden todas las ventas y las grandes no evaden nada. Si la función de costos es convexa, se presenta un grupo de empresas (medianas) que evadirán parte de las ventas.

${ }^{41}$ Rato y Vergue (2000) llegan al resultado opuesto: para la administración es óptimo eliminar la evasión de los contribuyentes con oportundiades de evasión bajas, con lo cual recibirán una probabilidad de auditoría mayor.
} 
bien no afectan desde el punto de vista teórico el beneficio esperado de la evasión. ${ }^{42}$ Lo que es claro es que las conclusiones de política que se toman asumiendo que la única forma de evadir impuestos es subdeclarando ingresos deben revisarse a la luz de una realidad más compleja. En uno de los pocos estudios empíricos donde se revisa esta temática, Martinez-Vazquez y Rider (2003) encuentran que fortalecer las herramientas que combaten una de las formas de evasión hace que aumenten otras formas, aunque aún así el impacto neto de las herramientas vinculadas a un mayor control es positivo.

\section{h. Omisión de presentación de declaración jurada}

La omisión implica que la administración tributaria no tiene información sobre el contribuyente. En los modelos en los cuales la selección surge de los datos declarados por el contribuyente la omisión genera problemas serios. Si la regla de auditoria utiliza exclusivamente la información de las declaraciones juradas presentadas [como es el caso, por ejemplo, de la función de $\phi=\phi(X)$ de Allingham y Sandmo (1972)], los contribuyentes que omiten presentar su declaración jurada nunca serán auditados, con lo cual puede ser óptimo para el contribuyente omitir presentar la declaración jurada y evadir la totalidad del impuesto.

Si bien este tema no ha sido muy estudiado, hay suficiente evidencia que las funciones de probabilidad de auditoría deben reconsiderarse ante la presencia de omisión. El argumento de Cowell (2004) es que:

"Una fiscalización demasiado celosa en las áreas de bajo costo de reunir información puede exacerbar los problemas en las áreas de alto costo (donde están los que omiten)" (traducción propia, p. 21).

El problema de la omisión es sumamente importante en países en desarrollo, con administraciones tributarias débiles y una economía subterránea importante. De hecho, es muy probable que los altos niveles de evasión existentes en estos casos, la mayor parte corresponda a omisión: actividades comerciales desarrolladas por contribuyentes no registrados en la administración tributaria. La falta de inscripción y la omisión se la vincula con el costo administrativo del cumplimiento tributario, especialmente cuando el impuesto es progresivo. De hecho, se ha

\footnotetext{
${ }^{42}$ Yaniv (1988) analiza las retenciones en la fuente, mientras que Yaniv (1999) los anticipos a cuenta.
} 
encontrado que la mayor parte de los que omiten inscribirse y presentar declaración son contribuyentes sujetos a subsidios, más que a impuestos [Erard y Ho (2001)]. La recomendación usual es, entonces, simplificar y reducir los costos del cumplimientos, especialmente para pequeños contribuyentes.

\section{i. Coordinación y competencia fiscal}

En países federales, es usual que más de una administración tributaria tengan injerencia sobre la misma base imponible, lo cual produce externalidades fiscales que han sido estudiadas en la literatura especializada. ${ }^{43}$

Cuando las bases imponibles son similares, las decisiones del contribuyente respecto a evadir un impuesto local, se tomarán teniendo en cuenta el impuesto nacional. Si esto es así, las administraciones tributarias locales (que en general tienen menos recursos que las centrales) encontrarán productivo seguir el criterio de selección de la administración central, ya que tiene asegurada la productividad de las auditorías. Esto, a la vez, tiene implicancias respecto al comportamiento de la administración central, ya que sus auditorías producen una externalidad que al considerarlas en el calculo de costo beneficio de la administración modificará el valor óptimo de $\phi .^{44}$

Tanto esto es así, que se ha considerado como una característica positiva de la multiple imposición (impuestos con bases imponibles similares establecidos por diversos niveles de gobierno) la mayor productividad de las auditorías, lo que representa un sistema de control del cumplimiento doble. Sin embargo, Esteller-More (2004) ha demostrado que esta característica de la doble imposición se verifica solo si existe un alto nivel de coordinación entre las auditorías de ambos niveles de gobierno. Si no se da tal situación, los resultados de estática comparativa del modelo básico se modificarán: un aumento de $\phi$ o de $f$ en un nivel de gobierno podría dejar inalterada la evasión total, si el contribuyente aumenta en cantidad suficiente el nivel de evasión respecto al otro nivel de gobierno.

Cuando hay estados vecinos y hay movilidad del capital y del trabajo, existe la posibilidad de competencia fiscal. Cuando el análisis se ha centrado en impuestos al consumo, la mecánica

\footnotetext{
${ }^{43}$ Wilson (1999) presenta una revisión muy completa de la literatura sobre competencia fiscal.

${ }^{44}$ Estas interrelaciones son estudiadas a través de un modelo econométrico por Alm, Erard y Feinstein (1995).
} 
de competencia fiscal es mediante las compras a través de la frontera. En estos casos, lo que se asume es que un habitante de la región A puede trasladarse hasta la región B a comprar determinado bien o consumir un servicio, debido a que los impuestos al consumo son mas bajos en la región B (y viceversa). Así, los estados nacionales (o subnacionales) tienen un incentivo en al reducción de su tasa impositiva ya que podrían captar consumo de estados vecinos, cuyos habitantes se acercarían a comprar (cruzando la frontera, por lo cual se denomina a esta mecánica cross border shopping) donde es más barato como consecuencia de una menor carga impositiva.

En estos modelos, el aspecto espacial, los costos de transporte, así como el tamaño de la jurisdicción juegan un papel importante. En general, se encuentra que las jurisdicciones más grandes tienden a fijar tasas impositivas mayores, mientras que las pequeñas intentan captar una parte de la mayor base imponible de las grandes con tasas menores. ${ }^{45}$ Para las jurisdicciones pequeñas, la pérdida de recaudación generada en sus propios habitantes debido a la menor tasa impositiva es más que compensada con un aumento de la base imponible. La misma conclusión rige para jurisdicciones grandes pero con baja densidad de población respecto a otras jurisdicciones densamente pobladas, las primeras tenderán a fijar tasas impositivas menores. ${ }^{46}$

Por este motivo, las jurisdicciones chicas tenderán a ser perjudicadas por la coordinación fiscal. Si hay muchas jurisdicciones chicas y pocas grandes, la posibilidad de coordinación será más lejana.

$\mathrm{Al}$ incorporar la evasión fiscal el análisis es necesariamente más rico. Cuando existe más de una jurisdicción con diversas políticas tributarias y distintas tecnologías de control del cumplimiento tributario en aplicación, la decisión del contribuyente es más compleja, tiene que decidir si pagar o no impuestos, y en que jurisdicción (pagarlos o evadirlos). En el caso del impuesto al capital móvil, el contribuyente deberá decidir donde localizarse y luego si pagar el impuesto que le exige la administración tributaria de esa región. Por otro lado, el gobierno tiene también varias decisiones: la tasa impositiva, el nivel de control de cumplimiento y si se aplicará coordinación con otros fiscos. Tanto la posibilidad de competencia como de coordinación puede darse

\footnotetext{
${ }^{45}$ Ver Kanbur y Keen (1993), Edwards y Keen (1995), Lockwood (2001) y Wang (1999).

${ }^{46} \mathrm{La}$ competencia fiscal no se da solo respecto a la fijación de una política impositiva: se ha notado que los estados de una federación también compiten en aspectos regulatorios, reduciendo los requerimientos ambientales, por ejemplo, en pos de atraer mayores inversiones a su región [Oates (1999)].
} 
respecto a una o varias herramientas de política pública.

Los modelos que se han utilizado para analizar una situación de este tipo son variados. En principio hay que considerar que tipo de impuesto se analizará, el grado de movilidad de los contribuyentes y cual es la posibilidad de evadir que existe. En la literatura hay al menos dos enfoques diferentes para incluir la evasión fiscal dentro de los modelos de competencia fiscal. Los primeros análisis de este tipo fueron realizados por Cremer y Gahvari $(1997,2000)$ que presentan un modelo a fin de analizar las consecuencias de la integración económica y la coordinación fiscal cuando existe evasión de impuestos indirectos. Cremer y Gahvari (2000) primero demuestra que en economías cerradas cuando existe evasión fiscal las tasas impositivas son subóptimas, respecto a una situación de contribuyentes totalmente honestos. Si en ambos países existe evasión fiscal, la competencia impositiva producirá tasas impositivas y probabilidades de auditoría subóptimas. Es más, si se da coordinación entre tasas impositivas, la competencia se trasladará a las auditorías y se adoptarán políticas que favorecerán la evasión fiscal. En cualquier caso, ambos países quedarán peor con la competencia impositiva que ante una situación de fronteras cerradas, o sea, previa a la integración económica.

Una de las ventajas del modelo de Cremer y Gahvari (2000) es que la evasión es una característica endógena del modelo, vinculada a la tecnología de control del cumplimiento y de hecho encuentra situaciones donde en un país no existe evasión cuando las fronteras permanecen cerradas, pero con competencia fiscal y armonización de tasas la situación de equilibrio implica evasión.

En Cremer y Gahvari (2000) la competencia fiscal se da mediante un mecanismo (la compra a través de la frontera) que es marginal, salvo para jurisdicciones pequeñas y densamente pobladas (como puede ser algunos países europeos, que es en última instancia adonde apunta el trabajo). Las empresas no puede movilizarse, solo se mueven los ciudadanos. Otro elemento particular del análisis de Cremer y Gahvari (2000) es el interés en comparar las situaciones entre un país con sus fronteras cerradas versus integración económica (o sea coordinación impositiva). Esta comparación no se aplica si lo que se quiere analizar es la competencia entre estados subnacionales dentro de una federación, donde el escenario de fronteras cerradas es inexistente.

Un esquema diferente es el de Gándelman y Hernández-Murrillo (2004) que presentan un modelo en donde los gobiernos pueden monitorear parcialmente donde viven los ciudadanos, 
con lo cual existe la posibilidad de mentir al respecto y pagar los impuestos en la jurisdicción donde son más baratos. A diferencia de los modelos clásicos de evasión donde la decisión pasa por pagar o no el impuesto, en este modelo la decisión es pagar donde corresponda o donde es más barato, siendo contribuyentes adversos al riesgo y con la posibilidad de una auditoría que detecte que se ha mentido respecto al lugar de residencia. En este modelo, la posibilidad o no de coordinación fiscal se refiere a las tasas impositivas, ya que se asume que las probabilidades de auditoría y las multas son las mismas para ambas regiones. El principal resultado encontrado es que si las jurisdicciones son de igual tamaño, los tipos impositivos serán idénticos. En otro caso, la jurisdicción más chica podría beneficiarse de la competencia impositiva fijando tasas más bajas.

\section{j. Corrupción y detección parcial}

La evasión y la corrupción son conductas que están relacionadas, entre otros motivos porque los fondos que financian la corrupción deben provenir de ingresos no declarados, ya que de otro modo la transacción quedaría registrada. La literatura económica sobre corrupción y evasión tributaria es voluminosa, aunque en general está concentrado el análisis en evasión por parte de individuos de impuestos directos. ${ }^{47}$

Si se considera la posibilidad de soborno por parte de la empresa al inspector para evitar o reducir la profundidad de una determinada acción de auditoría, el problema de combate a la evasión aparece con un grado de complejidad mayor. Ahora no hay una asimetría de la información sino dos: entre la administración y el contribuyente y entre la administración y el inspector. La corrupción del auditor debilita la eficacia de las herramientas del control del cumplimiento tributario. Los modelos que consideran la posibilidad de corrupción del inspector concluyen efectos diferentes a aquellos donde tal posibilidad no existe. Mientras mayor es la penalidad a la evasión, es mayor el incentivo que se genera a la corrupción (el costo de la evasión detectada es mayor y por lo tanto el precio de un tratamiento favorable también es mayor). ${ }^{48}$

\footnotetext{
${ }^{47}$ Ver Sanyal et all (2000), Sanyal (2000), Ordoñez (2001), Hindriks et all (1999), Acconcia et all (2003a, 2003b), Akdede (2006) y Escobari (2007). Un estudio de corrupción y evasión por parte de empresas es Goerke (2006).

${ }^{48}$ Yitzhaki y Vakneen (1988) notando este problema, proponen un arbol de decisión en el cual la realización y continuación de un proceso de auditoría dependerá del incremento en la recaudación esperada (el precio sombra del inspector).
} 
Una de las principales preguntas que ha tratado la literatura sobre evasión y corrupción es, entonces, si el principio de la máxima pena se mantiene aún cuando se considera la posibilidad de soborno. También una cuestión relevante es como debe ser la política de monitoreo de los inspectores a fin de que la corrupción sea eliminada (si eso es lo que se desea), o sea reducida a un nivel óptimo (si se decide dejar de lado cuestiones morales).

El planteo más usual del problema es considerar una situación en la cual, una vez detectada la evasión por parte de un inspector con interés propio, el mismo debe decidir si reportarla o no. ${ }^{49} \mathrm{El}$ incentivo para corromperse del inspector (aceptar el soborno) estará determinado por el compromiso de monitoreo de inspectores que haya hecho el gobierno (o sea la probabilidad de ser detectado el acto de corrupción), la penalidad asociada a tal comportamiento y la penalidad de la evasión fiscal. ${ }^{50}$

Bajo está configuración, mayores penalidades asociadas a la evasión fiscal tendrán un efecto claro en el nivel de evasión, pero ambiguo respecto al nivel de corrupción. Por otro lado, la penalidad asociada a la corrupción tiene un efecto directo en su nivel, pero ambiguo en el nivel de evasión: si el nivel inicial es pequeño, un incremento podría producir mayor evasión fiscal. De todos modos, se mantiene el principio de la pena máxima para ambos tipos de comportamiento (evasión y corrupción). ${ }^{51}$

Estos resultados, sin embargo, son sensibles a la configuración del modelo. Ordonez (1999), por ejemplo, plantea un modelo ligeramente diferente en el cual una mayor penalidad a la evasión produce un impacto positivo en la corrupción, mientras que Sanyal, Gang y Goswami (1998) derivan un comportamiento de la recaudación tributaria del tipo curva de Laffer como consecuencia de una mayor corrupción (y por lo tanto más evasión y menos recuadación) asociada a mayores tasas impositivas, y también encuentran que las políticas de mayor control de la evasión pueden generar mayor corrupción.

\footnotetext{
${ }^{49}$ Ver Acconcia, D'Amato y Martina (2003 b).

${ }^{50}$ Una forma inversa de plantear el problema es que el auditor pueda extorsionar al contribuyente amenazando encontrar evasión donde no la hay. Al presentarse la asimetría de la información entre la administración tributaria y el inspector, éste último podría presentar informes incorrectos en ambos sentidos (informando más o menos de la evasión real del contribuyente). Hindriks, Keen y Muthoo (1999) plantean el modelo en estos términos, haciendo foco en las consecuencias distributivas que tiene este problema, si los contribuyentes de mayor ingreso tienen más posibilidad de acceder a los servicios ilegales de los inspectores.

${ }^{51}$ Acconcia, D'Amato y Martina (2003b). Escobari (2007) tamién encuentra que mayores penalidades (probabilidades de auditoría y multas) reducen la evasión, aunque plantea que cuando no se considera la corrupción tal efecto está sobreestimado.
} 
La posibilidad de soborno al inspector se ha utilizado para fundamentar esquemas de pago de incentivos al personal de la administración tributaria atado a los resultados de las auditorías o de la recaudación en general [Sanyal (2000) y Urbiztondo (1993)]. Los incentivos a los inspectores se han estudiando también como forma de alinear el esfuerzo de la auditoría con el interés de la administración tributaria. Incluso para inspectores no corruptos, la realidad es que no necesariamente tendrán el mismo interés que la administración y el grado de esfuerzo que dediquen a una auditoría influirá en su resultados. Nierdela y Summer (1999) estudian este problema y encuentran que la posibilidad de colusión entre el auditor y el evasor estará siempre presente, cualquiera sea el incentivo monetario para los inspectores (incluso los del tipo bounty hunter). Por tal motivo proponen esquemas en los cuales la motivación no sea solo económica.

Cuando se incluye en el modelo el monitoreo de los inspectores, aparece la pregunta de quien controla a los que monitorean. No habría dos asimetrías de información, sino tantas como niveles jerárquicos tenga la administración. Este aspecto se ha estudiado bajo el esquema de jerarquías de auditorías y cadenas de sobornos. Sanyal (2000) estudia el problema y compara dos esquemas de incentivos a toda la estructura jerárquica de la administración tributaria para combatir la corrupción: remuneraciones vinculadas con la evasión detectada y con la recaudación tributaria. Si bien ambos son eficientes en eliminar la corrupción, sólo el segundo resiste encuentros repetidos.

La relación entre evasión impositiva y corrupción por parte de empresas ha merecido poca atención. Goerke (2009) presenta un modelo donde se puede evadir el impuesto al beneficio y las empresas pueden sobornar funcionarios públicos para adquirir permisos de producción, pero que en principio se pueden asimilar a cualquier regulación estatal suceptible de asimetría de información. Encuentra en este contexto que las decisiones entre involucrase en evasión y en corrupción son separables, bajo diversos escenarios, aunque las modificaciones en las variables exógenas afectan al nivel de equilibrio de ambos comportamientos.

\subsubsection{Modelos de interacción estratégica}

Hasta ahora, se han presentado modelos en los cuales el equilibrio indica los valores estables en el nivel de evasión y en el nivel de recaudación de la administración tributaria. La decisión de optimización la toma el contribuyente, frente al conjunto de incentivos que el gobierno 
genera a través de las variables de política (exógenas al modelo). Ahora bien, ¿qué pasa si la administración tributaria también tiene un comportamiento maximizador? En última instancia, al decir de Graetz et all. (1986):

"la evidencia sugiere que es más probable que actúe de forma racional y optimizadora el IRS [la administración tributaria federal de los Estados Unidos de América] que los contribuyentes" (traducción propia, p. 5).

A partir de esta pregunta se abre un nuevo conjunto de trabajos, denominados de interacción estratégica, en los cuales se analizan en forma simultánea ambos problemas de maximización. ${ }^{52}$ La principal variable de elección de la administración tributaria no será la probabilidad de auditoría sino la "regla de auditoría", esto es, la regla, mecanismo o función a través del cual la administración tributaria determina la probabilidad de auditoria de cada contribuyente.

La administración tributaria tomará en cuanta variables conocidas para decidir la probabilidad de auditoría, la cual no puede asumirse que dependerá del nivel de evasión, pero pueden existir varias alternativas donde la probabilidad de auditoría no sea una variable exógena y, sobre todo, no sea una constante. En un primer momento se intentó considerar esta situación a través de funciones donde la probabilidad de auditoría es variable, y de hecho Allingham y Sandmo (1972) incluyen un capitulo donde la probabilidad de auditoría depende del nivel de ingreso del individuo. Pero allí no se incluye a la administración tributaria como un actor maximizador que toma en cuenta la decisiones del individuo (y viceversa), y esto es lo que cambia la configuración del problema. Si la probabilidad de auditoria es una variable que tendrán en cuenta los contribuyentes para tomar su decisión acerca de la evasión, y la administración tributaria para decidir la regla de auditoria tendrá en cuenta el comportamiento del contribuyente tenemos un modelo que exige la determinación simultánea de los valores de equilibrio de ambas variables.

Así, la auditoria impositiva es un juego dinámico e interactivo en el cual los contribuyentes reaccionan a las decisiones tomadas por la administración tributaria, y viceversa. Si se toman en cuenta tales reacciones las conclusiones que se derivan del modelo son diferentes a las de los modelos estáticos tradicionales. A modo de ejemplo, al considerar la selección de contribuyentes en

\footnotetext{
${ }^{52}$ Referencias obligadas son Reingnamun y Wilde (1985), Gratz et al. (1986), Border y Sobel (1987), Scotchmer (1987), Mookherjee y Png (1989) y Alm y McKee (2004).
} 
función del beneficio neto esperado de la auditoria, sin tener más información que la declaración jurada presentada por el contribuyente o asumiendo que es la única variable que diferencia a un contribuyente de otro, automáticamente se tiende a seleccionar a grandes empresas (en términos de los ingresos declarados). Esto se deriva del hecho de que los costos de la auditoria crecen en forma menos que proporcional a los ingresos generados por la misma, en la medida en que aumenta el tamaño del contribuyente.

Ahora bien, ¿cual será la reacción de los contribuyentes si detectan que la probabilidad de auditoria aumenta mientras más ingresos declaren? Naturalmente, declarar menos y por lo tanto evadir más. Las reglas de "grandes contribuyentes", por así llamarlas, si bien son las mejores desde un punto de vista estático, al incorporar el aspecto dinámico e interactivo de la evasión, es claramente la peor estrategia: inclusive una regla aleatoria pura (que no haría modificar la decisión de los contribuyentes) sería mejor.

En su configuración más simple, considerando solo el ingreso declarado como la única variable independiente, la regla de auditoria óptima es la de montos mínimos. Esta regla establece para todos los contribuyentes, o clase de contribuyente, un monto mínimo que tiene que superar su declaración de ingresos o ventas. Si la declaración supera el monto mínimo el contribuyente no es auditado y si no lo supera, sí lo es con una determinada probabilidad que puede asumir cualquier valor positivo, e incluso 1. Esta regla es óptima por el mismo motivo por el cual la regla de "grandes contribuyentes" es muy mala: al disminuir la probabilidad de auditoria con los ingresos, los contribuyentes tienden a declarar más y por lo tanto evadir menos, a fin de no ser auditados.

Tanto el modelo de Marrelli (1984) como el de Cremer y Gahvari (1993) asumen un escenario estático en el cual no existe interacción estratégica. El modelo de Marrelli (1984) asume una probabilidad de auditoria exógena. El modelo de Cremer y Gahvari (1993), si bien permite estudiar la probabilidad de auditoria óptima para cada industria o clase de contribuyente, asume que es fija e independiente del nivel de ventas: toma el mismo valor para todos los contribuyentes, al menos dentro de la misma industria. Esto indica que la regla de auditoria, para ambos modelos, es la aleatoria simple, aún advirtiendo que tal regla podría ser subóptima frente a una regla algo más sofisticada, como la de montos mínimos. ${ }^{53}$

\footnotetext{
${ }^{53}$ Ver Cremer y Gahvari (1993), p. 262.
} 
Literatura que trata las reglas de auditoría óptimas es bastante amplia y no se refiere exclusivamente a la auditoría impositiva, sino que es de aplicación a otras situaciones donde existen dos agentes (o un agente y un principal) y hay una transferencia de recursos de uno a otro dependendiendo de un reporte. Los contratos de seguros y de deuda, por ejemplo, son de este tipo. La regla de auditoría de monto mínimo para estas situaciones fue primero deducida por Townsend (1979) y luego la literatura fue incorporando diversas variantes, las cuales se analizan a continuación. ${ }^{54}$

Tomando el nivel de ingresos declarado como argumento, las reglas de auditoria que se consideran en la literatura son: la regla de montos mínimos, la regla condicional futura (en la cual la administración se compromete a auditar las posiciones del futuro de aquellos contribuyentes que en el período actual se encuentra han evadido), la regla condicional pasada (similar pero en relación a declaraciones anteriores a la auditada) y la regla aleatoria simple, en la cual la administración tributaria se compromete a auditar una determinada proporción seleccionada aleatoriamente del total de las declaraciones juradas presentadas. ${ }^{55}$ Si se trabaja con señales o clases de auditorias, la regla de auditoria pasará a estar condicionada a tales señales o clases. El abordaje del problema toma caminos diferentes según se asuma que la administración define previamente la regla de auditoria y se compromete a seguirla (compromiso previo) o no (sin compromiso previo). A continuación, se analiza con mayor detalle ambas alternativas.

\section{a. Existe compromiso previo}

Si la administración asume un compromiso acerca del criterio para seleccionar los contribuyentes a auditar, lo hace público y lo respeta una vez recibidas las declaraciones juradas, el esquema puede estudiarse bajo un modelo de principal-agente. La administración tributaria (principal) debe diseñar la regla de auditoria de forma tal que funcione como un sistema de incentivos eficaz para que el contribuyente (agente) evada lo menos posible.

Si bien es posible encontrar referencias anteriores que se aplican al caso de auditorias impositivas, especialmente en la literatura sobre contratos de deuda y de seguros [Towsend (1979)], el primer trabajo que deduce analíticamente una regla de auditoria óptima con compromiso previo

\footnotetext{
${ }^{54}$ Para una revisión reciente completa ver Macho-Stadler y Pérez-Castrillo (2005).

${ }^{55}$ Ver Alm y McKee (2004), Andreoni, Erard y Feinstein (1998), Alm (1999) y Myles (1995).
} 
es Reinganum y Wilde (1985). Tal modelo, fue enriquecido por Scotchmer (1987), que incluye como agregado las clases de auditorías, las cuales son relevantes para los impuestos indirectos. Scotchmer (1987) trabaja con los siguientes supuestos:

i) Neutralidad frente al riesgo del agente.

ii) Esquema de penalidad lineal ( $f$ constante).

iii) El nivel de ingresos de los contribuyentes es una variable aleatoria independiente e idénticamente distribuida según la función $F(y)$, donde $f(y)=F^{\prime}(y)$.

iv) Si bien la administración no conoce el ingreso real $y_{r}$, observa una variable correlacionada a $y_{r}$, que es $q$.

v) La administración no tiene restricción presupuestaria con respecto a la cantidad de auditorias a realizar.

La función de auditoria o regla de selección será en este caso $\phi\left(y_{d}, q\right)$, siendo $y_{d}$ el ingreso declarado. Los contribuyentes intentan minimizar los pagos a la administración (lo cual es similar a maximizar su ingreso esperado), para lo cual eliguen $y_{d}$.

En este esquema dos elementos surgen acerca de la regla de auditoria óptima: i) $\phi^{*}$ (la probabilidad de auditoria óptima) es siempre menor o igual a $1 /(1+f)$; ya que a ese nivel la evasión desaparece y seguir aumentando $\phi^{*}$ no produce resultado alguno, mientras que las auditorias con costosas, ii) la función de auditoria es decreciente con respecto a $y_{d}$.

A partir de este modelo, Scotchmer (1987) deduce una regla de auditoria óptima que tiene la siguiente forma, para algún $y_{q}$,

$$
\begin{aligned}
\phi\left(q, y_{d}\right) & =1 /(1+f) \quad \text { para todo } y<y_{q} \\
& =0 \text { en cualquier otro caso }
\end{aligned}
$$

Si las ventas del contribuyente son menores al monto mínimo $y_{q}$, la declaración será $y_{d}=y_{q}$, ya que la tasa de retorno es: $r_{e}=1-\phi-\phi f=1$ (da lo mismo evadir que no evadir). Por otro lado, si $y_{r}>y_{q}$, el contribuyente declarará $y_{d}=y_{q}$, ya que nunca será auditado y declarar cualquier valor mayor a $y_{q}$ implica un costo innecesario. Este es uno de los resultados más interesantes -y problemáticos- de la regla de auditoria de montos mínimos: los contribuyentes auditados no evaden, mientras que los que evaden no son auditados. 
Dixit y Nalebuff (1991) plantean esta consecuencia del compromiso previo y por tal motivo concluyen que es necesario "mezclar planes" o sea ser impredecible. El argumento, que es aplicable a cualquier regla de auditoria con compromiso previo, es que una regla de auditoria con compromiso previo es idéntico a asumir que existe una fórmula conocida que determina quién será auditado. Por lo tanto, es posible, antes de remitir la declaración jurada, aplicar la formula para saber si esa declaración será auditada. Si se predice una auditoria, pero es posible cambiar la declaración lo mínimo imprescindible hasta evitar toda futura auditoria, es muy probable que el contribuyente haga eso. Si la auditoria es inevitable se decidirá por la honestidad. Por esto se concluye

"El resultado para el IRS de ser totalmente predecible, es que auditará exactamente a las personas equivocadas" (traducción propia, p. 23).

Sin embargo, la función objetivo de la administración tributaria no es en este modelo encontrar evasores, sino maximizar la recaudación esperada. Esto es, se estudia el impacto sobre la recaudación neta de diversas reglas de auditoria. De hecho, la regla de montos mínimos domina reglas "impredecibles" (o sea una regla aleatoria) en términos de recaudación neta, por más que en forma directa las auditorias no detecten evasión.

Tanto el modelo original de Scotchmer (1987) como sus extensiones se refieren a impuestos pagados por personas. Marhuenda, Vasin y Vasina (2002) discuten la regla de auditoria óptima para un impuesto indirecto pagado por empresas en un modelo de asimetría de la información, en donde el gobierno conoce la capacidad productiva de la firma, pero no sus costos ni sus ventas. La regla óptima en este caso es la de montos mínimos con respecto a la capacidad productiva.

La regla de auditoría de montos mínimos se flezibiliza ante modelos con compromiso previo pero con aversión al riesgo. Mookherjee y Png (1989) plantean un modelo general de agente y principal, donde hay transferencias que dependen de declaraciones sobre el estado por parte del agente. El principal (que recibe la declaración) tiene siempre la posibilidad de auditar, aunque no a todos porque las auditorías tienen un costo. En este modelo donde los agentes son aversos al riesgo y existe riesgo moral (la probabilidad de la situación ex post no es exogena de las acciones del individuo) se encuentra lo siguiente respecto a la regla de auditoría: 
a) Existen esquemas óptimos.

b) Todos los reportes de ingresos que son auditados deben ser auditados en forma aleatoria $(\phi<1)$. A nadie se le garantiza $\phi=1$

c) Todos los esquemas óptimos tienen la propiedad que si el contribuyente es auditado y su reporte no tiene inconvenientes, debe ser premiado. ${ }^{56}$

d) El reporte de maxima transferencia no será auditado, mientras menor el reporte, mayor la probabilidad de ser auditado. Para reportes mayores la probabilidad tienen que ser menor o igual.

e) Si no hay riesgo moral, los reportes son monotonos respecto al nivel de ingreso real. ${ }^{57}$

f) La regla de montos mínimos no es nunca óptima en este modelo.

\section{b. No existe compromiso previo}

Si la administración tributaria no asume un compromiso previo, se presenta una situación en la cual cada uno de los jugadores (los contribuyentes y la administración tributaria) adoptan la mejor estrategia, dada la estrategia que ha adoptado el otro jugador (que a su vez es maximizadora), situción que se puede analizar con la teoría de los juegos. El primer análisis del problema realizado en el contexto de tal teoría es Graetz, Reingnamun y Wilde (1986). Este modelo, además de incluir a la administración como un jugador estratégico clasifica a los contribuyentes en dos categorías: jugadores estratégicos (que se comportan de acuerdo al modelo básico de evasión impositiva) y cumplidores habituales, los cuales nunca evaden. Esta clasificación se realiza a fin de lograr resultados más convincentes con respecto a la evidencia empírica, donde habitualmente hay contribuyentes que cumplen con sus obligaciones independientemente de la rentabilidad de evadir.

El modelo es sumamente estilizado, tiene solo dos niveles de ingresos, alto y bajo, y la posibilidad de evadir se le presenta exclusivamente al contribuyente de altos ingresos, si declara tener bajos ingresos. La evasión es por lo tanto una variable dicotómica indicativa de "incumplimiento": si tiene altos ingresos y declara bajos es evasor, si tiene altos ingresos y declara altos o si tiene bajos ingresos es cumplidor (el caso de tener bajos ingresos y declarar altos se deja fuera

\footnotetext{
${ }^{56}$ Esta opción no es usualmente considerada por la literatura en los modelos de evasión impositiva.

${ }^{57}$ La posibilidad de riesgo moral se presenta en contratos voluntarios (caso de seguros o contratos de deuda), pero no es el caso ante un contrato compulsivo (una regulación del gobierno).
} 
de análisis). El equilibrio es en términos de la probabilidad de auditoria para cada grupo y la probabilidad de incumplimiento para los contribuyentes de altos ingresos.

Las conclusiones a las cuales es posible arribar en estos modelos son más débiles y dependientes del modelo que las de los esquemas con compromiso previo, aunque también son más realistas. La regla aleatoria simple siempre es la peor de todas, siendo dominada por la condicional futura y por la condicional pasada, además de la regla de montos mínimos. Cuando se trabaja con varios niveles de ingresos posibles, la probabilidad de auditoria es una función decreciente de los ingresos declarados, siendo $\phi=0$ en el máximo ingreso.

Siguiendo a Cowell (2004), otras conclusiones interesantes a las que en general se arriba con estos modelos son:

a) Disminuir el costo marginal de las auditorias reduce el nivel de incumplimiento, pero mantiene sin modificar la probabilidad de auditoria óptima.

b) Incrementos en $f$ reducirá la tasa de probabilidad de auditoria óptima y también el grado de evasión de equilibrio.

c) Incrementos en la tasa impositiva disminuye el nivel de evasión y puede aumentar o mantener sin cambios la probabilidad de auditoria óptima.

Si existe restricción presupuestaria, y la probabilidad óptima de auditoria no puede ser alcanzada (o sea que opera la restricción), la regla del monto mínimo implica congestión y se transforma en un juego de coordinación. El hecho de que una persona sea o no auditada depende no solo de su propio comportamiento sino también del comportamiento de los demás contribuyentes. Aquí pueden existir múltiples equilibrios, aunque los modelos más simples, como el inicialmente presentado por Graetz et. all. (1986) generan total grado de incumplimiento como estrategia óptima para los contribuyentes ante la congestión. Esto es bastante problemático, porque la restricción presupuestaria es un supuesto muy realista.

El tema fue luego analizado con mayor profundidad, como respuesta a una crítica mas general a todos los modelos de interacción hasta aquí presentados: plantean el juego como una relación uno a uno, cuando en la realidad hay por un lado una administración tributaria y por la otra un conjunto de contribuyentes con intereses no necesariamente comunes. Alm y McKee (2004) estudian reglas de auditorias en las cuales se incorpora el comportamiento del contribuyente relativo al comportamiento del resto de los contribuyentes, lo que denominan una 
"regla de auditoria condicional". Según tales autores, esta es la mejor forma de reflejar lo poco que se sabe sobre como el Internal Revenue Services (IRS, la Administración Tributaria Federal de los Estados Unidos de América) construye el Discriminant Index Function (DIF). Esta última es una función construida por el IRS para decidir qué contribuyentes auditar basado en los items reportados en el periodo corriente. Según Alm y McKee (2004), el DIF se construiría a partir de las desviaciones de los ingresos declarados y otros ítems reportados con respecto a la misma información presentada por contribuyentes "similares".

Si este fuese el caso, el juego es también entre contribuyentes y los mismos tendrán un incentivo para actuar en forma coordinada a fin de que pocos contribuyentes se desvíen del DIF. Si existe un alto nivel de coordinación la regla de auditoria condicional puede no ser buena. Todos los contribuyentes podrían acordar un determinado grado de evasión similar, nadie tendría una DIF demasiado alto y la recaudación podría ser mínima. Por supuesto que es un caso de "dilema del prisionero", ya que una vez que se pusieron de acuerdo en reportar el mínimo nivel de ingresos, o inclusive cero, cada contribuyente tendrá un incentivo de romper el acuerdo, declarar un poco más y de esa forma asegurarse que no será auditado.

En los juegos de coordinación, no hay una estrategia dominante para todos los jugadores, sino más bien una respuesta óptima condicional, que implica un matching entre las estrategias de varios jugadores.

Alm y McKee (2004), a través de técnicas experimentales, encuentran que a los contribuyentes les cuesta coordinar niveles muy bajos de reporte [la preocupación de Graetz et all. (1986)], aunque la coordinación previa tiene cierto efecto en una algo menor declaración de ingresos. Además, la combinación de una regla aleatoria simple con la regla condicional aumenta significativamente el nivel de cumplimiento tributario, con respecto de una regla condicional pura, lo que apoya la aleatoriedad en la selección de casos. ${ }^{58}$

\footnotetext{
${ }^{58} \mathrm{El}$ problema de la coordinación entre contribuyentes adquiere una mayor relevancia para empresas que para individuos ya que la decisión de evasión impositiva en el caso de empresas es en muchos casos una decisión coordinada. En el caso de un impuesto indirecto que grava operaciones comerciales entre empresas (o el IVA) una determinada venta en negro implica que esa compra tampoco sea registrada por la otra empresa. Liptov (2006) analiza el tema formalmente.
} 


\subsection{Prescripciones de política}

Los modelos teóricos así como algunos trabajos empíricos mencioandos, generan una interesante riqueza respecto a posibles fundamentaciones de diversas políticas públicas. En particular, permiten interpretar con mayor flexibilidad (y realismo) el impacto de determinada política impositiva, el cual no puede establecerse sin considerar el incumplimiento tributario como un factor importante. Por otro lado, genera un fundamento a las alternativas de política de la administración tributaria, como ser: ¿cuán grande debe ser la administración tributaria o hasta que punto se debe aumentar la probabilidad de auditoría? ¿cuán altas deberían ser las penalidades? ¿cuál es la regla de auditoría óptima? Estas, entre otras, son las preguntas que pueden analizarse con mayor precisión a partir de estos modelos. En este apartado se analiza la literatura al respecto.

Un elemento central en la discusión de las políticas públicas es la correcta identificación de los objetivos de la misma. Por tal motivo, antes de presentar en detalle las prescripciones de política, se discute brevemente los objetivos de política que están por detrás. Una vez revisados los mismos, se presentan las prescripciones de política dentro del modelo básico, así como las que surgen de las extensiones del mismo.

\subsubsection{Objetivos de la administración tributaria}

En la literatura se han planteado, al menos, tres objetivos para las administraciones tributarias con dos variantes adicionales, los que se discuten a continuación.

\section{a. Maximizar el bienestar social, sujeto a un monto fijo a recaudar}

Este objetivo refleja la misión del gobierno en general y por lo tanto es ampliamente utilizada en la literatura sobre economía del bienestar e imposición. ${ }^{59}$ De modelos con este esquema se deriva la regla de Ramsey sobre imposición óptima. El modelo de Cremer y Gahvari (1993), plantea el problema en términos de un gobernante benevolente, que desea maximizar la utilidad del consumidor representativo, sujeto a una restricción en términos de recaudación impositiva a alcanzar. No se diferencia en este caso al gobierno en general, de la administración tributaria

\footnotetext{
${ }^{59}$ Ver, entre otros, Kaplow (1989) y Cremer y Ghavari (1993).
} 
en particular.

Si bien este objetivo es ampliamente aceptado en el análisis de la política impositiva, cuando se analiza en particular la actuación de la administración tributaria el objetivo de maximización del bienestar aparece como excesivamente amplio. El bienestar social es afectado por las tasas impositivas, por la penalidad y especialmente por el uso de los fondos recaudados para la provisión de bienes públicos, herramientas fuera del control de la administración tributaria y que, en general, los modelos de evasión impositiva dejan de lado. ${ }^{60}$ Asignar el objetivo de maximizar el bienestar social a una administración tributaria, en este sentido, implica cierta incompatibilidad entre objetivos e instrumentos. Parece más adecuado, si se focaliza el análisis en una herramienta que maneja la administración tributaria, utilizar un objetivo que está dentro de su alcance, un objetivo más acorde con la misión de un servicio de recaudación de impuestos.

\section{b. Maximizar la recaudación neta de los costos incurridos para alcanzarla o Maxi- mizar la recaudación, sujeta a una restricción presupuestaria.}

Este es el objetivo de la administración tributaria usualmente encontrado en los modelos de interacción estratégica, aunque también es utilizado en modelos econométricos que intentan estimar las funciones de auditoría. ${ }^{61}$ La definición de la regla de auditoría de monto mínimo como óptima surge de este objetivo.

Slemrod y Yitzhaki (2000) han planteado que cual de los dos objetivos hasta aquí presentados es el correcto dependerá de cual es la pregunta que intenta responderse. El objetivo referido al bienestar social es más acorde con la pregunta sobre cuan grande debe ser la administración tributaria o sea cual debería ser su presupuesto, mientras que el objetivo de recaudación plantea su rendimiento óptimo para un presupuesto dado. Si se analiza el problema del tamaño óptimo de la administración desde un punto de vista del objetivo de recaudación, estaríamos sobreestimandola, ya que una medición adecuada de los beneficios sociales de la tarea de la administración tributaria no es la recaudación que genera (que es una transferencia de recursos) sino la disminución en la evasión. Al analizar el comportamiento de la administración tribu-

\footnotetext{
${ }^{60}$ Una excepción es Besfamille y Olmos (2009) que, con un modelo de diseño de mecanismos similar a Mookherjee y Png (1989), describen una política fiscal óptima que incluye las variables de control de cumplimiento (con detección imperfecta), las tasas impositivas y los bienes públicos.

${ }^{61}$ Ver por ejemplo Alm, Blackwell y McKee (2004).
} 
taria, sin embargo, aparece mucho más lógico trabajar con el objetivo de recaudación ya que tal agencia habitualmente no tiene ingerencia en la determinación de un propio presupuesto. Por el mismo motivo, es más lógica la variante con restricción presupuestaria, lo cual genera algunos inconvenientes analíticos ya revisados respecto a congestión.

\section{c. Maximizar los recaudación neta de las fiscalizaciones o Maximizar la recaudación de las fiscalizaciones sujeta a una restricción presupuestaria.}

Esta es el objetivo que mejor refleja las decisiones que realmente toman las administraciones tributarias al tomar decisiones que están a su cargo, por ejemplo, las reglas de auditoria. Tanto es así que Murray (1995), en uno de los pocos estudios que intentan estimar empíricamente una regla de auditoria, utiliza este objetivo sin discutir siquiera si es razonable.

Es interesante observar hasta que punto este objetivo es contradictorio con el de maximizar las recaudación neta. La regla de monto mínimo, óptima utilizando el objetivo de maximizar la recaudación es quizás la peor si se utiliza el objetivo de maximizar la evasión detectada.

\subsubsection{Optimización en el modelo básico}

\section{a. Penalidad}

Christiansen (1980) notó que si el contribuyente exhibe aversión al riesgo, las penalidades y las probabilidad de auditoría no son substitutos perfectos. En particular, si se aumentan las penalidades reduciendo la probabilidad de auditoría para mantener la ganancia esperada de la evasión inalterada, la evasión disminuye. Además, $\phi$ tiene costo, mientras que $f$ no lo tiene, por lo cual lo óptimo son penas altas con una probabilidad muy baja, lo cual es un resultado usual en la teoría económica del crimen [Becker (1968)]. Sin embargo, diversas consideraciones de tipo moral (por ejemplo, se busca que las penalidades sean acordes a la gravedad del crimen) o prácticas evitan que se tomen decisiones de ese tipo. Es válido preguntarse si tal política no aumenta las posibilidades de corrupción dentro de la administración tributaria. Acconcia, D'Amato y Martina (2003) analizan este tema a través de un modelo donde las empresas pueden sobornar a los inspectores, y la administración tributaria tiene un costo de monitoreo a fin de reducir la corrupción interna. Encuentran que, incluso permitiendo la posibilidad de soborno, se mantiene el principio de la pena máxima. También demuestran que una mayor $f$ reduce la 
evasión, mientras que el efecto en el nivel de corrupción es ambiguo. Esto es así debido a que el incentivo a la corrupción del inspector está atado al impuesto evadido más la penalidad, un incemento en $f$ implica obviamente una mayor penalidad, pero también menor evasión, por tal motivo el efecto final es ambiguo. Estos resultados, sin embargo, no se mantienen en modelos de interacción estratégica donde se incorpora la posibilidad de corrupción [Sanyal, Gang y Goswami (2000)].

De todos modos, es claro que el proceso de aplicar una pena máxima se hace más complejo y se encarece. En los modelos donde hay posibilidades de modelar la interacción entre los beneficios (bajar la evasión) y los costos (administración más compleja) de penalidades mayores, se supone un techo a $f$, ya que se asume que las penas están dadas más por una valoración social del fraude fiscal en relación a otros comportamientos ilegales dentro de esa sociedad que por un cálculo costo beneficio del gobierno [Slemrod y Yitzhaki (2000)]. ${ }^{62}$

No siempre la pena es lineal, sino que puede ser perfectamente convexa. En el caso de China, por ejemplo, la gravedad de la pena va a aumentando de acuerdo al tamaño del fraude, llegando a partir de determinado nivel a la pena capital [Hashimzade, Huang y Myles (2006)]. Los esquemas de penalidad convexos resuelve uno de los problemas de los modelos de evasión impositiva para empresas, que necesitan aversión al riesgo (o costos directos de evadir convexos) para que no genere siempre soluciones de esquina. ${ }^{63}$

\section{b. Tasas impositivas}

Obviamente el elemento principal de la política tributaria es fijar las tasas impositivas y el nivel de las tasas afecta la evasión, aunque su impacto no es totalmente claro. Si bien la mayoría de los estudios empíricos y experimentales concluyen en una relación directa entre tasas impositivas y evasión (mayores tasas implica una mayor evasión), en los modelos teóricos

\footnotetext{
${ }^{62}$ Besfamille y Olmos (2009) fijan como techo de la tasa impositiva y la penalidad a la restricción presupuestaria del contribuyente, o sea los ingresos en el período corriente.

${ }^{63} \mathrm{Si}$ bien el caso de China es poco usual, las penalidades convexos no lo son. En Argentina, la ley penal tributaria implica que la evasión impositiva a partir de determinado nivel puede impicar un castigo corporal (prisión). Además, es común que la multa sea un porcentaje creciente del monto evadido. Hashimzade, Huang y Myles (2006) estudian el efecto en un modelo de evasión por parte de empresas con esquemas de penalidad convexos tomando como ejemplo a China.
} 
esta situación no es tan clara: depende del modelo en sí. ${ }^{64}$ La mayoría de los modelos en los cuales la penalidad es una función del ingreso no declarado, el efecto de la tasa impositiva en el nivel de evasión es ambiguo. En cambio, si la penalidad es función del impuesto evadido, y no de la base imponible no declarada (como es en general en la legislación de occidente), en ese caso sí la tasa impositiva tendrá un efecto negativo en la evasión: si la tasa impositiva es mayor, el impuesto no declarado es menor. Esta fue la primer "correción" al modelo de Allingham y Sandmo (1972), donde la relación entre tasas impositivas y evasión era ambigüa, propuesta por Yitzhaki (1974). ${ }^{65}$ Claro que el costo de eliminar la ambiguedad del modelo original en un aspecto central, es quedar atado a una respuesta que va en contra de lo que mayoría de la gente piensa al respecto y de lo que la evidencia en general suguiere: cuando las tasas impositivas aumentan, la evasión aumenta porque el beneficio de evadir es mayor. ${ }^{66}$

Sin embargo, este es el caso de los modelos con impuestos directos y con aversión al riesgo, variando estos supuestos las conclusiones se modifican. En el modelo de Cremer y Gahvari (1993) la tasa impositiva tendrá un efecto positivo sobre la evasión. En tal trabajo se incorpora la evasión dentro del marco teórico de imposición óptima, con el argumento de que una determinada tasa efectiva de imposición puede ser obtenida con distintas variantes de $t$ y de $\alpha$. En este sentido, se deriva un trade off entre las tasas de imposición y las probabilidades de auditoria así como una regla de Ramsey "modificada", que incorpora el nivel de evasión. Las tasa de imposición óptima, en lugar de igualar la reducción en la demanda compensada de cada bien (como es el caso de la regla de Ramsey tradicional), tienden a generar una mayor reducción en aquellos bienes en los cuales la evasión es menor. Este es, ceteris paribus, una mayor tasa para aquellos sectores con menor evasión.

Ray (1994), utilizando un modelo similar al de Cremer y Gahvari (1993), presenta las siguientes proposiciones vinculadas con la imposición óptima con evasión (p.11-12):

i) En la presencia de evasión en impuestos al consumo, las tasas impositivas uniformes

\footnotetext{
${ }^{64}$ Fisman y Wei (2001) determinan, por ejemplo, que un incremento del $1 \%$ de las tasas impositivas (tarifas) aumentan la evasión en un $3 \%$. Joulfaian y Rider (1998) estudian el impacto de las tasas en empresas personales o muy pequeñas. Poterba (1987) muestra el impacto de los cambios en las tasas sobre la evasión en impuestos sobre ganancias de capital. Das-Gupta y Gang (2000) presentan un modelo general para descomponer los cambios en la recaudación entre cambios en las tasas impositivas, las deducciones y la evasión.

${ }^{65}$ Christiansen (1980) también obtiene el mismo resultado.

${ }^{66}$ Este argumento utiliza Sandmo (2005) para defender el modeo original, cuarenta años después publicado el mismo.
} 
generalmente no serán óptimas, inclusive para una autoridad tributaria utilitaria.

ii) Si la evasión impositiva el costo de evadir por unidad de producto y la probabilidad de auditoria son los mismos para todos los bienes, entonces una autoridad tributaria utilitaria encontrará óptimas a tasas impositivas uniformes.

iii) Si no hay costos de evasión y la autoridad tributaria es utilitaria, entonces las tasas impositivas "generalizadas" serán uniformes.

iv) Si no hay costos de evasión y las tasas de evasión impositiva son las mismas en todas las industrias y la autoridad tributaria es utilitaria, entonces las industrias con una mayor probabilidad de auditoria tendrán tasas de evasión menores. Alternativamente, si las probabilidades de auditoria son las mismas para todos los bienes, entonces las industrias con menor evasión atraerán las tasas impositivas más bajas.

Un tema relevante vinculado con las tasas impositivas óptimas y la evasión, mencionado por Slemrod y Yitzhaki (2000) es que, salvo condiciones bastante especiales, la teoría de la imposición óptima implica que todos los bienes deben ser gravados por tasas diferentes. Sin embargo, esto tiene un costo muy alto de administración e implicará (dado un presupuesto fijo de la administración tributaria) menos auditoria y por lo tanto mayor evasión. Esto está muy vinculado con la necesidad de involucrar el costo de la administración en el análisis de la imposición óptima y la evasión.

Como muestra Lee (2001), si los contribuyentes puede autoasegurarse contra la auditoría, una mayor tasa impositiva implica mayor evasión. Por autoasegurarse se entiende la posibilidad de eludir impuestos. Si tal posibilidad existe, el incumplimiento será mayor ante mayores tasas impositivas.

\section{c. Probabilidad de auditoría}

El sentido común diría que lo óptimo es incrementar $\phi$ hasta que el beneficio marginal en impuestos recuperados por la auditoria se iguale al costo marginal de la auditoria. Sin embargo, como demostraron Slemrod y Yitzhaki (1987), esta regla es incorrecta. El costo de $\phi$ es un costo real para la sociedad, pero el beneficio (mayor recaudación) es una transferencia de recursos entre el contribuyente y el estado. La administración tributaria no es una actividad generadora de riqueza, sino de ingresos al Estado. 
La regla correcta es igualar el costo de la auditoria con el beneficio por reducir la evasión, el cual está determinado por la eliminación del costo social producido por tal actividad. La pregunta es entonces cual es el costo social de la evasión. El concepto de costo social o carga excedente producida por la evasión para el modelo básico de utilidad esperada (y principalmente para los impuestos a los ingresos) surge de Slemrod y Yitzhaki (1987). Ellos definen a la carga excedente como la diferencia entre la utilidad esperada obtenida por el individuo pagando los impuestos con incertidumbre y la utilidad obtenida pagando exactamente el mismo monto pero con certeza. Si el contribuyente tiene aversión al riesgo siempre preferirá pagar el monto que en definitiva pagaría en el modelo con evasión (el impuesto esperado $t_{e}$ ) pero con certeza, que con el grado de incertidumbre que implica evadir. En última instancia la carga excedente de la evasión está generada por la incertidumbre: es la pérdida de utilidad que produce pagar los impuestos como una lotería, en lugar de con certeza. ${ }^{67}$

Para el caso de impuestos a las ventas, Palda (2001) propone como costo social de la evasión el incremento en los costos promedio de la industria generados por la existencia de empresas de menor productividad, pero con mayor habilidad en la evasión. El argumento es que si existe una relación negativa entre productividad y habilidad para evadir (las empresas menos productivas son las que más evaden), la existencia de la evasión aumenta el costo promedio de los bienes que se producen y se comercializan. De no existir evasión, las empresas más ineficientes serían expulsadas del mercado. Palda (2001) llama displacement loss al costo social generado por la evasión y considera que puede superar la carga excedente de la imposición.

En este contexto, si la administración tributaria intenta igualar el costo marginal de la auditoria con los impuestos que se recuperan medianter la misma, la administración tributaria estará sobredimensionada y estará generando una pérdida en el bienestar.

\footnotetext{
${ }^{67}$ Cowell (1990) define el costo de la evasión como el dinero que la persona estaría dispuesta a pagar a fin de que le garanticen que no será auditado y que, por lo tanto, podrá quedarse con el monto evadido. Por otro lado, Bayer y Sutter (2003) afriman que la evasión fiscal implica costos sociales asociados a la inversión que hacen los contribuyentes en esfuerzo y dinero para ocultar sus ingresos y también en los costos asociados al control del cumplimiento tributario por parte de la administración. Estas actividades son un desperdicio de recursos y las genera la evasión fiscal.
} 


\subsubsection{Reglas de auditoría}

Dentro de los modelos de interacción estratégica una de las cuestiones centrales es la definición de la regla de auditoría óptima. Como siempre, las conclusiones que pueden extraerse depende en gran parte del modelo utilizado y de los supuestos que se adopten, aunque en general se encuentra que la estrategia dominante es la regla de montos mínimos. Según Andreoni, Erard y Feinstein (1998) en un modelo en el cual se cumplan con las siguientes dos condiciones la regla de montos mínimos es dominante: neutralidad respecto al riesgo y función de penalidades lineal. ${ }^{68}$

La intuición que está por detrás de este resultado es que cuando $\phi$ es una función creciente del ingreso o de las ventas declaradas (y asumiendo que depende exclusivamente de esa variable) los contribuyentes tenderán a declarar menos, ya que de ese modo maximizan la utilidad esperada. Si los contribuyentes conocen la regla de auditoria, lo óptimo es que la misma no sea una función creciente del ingreso o ventas.

Como se analizó en la sección 1.2, la definición de cual es la regla de auditoría óptima dependerá en forma crítica de si la administración tributaria asume o no un compromiso previo al respecto. El tema central es entonces analizar los beneficios y costos de comprometerse ex ante a una determinada estrategia, para lo cual hay que considerar además hasta que punto un compromiso de la administración tributaria es totalmente creíble o que herramientas deberían aplicarse para lograr esa credibilidad. ${ }^{69}$ Otro tema central, que de algún modo limita fuertemente la aplicación de estos modelos es que todos ellos suponen que el contribuyente conoce la regla de auditoria aplicada por la administración tributaria [Alm (1999)]. Sin embargo, es bastante común que la administración tributaria trate al criterio de selección con estricto secreto, lo que indica que los administradores tributarios tienen una concepción bastante diferente acerca del tema [Tanzi y Shome (1993)]. Algunos estudios indican que los contribuyentes conocen muy poco acerca de la probabilidad de auditoria y de cómo varía esa probabilidad con los montos

\footnotetext{
${ }^{68}$ Marchese y Privileggi (2002) analizan la regla de montos mínimos en un modelo con aversión al riesgo, pero para determinar cual es el impacto en la equidad horizontal y vertical. No se compara tal regla con otras alternativas a fin de determinar si es óptima.

${ }^{69}$ Esto es importante, ya que si los contribuyentes no creen en el compromiso obviamente no se comportarán como lo esperado. Por ejemplo, en la regla de montos mínimos, algún administrador tributario podría verse tentado de romper el compromiso y auditar sólo aquellas declaraciones que superan el valor límite fijado, con lo cual aumentaría fuertemente el resultado de la auditoria. Por el mismo motivo, es difícil que un compromiso previo de montos mínimos sea creíble [Slemrod y Yitzhaki, (2000)]
} 
declarados..$^{70}$

Una regla muy simple de compromiso previo sobre la cual existe experiencia e incluso se han realizado estudios acerca de su impacto es la de seleccionar algunos contribuyentes y, por algún motivo, avisarles previamente que su declaración jurada será auditada. Slemrod, Blumenthal y Christian (2001) estudiaron el impacto de tal política en el estado de Minnesota a través de un experimento controlado y encontraron algunos elementos desconcertantes: si bien los contribuyentes pequeños aumentaron el ingreso declarado respecto al grupo control, los contribuyentes más grandes lo disminuyeron. La interpretación de los autores es que, dada la incertidumbre sobre los ingresos gravados, los contribuyentes grandes utilizan la auditoria como un proceso de negociación en el cual prefieren comenzar con un monto bajo. Este hallazgo también es consistente con la evasión decreciente respecto del nivel de ingresos, elemento también usualmente encontrado en los estudios empíricos.

Por otro lado, Alm y McKee (2004) demuestran mediante una técnica experimental que, como es de esperar, avisar con anticipación quien será auditado mejora el cumplimiento de los contribuyentes a audiar, pero reduce el de los no alzanzados por el control. El nivel de cumplimiento agregado, bajo una política de compromiso previo, también cae, lo cual daría sustento a la práctica mucho más usual de las administraciones tributarias de no dar a conocer previamente, ni asumir un compromiso, respecto a las reglas de auditoría.

Un elemento central de la regla de selección es que las administraciones tienden a recibir bastante información de los contribuyentes y no solamente el ingreso o ventas declaradas y tienden a utilizar toda esa información para decidir a quien auditar [Alm (1999)]. Otro elemento relevante es qué regla de auditoría adoptar cuando existen grupos con distintas oportunidades de evadir. Ratto y Vergue (2000) demuestran que en tal caso, cuando la administración tributaria tienen un presupuesto no tan bajo, tendrá como política óptima eliminar la evasión de aquellos contribuyentes con pocas oportunidades de evadir.

\subsubsection{Integridad y calidad de la ley impositiva}

La principal preocupación detrás de los esfuerzos de simplificación de las leyes impositivas, está vinculada con los costos privados del cumplimiento tributario, más que con la evasión en sí

\footnotetext{
${ }^{70}$ Ver las referencias en Andreoni, Erard y Feinsten (1998).
} 
misma. Sin embargo, estos esfuerzos también tienen su justificación desde el punto de vista de la evasión. La ley impositiva es la que genera u obstaculiza las oportunidades de evadir que, según Tanzi y Shome (1993), es uno de los factores más importantes en la explicación del alto grado de evasión existente en países en desarrollo. La diversidad de tasas impositivas para cada uno de las ramas o industrias, por ejemplo, genera enormes oportunidades de evasión, por la dificultad de ejercer controles efectivos. Las tasas igual a cero para algunos contribuyentes ("exenciones subjetivas"), regiones o sectores económicos es el caso extremo, que facilita la evasión.

\subsubsection{Moral tributaria}

Si bien casi todos los modelos teóricos que incluyen a la moral tributaria o normas sociales lo toman como un parámetro del sistema, se han mencionado algunos elementos bajo control del gobierno (no necesariamente de la administración tributaria) que tienden a generar una mayor moral tributaria: la satisfacción en general con el gobierno y en particular con los bienes públicos que reciben o el nivel de participación en las elecciones. También el nivel de participación en el proceso de toma de decisiones respecto a la confección del presupuesto público [Hanousek y Palda (2001, 2004)].

Feld y Frey (2002) han demostrado además que en aquellos lugares en los cuales existe una alta moral tributaria, los contribuyentes son tratados con respeto y consideración: por ejemplo, ante la detección de la falta de declaración de alguna operación comercial o ingreso, se asume que el contribuyente cometió un error y se invita a corregirlo, en lugar de asumir que existió la voluntad de engañar al fisco y evadir impuestos.

Los esfuerzos amplios de control tributario (por ejemplo, incrementos significativos de $\phi$ y f) pueden dar la señal a los contribuyentes de que la evasión es generalizada. Si esto sucede disminuirá la moral tributaria ya que, como vimos, las normas son sociales y dependen fundamentalmente de lo que la gente piensa es el comportamiento del resto de los miembros de la sociedad. Por tal motivo, algunas veces se han visto como contradictorias las políticas basadas en el control con aquellas centradas en la moral tributaria. ${ }^{71}$ Lederman (2003) presenta el caso de que ambas políticas pueden ser complementarias, en la medida en que se segmente

\footnotetext{
${ }^{71}$ En la misma dirección, Rhoades (1998) concluye que, debido a la posibilidades de errores durante las auditorias, existe un trade off entre los derechos de los contribuyentes (moral tributaria) y las efectividad de las auditorias.
} 
adecuadamente a los contribuyentes y se apliquen estrategias diferenciadas a cada grupo.

La evasión tributaria cae en un juego del tipo de free rider. En la medida en que son más los que evaden, la carga pública caerá en menos personas y por lo tanto el incentivo de evadir es más alto. Por este motivo es también importante tratar de incluir los bienes públicos en el juego. Relacionar al máximo posible lo que se recibe por lo que se paga. Los estudios experimentales muestran que es mayor el nivel de "moral tributaria" en los juegos en los cuales interviene la provisión de bienes públicos y tal efecto se fortalece en la medida de que existe participación en la selección de los bienes públicos a proveer. Lo mismo en relación a la posibilidad de votar, y la satisfacción general con el gobierno.

\subsubsection{Moratorias}

Los modelos de evasión fiscal se han utilizado para analizar el impacto de las moratorias o aministías tributarias, herramientas de la administración tributaria a través de las cuales se reducen o eliminan por un tiempo limitado la penalidad por haber evadido, si se reconoce voluntariamente tal situación. ${ }^{72}$ La principal preocupación de los administradores es que si los contribuyentes anticipan futuras moratorias, las mismas reducen el cumplimiento tributario en el período actual. Por otro lado, las moratorias se consideran iniciativas inequitativas, ya que benefician al incumplidor, que puede terminar pagando menos que el cumplidor. ${ }^{73}$ Aun así, estos programas son muy utilizados por las administraciones tributarias. Los objetivos de las moratorias son dos: i) incrementar la recaudación en el período corriente, ii) incorporar al conjunto de contribuyentes cumplidores a evasores para los cuales las sanciones legisladas les genera una barrera de entrada. ${ }^{74}$ Otras veces se han tomado las moratorias como una transición más "suave" a una política más firme de control de la evasión, que implica mayores penalidades. $^{75}$

Dentro de los modelos de evasión fiscal, las moratorias pueden analizarse como iniciativas

\footnotetext{
${ }^{72}$ Ver Alm, McKee y Beck (1990), Andreoni (1991), Alm y Beck (1993), Franzoni (1996), Macho-Stadler y Pérez-Castrillo (2002a) y Marchese y Privileggi (2004).

${ }^{73}$ Este argumento se aplica fuertemente en contextos inflacionarios, ya que un componente usual de las moratorias es reducir (o incluso eliminar) los interes por mora, además de las multas.

${ }^{74}$ Son comunes en EUA las aministías de las bibliotecas públicas: a fin de recuperar libros y clientes perdidos, por un tiempo eliminan la penalidad por devolver tarde algun ejemplar. En este sentido es que la sanción funciona como una barrera de entrada.

${ }^{75}$ Alm, McKee y Beck (1990) resumen los argumentos a favor y en contra de las moratorias.
} 
tomadas por la administración tributaria en las cuales se reduce, en forma temporaria o aún permanente, la penalidad $f$ para aquellos contribuyentes que voluntariamente reconocen todo o parte de la fracción del ingreso no declarada en períodos pasados $(1-\alpha)$. Andreoni (1991) analiza el peor caso posible: una moratoria permanente, que puede ser anticipada en forma total por los contribuyentes, en un modelo de evasión fiscal de impuestos directos de dos períodos. Incorpora un componente de incertidumbre respecto al nivel de consumo del período 2 , mientras que los contribuyentes son aversos al riesgo. Ante este modelo, lo interesante es que se encuentra que las moratorias permanentes pueden mejorar tanto la eficiencia como la equidad del sistema tributario, por dos motivos.

En primer lugar, las moratorias tienden a un "equilibrio presupuestario". Esto es, las perdidas de ingresos por incremento en la evasión debido a la moratoria en un periodo tiende a ser recuperada luego a través de la misma moratoria.

En segundo lugar, cuando hay moratoria el impuesto evadido funciona como una "opción". La amnistía le permite a los de bajo riesgo (o buena suerte, o sea que les va bien en los negocios) separarse de los de alto riesgo (o mala suerte). La moratoria transfiere ingresos (ex ante) desde los estados buenos a los malos, mientras que ex post incrementa la utilidad de aquellos a los que efectivamente se confirmó la mala suerte (y tuvieron shocks de ingreso). De este modo, aún cuando la moratoria no genere mayor recaudación tributaria, puede producir mejoras de Pareto en el bienestar general. Se encuentra también que el impacto de la moratoria en la recaudación dependerá del nivel de evasión al inicio: si el mismo es alto es mas probable que la moratoria incremente la recaudación en los periodos futuros.

Franzoni (1996) presenta además de la moratoria típica analizada por Andreoni (1991) dos casos adicionales de amnistías bastante usuales en los países centrales: i) amnistía respecto a persecusión penal (si el contribuyente conforma la deuda, no es perseguido penalmente), ii) eliminación de posibilidad de auditoría (o bloqueo fiscal), de rectificar en determinada cantidad declaraciones juradas pasadas. ${ }^{76}$ En tal estudio se derivan las condiciones bajo las cuales este tipo de amnistías son beneficiosas para el gobierno. Este tipo de amnistía funciona como un mecanismo de autoselección (screening device), donde los contribuyentes que más evaden

\footnotetext{
${ }^{76}$ Otra alternativa similar es cuando, durante una auditoría, la misma puede bloquearse o suspenderse de conformar una parte del impuesto evadido. Esta alternativa es analizada en un modelo teórico de evasión fiscal en impuesto directos por Macho-Stadler y Pérez-Castrillo (2002a).
} 
ingresarán a la amnistía, sobretodo si no son anunciadas previamente (son no esperadas).

Desde este punto de vista se justifican las aministías como una herramienta válida de incremento en la recaudación y disminución de la evasión: los que evadieron poco o no evadieron no ingresarán y los que evadieron mucho si lo harán, se recuperan ingresos fiscales disminuyendo la evasión y de paso la administración tributaria ahorra costos de auditoría. El problema es que, si los que más evaden tienen mayor aversión al riesgo, no entrarán en la aministía. Marchese y Privileggi (2004) modelan esta situación y encuentran que los dos extremos (los que mas evaden y los que menos) no ingresarán a la amnistía, con lo cual el argumento de eficaz herramienta de autoselección sería, ante estas condiciones, falaz.

\subsection{Teoría económica de la elusión fiscal}

En contraposición a la importante literatura que existe sobre evasión fiscal, la elusión fiscal no es un tema muy abordado por la teoría económica, siendo que es un conducta frecuente en las economías modernas. ${ }^{77}$ El trabajo de Stiglitz (1985) fue el primero que presenta una teoría general de la elusión, focalizada en el impuesto a las ganancias personales tal cual era aplicado en la época en los EUA. Una vez concentrado en tal impuesto, se excluye la conducta de las empresas, o sea las posibilidades de elusión del impuesto a las ganancias corporativas. Si bien el foco es distinto, es interesante la metodología de Stiglitz (1985) quien clasifica en tres las alternativas de elusión del impuesto:

1. Posponer impuestos: el valor presente de un impuesto pospuesto puede ser menor que el valor a pagar en el período corriente. Esta posibilidad de elusión estará presente sólo para impuestos que sigan el criterio del percibido, y no del devengado. ${ }^{78}$

2. Arbitraje entre individuos que enfrentan tasas impositivas distintas: dentro de una familia o generando transacciones "ad hoc", o sea diseñadas con el único objeto de reducir la carga tributaria de uno de los agentes que participan de la misma

\footnotetext{
${ }^{77}$ Slemrod (1996) afirma que existe fuerte evidencia de que las respuestas vinculadas a la elusión fiscal ante cambios en las tasas impositivas son más fuertes que las respuestas de sustitución reales. En tal estudio, analiza detalladamente la respuesta de los individuos, especialmente los de altos ingresos, a los cambios impositivos en EEUU durante la década del 80'.

${ }^{78}$ Korinek y Stiglitz (2009) analizan formalmente el caso de elusión del impuesto a los dividendos mediante arbitraje intertemporal, cuando las modificaciones en las tasas impositivas pueden ser anticipadas por los contribuyentes.
} 
3. Arbitraje entre fuentes de ingreso con distinto tratamiento impositivo.

Stiglitz (1985) demuestra que bajo los supuestos de información perfecta y mercado de capitales perfectos, los agentes económicos están en condiciones de eludir la totalidad del impuesto, aunque reconoce a la vez que en la realidad tal impuesto es pagado por la mayoría de las contribuyentes, lo cual atribuye principalmente a imperfecciones del mercado de capitales. Una de las principales conclusiones es que muchas de las posibilidades de elusión se eliminarían con una tasa impositiva plana, especialmente las generadas en modelos de equilibrio general y establece como consecuencia que las reformas impositivas que estén orientadas a reducir las diferencias en las tasas impositivas marginales reducirán la elusión. El problema de esta sugerencia, claramente, es que el impuesto a las ganancias intenta ser progresivo lo cual implica necesariamente diveresas alícuotas marginales: aparece un caso típico de trade off entre eficiencia y equidad.

A partir del trabajo de Stiglitz (1985), varios autores ampliaron en diversas direcciones el estudio de la elusión, aunque en general también con respecto al impuesto a las ganancias. Parte de esta literatura se dedicó a analizar diversas propuestas de reforma impositiva, en términos de hasta que punto podrían favorecer o perjudicar las posibilidades de elusión señaladas por Stiglitz (1985). ${ }^{79}$

Grubert y Newlon (1995) analiza las posibilidades de elusión de un impuesto federal al consumo vinculadas con el comercio internacional, situación que en alguna medida es asimilable a un impuesto subnacional al consumo respecto al comercio interjurisdiccional (que es en general mucho mas significativo que el comercio internacional y por lo tanto las posibilidades de elusión son más graves). Plantea los siguientes problemas y posibilidades de elusión:

1. La identificación de las importaciones (gravadas) y las exportaciones (exentas) bajo el principio de destino implica controles de frontera difíciles de realizar.

2. Ubicación de activos intangibles (patentes y know how).

3. Ubicación de la deuda.

4. Como gravar la importación de servicios (lugar de facturación o de realización del servicio, que pasa si esto último es no presencial). En última instancia se genera un incentivo a utilizar servicios extranjeros, tales como procesamiento de tarjetas de credito, etc.

\footnotetext{
${ }^{79}$ McLure (1993), Grubert y Newlon (1995), Murray (1997) y Gale (1999) analizan un impuesto federal al consumo, Ginsburg (1995) un impuesto a los ingresos de las empresas, Feld (1995) y Calegari (1998) la propuesta del impuesto federal a los ingresos con tasa plana, denominada Hall y Rabushka, por sus autores en la Congreso.
} 
Algunas de estas posibilidades de elusión por parte de las empresas son mencionadas por Murray (1997), quién hace una análisis un poco más general. Menciona las siguientes posibilidades de elusión:

1. Si los insumos están gravados, aparecen necesariamente distorsiones sobre la elección de los mismos, incluyendo la posibilidad de integración vertical, asi como la localización de unidades productivas.

2. Para servicios financieros y de seguros, el problema se genera debido a que no existe un precio explicito pagado en el mercado, debido a la carateristica de inversión de muchos gastos.

3. La importación de servicios, especialmente los de entrega por correo y los servicios de información.

4. Las firmas pueden utilizar agresivamente tecnologías que unan compradores y vendedores, y recaudar comisiones.

Un tema que enfatiza Murray (1997) es que el grado de cumplimiento (uniendo en tal concepto la evasión y la elusión) dependerá de i) la tasa impostiva y la estructura tributaria, que es lo que introduce incentivos y posibilidades de abuso; ii) actitudes, que determina si los contribuyentes explotarán o no las posibilidades existentes y iii) la administración tributaria, que debe realizar supervisión y control.

Calegari (1998) estudia las posibilidades de elusión que persistirían bajo un régimen de impuesto a los ingresos personales y corporativos con tasa plana, analizando puntualmente una propuesta legislativa de reemplazar el impuesto a las ganancias federal por tal impuesto (el impuesto Hall y Rabushka). Este impuesto, en su versión original, implicaba un tasa del $19 \%$ para todo tipo de ingresos personales y corporativos que superen los $\$ 9500$ anuales, eliminando la gran mayoría de deducciones y exenciones vigentes para el impuesto federal a las ganancias. Lo interesante del trabajo de Calegari (1998) es que incluye explicitamente las posibilidades de elusión por parte de empresas, las que siguen en cierta medida la clasificación de Sitglitz (1985). Las posibilidades de elusión son:

1. Posponer impuestos: como el impuesto es sobre los ingresos percibidos y no devengados, existe la posibilidad de posponer la cobranza y de ese modo pagar el impuesto en el futuro. Lo contrario hará el contribuyente con los gastos que son deducibles, anticipará su pago.

2. Arbitraje entre fuente de ingresos: ya que la propuesta incluye algunas actividades exentas, 
permanece la posibilidad de convertir ingresos que pagan impuestos en impuestos exentos. Por ejemplo:

2.1. Convertir ingresos por ventas en ingresos por intereses.

2.2. Convertir ventas de propiedades corporativas en venta de bienes de uso personal.

2.3. Convertir acuerdos de alquiler en acuerdos de venta.

3. Arbitraje entre tasas impositivas. El esquema de tasa única (19\%) con una deducción de monto fija (\$9500) implica tasas impositivas marginales variables, con lo cual existe el incentivo de arbitraje entre individuos, pasando ingreso de los que tienen tasas mayores a los que tienen tasas menores (o incluso tasa cero para aquellos individuos con ingresos menores a $\$ 9500$ ).

Por otro lado, Cowell (1990) presenta un modelo en el cual estudia la decisión del contribuyente maximizador de la utilidad que enfrenta las siguientes posibilidades respecto a un impuesto a los ingresos: i) cumplimiento tributario, ii) evasión fiscal y iii) elusión fiscal. En el modelo presentado, tanto la evasión como la elusión tienen un costo, y a partir de la forma que tenga la función de costos de ambas alterntivas, de las tasas impositivas marginales, y de la aversión al riesgo, el resultado puede implicar soluciones de estrategias mixtas (en el cual el contribuyente toma las tres conductas posibles respecto de al menos una porción de su ingreso) o de esquina. El mismo estudio también presenta los problemas de asimetría de información que implica la evasión fiscal, a diferencia de la elusión que es una conducta abierta y conocida por la administración tributaria. Considerando la asimetría de información, el resultado más factible es la polarización (evasión o elusión total). En general, también se concluye que los contribuyentes de mayores ingresos y aversos al riesgo optarán por eludir el impuesto, mientras que los de bajos ingresos optarán por evadir. ${ }^{80}$

Una justificación de una conducta de este tipo también la brinda Slemrod (1998), que analiza respecto a un impuesto a los ingresos pagado por contribuyentes individuales la interrelación entre las respuestas de sustitución reales y la elusión fiscal. Si el costo de la elusión está vinculado con el nivel de ingresos (o de ahorros) de los invididuos, lo cual parece ser un supuesto realista, las personas de mayor ingresos soportarán una tasa impositiva efectiva más baja que la tasa

\footnotetext{
${ }^{80}$ Es interesante el estudio de Desai y Dharmapala (2005) que concluyen que la habilidad para eludir impuestos es variable entre las empresas y que sólo aquellas empresas bien gobernadas la actividad de elusión tiene un impacto en el valor de la firma. A nivel agregado, el efecto de la elusión en el valor de la firma no es significativamente distinta de cero.
} 
legal. Para el caso de empresas, Slemrod (1998) afirma que la posibilidad de realizar arbitraje y planificación fiscal entre fuentes de ingreso con distinto tratamiento (por ejemplo, originadas en países con tasas impositivas diversas) se ve favorecida para aquellas empresas que efectivamente organizan su actividad económica a fin de aprovechar las diferencias impositivas reales. Desde este punto de vista, afirman que la posibilidad del arbitraje funciona como un subsidio a tales decisiones empresariales. Por ejemplo, si instalar fábricas o puntos de ventas en paraísos fiscales favorece la elusión fiscal mediante precios de transferencia, tal posibilidad implica un subsidio encubierto a la instalación del capital en los paraísos fiscales.

Las posibilidades de elusión dependen del tipo de impuesto que se aplica, y por este motivo, es más comun que la literatura sobre elusión se refiera a impuestos tal cual están legislados en situaciones concretas, y no a los efectos económicos de impuestos más genéricos. Por ejemplo, los impuestos indirectos (y particularmente el IVA) tiene como principal característica que se pueden eludir mediante compras a través de la frontera, pero esa no será una característica de países grandes, o federaciones (salvo por supuesto que existan IVA subnacional, como el caso de Brasil o Canada). La recomendación de política es utilizar en forma más intensa los impuestos más difíciles de eludir. ${ }^{81}$

\subsection{Comentarios finales}

Los determinantes de la evasión impositiva encontrados en la literatura pueden clasificarse en tres grandes grupos: los que afectan la utilidad esperada de la evasión $(t, \phi$ y $f)$, las normas sociales y las oportunidades de evadir (claridad de la ley impositiva, sistemas de retención e información, etc.). Hay también estudios que muestran que hay diferencias significativas entre el grado de evasión de personas con determinadas características sociodemográficas. Sin embargo, los modelos teóricos incorporan pocos de estos factores a la vez, e incluso normalmente grandes dimensiones de la evasión (como las normas sociales o la oportunidad de evadir) no son incluidas en detemerminados modelos. Por supuesto que tampoco hay a la fecha un modelo comprehensivo de la evasión, que intente considerar todos los elementos a la vez.

Las preocupaciones vigentes en los países en desarrollo acerca de la evasión tampoco han

\footnotetext{
${ }^{81}$ Gordon y Nielsen (2006).
} 
sido suficientemente tratados por la investigación económica: hay grandes lagunas de alto interés que prácticamente no han sido abordadas. Una de estas lagunas se refiere a los aspectos institucionales del combate a la evasión. Por ejemplo, en el modelo básico de la utilidad esperada se toman como sustitutos a $t, \phi$ y $f$ para llegar una determinada recaudación, y se intentan ubicar valores óptimos para cada una de las variables. Sin embargo, $t$ es fijado normalmente por el cuerpo legislativo, $\phi$ por la administración tributaria (sujeta al nivel de recursos que tenga aprobado) y $f$ se fija entre el cuerpo legislativo y el judicial [Myles (1995]). Desde este punto de vista, es probable que el proceso de determinación de cada uno de estos valores implique un juego institucional no tenido en cuenta por estos modelos.

No obstante estas limitaciones, es claro que la investigación en evasión fiscal en los últimos 40 años ha producido un conocimiento valioso y de aplicación práctica acerca de los determinantes de la evasión y de las interacciones entre la administración tributaria y los contribuyentes. Tanto la definición de la estructura tributaria como las políticas, estrategias y herramientas puestas en práctica por parte de las administraciones tributarias deben tener en cuenta tal conocimiento.

Ahora bien, si se consideran cuatro factores críticos (tipo de mercado, función impositiva, conducta frente al riesgo y probabilidad de auditoría) existen importantes lagunas en la literatura. En la Tabla 1.3 se presentan los diversos trabajos teóricos de evasión fiscal por parte de empresas analizados en este capítulo, clasificados según estos cuatro factores críticos. 
Tabla 1.3. Revisión Literatura Evasión Fiscal de Empresas

\begin{tabular}{|c|c|c|c|c|c|}
\hline Impuesto & Riesgo & Prob Auditoria & Competitivo & Monopolio & Comp. Imperfecta \\
\hline \multirow[t]{4}{*}{ Ad Valorem } & \multirow[t]{2}{*}{ Neutral } & Fija & & & \\
\hline & & Variable & (5) & & \\
\hline & \multirow{2}{*}{ Aversión } & Fija & & $(1),(7)$ & (3) \\
\hline & & Variable & & (1) & (3) \\
\hline \multirow[t]{4}{*}{ Específico } & \multirow{2}{*}{ Neutral } & Fija & $(6)$ & $(8)$ & \\
\hline & & Variable & & & \\
\hline & \multirow[t]{2}{*}{ Aversión } & Fija & & (7) & (3) \\
\hline & & Variable & & & (3) \\
\hline \multirow[t]{4}{*}{ Beneficio } & \multirow[t]{2}{*}{ Neutral } & Fija & & (12) & \\
\hline & & Variable & & $(12)$ & $(11)$ \\
\hline & \multirow[t]{2}{*}{ Aversión } & Fija & & $(1),(2),(7)$ & $(3),(9),(10)$ \\
\hline & & Variable & & $(1),(2),(4)$ & (3) \\
\hline
\end{tabular}

Referencias: (1) Marrelli (1984), (2) Wang y Conant (1988), (3) Marrelli y Martina (1988), (4) Lee (1998) (5) Virmani (1989), (6) Cremer y Ghavari (1993), (7) Yaniv (1995), (8) Myles (2001), (9) Eichborn (2005) (10) Goerke y Runkel (2006), (11) Lee (2006), (12) Bayer y Cowell (2009).

Hay que considerar que tanto la situación de aversión al riesgo como de neutralidad al riesgo son supuestos relevantes para el caso de emrpesas: mientras que empresas grandes se comportarán como neutrales al riesgo, es esperable que pequeños empresarios o empresas individuales tengan aversión al riesgo. El tipo de impuesto es un componente importante de los modelos ya que permite vincular la literatura de evasión impositiva con la de comparación entre funciones impositivas. La pregunta principal al respecto sería, ¿se mantendrán los resultados respecto a la superioridad del impuesto ad valorem con competencia imperfecta o monopolio si existe la posibilidad de evasión?.

En el Capítulo 2 se presentan modelos teóricos de evasión impositiva no tocados previamente por la literatura, referidos a entornos competitivos y de monopolio. Debido a que el análisis se hace tanto para un impuesto ad valorem como para un impuesto específico, se presentan también un conjunto de proposiciones referidas a los efectos comparativos de ambos impuestos.

En el Capítulo 3 se analiza otro aspecto de la evasión impositiva descuidado en la literatura: el efecto de la evasión fiscal dentro de una estructura vertical. En este caso, se vincularán los modelos de evasión fiscal con la literatura sobre control vertical. Una de las preguntas principales es que sucede con el principio de doble marginación cuando existe evasión impositiva en una de 
etapas, así como si existen herramientas de control vertical que logren neutralizar el efecto del doble margen en tal contexto.

La elusión fiscal ha sido un tema más descuidado por la teoría económica. Prácticamente no hay estudios formales sobre la elusión de impuestos indirectos. Claro que la elusión se relaciona con las características específicas que tenga determinada legislación tributaria que son dificiles de modelar. Por ejemplo, un elemento central para las posibilidades de elusión es si el impuesto es por lo devengado o por lo percibido, elemento descuidado en la teoría económica de los impuestos. Otro componente central, en el caso de los impuestos indirectos, es si el impuesto sigue el criterio de origen, de destino, o ambos. En el impuesto a las ganancias, un elemento central que genera posibilidades de elusión es el tratamiento de las ganancias de capital. En muchos países en desarrollo (por ejemplo Argentina) estas operaciones no están alcanzadas por el impuesto, con lo cual la elusión mediante la postergación de una realización de una ganancia de capital (tan usual en EUA) en estos paises no existe.

Por estos motivos, para el análisis que se presenta en el Capítulo 4 respecto a la elusión fiscal de impuestos indirectos se toma como referencia el Impuesto sobre los Ingresos Brutos. Es necesario trabajar con un impuesto real a fin de considerar que situaciones prácticas generan la posibilidad de elusión.

Hay que considerar que la concurrencia de la elusión con la evasión puede tener consencuencias en términos de política pública relevantes. Notemos que las posibilidades de elusión en general aumentan con el tamaño de la firma, mientras es conocido en la literatura que las posibilidades de evasión disminuyen. El impacto de los sistemas de retención en la fuente y de información son muy buenos para combatir la evasión, pero no necesariamente la elusión. ${ }^{82}$

En términos generales, las herramientas de combate a la evasión están en manos de la administración tributaria, mientras que las posibilidades de elusión se generan principalmente en la política tributaria. Además, las medidas que apuntan a una menor evasión (mayor fiscalización y penalidades más altas) pueden implicar más elusión, ya que los contribuyentes estarían dispuestos a asumir un costo mayor vinculado con la elusión, si el costo de la evasión está en aumento. Sin embargo, es muy probable que simplificar la política tributaria a fin de reducir

\footnotetext{
${ }^{82}$ Gale (1999) estima que la evasión del impuesto a las ganancias en USA es del $17 \%$, pero del $1 \%$ para aquellos sectores donde hay retención (ingresos en relación de dependencia) y del $30 \%$ en aquellos donde no la hay.
} 
la elusión también reduzca la evasión. Muchas exenciones y tratamientos diferenciales, que son un problema desde el punto de vista de la elusión, también tienen el efecto de aumentar la evasión. Las empresas tienen más opciones de evadir, sin trastocar necesariamente sus registros contables (declarando una actividad por otra) y la administración tributaria debe dedicar más recursos para auditar sistemas impositivos complejos. Ambas fuerzas implican mayor evasión. Por lo tanto, simplificar la ley impositiva y, en particular, unificar las alícuotas tiende a reducir tanto la elusión como la evasión. 


\subsection{Referencias bibliográficas}

Acconcia, A., M. D'Amato y R. Martina (2003a). "Tax Evasion and Corruption in Tax Administration". Septiembre. Manuscrito no publicado.

Acconcia, A., M. D'Amato y R. Martina (2003b). "Corruption and Tax Evasion with Competitive Bribes". CSEF, Universita Degli Studio di Salerno, Working Paper No 112.

Agell, J. y M. Persons (1998). "Tax Arbitrage and Labor Suply". Institute for International Economic Studies, Stockholm University, Seminar Paper No 647.

Akdede, S. H. (2006). "Corruption and Tax Evasion". Doğuş Üniversitesi Dergisi, vol 7 (2), pp 141-149.

Allingham, M. G. y A. Sandmo (1972). "Income tax evasion: A theoretical analysis". Journal of Public Economics, vol 1, pp 323-338.

Alm, J. (1999). "Tax Compliance and Administration". En Hildreth W.B. y J. A. Richardson (eds), Handbook on Taxation. New York: Marcel Dekker, pp 741-768.

Alm, J. y W. Beck (1993). "Tax Amnesties and Compliance in the Long Run: A Times Series Analysis". National Tax Journal, vol 45, pp 53-60.

Alm, J. y S. Wallace. (1998). "Which Elasticity? Estimating the Responsiveness of Taxpayer Reporting Decisions". Department of Economics, University of Colorado at Boulder, Discussion Papers in Economics. Working Paper No 98-18.

Alm, J., C. Blackwell y M. McKee (2004). "Audit Selection and Firm Compliance with a Broad-based Sales Tax". National Tax Journal, vol 42 (2), pp 209.227.

Alm, J., B. Erard y J. Feinstein (1995). "The Relationship Between State and Federal Tax Audits". NBER Working Paper N 5134.

Alm, J., B. Jackson y W. Beck (2004). "Audit Information Dissemination, Taxpayer Communication and Tax Compliance: an Experimental Investigation of Indirect $\mathrm{Au}-$ dit Effects". Trabajo presentado en la 97th Annual Conference of the National Tax Association, Minneapolis, Noviembre. 
Alm, J. y M. McKee (2000). "Tax Compliance as a Coordinated Game". Journal of Economic Behavior and Organization, vol 54 (3), pp 297-312.

Alm, J., M. McKee y W. Beck (1990). "Amazing Grace: Tax Amnesties and Compliance". National Tax Journal, vol 43, pp 23-37.

Andersen, P. (1977). "Tax Evasion and Labor Supply". The Scandinavian Journal of Economics, vol 79, pp 375-383.

Andreoni, J. (1991). "The Desirability of a Permanent Tax Amnesty". Journal of Public Economics vol 45, pp 143-159.

Andreoni, J. (1992). "IRS as loan shark. Tax compliance with borrowing constraints". Journal of Public Economics, vol 49, pp 23-46.

Andreoni J., B. Erard y J. Feinstein (1998). "Tax Compliance". Journal of Economic Literature, vol 36 (2), pp 818-860.

Banco Mundial (2004). "Tax Policy and Administration".

Bayer, R. y F. Cowell (2009). "Tax Compliance and Firms' Strategic Interdependence". Journal of Public Economics, vol 93, pp 1131-1143.

Bayer, R. y M. Sutter (2003). "The Excess Burden of Tax Evasion - An Experimental Detection-Concealment Contest". University of Adelaida School of Economics, Working Paper No 03-05.

Beck, P.J. y W. Jung (1989). "An Economic Model of Taxpayer Compliance Under Uncertainty". Journal of Accounting and Public Policy, vol 8, pp 1-27.

Becker, G. (1968). "Crime and Punishment: An Economic Approach". Journal of Political Economy, vol 76, pp 169-217.

Bernasconi, M. (1998). "Tax Evasion and Orders of Risk Aversion". Journal of Public Economics, vol 67, pp 123-134.

Besfamille, M y P. Olmos (2009). "Inspectors or Google Earth? Optimal fiscal policies under imperfect auditing". Documento presentado en las 42 Jornadas Internacionales de Finanzas Públicas, Cordoba, Argentina.

Border, K., y J. Sobel (1987). "Samurai Accountant: A Theory of Audit and Plunder". Review of Economic Studies, vol 54, pp 525-540. 
Bresnahan, T.F. y P.C. Reiss (1985). "Dealer and Manufacturer Margins". Rand Journal of Economics, vol 16 , pp 253-268.

Calegari, M. (1998). "Flat Taxes and Effective Tax Planning". National Tax Journal, vol 51, pp 689-713.

Castagnola, H. (2004). La Experiencia de la Administración Tributaria en la Crisis Económica: El Caso de la República Argentina. Buenos Aires: Administración Federal de Ingresos Públicos.

Chen, K.P y C.Y. Chu (2005). "Internal Control vs External Manipulation: A Model of Corporate Income Tax Evasion". RAND Journal of Economics, vol 36, pp 151-164.

CIAT (2003). Manual de Fiscalización: Refuerzo de la Función de Fiscalización en las Adinistraciónes Tribuitarias de América Latina y el Caribe. Amsterdam: IBFD Publications BV.

Cowell, F. (1990). "Tax Sheltering and the Cost of Evasion". Oxford Economic Papers, vol 42, pp 231-243.

Cowell, F. (1995). Engañar al Estado. Una Análisis Económico de la Evasión. Madrid: Alianza Editorial S.A.

Cowell, F. (2004). "Carrots and Sticks in Enforcement". En The Crisis in Tax Administration. Washington DC: The Brookings Institution, pp 230-275.

Cremer, H. y F. Gahvari (1993). "Tax Evasion and Optimal Commodity Taxation". Journal of Public Economics, vol 50, pp 261-275.

Cremer, H. y F. Gahvari (1997). "Tax Competition and Tax Evasion”. Nordic Journal of Political Economy, vol 24, pp 89-104.

Cremer, H. y F. Gahvari (2000). "Tax Evasion, Fiscal Competition and Economic Integracion”. European Economic Review, vol 44, pp 1633-1657.

Christiansen, V. (1980). "Two Comments on Tax Evasión". Journal of Public Economics, vol 13, pp 389-393.

Crocker, K. y J. Slemrod (2005). "Corporate Tax Evasion with Agency Costs". Journal of Public Economics, vol 89, pp 1593-1610. 
Das-Gupta, A. (2004). "The Economic Theory of Tax Compliance with Special Reference to Tax Compliance Costs", en Bagchi, A. (ed), Readings in Public Finance, New Delhi: Oxford University Press.

Das-Gupta, A. y I.A. Gang (2000). "Decomposing Revenue Effects of Tax Evasion and Tax Structure Changes". International Tax and Public Finance, vol 7, pp 177-194.

Derrick, F. y Ch. E. Scott (1998). "Sales Tax Equity: Who bears the burden". The Quarterly Review of Economics and Finance, vol 38, pp 227-237.

Desai, M.A. y D. Dharmapala (2005). "Corporate Tax Avoidance and Firm Value". NBER Working Paper No 11241.

Dixit, A. y B. Nalebuff (1991). Thinking Strategically. New York: W. W. Norton \& Company, Inc.

Dubin, J.A. y L.L. Wilde (1988). "An Empirical Analysis of Federal Income Tax Auditing and Compliance". National Tax Journal, vol 71, pp 61-74.

Due, J. (1975). "Evaluation of the Effectiveness of State Sales Tax Administration". National Tax Journal, vol 27, pp 97-219.

Dyreng, S., M. Hanlon y E. L. Maydew (2007). "Long-Run Corporate Tax Avoidance". Accounting Review, vol 83, No 1.

Edwards, J. y M. Keen (1996). "Tax Competition and Leviathan.” European Economic Review, vol 40, pp 113-34.

Engel, E. y J. Hines (1999). "Understanding Tax Evasion Dynamics". NBER Working Paper No 6903.

Erard, B. (1997). "Self-Selection with Measurement Errors. A Microeconometric Analysis of the Decision to Seek Tax Assistence and its Implications for Tax Compliance". Journal of Econometrics, vol 81, pp 319-356.

Erard, B. y Ch. Ho (2001). "Searching for Ghost: Who are the Nonfilers and How Much Tax Do They Owe?". Journal of Public Economics, vol 81, no 52-60.

Erard, B. y J. Feinstein (1994a). "The Role of Moral Sentiments and Audit Perceptions in Tax Compliance". Public Finance, vol 49 (Suppl.), pp 70-89. 
Erard, B. y J. Feinstein (1994b). "Honesty and Evasion in the Tax Compliance Game". RAND Journal of Economics, vol 25, pp 1-19.

Erickson, M., A. Goolsbee y E. Maydew(2003). "How prevalent is tax arbitrage? Evidence from the Market for Municipal Bonds". National Tax Journal, vol 41 (2), pp 259-270.

Escobari, D. (2007). "Imperfect Detection of Tax Evasion in a Corrupt Tax Administration". Documento no publicado.

Esteller, Moré, A. (2004). "Tax Evasion in Interrelated Taxes". Universitat de Barcelona \& Institut d'Economia de Barcelona (IEB). Document de treball 2004/2.

Falkinger, J. (1995). "Tax Evasion, Consumption of Public Goods and Fairness". Journal of Economic Psychology, vol 16, pp 63-72.

Feinstein, J. y B. Erard (1994). "The Role of Moral. Sentiments and Audit Perceptions in Tax Compliance". Public Finance, vol 49 (suppl), pp. 70-89.

Feld, A. (1995). "Living with the Flat Tax". National Tax Journal, vol 48, pp 603-17.

Feld, L.P. y B.S. Frey (2002). "Trust Breeds Trust: How Taxpayers are Treated". Economics of Governance, vol 3, pp 87-99.

Fjeldstad, O. y J. Semboja (2001). "Why People Pay Taxes: The Case of the Development Levy in Tanzania”. World Development, vol 29, pp 2205-2274.

Fisman, R. y S. Wei (2001). "Tax Rates and Tax Evasion: Evidence from Missing Imports in China". NBER Working Paper No 8551.

Franzoni, L.A. (1996). "Punishment and Grace: On the Economics of Permanent Amnesties". Public Finance, vol 51, pp 353-68.

Franzoni, L.A. (1999). "Tax Evasion and Tax Compliance". En Bouckaert B. and G. De Geest (eds.), Encyclopedia of Law and Economics, Cheltenham, UK: Edward Elgar, pp. 52-94.

Fugazza M. y J. F. Jacques (2004). "Labor Market Institutions, Taxation and the Underground Economy". Journal of Public Economics, vol 88, pp 395-418.

Gale, W.G. (1999). "The Required Tax Rate in a National Retail Sales Tax". National Tax Journal, vol 52, pp 443-458. 
Gandelman, N, y R. Hernandez-Murillo (2004). "Tax Competition and Tax Harmonization With Evasion". Topics in Economic Analysis \& Policy, vol 4 (1), pp 3-21.

Ginsburg, M. D. (1995). "Life Under a Personal Consumption Tax: Some thoughts on Working, Saving, and Consuming in Nunn-Domenici's World". National Tax Journal, vol 48, pp 585-602.

Goerke, L. (2006). "Bureaucratic Corruption and Profit Tax Evasion". CESifo Working Paper No 1666.

Gordon, R.H. y S.B. Nielsen, S.B. (1996). "Tax Avoidance and Value-Added vs. Income Taxation in an Open Economy". NBER Working Paper No 5527.

Graetz, M., J. Reinganum y L. Wilde (1986). "The Tax Compliance Game: Toward an Interactive Theory of Law Enforcement". Journal of Law, Economics and Organization, vol 2, pp 1-32..

Graetz, M. J., y L.L. Wilde (1985). "The Economics of Tax Compliance: Fact and Fantasy". National Tax Journal, vol 38, pp 355-363.

Grubert, H, y T.S. Newlon, T.S.(1995). "The International Implications of Consumption Tax Proposals". National Tax Journal, vol 48, pp 619-47.

Hanousek, J. y F. Palda (2001). "Why People Evade Taxes in the Czech and Slovak Republics: A Tale of Twins". Public Economics (EconWPA).

Hanousek, J y F. Palda (2004). "Quality of Government Services and the Civic Duty to Pay Taxes in the Czech and Slovak Republics, and other Transition Countries". Kyklos, vol 57, pp 237-252.

Hindriks, J., M. Keen y A. Muthoo (1999). "Corruption, Extortion and Evasion”. Journal of Public Economics, vol 74, pp 395-430.

Jones, M. (2001). "Ability to Evade Taxes and Equilibrium Tax Reporting and Auditing". Department of Economics. State University of New York - Binghamton. September 28.

Joulfaian, D. y M. Rider. (1998). "Differential Taxation and Tax Evasion by Small Business". National Tax Journal, vol 51, pp 676-87. 
Kanbur, R. y M. Keen (1993). "Jeux Sans Frontieres: Tax Competition and Tax Coordination When Countries Differ in Size," American Economic Review, vol 83, pp 877-892.

Kaplow, L. (1989). "Optimal Taxation with Costly Enforcement and Evasion". NBER Working Paper No 2996.

Kaplow, L. (1994). "Accurecy, Complexity and the Income Tax". NBER Working Paper No 4631.

Kaplow, L. (1995). "How Tax Complexity and Enforcement Affect the Equity and Efficiency of the Income Tax". NBER Working Paper No 5391.

Kaplow, L. (2006). "Taxation". NBER Working Paper No 12061.

Kirchler, E., B. Maciejovsky y F. Schneider (2003). "Everyday Representations of Tax Avoidance, Tax Evasion, and Tax Flight: Do Legal Differences Matter?". Journal of Economic Psychology, vol 24, pp 535-553.

Korinek A. y J. Stiglitz (2009). "Dividend Taxation and Intertemporal Tax Arbitrage". Journal of Public Economics, vol 93, pp 142-159.

Lederman, L. (2003). "The Interplay Between Norms and Enforcement in Tax Compliance". George Mason Law \& Economics Research Paper No 03-12; U of Texas, Public Law Research Paper No 49.

Lee, K. (1998). "Tax Evasion, Monopoly and Nonneutral Profit Taxes". National Tax Journal, vol 51, pp 333-38.

Lee, K. (2001). "Tax Evasion and Self-insurance". Journal of Public Economics, vol 81, pp 73-81.

Lee, S. (2006). "Tax Evasion and Monopoly Output Decisions Revisited: Strategic Firm Behavior". International Journal of Business and Economics, vol 5, pp 83-92.

Lipatov, V. (2003). "Evolution of Tax EvasionTax evasion and self-insurance". European University Institute, MPRA Paper No 966.

Loayza, N. V. (1996). "The Economic of the Informal Sector: A Simple Model and Some Empiric Evidence From Latin America". Carnegie-Rochester Conference Series on Public Policy No 45. 
Lockwood, B. (2001). "Tax Competition and Tax Co-ordination Under Destination and Origin Principles: A Synthesis". Journal of Public Economics, vol 81, pp 279-319.

Macho-Stadler, I. y J.D. Perez-Castrillo (1997). "Optimal Auditing with Heterogeneous Income Sources." International Economic Review, vol 38, pp 951-968.

Macho-Stadler, I. y J.D. Perez-Castrillo (2002a). "Settlement in Tax Evasion Prosecution”. CESifo Working Paper Series CESifo Working Paper No 814.

Macho-Stadler, I. y J.D. Perez-Castrillo (2002b). "Auditing With Signals". Economica, vol 69, pp 1-20.

Macho-Stadler, I. y J.D. Perez-Castrillo (2005). "Políticas de Inspección Óptimas y Cumplimiento Fiscal”. Hacienda Pública Española / Revista de Economía Pública, vol 173, pp 9-45.

Marchese, C. y F. Privileggi (2002). "The Cutoff Policy of Taxation when Taxpayers are Risk Averse". Dipartimento di Scienze Economiche e Finanziarie, Università di Genova, Working Paper No 7.

Marchese, C. y F. Privileggi (2004). "Tax Amnesties and the Self-Selection of RiskAverse Taxpayers". European Journal of Law and Economics, vol 18, pp 319-341.

Marhuenda, F., Vasin, A y P. Vasina (2002). "Tax Enforcement for Heterogueneos Firms". Contribution Paper to the Conference Transforming Government in Economics in Transition.

Marrelli, M. (1984). "On Indirect Tax Evasion". Journal of Public Economics, vol 25, pp 181-196.

Marrelli, M. y R. Martina (1988). "Tax Evasion and Strategic Behaviour of the Firms". Journal of Public Economics, vol 37, pp 55-69.

Martinez-Vazquez, J. y M. Rider (2003). "Multiples Modes of Tax Evasion: Theory and Evidence from the TCMP". Georgia State University. Andrew Young School of Public Policy. International Studies Program. Working Paper No 03-06.

Mathewson, G.F. y R.A. Winter (1984). "An Economic Theory of Vertical Restraints," RAND Journal of Economics, vol 15, pp 27-38. 
Mayshar, J. y S. Yitzhaki (1995). "Dalton-Improving Tax Reform" . American Economic Review, vol 85, pp 793-807.

McLure, C.E. (1993). "Economic, Administrative, and Political Factores in Choosing a General Consumtion Tax". National Tax Journal, vol 46, pp 345-58.

Mikesell, J. (1999). Fiscal Administration. Orlando: Harcourt Brace \& Company.

Mills L., Newberry K. y W. Trautman (2002). "Trends in Book-Tax Income and Balance Sheet Differences". 2002 IRS Research Conference.

Molero, J. C. y F. Pujol (2006). "Walking inside the Potential Tax Evader's Mind" FCCEE Universidad de Navarra, Working Paper No 01/05,

Mookherjee, D y I. Png (1989). "Optimal Auditing, Insurance, and Redistribution". The Quaterly Journal of Economics, vol 104, pp 399-415.

Murray, M. (1995). "Sales Tax Compliance and Audit Selection". National Tax Journal, vol 48, pp 515-530.

Murray, M. (1997). "Would Tax Evasion and Tax Avoidance Undermine a Nacional Retail Sales Tax?". National Tax Journal, vol 50, pp 167-82.

Myles, G.D. (1995). Public Economics. London: Cambridge University Press.

Myles, G.D. y R.A. Maylor (1995). "Tax Evasion, Social Customs and Optimal Auditing". No publicado.

Niederle, M y M. Summer (1999). "Income-Tax Enforcement With a Self-Interested Auditor". No publicado.

Oates, W.E. (1999). "An Essay on Fiscal Federalism”. Journal of Economic Literature, vol 37, pp 1120-1149.

Oi, W. (1971). "A Disneyland Dilemma: Two-Part Tariffs for a Mickey Mouse Monopoly". The Quarterly Journal of Economics, vol 85, pp 77-96.

Omer, T. y Yetman, R. (2005). "Tax Evasion and Avoidance by Nonprofit Organizations". No publicado.

Ordoñez, G. (2001). "Lucha contra la Evasión Fiscal y la Corrupción". Revista de Análisis Económico, vol 16, pp 43-75. 
Palda, F. (2001). "A New Look at the Laffer Curve and the Displacement Loss from Tax Evasion". Working Paper in Public Economics. Ecole nationale d'administration publique in Montreal.

Plesko, G.A. (2003). "Estimates of the Magnitude of Financial and Tax Reporting Conflicts". 2003 Illinois Tax Research Symposium.

Poterba, J.M. (1987). "Tax Evasion and Capital Gains Taxation". NBER Working Paper No 2119.

Ratto, M y T. Vergue (2002). "Optimal Audit Policy and Heterogenous Agents". CMPO Working Paper Series No 02/054.

Ray, R. (1994). "The Reform and Design of Commodity Taxes in the Presence of Tax Evasion with Illustrative Evidence from India". Department of Economics, Dehli School of Economics. Dehli University.

Reinganum, J. F. y L. Wilde (1985). 'Income Tax Compliance in a Principal-Agent Framework', Journal of Public Economics, vol 26, pp 1-18.

Rey, P. y J. Stiglitz (1988). "Vertical Restraints and Producers' Competition". NBER Working Paper No 2601.

Rey, P. y J. Tirole (1986). "The Logic of Vertical Restraints". The American Economic Review, vol 76, pp 921-939.

Rey, P. y T, Verge (1986). "The Economics of Vertical Restraints". Conferencia sobre Advances of the Economics of Competition Law". Roma.

Rhoades, S. (1998). "The Tax Compliance and Audit Policy Implications of Costly False Detection Errors". Villanova University, Working Paper.

Sandmo, A. (2005). "The Theory of Tax Evasion: A Retrospective View Department of Economics". National Tax Journal, vol 63, pp 643-663.

Sánchez, M. (2006). "Divide and Conquer: Tax Evasion as a Global Game". Distributional Analysis Discussion Paper No 80, STICERD, London School of Economics.

Sanyal, A. (2000). "Audit Hierarchy in a Corrupt Tax Administration". Journal of Comparative Economics, vol 28, pp 364-378. 
Sanyal, A., Gang, I. y O. Goswami (2000). "Corruption, Tax Evasion and the Laffer Curve". Public Choice, vol 105, pp 61-78.

Schneider, F. y R. Klinglmair (2004). "Shadow Economies Around the World: What Do We Know?". University of Bonn. IZA Discussion Papers N 1043.

Scotchmer, S. (1987). "Audit Clasess and Tax Enforcement Policy" . American Economic Review, vol 77, pp 229-233.

Scotchmer, S. y Slemrod, J. (1988). "Randomess in Tax Enforcement". NBER Working Paper No 2512.

Serra, P. (2000). "Evasión Tributaria: ¿Cómo Abordarla?”. 80 Estudios Públicos, Servicio de Impuestos Internos.

Shome, P. (1999). "Taxation in Latin America: Structural Trends and the Impact of Administration". International Monetary Fund Working Paper No 99/19.

Silvani, C. y K. Baer (1997). "Designing a Tax Administration Reform Strategy: Experiences and Guidelines". International Monetary Fund Working Paper No 97/30.

Slemrod, J. (1996). "High-Income Families and the Tax Changes of the 1980s: The Anatomy of Behavioral Response". En Feldstein, M. y J. Poterba (eds), Empirical Foundations of Household Taxation, Chicago: University of Chicago Press.

Slemrod, J. (1998). "A General Model of the Behavioral Response to Taxation". NBER Working Paper No 6582.

Slemrod, J. (2004). "The Economics of Corporate Tax Selfishness". National Tax Journal, vol 42, pp 877-899.

Slemrod, J. (2007). "Cheating Ourselves: The Economics of Tax Evasion". Journal of Economic Perspectives, vol 21, pp 25-48.

Slemrod, J. y S. Yitzhaki (1987). "The Optimal Size of a Collection Agency". NBER Working Paper No 1759.

Slemrod, J. y S. Yitzhaki (2000). "Tax Avoidance, Evasion, and Administration". NBER Working Paper No 7476. 
Slemrod, J., M. Blumenthal y Ch. Christian (2001). "Taxpayer Response to an Increased Probability of Audit: Evidence from a Controlled Experiment in Minnesota". Journal of Public Economics, vol 79, pp 455-483.

Spengler, J.J. (1950). "Vertical Integration and Antitrust Policy". The Journal of Political Economy, vol 58, pp 347-352.

Stigler, G. (1963). "United States v. Loew's Inc.: A note on block booking”. Supreme Court Review, vol 152, pp 152-157.

Stiglitz, J. (1985). "The General Theory of Tax Avoidance". NBER Working Paper No 1868.

Stiglitz, J. (2000). La Economía del Sector Público. Barcelona: Antoni Bosch.

Tanzi, V. y G. Tsibouris (2000). "Fiscal Reform over Ten Years of Transition". International Monetary Fund Working Paper No 00/113.

Tanzi, V. y P. Shome (1993). "A Primer on Tax Evasion". International Monetary Fund Working Paper No 93/21.

Tanzi, V. y H. Zee (2001). "Tax Policy for Developing Countries". International Monetary Fund. Working Paper No 00/35.

Telser, L.G. (1960). "Why Should Manufacturers Want Fair Trade?" Journal of Law and Economics, vol 3, pp 86-105.

Torgler, B. (2003). "To Evade Taxes or Not To Evade: That is the Question". The Journal of Socio-Economics, vol 32, pp 283-302.

Townsend, R. M. (1979). "Optimal Contracts and Competitive Markets With Costly State Verification". Journal of Economic Theory, vol 21, pp 1-29.

Urbiztondo, S. (1993). "Un Sistema de Incentivos para Mejorar la Recaudacion Impositiva”. Económica, vol 29, pp 141-162.

Virmani, A. (1989). "Indirect Tax Evasion and Production Efficiency". Journal of Public Economics, vol 39, pp 223-237.

Wang, L.F.S. y J.L. Conant (1988). "Corporate Tax Evasion and Output Decisions of the Uncertain Monopolist". National Tax Journal, vol 41, pp 579-581. 
Wang, Y. (1999). "Commodity Taxes under Fiscal Competition: Stackelberg Equilibrium and Optimality". The American Economic Review, vol 89, pp 974-981.

Waud, R.N. (1986). "Tax Aversion, Deficits and the Tax Rate-Tax Revenue Relationship". NBER Working Paper No 1533

Wigger, B.U (2002). "Optimal Taxation in the Presence of Black Markets". Journal of Economics, vol 75, pp 239-254.

Wilson, J.D. (1999). "Theories of Tax Competition". National Tax Journal, vol 52, pp 269-304.

Yaniv, G. (1988). "Withholding and Non-Withheld Tax Evasion". Journal of Public Economics, vol 35, pp 183-204.

Yaniv, G. (1995). "A Note on the Tax Evading Firm". National Tax Journal, vol 48, pp 113-20.

Yaniv, G. (1999). "Tax Compliance and Advance Tax Payments: A Prospect Theory Analysis". National Tax Journal, vol 52, pp 753-764.

Yaniv, G. (2003). "Auditing ghosts by prosperity signals". Economics Bulletin, vol 8, pp. 1-10.

Yitzhaki, S. (1974). "A Note on Income Tax Evasion: A Theoretical Analysis". Journal of Public Economics, vol 3, pp 201-202.

Yitzhaki, S. y Vakneen, Y. (1988). "The Shadow Price of a Tax Inspector". The World Bank. Industrial Economics Department. WPS 76. 


\section{Capítulo 2}

\section{Efectos del Impuesto Específico y del Ad Valorem con Evasión}

\subsection{Introducción}

En el trabajo pionero de Allingham y Sandmo (1972), se aplicaron desarrollos que eran recientes para la época referidos a la economía de la incertidumbre y la economía del crimen para analizar la decisión del contribuyente individual respecto a si deliberadamente evadir parte o todos los impuestos a través de la subdeclaración de ingresos. El estudio de Allingham y Sandmo (1972) se refería a impuestos directos.

El interés de los investigadores en la evasión fiscal de impuestos indirectos es más reciente. Una característica relevante de esta literatura es que sus resultados son divergentes de acuerdo a los supuestos de cada modelo. ${ }^{1}$ De hecho, algunos supuestos no son siempre explícitos y no resulta claro qué sucede bajo diferentes supuestos clave. En este capítulo se realizan algunos ejercicios teóricos que surgen de modifica algunos de estos supuestos clave. En particular, se analizan dos cuestiones de relevancia para la política pública.

La primera de ellas es la comparación entre diferentes impuestos indirectos respecto al nivel de evasión y producción óptimos para la firma, y en cuanto a la separabilidad entre las decisiones de producción y evasión. Este último punto es muy relevante a fin de evaluar los efectos

\footnotetext{
${ }^{1}$ Algunas revisiones de esta literatura son Andreoni, Erard y Feistein (1998), Franzoni (1999), Alm (1999), Slemrod y Yitzhaki (2000) y Cowell (2004).
} 
de eficiencia económica de la evasión fiscal, particularmente en ambientes no competitivos. De particular interés resulta la comparación entre la incidencia del impuesto ad valorem y el específico en presencia de un productor monopolista que tiene la posibilidad de ocultar una parte de su nivel de actividad. Lo usual en la literatura, desde Suits y Musgrave (1953) es realizar la comparación para dos tasas impositivas que producen la misma recaudación, o bien la recaudación que se logra con el mismo nivel de producción. Al agregar la posibilidad de evasión, cualquiera de las dos opciones exige considerar que existe una diferencia entre recaudación teórica y esperada.

Por otro lado, la evasión debe considerase como una conducta que genera pérdidas de bienestar, por lo cual existe interés respecto a cuál impuesto genera menor evasión impositiva. En definitiva, el objetivo es comprobar si los resultados previos de la literatura sobre comparación entre estos dos impuestos son robustos a la inclusión de la evasión impositiva. A tal fin, se aplica un modelo de evasión fiscal por parte de empresas a la comparación de la incidencia de ambos impuestos y se realiza una simulación numérica para ilustrar y ayudar a la interpretación de los principales resultados.

La segunda cuestión de relevancia, es el análisis de los efectos sobre la evasión fiscal de las principales herramientas de la política pública presentes: la tasa impositiva, la probabilidad de auditoria y las penalidades.

Los resultados principales de este capítulo son que cuando hay competencia y las empresas son neutrales al riesgo, tanto con impuesto ad valorem como específico existe separabilidad de la decisión de producción de la de evasión, aunque no necesariamente viceversa. El nivel de evasión no es afectado en ningún caso por el nivel de producción, aunque si los costos marginales no son constantes, el nivel de producción de equilibrio depende del nivel de evasión de equilibrio. Los resultados de estática comparativa son similares para ambos impuestos, salvo en el efecto de la tasa impositiva en el precio del bien. Por otro lado, las consecuencias en términos de bienestar de un impuesto ad valorem y un impuesto específico que pueden ser evadidos son idénticas bajo competencia perfecta.

Si las empresas son aversas al riesgo la separabilidad se mantiene bajo condiciones específicas. Si se asume que la decisión de evasión es respecto una cantidad, la separabilidad se da incluso para soluciones de esquina, mientras que si la decisión es respecto a una proporción del nivel 
total de ventas, la separabilidad se presenta solamente para equilibrios interiores en el nivel de evasión. Los resultados de estática comparativa también varían según como se configure la decisión de evasión. En especial, el efecto de la tasa impositiva en el nivel de evasión óptimo depende de tal supuesto.

Si hay monopolio y las empresas son neutrales al riesgo la separabilidad se mantiene si el costo directo de la evasión es proprocional a la base imponible, lo que en el modelo presentado se cumple sólo para el impuesto específico. Los resultados de estática comparativa son esencialmente similares para ambos impuestos, salvo aquellos afectados por la ausencia de separabilidad presente para el caso del impuesto ad valorem.

Respecto a la superioridad en términos de bienestar de un impuesto ad valorem aplicado a las ventas de un monopolista, se demuestra que la misma se mantiene cuando existe la posibilidad de evasión pero bajo condiciones especiales. El impuesto ad valorem domina al específico en términos de recaudación esperada y de bienestar, en la medida en que exista una relación positiva entre tasas impositivas y recaudación esperada. Esto implica que para tasas impositivas altas, es posible (y la simulación numérica así lo confirma) que el mismo nivel de caída en las cantidades puede ser obtenido por un impuesto específico que genere una recaudación esperada mayor que el impuesto ad valorem correspondiente.

En la siguiente sección se realiza una revisión breve de la literatura, para luego presentar en la sección 3 el modelo básico de evasión fiscal bajo competencia. En la sección 4 se presenta un modelo bajo monopolio y neutralidad frente al riesgo. Por último, en la sección 5 se concluye el capítulo con comentarios finales.

\subsection{Antecedentes}

En esta sección se analizan los principales resultados obtenidos por la literatura sobre evasión impositiva por parte de empresas. ${ }^{2}$ Marrelli (1984) realizó la primera aplicación de la economía de la incertidumbre a la evasión fiscal de impuestos indirectos. El objetivo del trabajo es estudiar la decisión de evasión de un monopolista averso al riesgo mediante la subdeclaración de ventas de un impuesto ad valorem y de uno sobre los beneficios. Se obtiene un resultado que luego se

\footnotetext{
${ }^{2}$ Las referencias obligadas son Marelli (1984), Wang y Conant (1988), Virmani (1989), Yaniv (1988), Cremer y Ghavari (1993) y Yaniv (1995).
} 
repite en la literatura bajo diversos escenarios: en equilibrios interiores, si la probabilidad de auditoria es constante, la decisión de evasión impositiva no tiene influencia en la traslación de la carga impositiva. Esto es, las condiciones de maximización de beneficios después de impuestos son similares con o sin la posibilidad de evasión. Este resultado se conoce en la literatura somo la "separabilidad" entre las decisiones de cantidades producidas y de evasión fiscal. Otros estudios que tratan el caso de monopolio con algunas variaciones son Wang y Conant (1988), Yaniv (1988, 1995)

Los mismos temas son analizados para competencia imperfecta en Marrelli y Martina (1988). En este caso se utilizan tres impuestos (beneficios, ad valorem y específico) para estudiar el impacto de la colusión en la evasión fiscal. El modelo se construye para empresarios aversos al riesgo que deben decidir la cantidad a subdeclarar. Los resultados respecto a separabilidad son aún más fuertes que en el caso de monopolio, ya que se mantiene inclusive para soluciones de esquina. Sin embargo, el origen de este resultado surge de como se modela la decisión de evasión del empresario y no de la configuración del mercado analizado. ${ }^{3}$

Virmani (1989) incorpora la evasión de un impuesto ad valorem en mercados competitivos con libre entrada, empresarios neutrales frente al riesgo y curvas de costos medios en forma de U, mientras que Cremer y Gahvari (1993) presenta un modelo de evasión fiscal de impuestos específicos, pero a fin de estudiar el tema de imposición óptima bajo evasión fiscal.

Algunos desarrollos recientes respecto a la evasión por parte de empresas incorporan la teoría de la agencia para explicar la divergencia de objetivos entre los que preparan y presentan las declaraciones de impuestos a la administración tributaria (los agentes) con los de los accionistas (el principal). ${ }^{4}$ También se ha analizado la evasión fiscal en presencia de interacciones estratégicas entre las firmas así como en modelos de oligopolio con diferenciación de productos. ${ }^{5}$

Los modelos teóricos estuvieron dominados al inicio por la discusión respecto a la separabilidad de las decisiones de un monopolista averso al riesgo. Sin embargo, en los últimos años son más usuales los modelos donde el empresario, y especialmente los agentes, son neutrales al riesgo. No se tiene conocimiento de la existencia de trabajos que utilicen los modelos de evasión

\footnotetext{
${ }^{3}$ Mientras que en Marrelli (1984) la decisión del empresario respecto a la evasión es la proporción de ventas a ocultar, en Marrelli y Martina (1988) es una cantidad menor o igual al nivel de ventas.

${ }^{4}$ Chen y Chu (2005) y Crocker y Slemrod (2004).

${ }^{5}$ Goerke y Runkel (2006), Bayer y Cowell (2009) y Eichhorn (2006).
} 
fiscal para comparar la incidencia de impuestos ad valorem y específicos, el cual es uno de los temas aquí tratados.

Suits y Musgrave (1953) demuestran que un impuesto ad valorem domina en términos de recaudación a un impuesto específico; esto es, que el impuesto ad valorem produce mayor recaudación para el mismo nivel de producción, o que el mismo nivel de recaudación se alcanza con una producción de equilibrio mayor. Delipalla y Keen (1991) ampliaron el análisis a un modelo de competencia imperfecta (oligopolio con y sin entrada), donde la comparación se realiza en términos del cambio del bienestar (excedente del consumidor) obtenido por una reforma tributaria que no tiene efectos en la recaudación si se mantienen las cantidades fijas ("no first round effects"). Se selecciona esta base de comparación porque, si bien se considera inferior a la que mantiene la recaudación constante, permite obtener conclusiones más firmes.

Skeath y Trandel (1994) prueban un resultado más fuerte: demuestran que bajo monopolio, para cualquier nivel de un impuesto específico, existe una tasa de un impuesto ad valorem que lo domina en términos de Pareto; o sea, que produce mayor recaudación, mayor producto (y excedente del consumidor) y mayor beneficio para la firma. Tal resultado se extiende, con restricciones respecto a un determinado nivel de impuesto específico y para demandas lineales, a cualquier oligopolio Cournot-Nash. Esta conclusión deja poco espacio, en el ámbito teórico, a justificar la elección de impuestos específicos, relegando tal decisión a cuestiones prácticas o administrativas. $^{6}$

\subsection{Competencia perfecta}

Como punto de partida, se presenta un modelo en el cual existe un impuesto ad valorem a las ventas en un mercado competitivo con empresas neutrales al riesgo. El modelo es esencialmente similar al de Cremer y Gahvari (1993), pero para un impuesto ad valorem. Por tal motivo, se

\footnotetext{
${ }^{6}$ La literatura no se ha detenido aquí. Myles (1996) analiza la combinación óptima de impuestos ad valorem y específicos, cuando las tasas impositivas pueden tener valores negativos. Hamilton (1999) demuestra que bajo monopsonio, el impuesto específico domina en términos de bienestar al impuesto ad valorem. Anderson, de Palma y Kreider (2001 y 2001b) comparan ambos impuestos bajo modelos de oligopolio con diferenciación de producto. Blackorby y Murty (2006) compara ambos impuestos en modelos de monopolio en equilibrio general. Bossi (2007) analiza la comparación en un modelo de monopolio dinámico. Por último, Kind, Koethenbuerger y Schjelderup (2009) encuentran que el impuesto específico puede dominar a un impuesto ad valorem, tanto en términos de recaudación como de bienestar, cuando el monopolista dispone de mercados de dos lados (two-sided marktes).
} 
comparan los principales resultados encontrados en esta sección con los de tales autores.

La empresa puede subdeclarar las ventas con el objetivo de pagar menos impuestos. Debido a que el gobierno no conoce las ventas reales de las empresas, auditará algunas de ellas y en caso de encontrar evasión, le cobra el impuesto omitido más una penalidad económica. La empresa es neutral frente al riesgo y la evasión fiscal tiene un costo directo para la empresa. Bajo estas condiciones, la firma maximizará la siguiente función de beneficios esperados:

$$
\begin{aligned}
\operatorname{Max}_{\alpha, x} E[\Pi] & =(1-\phi) \Pi^{n d}+\phi \Pi^{d} \\
\Pi^{n d} & =I-C-I t \alpha-g(1-\alpha) q \\
\Pi^{d} & =\Pi^{n d}-I t(1-\alpha) f
\end{aligned}
$$

Donde:

$\phi$ : Probabilidad de detección de la evasión fiscal, o probabilidad de auditoria. Se asume que la selección de casos a auditar es aleatoria, y por lo tanto $\phi$ es una constante (todas las empresas enfrentan la misma probabilidad de auditoria).

$\Pi^{n d}$ : Beneficio si la evasión fiscal no es detectada, lo cual ocurre con probabilidad $(1-\phi)$.

$\Pi^{d}$ : Beneficio si la evasión fiscal es detectada, lo cual ocurre con probabilidad $\phi$.

$I=p q:$ Ventas totales.

$C=c q:$ Costos totales. Se asumen costos marginales constantes.

$c$ : Costos Medios y Marginales.

$t$ : Tasa del Impuesto Ad Valorem a las Ventas.

$\alpha$ : Proporción de ventas declaradas.

$g(1-\alpha)$ : Costo directo asociado a la evasión por unidad de producto. Se supone que es una función monotónica creciente y estrictamente convexa $\left[g^{\prime}(1-\alpha)>0 ; \quad g^{\prime \prime}(1-\alpha)>0\right]$. Se supone además que $g(1)=\infty \quad$ y $g(0)=0$.

$f-1$ : Penalidad asociada a la evasión detectada $(f>1)$.

$q$ : Nivel de producción.

$p:$ Precio. 
Reemplazando (2.2) y (2.3) en la función de beneficios esperados (2.1), se tiene:

$$
\begin{aligned}
E[\Pi] & =(1-\phi)[I-C-I t \alpha-g(1-\alpha) q]+ \\
& +\phi[I-C-I t \alpha-g(1-\alpha) q-I t(1-\alpha) f] \\
E[\Pi] & =I-C-g(1-\alpha) q-I t[\alpha+\phi f(1-\alpha)]
\end{aligned}
$$

De esta última expresión surge que la empresa subdeclarará sus ventas si y solo si $\phi f<1$; en otro caso, siempre es rentable declarar todas las ventas, inclusive si el costo directo de la evasión fuese cero. A los efectos de descartar soluciones triviales $(\alpha=1)$, de aquí en adelante se asume:

$$
\phi f<1
$$

La condición de primer orden respecto a $q$ será:

$$
\begin{aligned}
& 0 \leqq p-c-p t \alpha-g(1-\alpha)-\phi f[p t(1-\alpha)] \\
& p \leqq \frac{c+g(1-\alpha)}{1-t[\alpha+\phi f(1-\alpha)]}
\end{aligned}
$$

La condición (2.5) puede ser expresada como:

$$
p \leqq \frac{c+g(1-\alpha)}{\left(1-t^{e}\right)}
$$

donde:

$$
t^{e}=t[\alpha+\phi(1-\alpha) f]
$$

La condición de primer orden respecto a $\alpha$ será:

$$
q\left[-p t+g^{\prime}(1-\alpha)+\phi p t f\right] \leqq 0
$$

Debido a que en una solución interior $q>0$; esto implica que:

$$
\begin{aligned}
g^{\prime}(1-\alpha)-p t(1-\phi f) & \leqq 0 \\
g^{\prime}(1-\alpha) & \leqq p t(1-\phi f)
\end{aligned}
$$


Se observa que en el equilibrio $\alpha$ es independiente de $q$, y por lo tanto la decisión respecto a la evasión es independiente de la decisión respecto a la producción; esto es, se mantiene la condición de "separabilidad". ${ }^{7}$ De acuerdo a los supuestos realizados respecto de $g(1-\alpha)$ y dado que el beneficio marginal de la evasión fiscal [lado derecho de la ecuación (2.8)] es constante y positivo, existe una solución interior para $\alpha$ y se cumplen las condiciones de segundo orden.

\subsubsection{Estática comparativa}

Diferenciando las ecuaciones (2.5) y (2.8) y usando las expresiones (2.4) y (2.7) es posible obtener los siguientes resultados de estática comparativa respecto a la tasa impositiva, la probabilidad de auditoria y la multa: ${ }^{8}$

$$
\begin{aligned}
& \frac{\partial \alpha}{\partial t}=-\frac{p(1-f \phi)}{\left.g^{\prime \prime}[1-t[\alpha+(1-\alpha) f \phi)]\right]}<0 \\
& \frac{\partial t^{e}}{\partial t}=\alpha+(1-\alpha) \phi f-\frac{t p(1-\phi f)^{2}}{\left.g^{\prime \prime}[1-t[\alpha+(1-\alpha) f \phi)]\right]} \gtrless 0 \\
& \frac{\partial p}{\partial t}=\frac{p[\alpha+(1-\alpha) f \phi)]}{1-t(\alpha+(1-\alpha) f \phi)}>0 \\
& \frac{\partial \alpha}{\partial \phi}=\frac{p t f(1-t)}{\left.g^{\prime \prime}[1-t[\alpha+(1-\alpha) f \phi)]\right]}>0 \\
& \frac{\partial t^{e}}{\partial \phi}=t\left[\frac{p t f(1-t)(1-f \phi)}{\left.g^{\prime \prime}[1-t[\alpha+(1-\alpha) f \phi)]\right]}+f(1-\alpha)\right]>0 \\
& \frac{\partial p}{\partial \phi}=\frac{p t f(1-\alpha)}{1-t[\alpha+(1-\alpha) f \phi)]}>0
\end{aligned}
$$

\footnotetext{
${ }^{7}$ En este caso, la condición de separabilidad se mantiene con costos marginales crecientes (la evasión es independiente del nivel de producción), aunque en tal caso la cantidad depende del nivel de evasión. Exactamente lo mismo sucede con el modelo de impuesto específico de Cremer y Gahvari (1993).

${ }^{8}$ En el Apéndice se detallan las derivaciones correspondientes.
} 


$$
\begin{aligned}
& \frac{\partial \alpha}{\partial f}=\frac{p t \phi(1-t)}{\left.g^{\prime \prime}[1-t[\alpha+(1-\alpha) f \phi)]\right]}>0 \\
& \frac{\partial t^{e}}{\partial f}=t\left[\frac{p t \phi(1-t)(1-f \phi)}{\left.g^{\prime \prime}[1-t[\alpha+(1-\alpha) f \phi)]\right]}+\phi(1-\alpha)\right]>0 \\
& \frac{\partial p}{\partial f}=\frac{p t \phi(1-\alpha)}{1-t[\alpha+(1-\alpha) f \phi)]}>0
\end{aligned}
$$

De este primer análisis se concluye:

- Las herramientas de políticas públicas tienen el impacto esperado en la evasión fiscal expresiones (2.9), (2.12) y (2.15)-.

- Los cambios en la penalidad y la probabilidad de auditoria tienen efectos cualitativamente similares -expresiones (2.12)-(2.14) versus (2.15)-(2.17).

- Un aumento en la tasa impositiva tiene un efecto positivo en la evasión fiscal, con lo cual el signo del cambio en la tasa esperada es indeterminado -expresiones (2.9) y (2.10). ${ }^{9}$

- Incrementos en la tasa impositiva siempre tienen un impacto positivo en los precios, expresión (2.11).

- Aumentos en la probabilidad de auditoria o en la penalidad tienen un impacto positivo en las tasas impositivas esperadas y en los precios -expresiones (2.13), (2.14), (2.16) y (2.17).

\subsubsection{Actitud frente al riesgo}

Los modelos de evasión fiscal para impuestos indirectos tienen dos diferencias importantes respecto de aquellos referidos a impuestos directos: se asume en general neutralidad frente al riesgo y se incorpora una función de costos directos de la evasión. Por otro lado, los modelos existentes con aversión al riesgo e impuestos indirectos se han construido para estudiar situaciones de competencia imperfecta. Sin embargo, la aversión al riesgo puede considerarse como

\footnotetext{
${ }^{9}$ En función de la expresión (2.10), es esperable que si la tasa impositiva es baja, un aumento de la misma aumentará la tasa esperada, mientras que el caso contrario se dará si la tasa impositiva es suficientemente alta.
} 
un supuesto más razonable para el caso de empresas pequeñas o unipersonales. ${ }^{10}$

En esta sección se demuestra que es totalmente viable una adaptación directa del modelo original de Allingham y Sandmo (1972) (A-S) a la evasión fiscal por parte de empresas en un ambiente competitivo. Así, se trabajará bajo el supuesto de aversión al riesgo y en ausencia de costos directos de la evasión, ya que la propia aversión al riesgo genera un costo creciente de la evasión. Los resultados serán similares a los de A-S y la separabilidad se mantendrá bajo condiciones específicas. Esta configuración también permite estudiar el esquema original de A-S, donde la evasión fiscal no es proporcional a la base imponible, sino una cantidad fija. Algunos resultados dependen del mecanismo de evasión seleccionado.

De aquí en adelante, se asume que la función de utilidad es cóncava $\left(U^{\prime}(\Pi)>0\right.$ y $\left.U^{\prime \prime}(\Pi)<0\right)$ y se utilizarán las medidas de aversión al riesgo absoluta de Arrow-Pratt :

$$
\begin{aligned}
R_{A}\left(\Pi^{n d}\right) & =-\frac{U^{\prime \prime}\left(\Pi^{n d}\right)}{U^{\prime}\left(\Pi^{n d}\right)} \\
R_{A}\left(\Pi^{d}\right) & =-\frac{U^{\prime \prime}\left(\Pi^{d}\right)}{U^{\prime}\left(\Pi^{d}\right)}
\end{aligned}
$$

En particular, se asume que la aversión al riesgo absoluta es decreciente respecto de П. Esto es, $R_{A}\left(\Pi^{d}\right)>R_{A}\left(\Pi^{n d}\right)$.

\section{a. Evasión como cantidades}

En este caso, se asume que las empresas deben seleccionar una monto $S$, que es el total de impuestos que el contribuyente no declara $(0 \leq S \leq I t)$. Si el ingreso disponible es el único argumento de la función de utilidad, los contribuyentes maximizan:

$$
\operatorname{Max}_{s, q} E(U)=(1-\phi) U\left(\Pi^{n d}\right)+\phi U\left(\Pi^{d}\right)
$$

Donde:

$\Pi^{n d}=I-C-I t+S$ : Beneficio si la evasión fiscal no es detectada.

\footnotetext{
${ }^{10}$ Este tipo de empresas en general son las que optan por un esquema evasión fiscal mediante la subdeclaración de la base imponible.
} 
$\Pi^{d}=I-C-I t+S-f S$ : Beneficio si la evasión fiscal es detectada.

Las condiciones de primer orden son respecto a $S$ y $q$ son, respectivamente: ${ }^{11}$

$$
\begin{array}{r}
(1-\phi) U^{\prime}\left(\Pi^{n d}\right)+\phi U^{\prime}\left(\Pi^{d}\right)(1-f) \leq 0 \\
{\left[(1-\phi) U^{\prime}\left(\Pi^{n d}\right)+\phi U^{\prime}\left(\Pi^{d}\right)\right] \Pi_{q} \leq 0}
\end{array}
$$

Debido a que $U^{\prime}(\Pi)>0$, la última ecuación implica que $\Pi_{q} \leq 0 .{ }^{12}$ Como señala Yaniv (1995) "El nivel de actividad es independiente de los intentos de la firma de evadir impuestos mediante el reporte fraudulento, sin importar si la subdeclaración es óptima o no" (traducción propia, p.114).

Las condiciones de segundo orden se satisfacen debido a los supuestos realizados sobre la función de utilidad. Los resultados de estática comparativa dependerán en general de la forma de la función de utilidad, y en varios casos los resultados son ambiguos. Sin embargo, los efectos de las herramientas de política sobre el monto de impuestos evadidos están definidos:

$$
\begin{aligned}
& \frac{\partial S}{\partial t}=\frac{I}{D} \phi(1-f) U^{\prime}\left(\Pi^{n d}\right)\left[R_{A}\left(\Pi^{n d}\right)-R_{A}\left(\Pi^{d}\right)\right] \leq 0 \\
& \frac{\partial S}{\partial \phi}=-\frac{U^{\prime}\left(\Pi^{n d}\right)-U\left(\Pi^{d}\right)(1-f)}{D} \leq 0 \\
& \frac{\partial S}{\partial f}=\frac{U\left(\Pi^{d}\right)}{D} \leq 0
\end{aligned}
$$

donde $D$ es:

$$
\left[(1-\phi) U^{\prime \prime}\left(\Pi^{n d}\right)+\phi U^{\prime \prime}\left(\Pi^{d}\right)\right] \Pi_{q}^{2} \leq 0
$$

La expresión (2.20) es negativa sí y solo sí se asume que la aversión al riesgo absoluta es decreciente. ${ }^{13}$

\footnotetext{
${ }^{11}$ Ver en el Apéndice las derivaciones correspondientes.

${ }^{12}$ Para simplificar la notación, se utilizan subíndices para expresar derivadas parciales: $\Pi_{q}=\partial \Pi / \partial q$.

${ }^{13}$ Notar que en este caso $D \leq 0 ;(1-f) \leq 0$ y $\left[R_{A}\left(\Pi^{n d}\right)-R_{A}\left(\Pi^{d}\right)\right]<0$.
} 


\section{b. Evasión como porcentaje}

En este caso se analiza la decisión de la empresa cuando, en lugar de elegir un monto de impuestos a evadir $(S)$, elige un porción de la base imponible no declarada $(\alpha)$. La función objetivo es entonces:

$$
\begin{aligned}
\operatorname{Max}_{\alpha, q} E(U) & =(1-\phi) U\left(\Pi^{n d}\right)+\phi U\left(\Pi^{d}\right) \\
\Pi^{n d} & =I-C-I t \alpha \\
\Pi^{d} & =I-C-I t \alpha-I t(1-\alpha) f
\end{aligned}
$$

Las condiciones de primer orden respecto $\alpha$ y $q$ serán, respectivamente:

$$
\begin{gathered}
\frac{(1-\phi)}{\phi(f-1)} \geq \frac{U^{\prime}\left(\Pi^{d}\right)}{U^{\prime}\left(\Pi^{n d}\right)} \\
(1-\phi) U^{\prime}\left(\Pi^{n d}\right) \Pi_{q}^{n d}+\phi U^{\prime}\left(\Pi^{d}\right) \Pi_{q}^{d} \leq 0
\end{gathered}
$$

La última expresión puede ser escrita como:

$$
E(U)_{q}=\phi f U^{\prime}\left(\Pi^{d}\right) \Pi_{q}
$$

Debido a que $0<\phi f<1 ; U^{\prime}\left(\Pi^{d}\right)>0$; esto implica que $\Pi_{q} \leq 0$ en la solución, con lo cual se mantiene la separabilidad. ${ }^{14}$

Los efectos en la evasión fiscal de los parámetros de política son:

$$
\begin{gathered}
\frac{\partial \alpha}{\partial t}=-\frac{I^{2} t}{D} \phi(1-f) U^{\prime}\left(\Pi^{n d}\right)\left[R_{A}\left(\Pi^{n d}\right)(\alpha+\ldots\right. \\
\left.\ldots+(1-\alpha) f)-R_{A}\left(\Pi^{d}\right)\right] \lessgtr 0
\end{gathered}
$$

\footnotetext{
${ }^{14}$ En el Apéndice se presenta la derivación de la expresión (2.26), la cual requiere asumir que (2.24) se cumple como igualdad. Esto significa que la condición de separabilidad, en este caso, se presenta solamente cuando hay una solución interior para el nivel de evasión.
} 


$$
\begin{aligned}
& \frac{\partial \alpha}{\partial \phi}=-\frac{I t}{D}\left[U^{\prime}\left(\Pi^{n d}\right)-U^{\prime}\left(\Pi^{d}\right)(1-f)\right] \geq 0 \\
& \frac{\partial \alpha}{\partial f}=-\frac{U^{\prime}\left(\Pi^{d}\right) I t}{D} \geq 0
\end{aligned}
$$

donde $D$ es:

$$
(1-\phi) U^{\prime \prime}\left(\Pi^{n d}\right)(-R t)^{2}+\phi U^{\prime \prime}\left(\Pi^{d}\right)(1-f)^{2}(-R t)^{2} \leq 0
$$

Se observa que en este caso, no hay un resultado claro del efecto de la tasa impositiva en la evasión fiscal -ecuación (2.27) El resto de los resultados son similares al del modelo anterior -expresiones (2.21)-(2.22) versus (2.28)-(2.29).

\subsubsection{Comparación entre funciones impositivas}

Un resultado conocido en la literatura es el de la equivalencia entre un impuesto ad valorem y un impuesto específico bajo condiciones de competencia perfecta. ${ }^{15}$ En este apartado se demuestra que lo mismo se mantiene con evasión, y que además el nivel de evasión será el mismo para dos tasas impositivas que alcancen la misma recaudación teórica, para lo cual se utilizarán los resultados obtenidos hasta ahora (en especial los del modelo A1) y los del modelo C1, el cual es desarrollado por Cremer y Gahvari (1993). Para comenzar, se asume que la penalidad, la probabilidad de auditoria y el costo de la evasión son idénticos para ambos impuestos. La condición de primer orden del modelo de Cremer y Gahvari es:

$$
g^{\prime}(1-\beta)=\tau(1-\phi f)
$$

donde:

$\tau$ : Impuesto a las ventas específico.

$\beta$ : Proporción de las ventas declaradas.

\footnotetext{
${ }^{15}$ Bishop (1968) presenta el caso formalmente, realizando la comparación del efecto del impuesto ad valorem y específico bajo competencia perfecta y monopolio.
} 
Para el caso de un impuesto ad valorem (ecuación 2.8):

$$
g^{\prime}(1-\alpha)=p t(1-\phi f)
$$

Fijando la tasa del impuesto específico en $\bar{\tau}$; la recaudación teórica $(R)$ será:

$$
R=\bar{\tau} Q(p)
$$

La condición de igual recaudación teórica es:

$$
t p Q(p)=\bar{\tau} Q^{*}\left(p^{*}\right)
$$

Dado que las cantidades y precios son idénticos para tasas impositivas de un impuesto ad valorem y de uno específico (que generan la misma recaudación teórica), esto implica que:

$$
t p=\bar{\tau}
$$

Observando las ecuaciones de determinación de los valores óptimos de la evasión fiscal bajo cada función impositiva [expresiones (2.8) y (2.30)], esta última igualdad implica que :

$$
\alpha^{*}=\beta^{*}
$$

Siendo la recadación teórica y el nivel de evasión el mismo, también la recaudación esperada será idéntica. La Tabla 2.1 compara las ecuaciones (2.9)-(2.17) con las correspondientes de Cremer y Gahvari, lo cual permite observar la similitud de los resultados de estática comparativa bajo un impuesto ad valorem y uno específico. ${ }^{16}$

\footnotetext{
${ }^{16}$ Expresiones (9a), (9b), (9c), (10a), (10b) y (10c) de Cremer y Gahvari (1993). La discrepancia que se observa en el efecto de la tasa impositiva sobre los precios, está originada en la distinta unidad de medida del impuesto ad valorem (una tasa) y del impuesto específico (un monto).
} 
Tabla 2.1. Estática Comparativa Impuesto Específico y Ad Valorem en Competencia

\begin{tabular}{ccc}
\hline Específico & Ad Valorem & Comparación \\
\hline$\frac{\partial \beta}{\partial \tau}<0$ & $\frac{\partial \alpha}{\partial t}<0$ & $=$ \\
\hline$\frac{\partial \tau^{e}}{\partial \tau} \gtrless 0$ & $\frac{\partial t^{e}}{\partial t} \gtrless 0$ & $\neq$ \\
\hline $0<\frac{\partial p}{\partial \tau}<1$ & $\frac{\partial p}{\partial t}>0$ & \\
\hline$\frac{\partial \beta}{\partial \phi}>0$ & $\frac{\partial \alpha}{\partial \phi}>0$ & \\
\hline$\frac{\partial \tau^{e}}{\partial \phi}>0$ & $\frac{\partial t^{e}}{\partial \phi}>0$ & \\
\hline$\frac{\partial p}{\partial \phi}>0$ & $\frac{\partial p}{\partial \phi}>0$ & \\
\hline
\end{tabular}

\subsection{Monopolio}

Los resultados de los modelos de evasión analizados anteriormente varían en forma significativa bajo monopolio, lo cual ha sido analizado usualmente asumiendo aversión al riesgo. ${ }^{17}$ En esta sección se presenta un modelo de un monopolista neutral al riesgo en presencia de costos directos de la evasión, a fin de analizar cuestiones referidas a la incidencia de la carga tributaria cuando existe evasión. Una de las principales preguntas al respecto es si se mantiene el resultado formalizado por Suits y Musgrave (1953) respecto a la superioridad del impuesto ad valorem bajo monopolio. En primer lugar, se presenta un modelo de evasión de impuestos, tanto específico como ad valorem, por parte de un monopolista neutral al riesgo y luego se avanza en la comparación entre la incidencia de ambos impuestos.

El monopolista neutral al riesgo enfrenta una función de demanda inversa $p(q)$, dos veces diferenciable con $p^{\prime}(q)<0$ y posee un funcion de costos convexa $C(q)$. Existe un impuesto sobre las ventas el cual puede ser per unit o ad valorem, siendo $R$ el total de impuesto que debe pagar

\footnotetext{
${ }^{17}$ Una excepción es Myles (2004) que presenta las condiciones de equilbrio del monopolista neutral al riesgo con un impuesto específico.
} 
(o recaudación teórica): ${ }^{18,19}$

$$
\begin{aligned}
& R_{p u}=q \tau \\
& R_{a v}=p(q) q t
\end{aligned}
$$

donde $\tau$ y $t$ son las tasas impositivas respectivas.

El monopolista podrá ocultar una cantidad $e$ menor o igual a $q$, pudiendo evadir por lo tanto total o parcialmente su carga impositiva. La administración tributaria audita una porción $\phi$ del total de declaraciones juradas y aplica una multa $(f-1)$ sobre el monto del impuesto ocultado, donde $f>1$.

Existe una función de costos directos de la evasión $G(e)$, donde $G^{\prime}>0 \quad$ y $\quad G^{\prime \prime}>0 .{ }^{20,21}$

La recaudación esperada en ambos casos es:

$$
\begin{aligned}
& R_{p u}^{e}=q \tau-(1-\phi f) e \tau \\
& R_{a v}^{e}=p(q) q t-(1-\phi f) p(q) e t
\end{aligned}
$$

El monopolista maximiza su función de beneficios y selecciona el nivel de produccion real $(q)$ y el nivel de producción declarado $(e)$. La función a maximizar por el monopolista es:

$$
\begin{array}{r}
\operatorname{Max}_{e, q} E[\Pi]=\Pi-R^{e}-G(e) \\
\text { s.a. } \quad: \quad q \geq 0 ; \quad e \leq q
\end{array}
$$

\footnotetext{
${ }^{18}$ Los subindices $p u$ y $a v$ representan los valores de las variables ante la presencia de un impuesto específico o ad valorem respecticamente. A los efectos de simplificar la notación dichos subíndices se suprimen cuando no existe ambigüedad.

${ }^{19} \mathrm{Al}$ igual que la mayoría de la literatura, éste es un análisis de equilibrio parcial. Un análisis de equilibrio general exigiriá considerar los efectos que un determinado impuesto en un mercado pueda generar sobre el resto de los mercados relacionados.

${ }^{20}$ Esta función presenta el caso más general de la introducida por Virmani (1989) para el impuesto ad valorem y utilizada sin cambios por Cremer y Gavhari (1993) para un impuesto específico. En Virmani (1989) el costo total de la actividad de ocultamiento es $G(e)=g(1-\alpha) q$, donde $\alpha$ representa la proporción de producción declarada, siendo por lo tanto el costo proporcional al nivel de actividad.

${ }^{21}$ Algunos trabajos recientes, como Crocker y Slemrod (2004), Eichhorn (2005) y Bayer y Cowell (2009) presentan una función de costos de la evasión que depende de la base imponible ocultada. Tal opción no es factible en el presente trabajo, ya que las bases imponibles del impuesto ad valorem y específico son diferentes, lo cual haría no comparables los valores de $g(\cdot)$ entre ambos. Esto imposibilita la comparación de la incidencia de ambos impuestos bajo evasión, que es uno de los objetivos de este trabajo.
} 
donde $\Pi=p(q) q-C(q)$ es el nivel de beneficios sin considerar los impuestos ni la posibilidad de evasión.

Las condiciones de primer orden bajo ambos escenarios son:

$$
\begin{gathered}
G_{p u}^{\prime} \leq \tau(1-\phi f) \\
\Pi_{p u}^{\prime} \leq \tau \\
G_{a v}^{\prime} \leq p\left(q_{a v}\right) t(1-\phi f) \\
\Pi_{a v}^{\prime} \leq I^{\prime}\left(q_{a v}\right) t-p^{\prime}\left(q_{a v}\right) e_{a v} t(1-\phi f)
\end{gathered}
$$

Para que existan equilibrios interiores y por lo tanto la evasión mayor a cero, es necesario asumir que $\phi f<1$, supuesto que se mantendrá de aquí en adelante.Las condiciones de segundo orden se cumplen gracias a los supuestos realizados respecto a $p(q), C(q)$ y $G(e) .{ }^{22}$ Más adelante se utiliza en la siguiente relación, que se deriva en forma directa de (2.36) y (2.38):

$$
\frac{G_{p u}^{\prime}}{\tau}=\frac{G_{a v}^{\prime}}{p\left(q_{a v}\right) t}
$$

En el caso del impuesto específico, se mantiene la condición de separabilidad en ambos sentidos, ya que: i) la cantidad de equilibrio es independiente de la decisión respecto del nivel de evasión; y ii) la cantidad evadida es independiente del nivel de producción de equilibrio. ${ }^{23}$ Para el impuesto ad valorem, no hay separabilidad ya que la evasión y el nivel de producción de equilibrio son variables que se determinan en forma simultánea, al resolver las ecuaciones (2.38) y (2.39).

\footnotetext{
${ }^{22}$ En el caso del impuesto ad valorem, para que se cumpla la condición suficiente de segundo orden se precisa asumir que: $-G^{\prime \prime}\left[\Pi^{\prime \prime}-I^{\prime \prime}(q) t+p^{\prime \prime}(q) t e(1-\phi f)\right]>\left[p^{\prime}(q) t(1-\phi f)\right]^{2}$. Ver el Apéndice.

${ }^{23} \mathrm{El}$ modelo correspondiente al impuesto específico aquí presentado es técnicamente análogo al de Sandmo (2005), siendo la única diferencia que éste utiliza una función estrictamente convexa de penalidades $f(e)$, en lugar de costos directos de evasión. Sin embargo, lo usual en la legislación es que la penalidad dependa del impuesto evadido y no de las cantidades (o base imponible) ocultada.
} 


\subsubsection{Estática comparativa}

A continuación se presentan los resultados de estática comparativa para el caso del impuesto específico, los cuales se obtienen mediante la diferenciación total de las condiciones de primer orden (2.36) y (2.37) y utilizando (2.31) y (2.33):

$$
\begin{aligned}
\frac{d q}{d \tau} & =\frac{1}{I^{\prime \prime}-C^{\prime \prime}}<0 \\
\frac{d e}{d \tau} & =\frac{1-\phi f}{G^{\prime \prime}}>0 \\
\frac{d \beta}{d \tau} & =\frac{(1-\phi f)}{G^{\prime \prime} q}-\frac{e}{\left(I^{\prime \prime}-C^{\prime \prime}\right) q^{2}}>0 \\
\frac{\partial R}{\partial \tau} & =\frac{\tau}{I^{\prime \prime}-C^{\prime \prime}}+q \lessgtr 0 \\
\frac{\partial R^{e}}{\partial \tau} & =\frac{\tau}{I^{\prime \prime}-C^{\prime \prime}}+[q-e(1-\phi f)]-\frac{(1-\phi f)^{2}}{G^{\prime \prime}} \lessgtr 0
\end{aligned}
$$

Las ecuaciones (2.41) y (2.44) son las mismas que las correspondientes a un modelo con impuestos específicos pero sin la posibilidad de evasión. Esta última expresa que mientras sube $\tau$ llegará un determinado punto en el cual la recaudación teórica es máxima y a partir de allí empezará a bajar (curva de Laffer). Las ecuaciones (2.42) y (2.43) indican que tanto la cantidad como la proporción de producto ocultado aumentará con la tasa impositiva. La recaudación esperada primero aumentará y luego disminuirá cuando aumente $\tau$ (ecuación 2.45). Los puntos donde se maximiza la recaudación teórica y la esperada son, respectivamente:

$$
\begin{aligned}
\tau^{*} & =q\left(C^{\prime \prime}-I^{\prime \prime}\right) \\
\tau^{* *} & =\left(q-e(1-\phi f)-\frac{(1-\phi f)^{2}}{G^{\prime \prime}}\right)\left(C^{\prime \prime}-I^{\prime \prime}\right)
\end{aligned}
$$

Esto implica que siempre $\tau^{* *}<\tau^{*}$, y por lo tanto $q\left(\tau^{* *}\right)>q\left(\tau^{*}\right)$. Este es un resultado que se usará más adelante.

A continuación se presenta la estática comparativa del modelo correspondiente al impuesto 
específico respecto de la probabilidad de auditoría. que tiene el signo esperado. Los resultados de (2.46) son consecuencia directa de la separabilidad, mientras que (2.47)-(2.49) presentan la relación esperable:

$$
\begin{aligned}
\frac{d q}{d \phi} & =\frac{d R}{d \phi}=0 \\
\frac{d e}{d \phi} & =-\frac{\tau f}{G^{\prime \prime}}<0 \\
\frac{d \beta}{d \phi} & =-\frac{\tau f}{G^{\prime \prime} q}<0 \\
\frac{\partial R^{e}}{\partial \phi} & =(1-\phi f) \frac{\tau^{2} f}{G^{\prime \prime}}>0
\end{aligned}
$$

Con el mismo procedimiento, usando las condiciones de primer orden (2.38) y (2.39) y las expresiones (2.32) y (2.34), se obtienen los resultados de estática comparativa correspondientes al modelo con impuesto ad valorem, que se presentan a continuación (ver Apéndice para la derivación detallada):

$$
\begin{aligned}
\frac{d q}{d t} & =\frac{\left|A_{2}\right|}{|A|}<0 \\
\frac{d e}{d t} & =\frac{\left|A_{1}\right|}{|A|}>0 \\
\frac{d \beta}{d t} & =\frac{\left|A_{1}\right|}{|A| q}-\frac{\left|A_{2}\right| e}{|A| q^{2}}>0 \\
\frac{\partial R}{\partial t} & =\frac{\left|A_{2}\right| I^{\prime} t}{|A|}+p(q) q \lessgtr 0
\end{aligned}
$$




$$
\begin{gathered}
\frac{\partial R^{e}}{\partial \tau}=\frac{\partial R}{\partial t}-t\left[\frac{I^{\prime}\left|A_{2}\right|+(1-\phi f)\left[p^{\prime}(q)\left|A_{2}\right| e-\left|A_{1}\right| p(q)\right]}{|A|}\right]-\ldots \\
\ldots-p(q) e(1-\phi f) \lessgtr 0
\end{gathered}
$$

donde:

$$
\begin{gathered}
|A|=G^{\prime \prime}\left[\Pi^{\prime \prime}-I^{\prime \prime}(q) t+p^{\prime \prime}(q) t e(1-\phi f)\right]+\left[p^{\prime}(q) t(1-\phi f)\right]^{2}<0 \\
\left|A_{1}\right|=p(q)(1-\phi f)\left[\Pi^{\prime \prime}-I^{\prime \prime}(q) t+p^{\prime \prime}(q) t e(1-\phi f)\right]+\ldots \\
. .+p^{\prime}(q) t(1-\phi f)\left[I^{\prime}(q)-p^{\prime}(q) e(1-\phi f)\right]<0 \\
\left|A_{2}\right|=G^{\prime \prime}\left[I^{\prime}(q)-p^{\prime}(q) e(1-\phi f)\right]-p(q) p^{\prime}(q) t(1-\phi f)^{2}>0
\end{gathered}
$$

Respecto a cambios en la probabilidad de auditoría, los resultados son:

$$
\begin{aligned}
\frac{d q}{d \phi} & =\frac{\left|A_{4}\right|}{|A|}>0 \\
\frac{d e}{d \phi} & =\frac{\left|A_{3}\right|}{|A|}<0 \\
\frac{d \beta}{d \phi} & =\frac{\left|A_{3}\right|}{|A| q}-\frac{\left|A_{4}\right| e}{|A| q^{2}}<0 \\
\frac{\partial R}{\partial \phi} & =I^{\prime}(q) t \frac{\left|A_{4}\right|}{|A|}>0 \\
\frac{\partial R^{e}}{\partial \phi} & =\frac{\partial R}{\partial \phi}+t(1-\phi f)\left(\frac{p^{\prime}(q) e\left|A_{4}\right|+p(q)\left|A_{3}\right|}{|A|}\right) \lessgtr 0
\end{aligned}
$$


donde:

$$
\begin{aligned}
& \left|A_{3}\right|=-p(q) t f\left[\Pi^{\prime \prime}-I^{\prime \prime}(q) t+p^{\prime \prime}(q) t e(1-\phi f)\right]+\left[p^{\prime}(q) t\right]^{2}(1-\phi f) e f>0 \\
& \left|A_{4}\right|=G^{\prime \prime} p^{\prime}(q) e t f+p^{\prime}(q) p(q) t^{2} f(1-\phi f)<0
\end{aligned}
$$

Si bien la ausencia de la condición de separabilidad hace las ecuaciones mas complejas, los signos se mantienen en la dirección esperada. En las Tablas 2.2 y 2.3 se comparan los resultados de estática comparativa para ambos impuestos respecto a la tasa impositiva y la probabilidad de auditoría respectivamente.

Tabla 2.2. Estática Comparativa Impuesto Específico y Ad Valorem en Monopolio (I)

\begin{tabular}{ccc}
\hline Específico & Ad Valorem & Comparación \\
\hline$\frac{d q}{d \tau}<0$ & $\frac{d q}{d t}<0$ & $=$ \\
\hline$\frac{d e}{d \tau}>0$ & $\frac{d e}{d t}>0$ & $=$ \\
\hline$\frac{d \beta}{d \tau}>0$ & $\frac{d \beta}{d t}>0$ & $=$ \\
\hline$\frac{\partial R}{\partial \tau} \lessgtr 0$ & $\frac{\partial R}{\partial t} \lessgtr 0$ & $=$ \\
\hline$\frac{\partial R^{e}}{\partial \tau} \lessgtr 0$ & $\frac{\partial R^{e}}{\partial t} \lessgtr 0$ & \\
\hline
\end{tabular}


Tabla 2.3. Estática Comparativa Impuesto Específico y Ad Valorem en Monopolio (II)

\begin{tabular}{ccc}
\hline Específico & Ad Valorem & Comparación \\
\hline$\frac{d q}{d \phi}=0$ & $\frac{d q}{d \phi}>0$ & $\neq$ \\
\hline$\frac{d e}{d \phi}<0$ & $\frac{d e}{d \phi}<0$ & $=$ \\
\hline$\frac{d \beta}{d \phi}<0$ & $\frac{d \beta}{d \phi}<0$ & $\neq$ \\
\hline$\frac{d R}{d \phi}=0$ & $\frac{\partial R}{\partial \phi}>0$ & $\neq$ \\
\hline$\frac{\partial R^{e}}{\partial \phi}>0$ & $\frac{\partial R^{e}}{\partial \phi} \lessgtr 0$ & $\neq$ \\
\hline
\end{tabular}

Como se observa, los signos de la estática comparativa respecto a la tasa impositiva es la misma para ambos impuestos, que no es el caso respecto a la probabilidad de auditoría. En este último caso, al no presentarse separabilidad entre evasión y producción en el impuesto ad valorem la probabilidad de auditoría afecta las cantidades producidas, impactanto por lo tanto también en la recaudación teórica.

\subsubsection{Comparación entre funciones impositivas}

Para poder comparar la incidencia de dos impuestos con bases imponibles diferentes es necesario establecer un criterio de comparación apropiado. La literatura sobre esta questión ha utilizado tres alternativas: i) tasas impositivas que generan el mismo nivel de pérdida de bienestar, lo equivale en este caso a cantidades y precios al consumidor similares para ambos impuestos; ii) tasas impositivas que producen la misma recaudación teórica; y iii) tasas impositivas equivalentes a un precio dado.

La opción i) sirve para evaluar un objetivo de política consistente en maximizar la recaudación sujeto a una determinada pérdida del bienestar. Cuando se utilizan impuestos para regular una actividad con externalidades negativas, esta opción también sirve para evaluar el nivel de recaudación que podría obtenerse si se quiere limitar en un determinado nivel la producción final. La opción ii) se utiliza para evaluar el impacto en el bienestar de un nivel de 
recaudación dado. Por último, la opción iii) tiene una lógica más cercana a la de una reforma tributaria. Al utilizar $p\left(q_{p u}\right)$ como punto de partida, se estudia una reforma de reemplazo de un impuesto específico (situación inicial) por uno ad valorem, aplicando un tasa que implique la misma carga impositiva (y la misma recaudación teórica), antes de dejar al monopolista ajustar su precio y producción a tal reforma. ${ }^{24}$

Al considerar la evasión, las opciones de comparación se deben ampliar, a fin de considerar los efectos en la recaudación esperada y en la tasa de subdeclaración óptima. En las siguientes proposiciones, se agregan tales dimensiones a la comparación bajo los tres criterios clásicos.

Proposición 1: Sea un impuesto específico que genera el mismo nivel de producción de equilibrio que un impuesto ad valorem. Esto implica: $R_{a v}>R_{p u}, \beta_{a v}>\beta_{p u}$ y $R_{a v}^{e} \gtrless R_{p u}^{e}$.

Bajo la condición de igual nivel de producción, utilizando las ecuaciones (2.37) y (2.39), se tiene que:

$$
\tau=p(q) t+p^{\prime}(q) t\left[q-e_{a v}(1-\phi f)\right]
$$

Esto implica que $\tau<p(q) t$ siendo la recaudación teórica mayor para el impuesto ad valorem. Además, usando (2.40):

$$
G_{p u}^{\prime}<G_{a v}^{\prime}
$$

Así, la cantidad ocultada para el impuesto ad valorem es mayor que para el impuesto específico $\left(e_{p u}<e_{a v}\right)$. Dado que las cantidades en ambos casos son las mismas, esto implica que $\beta_{p u}<\beta_{a v}$. Es posible expresar la diferencia en la recaudación esperada del siguiento modo:

$$
\Delta R=q[p(q) t-\tau]+(1-\phi f)\left[\tau e_{p u}-p(q) t e_{a v}\right] \gtrless 0
$$

De acuerdo a ésta expresión, la recaudación esperada del impuesto ad valorem podría ser menor que la del impuesto específico.Q.E.D.

Esta proposición mantiene el dominio en términos de recaudación teórica del impuesto ad valorem respecto al específico. ${ }^{25}$ Sin embargo, tal dominio no se mantiene en términos espera-

\footnotetext{
${ }^{24}$ Suits y Musgrave (1953) utilizan como referencia el precio anterior a la aplicación de impuestos (esto es $\tau=p\left(q_{e}\right) t$, siendo $p\left(q_{e}\right)$ el precio de equilibrio sin impuestos). Por otro lado, Delipalla y Keen (1992) utilizan como criterio $d \tau=p\left(q_{p u}\right) d t$.

${ }^{25}$ Esto es, se mantiene la Proposición 1 de Suits y Musgrave (1953), pp. 598-599.
} 
dos: la producción final puede ser obtenida con tasas impositivas que genern una recaudación esperada mayor para el impuesto específico. Esto sucede porque las cantidades ocultadas son mayores para el impuesto ad valorem. El primer término del lado derecho de la ecuación (2.55) es siempre positivo: la recaudación teórica del impuesto ad valorem es mayor. El segundo término es siempre negativo: la recaudación perdida por la actividad de ocultamiento es también mayor para el impuesto ad valorem. Si la diferencia entre la recaudación teórica es menor que la diferencia entre la recaudación perdida, la recaudación esperada del impuesto específico será mayor.

La actividad del monopolista que enfrenta un impuesto ad valorem puede ser visualizada como el de una empresa que puede utilizar su plataforma para vender su producto en dos mercados, con externalidades negativas de uno hacia el otro. La siguiente expresión presenta la función de beneficios en estos términos:

$$
\begin{aligned}
& \operatorname{Max}_{e, q} E[\Pi]=[p(q) q-c(q)]+[p(q) t(1-\phi f) e-G(e)]-I(q) t \\
& \operatorname{Max}_{e, q} E[\Pi]=[p(q) q-c(q)]+[p(e, q, t, \phi, f) e-G(e)]-I(q) t
\end{aligned}
$$

donde $p(q) t(1-\phi f)=p(e, q, t, \phi, f)$ y la función de demanda inversa de $e$ tiene las siguientes características: $p_{e}=0, p_{q}<0, p_{t}>0, p_{f}<0, p_{\phi}<0$. Se ha demostrado que en este tipo de mercado, si existen externalidades positivas, el impuesto ad valorem no siempre domina a un impuesto específico. ${ }^{26}$

Las siguientes dos proposiciones permiten caracterizar las condiciones bajo las cuales se mantiene la dominancia del impuesto ad valorem sobre el específico, confirmando la literatura previa sobre el asunto.

Proposición 2: Sea un impuesto específico que genere la misma recaudación teórica que un impuesto ad valorem. Entonces: $q_{a v}>q_{p u}, R_{a v}^{e}>R_{p u}^{e} y \beta_{a v}<\beta_{p u}$; para todo $\tau$ menor que el que maximiza la recaudación teórica del impuesto específico.

\footnotetext{
${ }^{26}$ Kind, Koethenbuerger y Schjelderup (2009) analizan el comportamiento de un monopolista que vende el mismo bien a dos grupos de consumidores $(A, B)$ donde la demanda inversa es $p^{i}\left(q^{i}, q^{j}\right)$ con $p_{q^{i}}^{i}<0, p_{q^{j}}^{i}>0$, para $i=A, B$.
} 
Sea $t^{*}$ cualquier nivel de la tasa ad valorem, siendo $q_{a v}^{*}$ la cantidades de equilibrio asociada. Sea $\tau^{*}$ el nivel del impuesto específico tal que: $q_{p u}^{*}=q_{a v}^{*}$, donde $q_{p u}^{*}$ es la cantidad asociada a $\tau^{*}$. Surge de la proposición 1 que:

$$
\tau^{*} q_{a v}^{*}<t^{*} p\left(q_{a v}^{*}\right) q_{a v}^{*}
$$

Por lo tanto, para satisfacer la condición de igual recaudación teórica, es necesario aumentar la recaudación teórica del impuesto específico. De acuerdo a la expresión (2.44), asumiendo que la recaudación está por debajo de su máximo nivel posible, esto implica aumentar el impuesto específico hasta $\tau^{* *}$, tal que:

$$
\tau^{* *} q_{p u}^{* *}=t^{*} p\left(q_{a v}^{*}\right) q_{a v}^{*}
$$

Notar entonces que $q_{p u}^{* *}<q_{a v}^{*}$ y $\tau^{* *}>t^{*} p\left(q_{a v}^{*}\right)$. Así:

$$
\frac{G_{e p u}}{G_{e a v}}=\frac{\tau^{* *}}{t^{*} p\left(q_{a v}^{*}\right)}>1
$$

La cantidad ocultada es mayor para el impuesto específico $\left(e_{a v}<e_{p u}\right)$ y la tasa de ocultamiento también es mayor $\left(\beta_{a v}<\beta_{p u}\right)$. Al comparar la recaudación esperada, se observa que:

$$
R_{a v}^{e}-R_{p u}^{e}=(1-\phi f)\left[e_{p u} \tau-p\left(q_{a v}\right) t e_{a v}\right]>0
$$

O sea, $R_{a v}^{e}>R_{p u}^{e}$. Q.E.D.

Si bien esta proposición significa confirmar el resultado de la proposición 3 de Suits y Musgrave (dominancia del impuesto ad valorem para dos tasas impositivas que generan la misma recaudación teórica), en un modelo con presencia de evasión es más relevante evaluar la dominancia en términos de igual recaudación esperada.

Proposición 3: Sea un impuesto específico que lleva a la misma recaudación esperada que un impuesto ad valorem. Entonces: $q_{a v}>q_{p u}, R_{a v}<R_{p u}$ y $\beta_{a v}<\beta_{p u}$; para todo $\tau$ menor que el que maximiza la recaudación esperada del impuesto específico. 
Para cualquier $\tau^{*}$, es posible encontrar un tasa del impuesto ad valorem $t^{*}$ tal que:

$$
\tau^{*} q_{p u}^{*}=t^{*} p\left(q_{a v}^{*}\right) q_{a v}^{*}
$$

Por la proposición 2, se tiene que para tales tasas impositivas $q_{a v}^{*}>q_{p u}^{*}$ y $R^{e}\left(\tau^{*}\right)>R^{e}\left(t^{*}\right)$. Para alcanzar la condición de igual recaudación esperada, es necesario aumentar $\tau$ hasta un cierto nivel $\tau^{* *}$, ya que hasta el punto de máxima recaudación esperada $\partial R^{e} / \partial \tau>0$ [ver la ecuación (2.45) de la estática comparativa]. Entonces:

$$
q_{p u}^{* *}<q_{p u}^{*}<q_{a v}^{*}
$$

El punto de máxima recaudación esperada corresponde siempre a una tasa impositiva menor que el punto de máxima recaudación teórica, por lo tanto $\partial R / \partial \tau>0$ para $\tau=\tau^{* *}$. Esto implica que $R\left(\tau^{* *}\right)>R\left(t^{*}\right)$.

De la proposición 2 se tiene que $\beta_{a v}\left(t^{*}\right)<\beta_{p u}\left(\tau^{*}\right)$, y dado $\partial \beta_{p u} / \partial \tau>0$ (expresión 2.43), esto implica $\beta_{a v}\left(t^{*}\right)<\beta_{p u}\left(\tau^{* *}\right)$. Q.E.D.

Esta proposición es el equivalente a la proposición 3 de Suits y Musgrave (1953) pero en términos esperados. Las proposiciones 2 y 3 restringen la posibilidad de dominio del impuesto específico (establecido en la proposición 1) al segmento de la curva de Laffer "esperada" con pendiente negativa. Esto es, en la medida en que la recaudación esperada del impuesto específico aumente ante incrementos de la tasa impositiva, el impuesto ad valorem lo dominará tanto en términos de recaudación como de cantidades. ${ }^{27}$

Proposición 4: La máxima recaudación teórica y la máxima recaudación esperada que puede obtenerse de un impuesto específico es siempre menor que la de un impuesto ad valorem.

Respecto a la máxima recaudación teórica, se aplica el mismo argumento de Suits y Musgrave (1953) para demostrar su proposición 2. A partir de la proposición 1, si el nivel de recaudación

\footnotetext{
${ }^{27}$ Marrelli (1984) compara los efectos de un impuesto sobre los beneficios versus un impuesto ad valorem tomando como referencia el mismo nivel de recaudación teórica. Sin embargo, las proposiciones 2 y 3 presentadas demuestran que puede suceder que exista dominación en términos de recaudación teórica, pero no en términos de recaudación esperada. Esta posibilidad existe en este caso para tasas impositivas mayores a la de máxima recaudación esperada pero menores a la de máxima recaudación teórica.
} 
teórica es siempre mayor para el impuesto ad valorem que genera la misma cantidad de equilibrio, también lo será para la cantidad correspondiente a la máxima recaudación teórica del impuesto específico.

Respecto a la recaudación esperada, debido a la proposición 2 siempre y cuando $\partial R / \partial \tau>0$, para cualquier $\tau^{*}$ existe un $t^{*}$ que genera la misma recaudación teórica y que además $R^{e}\left(t^{*}\right)>$ $R^{e}\left(\tau^{*}\right)$. Por otro lado, la máxima recaudación esperada del impuesto específico se genera para una tasa impositiva menor que la correspondiente a la máxima recaudación teórica, con lo cual la proposición 2 es cierta para el punto de máxima recaudación esperada del impuesto específico. Q.E.D.

Esta proposición es similar a la proposición 2 de Suits y Musgrave (1953) pero en términos esperados. Es una consecuencia lógica de las proposiciones anteriores e implica un resultado importante: la posibilidad de dominio del impuesto específico nunca se dará para el punto de máxima recaudación esperada.

Al trabajar la proposición 1 con ambos lados de la curva de Laffer "esperada", es válido preguntarse el sentido de analizar la incidencia de impuestos más allá del punto de máxima recaudación esperada. Para aquellos casos en los cuales los impuestos tienen un fin regulatorio, y no solo de recaudación, tal situación podría ser relevante si resultara necesario aumentar las tasas impositivas mas allá del punto de máxima recaudación esperada. La proposición 1 establece entonces que, en estos casos puede ser preferible un impuesto específico, ya que produce el mismo efecto regulatorio con una mayor recaudación esperada. El resto de las proposiciones establecen que si el objetivo es alcanzar un cierto nivel de recaudación esperada, siempre será preferible un impuesto ad valorem.

A fin de completar el análisis, la siguiente proposición compara el efecto de ambos impuestos en un escenario de reforma impositiva. La reforma estudiada será una en la cual se resuelve reemplazar un impuesto específico por uno ad valorem, aplicando una tasa tal que se mantenga inalterada la carga impositiva (impuesto recaudado por unidad vendida), a las cantidades anteriores a la reforma.

Proposición 5: Ante una reforma impositiva donde se sustituya el impuesto específico por un impuesto ad valorem con una tasa $t=\tau / p\left(q_{p u}\right)$, se cumple que: $q_{a v}>q_{p u}$, $\beta_{a v}<\beta_{p u}$, $R_{p u}<R_{a v}$ y $R_{p u}^{e}<R_{a v}^{e}$. 
Sea $\tau^{*}$ y $t^{*}$ tales que:

$$
\tau^{*}=p\left(q_{p u}^{*}\right) t^{*}
$$

La condición de primer orden correspondente al impuesto específico es:

$$
I^{\prime}\left(q_{p u}^{*}\right)-\tau^{*}=C^{\prime}\left(q_{p u}^{*}\right)
$$

El precio $p\left(q_{p u}\right)$ no es de equilibrio para el impuesto ad valorem cuando $t=t^{*}$, esto es:

$$
I^{\prime}\left(q_{p u}^{*}\right)-I^{\prime}\left(q_{p u}^{*}\right) t^{*} \neq C^{\prime}\left(q_{p u}^{*}\right)-p^{\prime}\left(q_{p u}^{*}\right) e_{a v} t^{*}(1-\phi f)
$$

Se define $k$ tal que

$$
I^{\prime}\left(q_{p u}^{*}\right)-I^{\prime}\left(q_{p u}^{*}\right) t^{*}=C^{\prime}\left(q_{p u}^{*}\right)-p^{\prime}\left(q_{p u}^{*}\right) e_{a v} t^{*}(1-\phi f)+k
$$

Sustrayendo (2.57) de (2.59) y usando (2.56), esta última expresión puede transformarse en:

$$
k=\tau^{*}\left(1-\frac{I^{\prime}\left(q_{p u}^{*}\right)}{p\left(q_{p u}^{*}\right)}\right)-p^{\prime}\left(q_{p u}^{*}\right) e_{a v} \frac{\tau^{*}}{p\left(q_{e}\right)}(1-\phi f)>0
$$

Esto implica que la diferencia entre el ingreso marginal neto del impuesto esperado y el costo marginal del monopolista, evaluado para la cantidad $q_{p u}^{*}$ es positiva y por lo tanto la reacción del monopolista ante la reforma impositiva será incrementar las cantidades, esto es $q_{a v}^{*}>q_{p u}^{*}$.

Respecto de la tasa de subdeclaración, nótese que (2.56) implica que $\tau^{*}>p\left(q_{a v}^{*}\right) t^{*}$ y así las cantidades ocultadas son mayores para el impuesto específico y por lo tanto $\beta_{a v}<\beta_{p u}$. La recaudación teórica del impuesto ad valorem será mayor, ya que como la producción de equilibrio del monopolista siempre sucede con ingreso marginal positivo, necesariamente:

$$
\tau^{*} q_{p u}^{*}=p\left(q_{p u}^{*}\right) q_{p u}^{*} t^{*}<p\left(q_{a v}^{*}\right) q_{a v}^{*} t^{*}
$$

Siendo la recaudación teórica mayor, las cantidades ocultadas menores y dado que $\tau^{*}>$ $p\left(q_{a v}^{*}\right) t^{*}$, necesariamente $R_{p u}^{e}<R_{a v}^{e}$ Q.E.D.

De este modo, un impuesto específico puede ser reemplazado por un impuesto ad valorem que implique la misma carga impositiva antes de la reforma y de ese modo aumentar la recauación 
esperada y disminuir la evasión. Además, la carga impositiva una vez que el monopolista ajuste su nivel de producción a la nueva tasa impositiva será menor a la del impuesto específico.

\subsubsection{Simulación numérica}

En esta apartado se realiza una simulación numérica de los principales resultados encontrados respecto a la comparación del impuesto ad valorem y específico bajo monopolio, a los efectos de ilustrar los resultados obtenidos. ${ }^{28}$ La especificación funcional del modelo es la siguiente:

Demanda lineal: $p(q)=A-B q$

Costos de producción con costos marginales constantes: $C(q)=c q$

Función de costos directos de evasión convexa: $G(e)=\frac{H e^{\gamma+1}}{\gamma}$

Donde $A, B, c, H, \gamma>0$. En una primera etapa, se eligen un conjunto de valores de los parámetros (ver Tabla 2.4) y se obtienen los valores de equilibrio de las variables endógenas: $q_{a v}, q_{p u}, e_{a v}$ y $e_{p u}$. (ver Tabla 2.5). Salvo que se indique lo contrario, los resultados que se mencionan en adelante corresponden a los valores de estos parámetros.

Tabla 2.4. Simulación Numérica. Parámetros

\begin{tabular}{|c|c|c|c|c|c|c|c|c|}
\hline$\phi$ & $f$ & $c$ & $\gamma$ & $H$ & $A$ & $B$ & $t$ & $\tau$ \\
\hline 0,05 & 1,5 & 1,2 & 1 & 1 & 5 & 1 & 0,2 & 1 \\
\hline
\end{tabular}

Tabla 2.5. Simulación Numérica. Valores de Equilibrio

\begin{tabular}{|c|c|c|c|c|c|}
\hline$q_{a v}$ & $q_{p u}$ & $e_{a v}$ & $e_{p u}$ & $\beta_{a v}$ & $\beta_{p u}$ \\
\hline 1,71 & 1,4 & 0,30 & 0,46 & 0,18 & 0,33 \\
\hline
\end{tabular}

En el caso de la proposición 1, el procedimiento consiste en elegir un determinado $\widehat{\tau}$, el cual determina la cantidad de equilibrio y por tanto la tasa $\widehat{t}$ que implica la misma producción de equilibrio. En el Gráfico 2.1 se presentan los resultados de este ejercicio en términos de recaudación teórica y esperada del impuesto ad valorem y del impuesto específico -estas dos últimas en líneas punteadas- para distintos $\widehat{\tau}$.

\footnotetext{
${ }^{28}$ Las simulaciones fueron realizadas con Mathematica 5.0., estando los programas disponibles previa solicitud.
} 


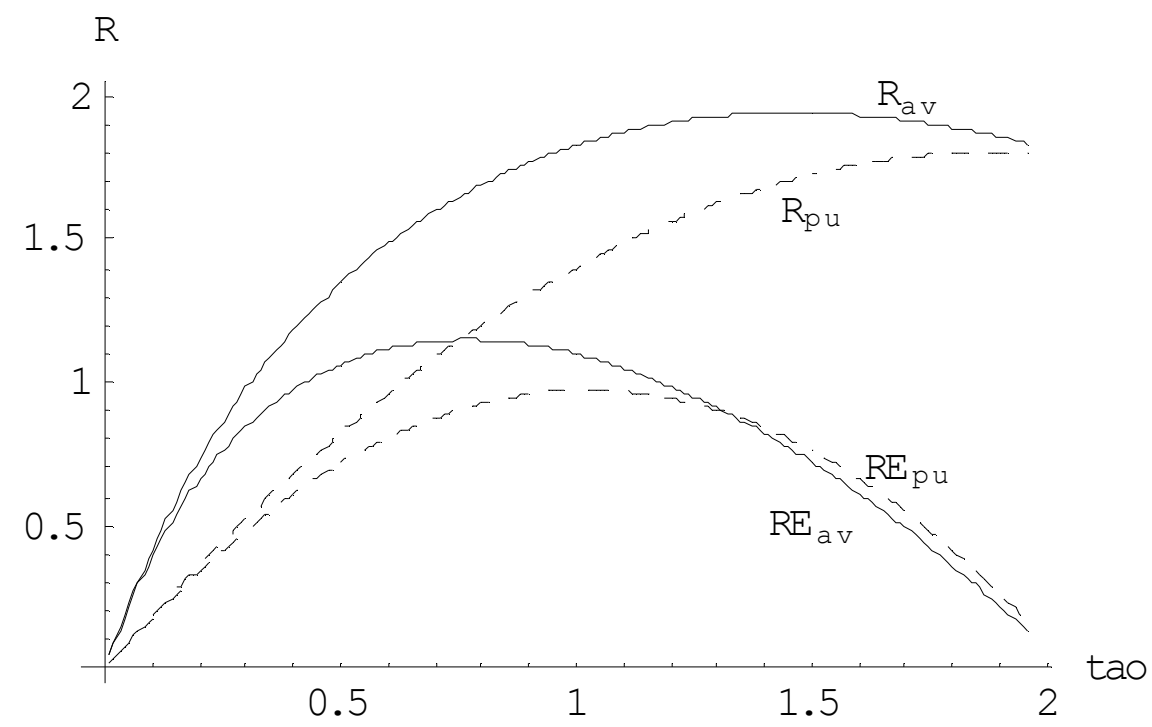

Gráfico 2.1. Recaudación Teórica y Esperada, para AV y PU

Se observa que para ambos impuestos, el punto de máxima recaudación esperada se da para una tasa impositiva menor que el de máxima recaudación teórica. También se observa que las curvas de recaudación teórica no se cruzan, siendo superior la del impuesto ad valorem. Por el contrario, las curvas de recaudación esperada se cruzan a niveles altos del impuesto específico $(\widehat{\tau} \simeq 1,32)$. Por último,nótese que el tramo en el cual la recaudación esperada del impuesto específico es mayor a la del impuesto ad valorem sucede, tal como se establece en la proposición 3, en el tramo de la curva de Laffer "esperada" con pendiente negativa.

El Gráfico 2.2 muestra la diferencia entre la recaudación esperada de ambos impuestos (linea entera: $\left.R_{a v}^{e}-R_{p u}^{e}\right)$ y en las líneas punteadas cada una de las partes de la expresión (2.55). En la línea punteada irregularmente se presenta la diferencia en la recaudación teórica $\left(R_{a v}-R_{p u}\right)$ y en la otra línea la diferencia en el monto monetario evadido, $D E=(1-\phi f)\left[p(q) t e_{a v}-\tau e_{p u}\right]$. En el punto en que ambas curvas punteadas se tocan, la diferencia en la recaudación esperada se hace cero. 


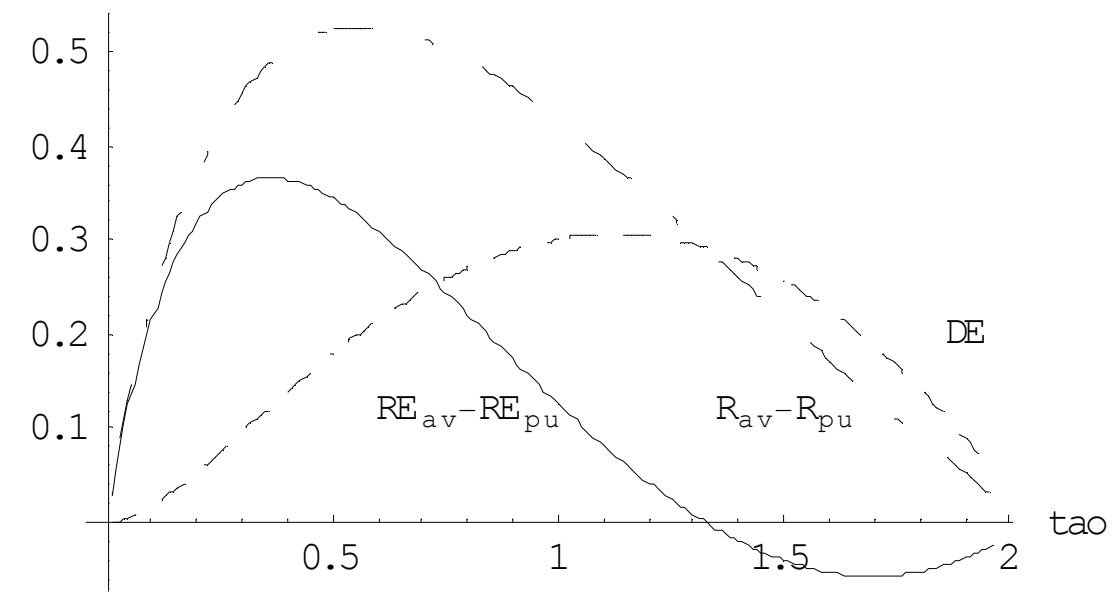

Gráfico 2.2. Diferencia en Recaudación Esperada

Por último, en el Gráfico 2.3 se presenta la diferencia $\beta_{a v}-\beta_{p u}$, que también es siempre mayor para el impuesto ad valorem.

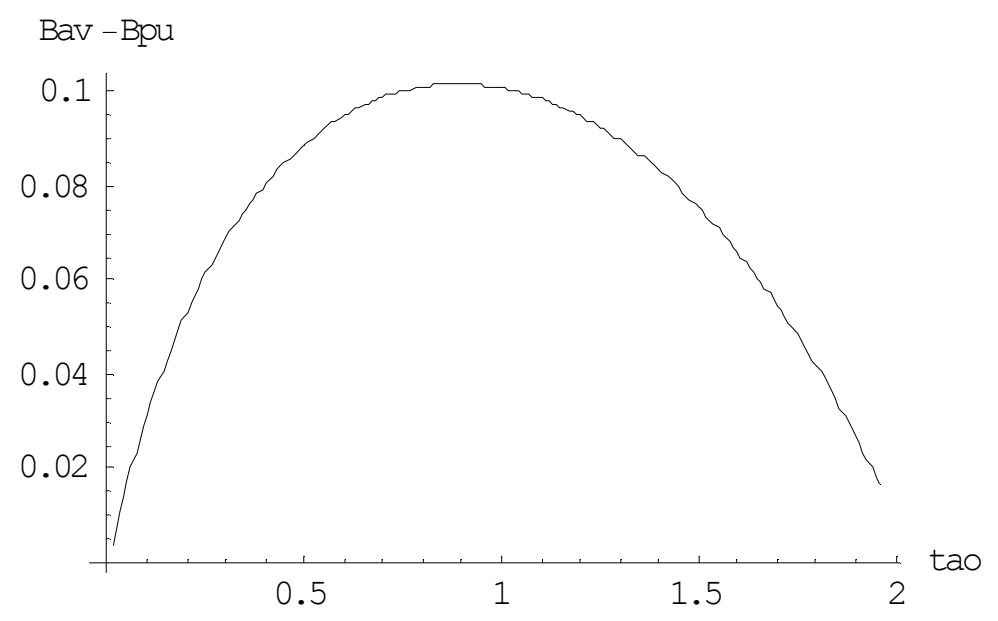

Gráfico 2.3. Diferencia en la Proporción Ocultada

Se considera relevante verificar la sensibilidad del resultado de una recaudación esperada mayor del impuesto específico (proposición 1). A tal fin se toma un valor de la tasa específica que implica una recaudación esperada mayor a la del impuesto ad valorem, para la configuración inicial $(\widehat{\tau}=1,4)$ y se varían individualmente el resto de los parámetros presentados en la Tabla 2.4 alrededor de sus valores iniciales. De este modo, siempre existe al menos un punto en el 
cual $R_{p u}^{e}>R_{a v}^{e}$. En los Gráficos 2-4 a 2-9 del Apéndice se repite el ejercicio del Gráfico 2-1 para variaciones en el resto de los parámetros del modelo (las líneas punteadas corresponden al impuesto específico $)^{29}$. En los Gráficos 2-10 al 2-15 se presenta la diferencia en la recaudación esperada $\left(R_{a v}^{e}-R_{p u}^{e}\right)$, para variaciones en los parámetros similares. En todos los casos, salvo con $B$ y con $c$, cuando el parámetro crece tal diferencia pasa nuevamente a ser positiva y cada vez mayor, fortaleciendo el dominio del impuesto ad valorem en términos de recaudación esperada.

\subsection{Conclusiones}

En este capítulo se realizaron un conjunto de ejercicios teóricos vinculados a la evasión de impuestos específicos y ad valorem, en los dos casos extremos de competencia perfecta y monopolio. Cuando existe competencia perfecta, se mantiene la equivalencia en términos de bienestar de ambos impuestos.

Por el otro lado, en el caso de monopolio, se ha demostrado que el impuesto ad valorem es superior a un impuesto específico en términos de bienestar y de recaudación, aún considerando la mayor evasión fiscal que produce, salvo en condiciones especiales. En particular, cuando las tasas impositivas son suficientemente altas para afectar en forma negativa a la recaudación esperada, podría darse que un impuesto específico produzca más recaudación que un impuesto ad valorem que disminuya en el mismo nivel la producción de la firma. Este resultado podría ser relevante en contextos en los cuales las tasas impositivas tienen un fin regulatorio (reducción de cantidades producidas). Si existe competencia perfecta, ambos impuestos tienen el mismo efecto, aún considerando la evasión.

Los modelos aquí presentados son estilizados y no incluyen aspectos que la literatura ha intentado considerar, como ser restricciones financieras, detección imperfecta, corrupción, problemas de agencia, reglas de auditoría, alternativas al paradigma de utilidad esperada, argumentos adicionales en la función de utilidad (bienes públicos), normas sociales, modelos intertemporales, otros tipos de incertidumbre, etc. ${ }^{30}$ De todos modos, permanencen diversos aspectos casi no tocados, como ser el análisis de la incidencia del impuesto ad valorem y el específico con

\footnotetext{
${ }^{29}$ No se presenta el gráfico respecto a $f$ ya que impacta en forma exactamente igual a $\phi$ y por lo tanto sería ocioso.

${ }^{30}$ En Cowell (2004) se presenta una revisión actualizada de la literatura y se tratan algunos de estos temas.
} 
evasión bajo competencia imperfecta, la inclusión en el análisis de los sistemas de retención, y las interrelaciones entre evasión y elusión fiscal, entre otros.

Respecto al resultado de superioridad del impuesto ad valorem notar que se ha mantenido aquí constante en la comparación entre funciones impositivas los costos directos de la evasión, así como las probabilidad de auditoría. Sin embargo, la auditoría de un impuesto específico es más simple que la de una impuesto ad valorem. En el primer caso hay una sola variable a controlar (cantidad), mientras que en el segundo hay dos (cantidad y precio). Esto podría implicar que la probabilidad de auditoria en el primer caso sea mayor que en el segundo: la misma cantidad de recursos asignados a la administración tributaria alcanzarían para más auditorias bajo un impuesto específico. Por otro lado, el costo de la evasión en el caso del impuesto específico debería ser mayor: es más difícil esconder cantidades, que cantidades y/o precios. Ambos aspectos generarían una evasión fiscal menor en el caso de un impuesto específico, tanto en competencia perfecta como en monopolio. 


\subsection{Apéndice}

\subsubsection{Estática comparativa bajo competencia}

Se necesitan las variables endógenas $(\alpha, p)$ dependiendo exclusivamente de las exógenas $(t, f, \phi)$. A tal fin, la metodología es calcular las diferenciales totales de la condiciones de primer orden (que previamente deben ser transformadas en igualdades), dividar por las variables de interés y resolver el sistema usando la Regla de Cramer.

Las condiciones de primer orden [ecuaciones (2.5) y (2.8)] como igualdades son:

$$
\begin{aligned}
g^{\prime}-p t(1-f \phi) & =0 \\
p-p t \alpha(1-f \phi)-p t f \phi-c-g(1-\alpha) & =0
\end{aligned}
$$

Las diferenciales totales de (2.60) y (2.61) son

$$
\begin{aligned}
& 0=-g^{\prime \prime} d \alpha-t(1-f \phi) d p-p(1-f \phi) d t+p t \phi d f+p t f d \phi \\
& 0=-p t(1-f \phi) d \alpha+g^{\prime} d \alpha+d p-t \alpha(1-f \phi) d p-t f \phi d p-\ldots \\
& \quad \ldots-p \alpha(1-f \phi) d t-p f \phi d t+p t \alpha \phi d f-p t \phi d f+p t \alpha f d \phi-p t f d \phi
\end{aligned}
$$

Utilizando estas expresiones, se pueden resolver los resultados de estática comparativa, de acuerdo a lo que sigue.

a) $\frac{\partial \alpha}{\partial t}$ y $\frac{\partial p}{\partial t}$

En (2.62) y (2.63) se hace $d f=d \phi=0$ y se divide ambas ecuaciones por $\partial t$, obteniendo un sistema de dos ecuaciones con dos variables:

$$
\begin{gathered}
-g^{\prime \prime} \frac{\partial \alpha}{\partial t}-t(1-f \phi) \frac{\partial p}{\partial t}=p(1-f \phi) \\
\left(g^{\prime}-p t(1-f \phi)\right) \frac{\partial \alpha}{\partial t}+(1-t \alpha(1-f \phi)-t f \phi) \frac{\partial p}{\partial t}=p \alpha(1-f \phi)+p f \phi
\end{gathered}
$$

Usando la regla de Cramer,

$$
\left[\begin{array}{cc}
-g^{\prime \prime} & -t(1-f \phi) \\
0 & 1-t[\alpha+(1-\alpha) f \phi)]
\end{array}\right]\left[\begin{array}{l}
\frac{\partial \alpha}{\partial t} \\
\frac{\partial p}{\partial t}
\end{array}\right]=\left[\begin{array}{c}
p(1-f \phi) \\
p[\alpha+(1-\alpha) f \phi)]
\end{array}\right]
$$




$$
\begin{aligned}
& \frac{\partial \alpha}{\partial t}=\frac{\left|A_{1}\right|}{|A|}=\frac{p(1-f \phi)[1-t[\alpha+(1-\alpha) f \phi)]]+p[\alpha+(1-\alpha) f \phi)] t(1-f \phi)}{\left.-g^{\prime \prime}[1-t[\alpha+(1-\alpha) f \phi)]\right]} \\
& \frac{\partial p}{\partial t}=\frac{\left|A_{2}\right|}{|A|}=\frac{\left.-g^{\prime \prime} p[\alpha+(1-\alpha) f \phi)\right]}{\left.-g^{\prime \prime}[1-t[\alpha+(1-\alpha) f \phi)]\right]}
\end{aligned}
$$

Se tiene que:

$$
\left|A_{1}\right|=p(1-f \phi)>0
$$

Con lo cual se obtienen las ecuaciones (2.9) y (2.11):

$$
\begin{aligned}
& \frac{\partial \alpha}{\partial t}=-\frac{p(1-f \phi)}{\left.g^{\prime \prime}[1-t[\alpha+(1-\alpha) f \phi)]\right]}<0 \\
& \frac{\partial p}{\partial t}=\frac{p[\alpha+(1-\alpha) f \phi)]}{1-t(\alpha+(1-\alpha) f \phi)}>0
\end{aligned}
$$

b) $\frac{\partial \alpha}{\partial \phi}$ y $\frac{\partial p}{\partial \phi}$

Utilizando el mismo procedimiento, se obtiene:

$$
\begin{aligned}
-g^{\prime \prime} \frac{\partial \alpha}{\partial \phi}-t(1-f \phi) \frac{\partial p}{\partial \phi} & =p t f \\
-p t(1-f \phi) \frac{\partial \alpha}{\partial \phi}+g^{\prime} \frac{\partial \alpha}{\partial \phi}+\frac{\partial p}{\partial \phi}-t \alpha(1-f \phi) \frac{\partial p}{\partial \phi}-t f \phi \frac{\partial p}{\partial \phi} & =p t f-p t f \alpha
\end{aligned}
$$

Regla de Cramer,

$$
\left[\begin{array}{cc}
-g^{\prime \prime} & -t(1-f \phi) \\
0 & 1-t[\alpha+(1-\alpha) f \phi)]
\end{array}\right]\left[\begin{array}{l}
\frac{\partial \alpha}{\partial \phi} \\
\frac{\partial p}{\partial \phi}
\end{array}\right]=\left[\begin{array}{c}
-p t f \\
p t f(1-\alpha)
\end{array}\right]
$$




$$
\begin{aligned}
& \frac{\partial \alpha}{\partial \phi}=\frac{\left|A_{1}\right|}{|A|}=\frac{-p t f[1-t[\alpha+(1-\alpha) f \phi)]]+p t f(1-\alpha) t(1-f \phi)}{\left.-g^{\prime \prime}[1-t[\alpha+(1-\alpha) f \phi)]\right]} \\
& \frac{\partial p}{\partial \phi}=\frac{\left|A_{2}\right|}{|A|}=\frac{-g^{\prime \prime} p t f(1-\alpha)}{\left.-g^{\prime \prime}[1-t[\alpha+(1-\alpha) f \phi)]\right]}
\end{aligned}
$$

Así se obtiene (2.12) y (2.14):

$$
\begin{aligned}
& \frac{\partial \alpha}{\partial \phi}=\frac{\left|A_{1}\right|}{|A|}=\frac{p t f(1-t)}{\left.g^{\prime \prime}[1-t[\alpha+(1-\alpha) f \phi)]\right]}>0 \\
& \frac{\partial p}{\partial \phi}=\frac{\left|A_{2}\right|}{|A|}=\frac{p t f(1-\alpha)}{[1-t[\alpha+(1-\alpha) f \phi)]]}>0
\end{aligned}
$$

c) $\frac{\partial \alpha}{\partial f}$ y $\frac{\partial p}{\partial f}$; debido a que $f$ siempre está multiplicando a $\phi$ :

$$
\begin{aligned}
& \frac{\partial \alpha}{\partial f}=\frac{\left|A_{1}\right|}{|A|}=\frac{p t \phi(1-t)}{\left.g^{\prime \prime}[1-t[\alpha+(1-\alpha) f \phi)]\right]}>0 \\
& \frac{\partial p}{\partial f}=\frac{\left|A_{2}\right|}{|A|}=\frac{p t \phi(1-\alpha)}{[1-t[\alpha+(1-\alpha) f \phi)]]}>0
\end{aligned}
$$


d) Con respecto a $t^{e}$, los efectos parciales pueden ser obtenidos directamente desde (2.7):

$$
\begin{aligned}
& t^{e}=t[\alpha+(1-\alpha) f \phi]=t A \\
& \frac{\partial t^{e}}{\partial t}=t^{\prime} A+A^{\prime} t \\
& A^{\prime}=\frac{\partial(\alpha+\phi(1-\alpha) f)}{\partial \alpha} \frac{\partial \alpha}{\partial t} \\
& A^{\prime}=-(1-\phi f) \frac{p(1-f \phi)}{\left.g^{\prime \prime}[1-t[\alpha+(1-\alpha) f \phi)]\right]} \\
& \frac{\partial t^{e}}{\partial t}=\alpha+(1-\alpha) \phi f-t p \frac{(1-\phi f)^{2}}{\left.g^{\prime \prime}[1-t[\alpha+(1-\alpha) f \phi)]\right]} \\
& \frac{\partial t^{e}}{\partial \phi}=t\left[\frac{\partial \alpha}{\partial \phi}+\frac{\partial(\phi f)}{\partial \phi}-\frac{\partial(\phi f \alpha)}{\partial \phi}\right] \\
& \frac{\partial t^{e}}{\partial \phi}=t\left[\alpha^{\prime}+f\left[1-\left(\alpha^{\prime} \phi+\alpha \phi^{\prime}\right)\right]\right] \\
& \frac{\partial t^{e}}{\partial \phi}=t\left[\alpha^{\prime}(1-f \phi)+f(1-\alpha)\right] \\
& \frac{\partial t^{e}}{\partial \phi}=t\left[\frac{p t f(1-t)}{\left.g^{\prime \prime}[1-t[\alpha+(1-\alpha) f \phi)]\right]}(1-f \phi)+f(1-\alpha)\right] \\
& \frac{\partial t^{e}}{\partial f}=t\left[\frac{p t \phi(1-t)}{\left.g^{\prime \prime}[1-t[\alpha+(1-\alpha) f \phi)]\right]}(1-f \phi)+\phi(1-\alpha)\right]
\end{aligned}
$$




\subsubsection{Solución al modelo de aversión al riesgo}

\section{a. Evasión como cantidad}

Condiciones de primer orden (ecuaciones 2.18 y 2.19)

$$
\begin{gathered}
(1-\phi) U^{\prime}\left(\Pi^{n d}\right) \frac{\partial \Pi^{n d}}{\partial S}+\phi U^{\prime}\left(\Pi^{d}\right) \frac{\partial \Pi^{d}}{\partial S} \leq 0 \\
(1-\phi) U^{\prime}\left(\Pi^{n d}\right)+\phi U^{\prime}\left(\Pi^{d}\right)(1-f) \leq 0 \\
\frac{(1-\phi)}{\phi(f-1)} \geq \frac{U^{\prime}\left(\Pi^{d}\right)}{U^{\prime}\left(\Pi^{n d}\right)} \\
(1-\phi) U^{\prime}\left(\Pi^{n d}\right) \Pi_{q}^{n d}+\phi U^{\prime}\left(\Pi^{d}\right) \Pi_{q}^{d} \leq 0 \\
\Pi_{q}^{n}=\Pi_{q}=p(1-t)-c \\
{\left[(1-\phi) U^{\prime}\left(\Pi^{n d}\right)+\phi U^{\prime}\left(\Pi^{d}\right)\right] \Pi_{q} \leq 0}
\end{gathered}
$$

Condiciones de segundo orden:

$$
\begin{aligned}
& E(U)_{s s}=(1-\phi) U^{\prime \prime}\left(\Pi^{n d}\right) \frac{\partial \Pi^{n d}}{\partial S}+\phi U^{\prime \prime}\left(\Pi^{d}\right) \frac{\partial \Pi^{d}}{\partial S}(1-f) \leq 0 \\
& E(U)_{s s}=(1-\phi) U^{\prime \prime}\left(\Pi^{n d}\right)+\phi(1-f)^{2} U^{\prime \prime}\left(\Pi^{d}\right) \leq 0 \\
& E(U)_{q q}=\left[(1-\phi) U^{\prime \prime}\left(\Pi^{n d}\right)+\phi U^{\prime \prime}\left(\Pi^{d}\right)\right] \Pi_{q}^{2} \leq 0
\end{aligned}
$$


Estática comparativa: ecuación (2.20), $\frac{\partial S}{\partial t}$. Calculando la diferential total de (2.18)

$$
\begin{aligned}
d & =(1-\phi) U^{\prime}\left(\Pi^{n d}\right)+\phi U^{\prime}\left(\Pi^{d}\right)(1-f) \\
\frac{\partial S}{\partial t} & =-\frac{d_{t}}{d_{S}} \\
d_{t} & =(1-\phi) U^{\prime \prime}\left(\Pi^{n d}\right)(-I)+\phi U^{\prime \prime}\left(\Pi^{d}\right)(1-f)(-I) \\
d_{S} & =D \\
\frac{\partial S}{\partial t} & =-\frac{(1-\phi) U^{\prime \prime}\left(\Pi^{n d}\right)(-I)+\phi U^{\prime \prime}\left(\Pi^{d}\right)(1-f)(-I)}{D} \\
\frac{\partial S}{\partial t} & =\frac{I}{D}\left[\phi(1-f) U^{\prime \prime}\left(\Pi^{d}\right)+(1-\phi) U^{\prime \prime}\left(\Pi^{n d}\right)\right]
\end{aligned}
$$

Donde $D$ es la condición de segundo orden. Por (2.18), se tiene:

$$
(1-\phi)=-\phi(1-f) \frac{U^{\prime}\left(\Pi^{d}\right)}{U^{\prime}\left(\Pi^{n d}\right)}
$$

Reemplazando:

$$
\begin{aligned}
\frac{\partial S}{\partial t} & =\frac{I}{D}\left[\phi(1-f) U^{\prime \prime}\left(\Pi^{d}\right)-\phi(1-f) \frac{U^{\prime}\left(\Pi^{d}\right)}{U^{\prime}\left(\Pi^{n d}\right)} U^{\prime \prime}\left(\Pi^{n d}\right)\right] \\
\frac{\partial S}{\partial t} & =\frac{I}{D} \phi(1-f) U^{\prime}\left(\Pi^{d}\right)\left[\frac{U^{\prime \prime}\left(\Pi^{d}\right)}{U^{\prime}\left(\Pi^{d}\right)}-\frac{U^{\prime \prime}\left(\Pi^{n d}\right)}{U^{\prime}\left(\Pi^{n d}\right)}\right] \\
\frac{\partial S}{\partial t} & =\frac{I}{D} \phi(1-f) U^{\prime}\left(\Pi^{n d}\right)\left[R_{A}\left(\Pi^{n d}\right)-R_{A}\left(\Pi^{d}\right)\right] \leq 0
\end{aligned}
$$

Estática comparativa: ecuación (2.21), $\frac{\partial S}{\partial \phi}$. Calculando la diferential total de (2.18):

$$
\begin{aligned}
d & =(1-\phi) U^{\prime}\left(\Pi^{n d}\right)+\phi U^{\prime}\left(\Pi^{d}\right)(1-f) \\
\frac{\partial S}{\partial \phi} & =-\frac{d_{\phi}}{d_{S}} \\
d_{\phi} & =-U^{\prime}\left(\Pi^{n d}\right)+U^{\prime}\left(\Pi^{d}\right)(1-f) \\
d_{S} & =D \\
\frac{\partial S}{\partial \phi} & =-\frac{U^{\prime}\left(\Pi^{n d}\right)-U\left(\Pi^{d}\right)^{\prime}(1-f)}{D} \leq 0
\end{aligned}
$$


Estática comparativa: ecuación (2.22), $\frac{\partial S}{\partial f}$. Calculando la diferential total de (2.18):

$$
\begin{aligned}
d & =(1-\phi) U^{\prime}\left(\Pi^{n d}\right)+\phi U^{\prime}\left(\Pi^{d}\right)(1-f) \\
\frac{\partial S}{\partial f} & =-\frac{d_{f}}{d_{S}} \\
d_{f} & =-U^{\prime}\left(\Pi^{d}\right) \\
d_{S} & =D \\
\frac{\partial S}{\partial f} & =\frac{U\left(\Pi^{d}\right)}{D} \leq 0
\end{aligned}
$$

\section{b. Evasión como porcentaje}

Condiciones de primer orden, ecuaciones (2.24 y 2.25):

$$
\begin{aligned}
\frac{\partial E(U)}{\partial \alpha} & =(1-\phi) U^{\prime}\left(\Pi^{n d}\right) \frac{\partial \Pi^{n d}}{\partial \alpha}+\phi U^{\prime}\left(\Pi^{d}\right) \frac{\partial \Pi^{d}}{\partial \alpha} \leq 0 \\
& =(1-\phi) U^{\prime}\left(\Pi^{n d}\right)(-I t)+\phi U^{\prime}\left(\Pi^{d}\right)(-I t+I t f) \leq 0 \\
\frac{(1-\phi)}{\phi(f-1)} & \geq \frac{U^{\prime}\left(\Pi^{d}\right)}{U^{\prime}\left(\Pi^{n d}\right)}
\end{aligned}
$$

Ecuación (2.26):

$$
\begin{aligned}
\Pi_{q} & =p-c-p t \\
A & \equiv p t\left(1-\alpha-q \alpha^{\prime}\right) \\
\Pi_{q}^{n d} & =p-c-p t\left(\alpha+q \alpha^{\prime}\right) \\
\Pi_{q}^{n d} & =\Pi_{q}+p t-p t\left(\alpha+q \alpha^{\prime}\right)=\Pi_{q}+A \\
\Pi_{q}^{d} & =p-c-p t\left(\alpha+q \alpha^{\prime}\right)-p f t \frac{\partial(q-q \alpha)}{\partial q} \\
\Pi_{q}^{d} & =p-c-p t\left(\alpha+q \alpha^{\prime}\right)-p f t\left(1-\alpha-q \alpha^{\prime}\right) \\
\Pi_{q}^{d} & =\Pi_{q}+p t\left(1-\alpha-q \alpha^{\prime}\right)-p f t\left(1-\alpha-q \alpha^{\prime}\right) \\
\Pi_{q}^{d} & =\Pi_{q}+(1-f) p t\left(1-\alpha-q \alpha^{\prime}\right)=\Pi_{q}+(1-f) A
\end{aligned}
$$


Reemplazando:

$$
E(U)_{q}=(1-\phi) U^{\prime}\left(\Pi^{n d}\right)\left(\Pi_{q}+A\right)+\phi U^{\prime}\left(\Pi^{d}\right)\left(\Pi_{q}+(1-f) A\right) \leq 0
$$

En caso de solución interior:

$$
U^{\prime}\left(\Pi^{n d}\right)=\frac{U^{\prime}\left(\Pi^{d}\right) \phi(f-1)}{(1-\phi)}
$$

Reemplazando nuevamente:

$$
\begin{aligned}
E(U)_{q} & =(1-\phi) \frac{U^{\prime}\left(\Pi^{d}\right) \phi(f-1)}{(1-\phi)}\left(\Pi_{q}+A\right)+\phi U^{\prime}\left(\Pi^{d}\right)\left(\Pi_{q}+(1-f) A\right) \\
E(U)_{q} & =\phi U^{\prime}\left(\Pi^{d}\right)\left[(f-1)\left(\Pi_{q}+A\right)+\Pi_{q}+(1-f) A\right] \\
B & \equiv(f-1)\left(\Pi_{q}+A\right)+\Pi_{q}+(1-f) A \\
B & \equiv f \Pi_{q}+f A-\Pi_{q}-A+\Pi_{q}+A-f A \\
B & \equiv f \Pi_{q} \\
E(U)_{q} & =\phi f U^{\prime}\left(\Pi^{d}\right) \Pi_{q}
\end{aligned}
$$

Condiciones de segundo orden:

$$
\begin{gathered}
E(U)_{s s}=(1-\phi) U^{\prime \prime}\left(\Pi^{n d}\right)(-I t)^{2}+\phi U^{\prime \prime}\left(\Pi^{d}\right)(1-f)^{2}(-I t)^{2} \leq 0 \\
E(U)_{s s}=\left[(1-\phi) U^{\prime \prime}\left(\Pi^{n d}\right)+\phi U^{\prime \prime}\left(\Pi^{d}\right)(1-f)^{2}\right](-I t)^{2} \leq 0 \\
E(U)_{q q}=(1-\phi) U^{\prime \prime}\left(\Pi^{n d}\right)\left(\Pi_{q}^{n d}\right)^{2}+\phi U^{\prime \prime}\left(\Pi^{d}\right)\left(\Pi_{q}^{d}\right)^{2} \leq 0
\end{gathered}
$$


Estática comparativa, ecuación $\left(2.27, \frac{\partial \alpha}{\partial t}\right)$. Diferenciando (2.25):

$$
\begin{aligned}
d & =(1-\phi) U^{\prime}\left(\Pi^{n d}\right)(-I t)+\phi U^{\prime}\left(\Pi^{d}\right)(1-f)(-I t) \\
\frac{\partial \alpha}{\partial t} & =-\frac{d_{t}}{d_{\alpha}} \\
d_{t} & =(1-\phi) U^{\prime \prime}\left(\Pi^{n d}\right)(-I \alpha)(-I t)+\phi U^{\prime \prime}\left(\Pi^{d}\right)(1-f)(-I t)(-I \alpha-I(1-\alpha) f) \\
d_{\alpha} & =D \\
\frac{\partial \alpha}{\partial t} & =-\frac{(1-\phi) U^{\prime \prime}\left(\Pi^{n d}\right)(-I \alpha)(-I t)+\phi U^{\prime \prime}\left(\Pi^{d}\right)(1-f)(-I t)(-I \alpha-I(1-\alpha) f)}{D} \\
\frac{\partial \alpha}{\partial t} & =\frac{I}{D}\left[\phi(1-f) U^{\prime \prime}\left(\Pi^{d}\right)(-I t)(\alpha+(1-\alpha) f)+(1-\phi) U^{\prime \prime}\left(\Pi^{n d}\right) \alpha(-I t)\right]
\end{aligned}
$$

Donde $D$ es la condición de segundo orden. Sabemos (2.24) que:

$$
(1-\phi)=-\phi(1-f) \frac{U^{\prime}\left(\Pi^{d}\right)}{U^{\prime}\left(\Pi^{n d}\right)}
$$

Reemplazando:

$$
\begin{aligned}
& \frac{\partial \alpha}{\partial t}=\frac{I}{D}\left[\phi(1-f) U^{\prime \prime}\left(\Pi^{d}\right)(\alpha+(1-\alpha) f)(-I t)-\phi(1-f) \frac{U^{\prime}\left(\Pi^{d}\right)}{U^{\prime}\left(\Pi^{n d}\right)} U^{\prime \prime}\left(\Pi^{n d}\right)(-I t)\right] \\
& \frac{\partial \alpha}{\partial t}=-\frac{I^{2} t}{D} \phi(1-f) U^{\prime}\left(\Pi^{d}\right)\left[\frac{U^{\prime \prime}\left(\Pi^{d}\right)}{U^{\prime}\left(\Pi^{d}\right)}(\alpha+(1-\alpha) f)-\frac{U^{\prime}\left(\Pi^{n d}\right)}{U^{\prime}\left(\Pi^{n d}\right)}\right] \\
& \frac{\partial \alpha}{\partial t}=-\frac{I^{2} t}{D} \phi(1-f) U^{\prime}\left(\Pi^{n d}\right)\left[R_{A}\left(\Pi^{n d}\right)(\alpha+(1-\alpha) f)-R_{A}\left(\Pi^{d}\right)\right] \leq 0
\end{aligned}
$$


Estática comparativa, ecuación $\left(2.28, \frac{\partial \alpha}{\partial \phi}\right)$. Diferenciando (2.24):

$$
\begin{aligned}
d & =(1-\phi) U^{\prime}\left(\Pi^{n d}\right)(-I t)+\phi U^{\prime}\left(\Pi^{d}\right)(1-f)(-I t) \\
\frac{\partial \alpha}{\partial \phi} & =-\frac{d_{\phi}}{d_{\alpha}} \\
d_{\phi} & =-U^{\prime}\left(\Pi^{n d}\right)(-I t)+U^{\prime}\left(\Pi^{d}\right)(1-f)(-I t) \\
d_{\alpha} & =D \\
\frac{\partial \alpha}{\partial \phi} & =-\frac{-U^{\prime}\left(\Pi^{n d}\right)(-I t)+U^{\prime}\left(\Pi^{d}\right)(1-f)(-I t)}{D} \\
\frac{\partial \alpha}{\partial \phi} & =-\frac{I t}{D}\left[U^{\prime}\left(\Pi^{n d}\right)-U^{\prime}\left(\Pi^{d}\right)(1-f)\right] \geq 0
\end{aligned}
$$

Estática comparativa, ecuación $\left(2.29, \frac{\partial \alpha}{\partial f}\right)$. Diferenciando (2.24):

$$
\begin{aligned}
d & =(1-\phi) U^{\prime}\left(\Pi^{n d}\right)(-I t)+\phi U^{\prime}\left(\Pi^{d}\right)(1-f)(-I t) \\
\frac{\partial \alpha}{\partial f} & =-\frac{d_{f}}{d_{\alpha}} \\
d_{f} & =U^{\prime}\left(\Pi^{d}\right) I t \\
d_{\alpha} & =D \\
\frac{\partial \alpha}{\partial f} & =-\frac{U^{\prime}\left(\Pi^{d}\right) I t}{D} \geq 0
\end{aligned}
$$

\subsubsection{Monopolio}

\section{a. Condición de segundo orden para impuesto ad valorem}

En el problema de maximización:

$$
\begin{array}{r}
\operatorname{Max}_{e}, q U=\Pi-R^{e}-G(e) \\
\text { s.a. } \quad: \quad q \geq 0 ; \quad e \leq q
\end{array}
$$


Las condiciones suficientes de segundo orden son:

$$
\begin{array}{r}
U_{q q}, U_{e e}<0 \\
U_{q q} U_{e e}-U_{q e}^{2}>0
\end{array}
$$

Lo que aquí implica que:

$$
\begin{aligned}
U_{q q} & =\left[\Pi^{\prime \prime}-I^{\prime \prime}(q) t+p^{\prime \prime}(q) t e(1-\phi f)\right]<0 \\
U_{e e} & =-G_{e e}<0 \\
U_{q q} U_{e e}-U_{q e}^{2} & =-G_{e e}\left[\Pi^{\prime \prime}-I^{\prime \prime}(q) t+p^{\prime \prime}(q) t e(1-\phi f)\right]-\left[p^{\prime}(q) t(1-\phi f)\right]^{2}>0
\end{aligned}
$$




\subsubsection{Gráficos de la simulación numérica}

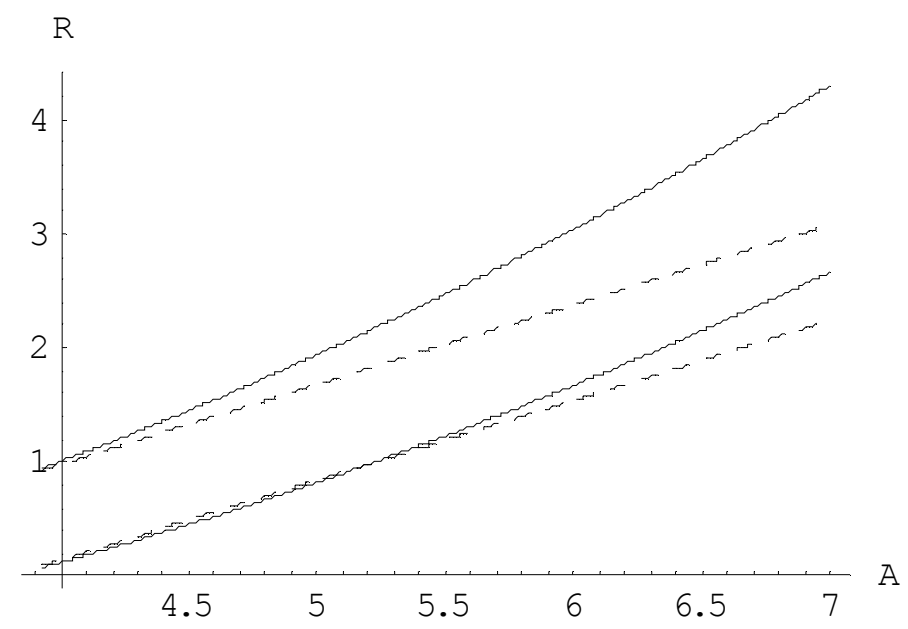

Gráfico 2.4. Recaudación Teórica y Esperada y A

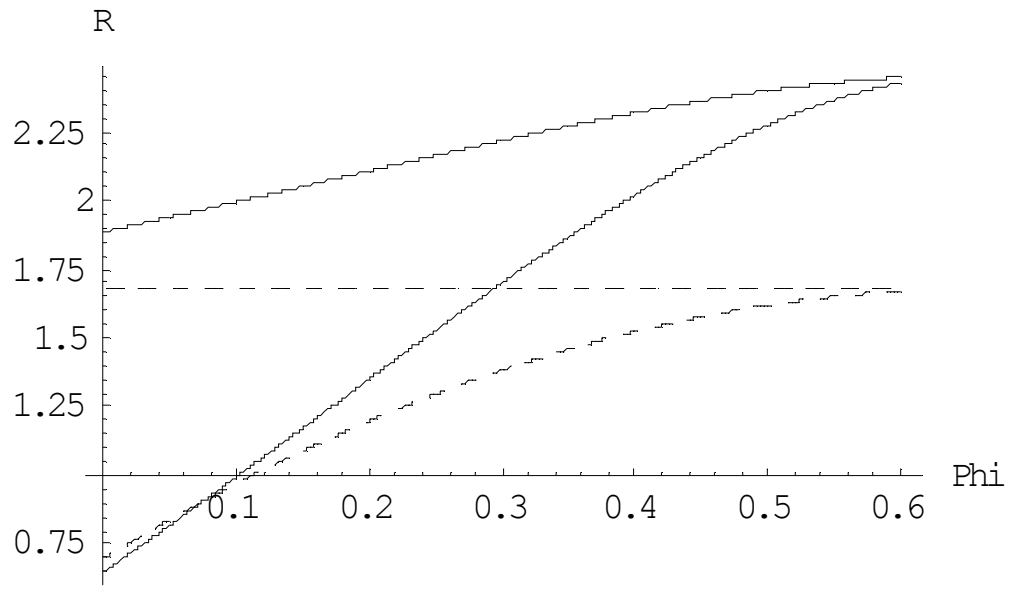

Gráfico 2.5. Recaudación Teórica y Esperada y Phi 


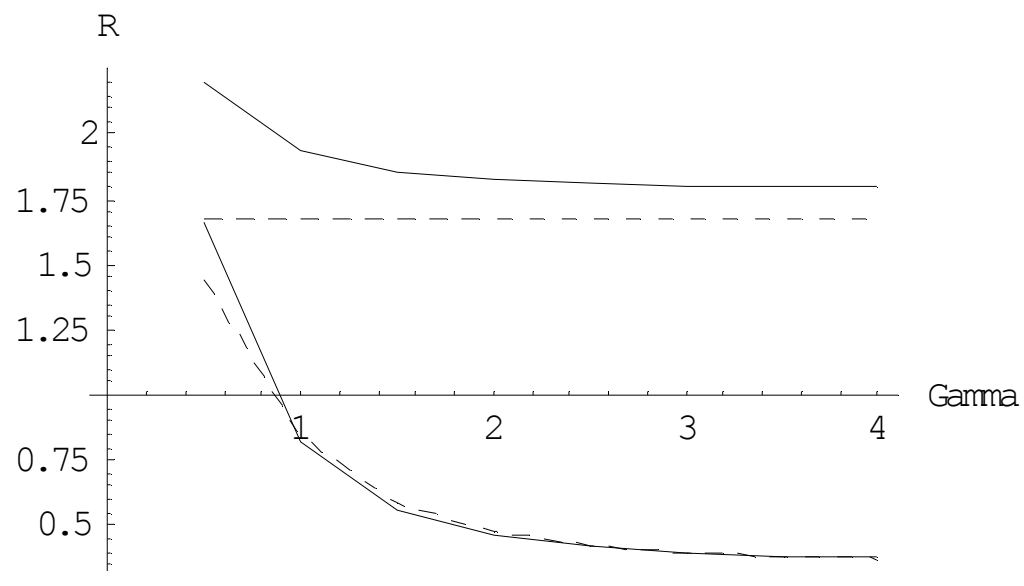

Gráfico 2.6. Recaudación Teórica y Esperada y Gamma

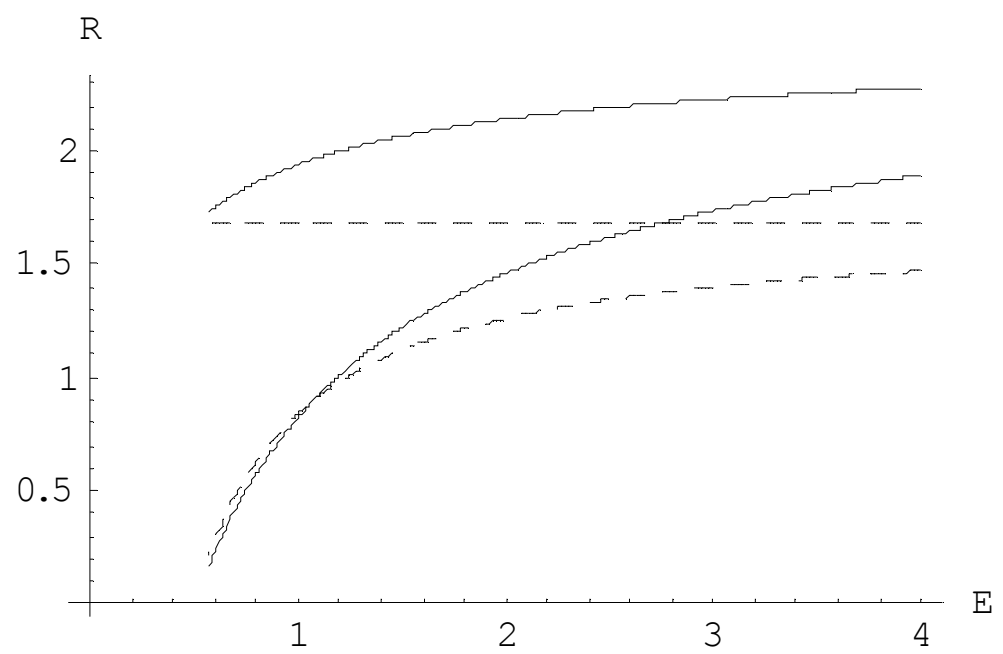

Gráfico 2.7. Recaudación Teórica y Esperada y E 


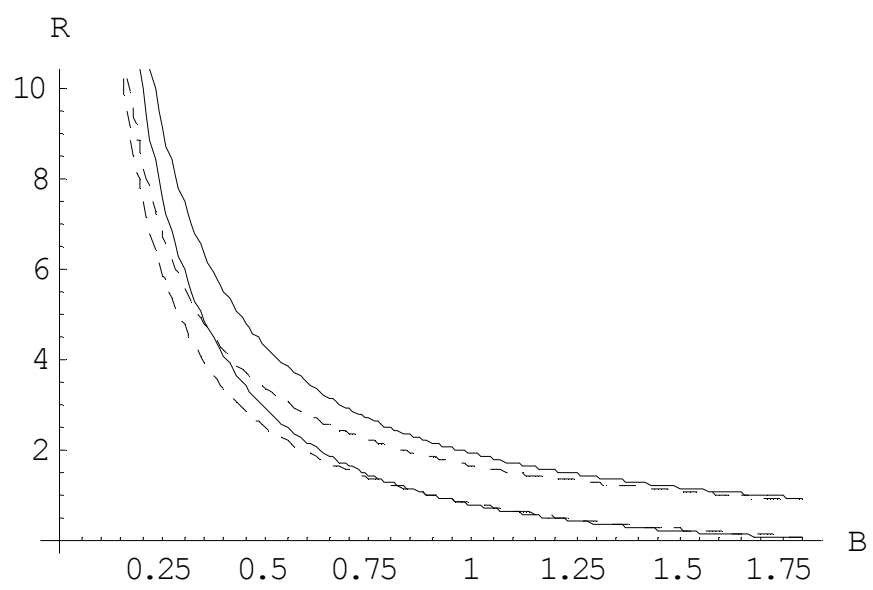

Gráfico 2.8. Recaudación Teórica y Esperada y B

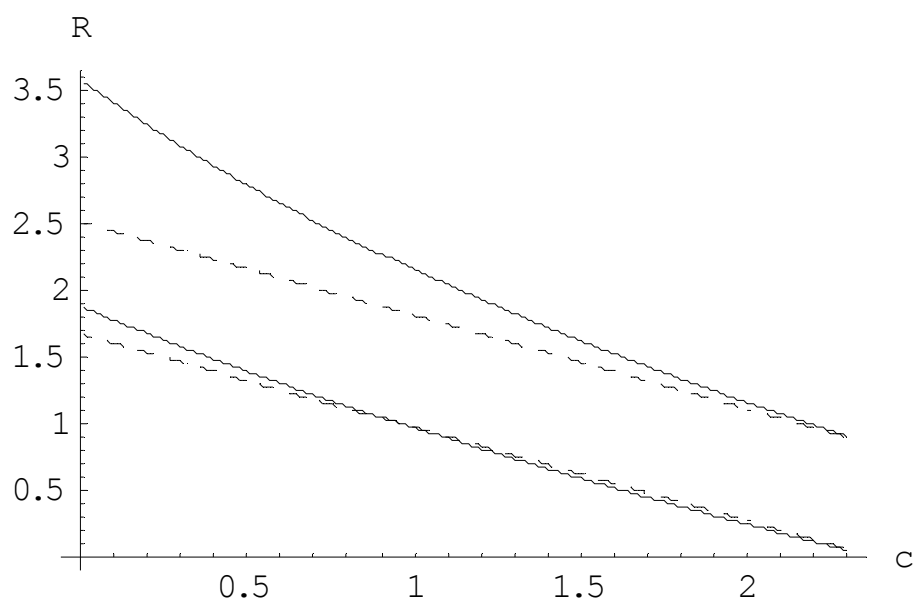

Gráfico 2.9. Recaudación Teórica y Esperada y c

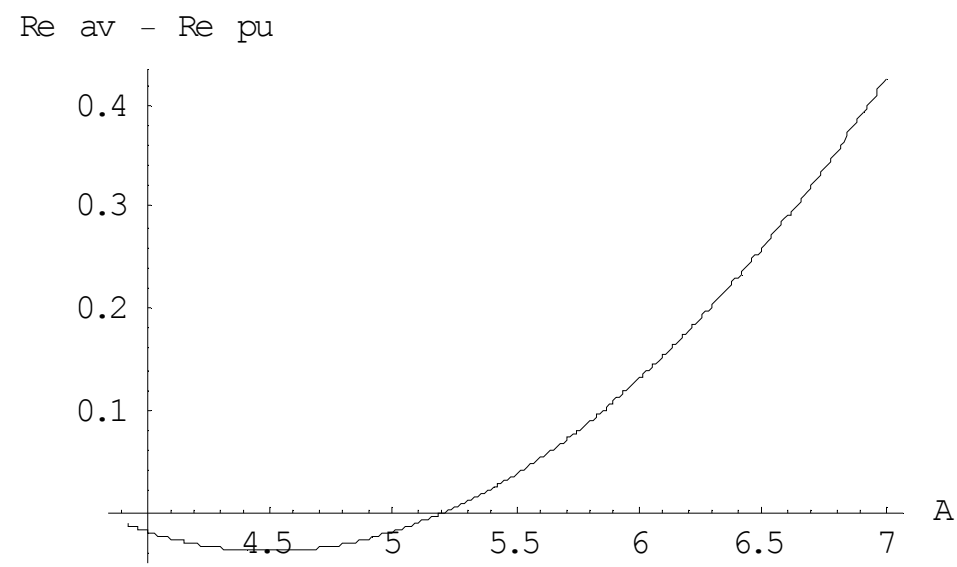

Gráfico 2.10. Diferencia en Recaudación Esperada y A 


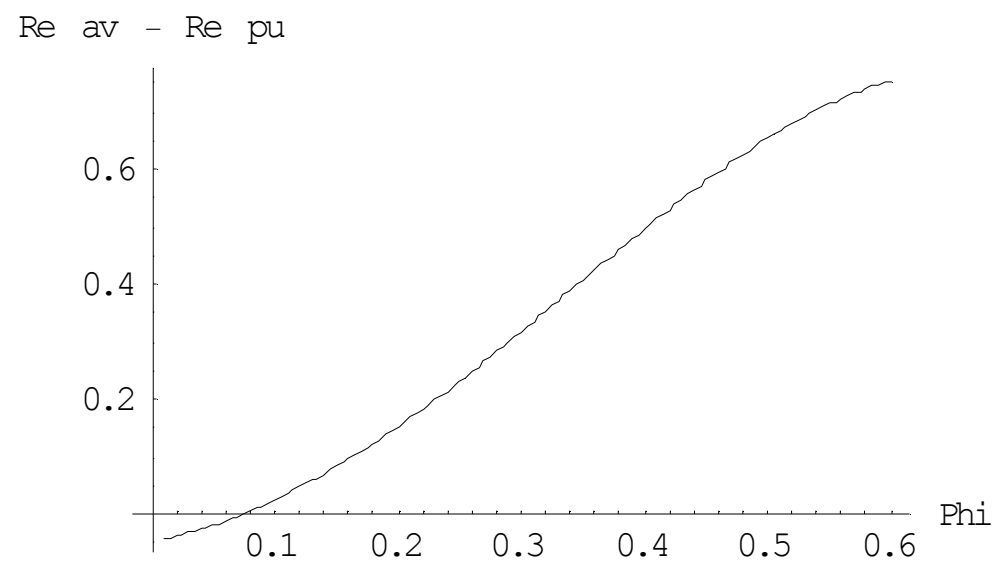

Gráfico 2.11. Diferencia en Recaudación Esperada y Phi

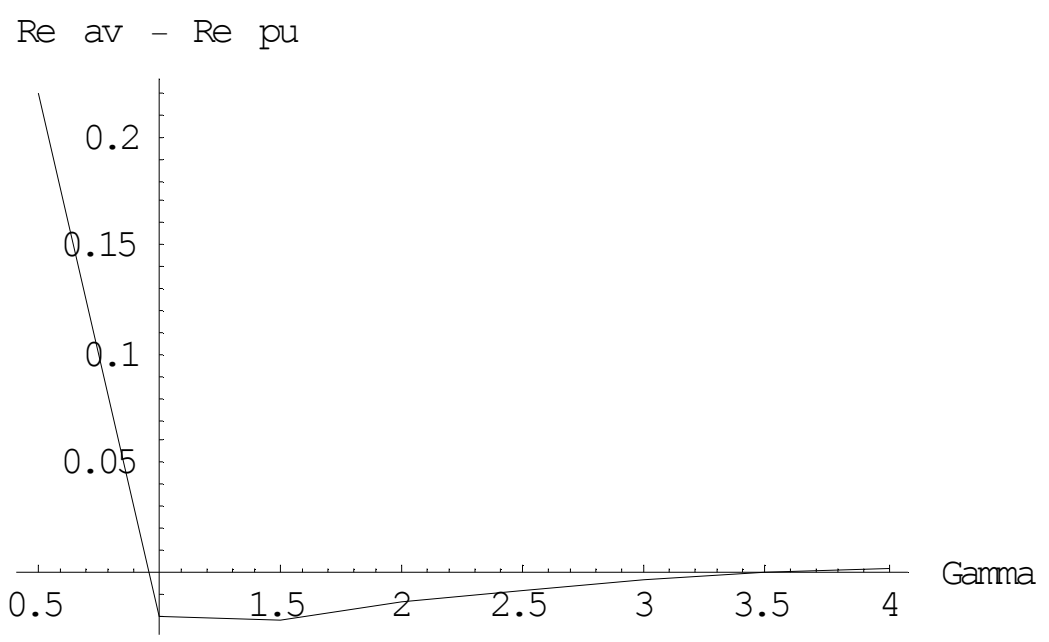

Gráfico 2.12. Diferencia en Recaudación Esperadad y Gamma 


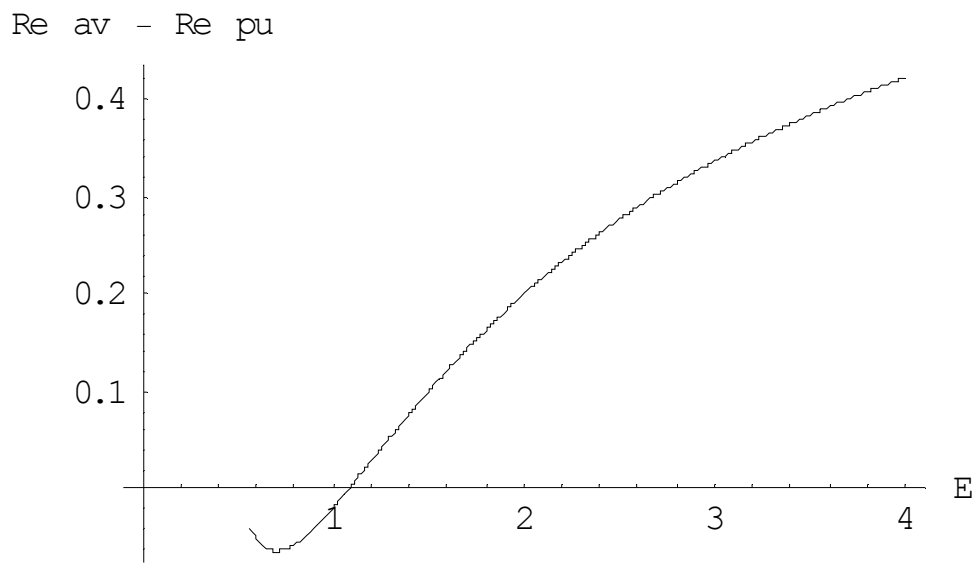

Gráfico 2.13. Diferencia en Recaudación Esperadad y E

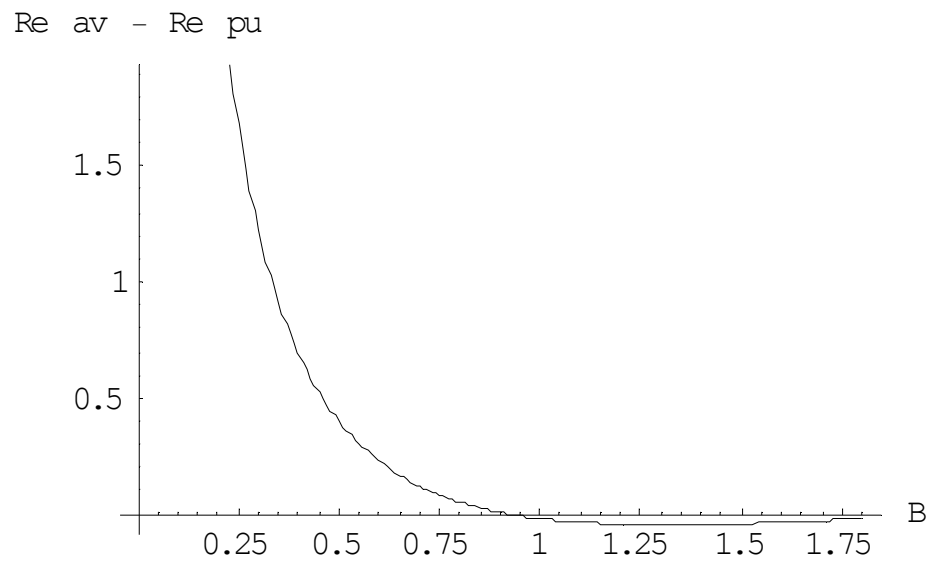

Gráfico 2.14. Diferencia en Recaudación Esperada y B

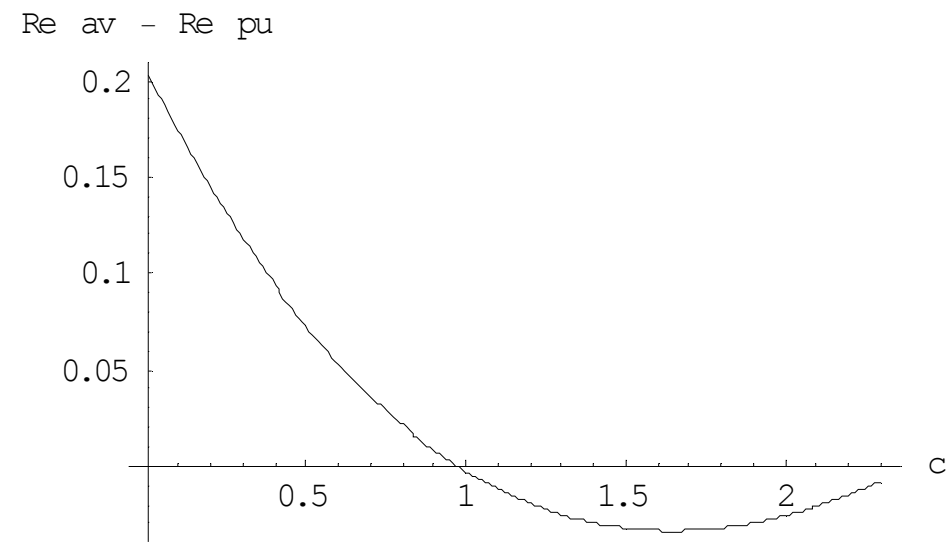

Gráfico 2.15. Diferencia en Recaudación Esperada y c 


\subsection{Referencias bibliográficas}

Allingham, M. G. y A. Sandmo (1972). "Income tax evasion: A theoretical analysis". Journal of Public Economics, vol 1, pp 323-338.

Alm, J. (1999). "Tax Compliance and Administration". En Hildreth, W.B. y J. A. Richardson (eds). Handbook on Taxation, New York: Marcel Dekker, pp 741-768.

Anderson, S.P., de Palma, A. y B. Kreider (2001a)."The Efficiency of Indirect Taxes Under Imperfect Competition". Journal of Public Economics, vol 81, pp 231-251.

Anderson, S.P., de Palma, A. y B. Kreider (2001b). "Tax Incidence in Differentiated Product Oligopoly". Journal of Public Economics, vol 81, pp 173-192.

Andreoni J., B. Erard y J. Feinstein (1998). "Tax Compliance". Journal of Economic Literature, vol 36 (2), pp 818-860.

Bayer, R. y F. Cowell (2009). "Tax Compliance and Firms' Strategic Interdependence". Journal of Public Economics, vol 93, pp 1131-1143.

Bishop, R.L. (1968). "The effects of specific and ad valorem taxes". Quarterly Journal of Economics, vol 82, pp 198-218.

Blackorby, Ch. y S. Murty (2006). "Unit Versus Ad Valorem Taxes: Monopoly In General Equilibrium". Warwick Economic Reaserch Papers No 761. Deparment of Economics. The University of Warwick.

Bossi, L. (2007). "Per Unit Versus Ad Valorem Taxes Under Dynamic Monopoly". Working Paper 2007-03. School of Business Administration. University of Miami.

Chen, K.P y C.Y. Chu (2002). "Internal Control vs External Manipulation: A Model of Corporate Income Tax Evasion". Noviembre.

Cowell, F. (2004). "Carrots and sticks in enforcement". En The Crisis in Tax Administration. Washington DC: The Brookings Institution.

Cremer, H. y F. Gahvari (1993). "Tax Evasion and Optimal Commodity Taxation". Journal of Public Economics, vol 50, pp 261-275.

Crocker, K. y J. Slemrod (2005). "Corporate tax evasion with agency costs". Journal of Public Economics, vol 89, pp 1593-1610. 
Delipalla S. y M. Keen (1992). "The comparison between ad valorem and specific taxation under imperfect competition". Journal of Public Economics, vol 49, pp 351-367.

Eichhorn, Ch. (2006). "Tax Evasion and Tax Enforcement in a Model of Imperfect Competition". Tesis doctoral no publicada. Ludwig-Maximilians-Universitat Munchen.

Goerke, L. y M. Runkel (2006). "Profit Tax Evasion under Oligopoly with Endogenous Market Structure". National Tax Journal, vol 59, pp 51-57.

Franzoni, L. A. (1999). "Tax Evasion and Tax Compliance”. En Bouckaert B. and G. De Geest (eds.), Encyclopedia of Law and Economics, Cheltenham, UK: Edward Elgar, pp 52-94.

Goerke, L. (2006). "Bureaucratic Corruption and Profit Tax Evasion". CESifo Working Paper No 1666. Febrero.

Hamilton, S.F. (1999). "The Comparative Efficiency of Ad Valorem and Specific Taxes Under Monopoly and Monopsony". Economics Letters, vol 63 (2), pp 235-238.

Kind, H.J., Koethenbuerger, M. y G. Schjelderup (2009). "On revenue and welfare dominance of ad valorem taxes in two sided markets". Economics Letters, vol 104(2), pp 86-88.

Lee, K. (1998). "Tax Evasion, Monopoly and Nonneutral Profit Taxes". National Tax Journal, vol 51, pp 333-38.

Marrelli, M. (1984). "On Indirect Tax Evasion". Journal of Public Economics, vol 25, pp 181-196.

Marrelli, M. y R. Martina (1988). "Tax Evasion and Strategic Behaviour of the Firms". Journal of Public Economics, vol 37, pp 55-69.

Murray, M. (1995). "Sales Tax Compliance and Audit Selection". National Tax Journal, vol 48, pp 515-530.

Myles, G. (1996). "Imperfect Competition and the Optimal Combination of Ad Valorem and Specific Taxation". International Tax and Public Finance, vol 3, pp 29-44.

Myles, G. (2001). Public Economics. Manuscrito no publicado.

Sandmo, A. (2005). "The Theory of Tax Evasion: A Retrospective View". National Tax Journal, vol 63, pp 643-663. 
Skeath, S. y G.A. Trandel (1994). "A Pareto comparison of ad valorem and unit taxes in noncompetitive environments". Journal of Public Economics, vol 53, pp 53-71.

Slemrod, J. y S. Yitzhaki (2000). "Tax Avoidance, Evasion, and Administration”. NBER Working Paper No 7476.

Suits D.B. y R.A. Musgrave (1953). "Ad Valorem and Unit Taxes Compared". The Quarterly Journal of Economics, vol 67, pp 598-604.

Virmani, A. (1989). "Indirect Tax Evasion and Production Efficiency". Journal of Public Economics, vol 39, pp 223-237.

Wang, L.F.S. y J.L. Conant (1988). "Corporate Tax Evasion and Output Decisions of the Uncertain Monopolist". National Tax Journal, vol 41, pp 579-581.

Yaniv, G. (1988). "Withholding and Non-Withheld Tax Evasion". Journal of Public Economics, vol 35, pp 183-204.

Yaniv, G. (1995). "A Note on the Tax Evading Firm". National Tax Journal, vol 48, pp 113-20. 


\section{Capítulo 3}

\section{Evasión Fiscal en un Monopolio en Cadena}

\subsection{Introducción}

En este capítulo se analiza un modelo de monopolio en cadena en el cual el impuesto que grava la venta final puede ser evadido por el contribuyente, sea el monopolista de la última etapa o un monopolista integrado. Al incluir la posibilidad de evasión en la etapa final de una estructura vertical de producción y comercialización, las preguntas principales que surgen son: i) el efecto de la evasión en el beneficio de toda la cadena y en la distribución de tal beneficio entre productor y minorista, así como el efecto de la evasión en el excedente del consumidor; y ii) si existe externalidad, cuales son las restricciones verticales que resuelven tal externalidad. ${ }^{1}$

Estas preguntas son las usuales en la literatura de organización industrial desarrollada con el

\footnotetext{
${ }^{1}$ En la literatura de organización industrial sobre estructuras de producción y comercialización, se califica como "externalidad" a aquellas situaciones en las cuales la decisión de un agente tiene efectos sobre el beneficio de un tercero y tales efectos no estarían presentes si toda la estructura actuaran como un agente único. El término fue introducido por Mathewson y Winter (1984), quienes identificaron tres "externalidades" asociadas a la decisión de un minorista: i) externalidad vertical, ii) externalidad horizontal por "derrame" de publicidad, y iii) externalidad horizontal conjetural. El mismo término es utilizado en contextos similares, entre otros, por Rey y Tirole (1986), Vickers y Waterson (1991), Dobson y Waterson (1996), Tan (2001) y Rey y Verge (2005). Sin embargo, este uso del término difiere de la definición tradicional de externalidad, la cual es más restrictiva. Tal definición refiere a una situación en la cual existe una divergencia entre el costo (o beneficio) social y el privado. Esto implica que, aún luego de haberse realizado todas las transacciones voluntarias entre los agentes económicos, aún quedan algunas que serían beneficiosas socialmente pero que no son llevadas a cabo (sea, por ejemplo, por la falta de una adecuada definición de los derechos de propiedad o por altos costos de transacción). Sobre esta definición, ver Mishan (1971) y Dahlman (1979).
} 
objeto de encontrar la motivación a herramientas de control vertical. ${ }^{2}$ Mediante la incorporación en un modelo de monopolio en cadena de un impuesto específico en la etapa final que puede ser evadido, se espera verificar si algunos de los resultados más generales en esta literatura de organización industrial se siguen sosteniendo. Conscientemente, se dejan de lado otras preguntas que aparecen ante la presencia del impuesto específico que puede ser evadido y que no se han tratado en modelos de monopolio en cadena. Entre tales preguntas, se encuentra la incidencia del impuesto en el bienestar, así como el diseño de políticas fiscales óptimas. Este tipo de preguntas son propias de la literatura sobre economía del bienestar y sobre finanzas públicas, y pueden considerarse ampliaciones futuras posibles del modelo presentado en este capítulo.

La metodología consistirá en presentar un modelo de monopolio en cadena donde existe un impuesto indirecto sobre las ventas finales (que no puede ser evadido) y se analiza la externalidad así como la distribución del beneficio dentro de toda la cadena. Este es el mundo de "honestidad". Luego se presenta un modelo que difiere solamente en la posibilidad de evasión del impuesto y se analizan los mismos aspectos (el mundo de la "evasión"). Comparando los resultados de ambos mundos, bajo equilibrio integrado y no integrado, se determina el efecto de la evasión fiscal sobre la externalidad dentro de un monopolio en cadena.

La externalidad en el caso tradicional de un monopolio en cadena se da a través de las cantidades: la decisión del minorista de igualar su ingreso marginal con el costo marginal no toma en cuenta el impacto que tiene la elección de cantidades comercializadas en el beneficio del productor. Por lo tanto, si la decisión de evasión del minorista tiene impacto en las cantidades comercializadas, existirá un externalidad similar a la del modelo tradicional de monopolio en cadena. La relación entre la decisión de evasión y de producción es un tema bastante estudiado en la literatura sobre evasión impositiva. ${ }^{3}$ En función de como esté configurado el modelo (nivel de aversión al riesgo, probabilidad de auditoría y costos directos de la evasión) tales decisiones serán "separables" o no. Por lo tanto, la separabilidad (especialmente la no existencia de la misma) tendrá un impacto importante en los resultados de este capitulo. A fin de considerar adecuadamente esta cuestión, se presentarán primero los resultados para un modelo donde existe separabilidad y luego para uno donde la decisión de evasión tiene un impacto en las cantidades

\footnotetext{
${ }^{2}$ En Rey y Verge (2005) se presenta una revisión reciente de esta literatura.

${ }^{3}$ Este es un tema analizado en extenso en el Capítulo 2.
} 
producidas (no hay separabilidad).

Se demuestra que si la separabilidad está presente, la ganancia para toda la cadena proveniente de la integración es la misma con o sin evasión, aunque la ganancia para el productor (y por lo tanto el incentivo a integrarse) es mayor cuando existe la posibilidad de evasión. Bajo el supuesto de información perfecta, una tarifa en dos partes resuelve la externalidad generada por el monopolio en cadena y le permite al productor apropiarse del beneficio que surge de la actividad de evasión de impuestos. Si no hay separabilidad, la ganancia tanto para toda la cadena y para el productor pueden ser mayor o menor cuando hay evasión respecto al caso de honestidad.

En la siguiente sección se presenta una revisión de la literatura de organizacion industrial sobre control vertical. La sección 3.3 analiza el modelo de doble monopolio con un impuesto específico en la etapa final que puede ser evadido y en el cual las decisiones de evasión y de producción son separables. La sección 3.4. se presenta un modelo similar, salvo por el hecho de que las decisiones ya no son separables, debido a que la probabilidad de auditoría se supone variable en función del monto declarado por el contribuyente. En la sección 3.5. se presenta una simulación numérica que permite ilustrar los resultados alcanzados. Se cierra el capítulo con comentarios finales.

\subsection{Antecedentes}

El análisis formal de monopolios en cadena fue realizado en primer lugar por Spengler (1950), quién observó que, a diferencia de lo que indicaba la intuición y la sabiduría convencional del momento, ante una situación inicial alejada de la competencia, la integración vertical puede operar para acercar los resultados a los de competencia. La metodología consitió en considerar una situación en donde hay tres etapas de la cadena de producción y comercialización. Se determina entonces que, cuando en ninguna de las etapas existe poder de mercado, el equilibrio integrado (una única firma) implica los mismos resultados que un equilibrio desintegrado (tres firmas independientes). Luego se analiza el mismo equilibrio cuando existe poder monopólico en más de una etapa y se encuentra que debido a la eliminación del "doble margen" (en más de una etapa las empresas aplican una política de precios que implica un mark up) la integración 
vertical puede mejorar tanto el bienestar del consumidor como el beneficio de toda la cadena. La principal conclusión de Spengler (1950) es que, en general, la integración horizontal produce pérdidas de bienestar (vía aumento del poder de mercado), pero una integración vertical podría producir mejoras en el bienestar, si la situación inicial es de poder de mercado en más de una etapa.

Este análisis simple se fue haciendo cada vez más completo a fin de encontrar una explicación a la utilización de diversas herramientas de control vertical por parte de empresas, diferentes al caso básico de integración. La explicación económica integral del control vertical aparece con los trabajos de Mathewson y Winter (1984), Rey y Tirole (1986) y Rey y Stiglitz (1988).

Rey y Verge (2005) resumen el estado actual de esta literatura y analizan las herramientas de control vertical establecidas en los contratos entre productores y distribuidores (o mayoristas y minoristas) agrupadas en: i) esquemas de pago más generales (no lineales, en dos partes, descuentos por cantidad, etc.), ii) limitaciones sobre las decisiones y derechos de una parte (cantidad o precios mínimos, etc,) y iii) cláusulas que hacen disminuir la competencia en el nivel minorista (distribuidor exclusivo, territorios exclusivos, etc.).

Una de las preguntas principales de esta literatura ha sido la motivación de la presencia de tales restricciones. En general, se identifican dos visiones contrapuestas al respecto. La primera considera que los acuerdos verticales aparecen con el objeto de mejorar la eficiencia debido a los problemas de coordinación vertical que se presentan [Mathwson y Winter (1984)], mientras que la segunda visión afirman que tales restricciones pueden disminuir la competencia entre marcas, lo que refleja un problema de coordinación horizontal [Rey y Stiglitz (1988)]. A continuación se analizan ambas posturas en mayor detalle.

\subsubsection{Coordinación vertical}

El problema clásico de Spengler (1950) puede ser generalizado en un esquema donde se toman decisiones en forma descentralizada acerca de variables que afectan el beneficio conjunto. Tal esquema puede generar externalidades y por lo tanto producir ineficiencias. En este sentido, el control vertical puede servir como herramienta para coordinar y restaurar la eficiencia de la estructura vertical. Esto no implica necesariamente que sea en beneficio de los consumidores corregir tales externalidades, aunque si lo será si la externalidad surge en forma exclusiva de la 
presencia del doble margen.

\section{a. Doble marginación}

El origen de la externalidad aquí es que cada firma, cuando fija su mark up, no toma en cuenta el impacto de la decisión en el beneficio de la otra firma. Bresnahan y Reiss (1985) presentan el modelo clásico de doble margen donde el productor es afectado por las prácticas de precio del minorista, debido a que las mismas determinan el volumen de ventas finales. El productor no tiene control respecto al precio final (ni al volumen), salvo en la medida en que puede afectar los costos del minorista fijando los precios al por mayor. En este esquema existe un solo minorista y varios minoristas con territorios exclusivos y poder de mercado. ${ }^{4}$

El productor tiene un costo constante por unidad de producción $c$, mientras que los minoristas tienen un costo constante por unidad de venta igual a $s$, además del costo del insumo $p_{w}$. Cuando se fijan los precios, el productor y el minorista actúan en forma secuencial: i) el minorista toma el precio del insumo como dado, ii) el productor considera las políticas de precios del minorista cuando fija el precio del insumo.

La decisión del vendedor minorista será:

$$
\underset{q}{\operatorname{Max}} \Pi^{v}=q\left[p(q)-p_{w}-s\right]
$$

Donde $q$ son las cantidades comercializadas y $p(q)$ es la función de demanda inversa, con pendiente negativa y dos veces diferenciable. La demanda inversa del insumo que surge de la condición de primer orden del problem toma la forma $p_{w}=p_{w}(q)$. Notar que cada una de las curvas de demanda de los minoristas que enfrenta el productor involucra el ingreso marginal del minorista respectivo. El productor resuelve el siguiente problema, tomando el problema del minorista como dado:

$$
\underset{q}{\operatorname{Max}} \Pi^{p}=q\left[p_{w}(q)-c\right]
$$

\footnotetext{
${ }^{4}$ Aquí se presenta el caso de un solo producto, aunque el mismo modelo puede generalizarse a $N$ productos [Bresnahan y Reiss (1985)]
} 
El problema del minorista es elegir $q^{*}\left(p_{w}+s\right)$ que resuelve:

$$
p(q)+q \frac{\partial p(q)}{\partial q}=p_{w}+s
$$

Esto es, ingreso marginal igual a costo marginal. Usando esta ecuación, es posible resolver el problema del precio mayorista óptimo. Notar que la curva de demanda que enfrenta el mayorista es:

$$
p_{w}=I^{\prime}(q)-s
$$

Donde $I^{\prime}(q)$ es el ingreso marginal. Esto es así porque el minorista iguala su costo marginal con su ingreso marginal y por lo tanto, el precio del insumo (costo marginal del minorista y también demanda inversa del mayorista) es igual al ingreso marginal del minorista. Por lo tanto,

$$
\begin{aligned}
& \Pi^{p}=q\left[p_{w}(q)-c\right] \\
& \Pi^{p}=q\left[R^{\prime}(q)-s-c\right]
\end{aligned}
$$

La solución al problema del productor suege de:

$$
I_{p}^{\prime}(q)=I^{\prime}(q)-s+q \frac{\partial I^{\prime}(q)}{\partial q}=c
$$

Esta es la condición de primer orden del productor que iguala su ingreso marginal a su costo marginal. El productor fija su precio mayorista tomando la curva de ingreso marginal del minorista como su función de demanda. Reemplazando (3.1) en ésta ultima expresión, esto implica que:

$$
p_{w}+q \frac{\partial I^{\prime}(q)}{\partial q}=c
$$

Por lo tanto, $p_{w}>c$ y la cantidad de equilibrio será menor a la de un monopolista integrado. Finalmente, se define la razón entre los beneficios del productor y el minorista. Esto es:

$$
\frac{\Pi^{v}}{\Pi^{p}}=\frac{p(q)-\left(p_{w}+s\right)}{p_{w}(q)-c}=\frac{1}{2+\eta}
$$


Donde $\eta=p^{\prime \prime}(q) q / p^{\prime}(q)$ es la elastidad-cantidad de la pendiente de la curva de demanda. Esto implica que la curvatura de la función de demanda determina cuán lejos se encontrará el margen del minorista del margen del mayorista: si la demanda es estrictamente convexa (concava), entonces el margen del minorista es mayor (menor) que la mitad del margen del productor. Este resultado establece, curiosamente, que la razón entre el margen del productor y el del minorista no depende de la pendiente de la curva de demanda. El factor de proporcionalidad variará con la curvatura de la demanda, pero no con su pendiente.

Las soluciones posibles a la doble marginación son [Rey y Verge (2005)]:

a) Si se controla el precio minorista, se lo podría igualar al precio final del monopolista integrado y fijar el precio mayorista de acuerdo a como se desee compartir el beneficio entre ambas empresas. Un techo al precio, o una cantidad mínima, son condiciones suficientes en este caso.

b) Tarifas en dos partes. Fijando un precio variable igual al costo maginal del productor, la condición de primer orden para el minorista es la misma que bajo integración. A diferencia del precio mayorista, la apropiación de la renta mediante una suma fija no afecta las decisiones del minorista. ${ }^{5}$

En ambos casos, la restricción vertical permite maximizar el beneficio conjunto e inclusive aumentar el excedente del consumidor. Debe notarse que el doble margen surge de la falta de competencia a nivel minorista. Si existe un productor monopólico pero en el nivel minorista existe competencia es similar al de un monopolio integrado.

Las restricciones verticales no resolverán en forma perfecta el problema de doble marginación cuando hay incertidumbre, tema analizado en detalle por Rey y Tirole (1986). Tales autorires consideran que la literatura de doble margen no explora la incertidumbre que implica el problema de delegación que aparece en una estructura vertical. En general, se asume que el principal (productor) puede observar qué sucede en el equilibrio del agente (minorista), cuando en realidad existe una "superioridad informativa" por parte del minorista. Bajo este nuevo escenario,

\footnotetext{
${ }^{5}$ Este resultado hace uso de la literatura económica sobre tarifas en dos partes y está desarrollado formalmente en Mathewson y Winter (1984). Oi (1971) demuestra que mediante una tarifa en dos partes es posible extraer todo el excedente del consumidor (se replica la discriminación perfecta de primer grado); que en este caso es asimilable a la renta del minorista.
} 
se encuentra que las restricciones verticales pueden o no ser deseables para el productor en este nuevo escenario. Las estrategias de precios minímos (o máximos) no son necesariamente sustitutas de los territorios exclusivos y, en general, el impacto en la eficiencia de cada herramienta dependerá del tipo de incertidumbre. Si hay incertidumbre de demanda, los precios máximos dominan a las tarifas en dos partes, y éstas a su vez dominan a los territorios exclusivos. Si hay incertidumbre en el costo, la tarifa en dos partes domina a los territorios exclusivos, los cuales dominan a los precios máximos. El grado de aversión al riesgo del minorista resulta crucial para el ordenamiento de estas prácticas.

\section{Servicios y competencia entre minoristas}

Los problemas de coordinación vertical pueden aparecer aún cuando exista competencia en el nivel minorista, si hay otras variables bajo control por parte del minorista que afecten el nivel de producción de equilibrio. Mathewson y Winter (1984) presentan un modelo que permite analizar este tema. Tales autores desarrollan una "teoría económica de las restricciones verticales" que identifica los incentivos económicos detrás de la elección de tales restricciones por parte de los productores, el impacto de las mismas en el bienestar y, por lo tanto, la política adecuada frente a tales comportamientos.

En ese trabajo se identifican las externalidades que produce el comportamiento del minorista y los paquetes de restricciones verticales que son suficientes para neutralizarlas. En la medida en que las restricciones verticales aparecen con el objetivo de resolver externalidades, el impacto de las mismas en el bienestar será en general positivo. La aplicación de la restricción vertical alcanzará a lo sumo el bienestar que produce un monopolista integrado, mayor al de equilibrio descentralizado, no solo por el doble margen sino también por otros factores que producen externalidades.

En particular, incorporan dos restricciones a la competencia dentro de una estructura vertical donde no necesariamente el minorista tiene poder de mercado: 1) los mercados tienen diferenciación espacial y 2) los minoristas tienen el rol de informar acerca de los productos a los consumidores.

Un supuesto clave del modelo es, entonces, que para que los consumidores sean informados del producto los minoristas deben hacer un gasto en publicidad, pero una porción de tal gasto 
$(\alpha)$ realizada por cualquier minorista alcanza a consumidores que se encuentran fuera de su mercado, lo cual genera una situación de free rider [formalizada previamente por Telser (1960)].

En este modelo, el equilibrio se define como un precio y un nivel de publicidad de cada firma y la densidad de firmas que lleva a cero beneficios y se compara el equilibrio "competitivo" versus el integrado, así como el efecto de las herramientas de control vertical. La principal conclusión de este análisis es que si no existen advertising spillovers $(\alpha=0)$, se alcanza el resultado clásico de doble margen, donde una tarifa en dos partes (o precios máximos) es condición suficiente para alcanzar el resultado integrado. Si existen advertising spillovers $(\alpha>0)$, al presentarse una restricción nueva deberá aplicarse alguna herramienta nueva, como ser, los territorios exclusivos. Con tal herramienta se elimina el advertising spillovers, luego el productor deberá aplicar alguna herramienta adicional para eliminar el doble margen. A diferencia del caso de doble marginación puro, resolver la externalidad no es necesariamente deseable desde el punto de vista social.

\subsubsection{Coordinación horizontal}

El principal problema que surge cuando se concentra el análisis en los problemas de coordinación vertical, es que se dejan de lado otras situaciones usuales en las cuales el productor monopolista puede utilizar el control vertical para aumentar su poder de mercado y no necesariamente para resolver ineficiencias. Rey y Stiglitz (1988) muestran que en diversas circunstancias tales restricciones tienen importantes efectos anti-competitivos. En particular, se muestra que cuando hay competencia imperfecta entre los productores, las restricciones verticales pueden servir para facilitar la colusión.

Podría darse que un acuerdo de territorios exclusivos aumente los beneficios conjuntos (eliminando el doble margen), pero a costa de los consumidores, con lo cual las restricciones verticales no serían socialmente deseables. Lo que se enfatiza aquí -cuestión dejada de lado por Mathewson y Winter (1984) y por Rey y Tirole (1985)- es la relación entre el diseño del contrato interno (productor/minorista) y la situación competitiva externa a nivel del productor.

El argumento principal es que los territorios exclusivos reducen la competencia "hacia abajo", pero pueden actuar también reduciendo la competencia "hacia arriba". En la medida en

que se le otorga poder de mercado al minorista, los precios en ese nivel serán mayores y este mark up tendrá un efecto sobre la elasticidad cruzada de la demanda (cuando hay dos produc- 
tores de bienes imperfectamente sustitutos). El productor que compite en el mismo mercado, notará una demanda menos elástica que cuando el mercado minorista es más competitivo. Esto puede inducir a que el resto de los productores también otorgen territorios exclusivos a sus distribuidores.

La cuestión de interés radica en la interacción estratégica entre estructuras verticales que compiten entre sí. Las restricciones verticales usadas en una determinada estructura probablemente afectarán las interacciones estratégicas entre ese canal de distribución y estructuras verticales rivales.

$\mathrm{Al}$ afectar la competencia en el mercado minorista, las restricciones verticales también afectarán en forma indirecta el comportamiento de los productores rivales y el tipo de contrato que fijen con sus propios minoristas. Podrían implementarse restricciones que reduzcan la competencia o generen un compromiso de limitar la competencia entre estructuras verticales reivales.

\subsubsection{Comentario final sobre los antecedentes}

La literatura sobre control vertical es abundante y diversa. Dentro de este marco heterogéneo, el objetivo de este capítulo presenta la dificultad de incluir dos nuevos elementos a los modelos existentes: el impuesto indirecto y la posibilidad de evadir el mismo. Por este motivo, la metodología consistirá en presentar un modelo que incluya el aspecto básico de la coordinación vertical (la doble marginación) e incorporar al mismo en forma secuencial el impuesto indirecto y la posibilidad de evadir. Se dejarán de lado el resto de las configuraciones presentadas en esta sección, como ser los servicios minoristas, la incertidumbre y la coordinación horizontal. En todo el capítulo se asume poder de mercado en todas las etapas, aunque en el Apéndice se presenta el ejercicio de monopolio en la etapa de producción y competencia en las ventas finales.

Como en la mayor parte de la literatura a la cual se hizo referencia en esta sección, en este capítulo se asume información perfecta. ${ }^{6}$ En los modelos sin impuestos ni evasión fiscal, las conclusiones se modifican sustancialmente si, por el contrario, se asume que el minorista tiene acceso a información privada respecto a valores de variables críticas (como parámetros

\footnotetext{
${ }^{6}$ Los primeros trabajos que presentaron modelos de control vertical con asimetrías de la información son Rey y Tirole (1986) y Gal-Or (1991).
} 
de demanda, el precio final o el costo de distribución). Ante tal escenario, si se restringe la aplicación de herramientas de control vertical a aquellas que son factibles desde un punto de vista informativo, el efecto de tales herramientas en el beneficio privado y en el bienestar social son diferentes al caso en el cual hay información perfecta. ${ }^{7}$ Es de esperar que lo mismo suceda con los modelos que se presentan en la próxima sección.

Debe notarse que en el modelo que se presenta en la próxima sección, información perfecta implica asumir que el productor monopolista conoce el nivel de evasión del vendedor monopolista, lo cual es por definición una actividad oculta. Justificaciones a este supuesto pueden provenir de dos razonamientos posibles. En primer lugar, al comparar el productor el resultado de equilibrio integrado versus el resultado no integrado se informará necesariamente sobre los factores que afectan el nivel de evasión, que coinciden con los presentes en el escenario de equilibrio no integrado. Un segundo escenario sería que el productor se reserve alguna boca de venta final (lo cual es usual, por ejemplo, en distribución de combustibles) que les permitiría conocer no solamente el nivel de evasión sino también el nivel de otras variables como los costos de distribución. Esta última alternativa es indicativa de que el nivel de evasión del minorista es tan oculto para el productor como los costos de distribución, los cuales son claramente información privada.

\subsection{Modelo con separabilidad}

\subsubsection{Monopolio doble y honestidad}

El objetivo de este apartado es verificar si se mantienen las principales características de un monopolio doble cuando existe un impuesto que se aplica a las ventas finales, que no puede ser evadido. ${ }^{8}$ De este modo, se espera descartar que los resultados que se encuentran en el caso de evasión se deben a tal comportamiento y no a la presencia del impuesto.

\footnotetext{
${ }^{7}$ En esta dirección, una de las principales conclusiones de Gal-Or (1991) es que ante asimetrías de la información el productor no logrará replicar el resultado de integración mediante las herramientas de control vertical clásicas (franquicias, precios mínimos o territorios exclusivos).

${ }^{8}$ Notar que el modelo y los resultados de esta sección son esencialmente similares a los resultados presentado por Bresnahan y Reiss (1985). Si bien Bresnahan y Reiss no incorporan impuestos, en ese caso la actividad del minorista tiene un costo fijo por unidad de producto. El impacto de esta variable en los costos del minorista y en la demanda que enfrenta el mayorista es idéntico al de un impuesto específico sobre la venta final, ya que ambos representan un monto fijo por unidad de producto vendido.
} 
Se asume una situación en la cual existe un insumo que se transforma en producto en una relación 1 a 1 dentro de una cadena de dos monopolios, un productor (o mayorista) y un vendedor (o minorista). El vendedor enfrenta una curva inversa de demanda con pendiente negativa $p(q)$, dos veces diferenciable, y tiene como costo marginal $p_{w}$, que es el precio que le cobra el productor por cada unidad del insumo. Se asume que el vendedor no tiene ningún costo adicional al precio del insumo y que tampoco hay acumulación de stock ni desperdicio, con lo cual todos los bienes comprados por el minorista son vendidos a los consumidores finales. El productor tiene un costo marginal constante, $c$. Además, hay un impuesto específico que se aplica a las ventas finales $(\tau)$ que no puede ser evadido. El vendedor maximizará su función de beneficios igual a:

$$
\operatorname{Max}_{q} \Pi^{h v}=q^{h}\left[p\left(q^{h}\right)-p_{w}^{h}-\tau\right]
$$

Donde el supraíndice $h$ hace referencia al caso de honestidad (para diferenciar el caso de evasión que se presenta más adelante) y el supraíndice $v$ indica vendedor. La condición de primer orden del vendedor es la usual:

$$
R^{\prime}\left(q^{h}\right)-\tau=p_{w}^{h}
$$

El problema del productor es elegir su nivel de producción de equilibrio, tomando como dada la última ecuación, con lo cual maximizará:

$$
\begin{aligned}
\operatorname{Max}_{q} \Pi^{h p} & =\left[p_{w}^{h}(q)-c\right] q^{h} \\
\operatorname{Max}_{q} \Pi^{h p} & =\left[R^{\prime}\left(q^{h}\right)-\tau-c\right] q^{h}
\end{aligned}
$$

Donde el supraíndice $p$ hace referencia a productor. La condición de primer orden del productor puede expresarse como:

$$
c=p_{w}^{h}(q)+\left[2 p^{\prime}\left(q^{h}\right)+p^{\prime \prime}\left(q^{h}\right) q^{h}\right] q^{h}
$$

Esto implica que $c<p_{w}^{h}$, ya que el cumplimiento de la condición de segundo orden del problema de maximización expresado en (3.2) supone que $2 p^{\prime}\left(q^{h}\right)+p^{\prime \prime}\left(q^{h}\right) q^{h}<0$. El beneficio 
de cada uno de los monopolistas y de toda la cadena será, respectivamente:

$$
\begin{gathered}
\Pi^{h v}=\left[p\left(q^{h}\right)-\tau-p_{w}^{h}\right] q^{h} \\
\Pi^{h p}=\left[p_{w}^{h}\left(q^{h}\right)-c\right] q^{h} \\
\Pi^{h}=\Pi^{h v}+\Pi^{h p}=\left[p\left(q^{h}\right)-\tau-c\right] q^{h}
\end{gathered}
$$

Si ambas firmas se integran, el monopolista productor-vendedor maximizará:

$$
\operatorname{Max}_{q} \Pi^{h m}=q^{h m}\left[p\left(q^{h m}\right)-c-\tau\right]
$$

Donde el supraíndice $m$ denota monopolista integrado. La condición de primer orden será similar a (3.3), pero con costo marginal $c$ y cantidad de equilibrio $q^{h m}$, mientras que el beneficio será:

$$
\Pi^{h m}=\left[p\left(q^{h m}\right)-\tau-c\right] q^{h m}
$$

La siguiente proposición se refiere a la distribución del beneficio entre el vendedor y el productor en un equilibrio no integrado, en este modelo de monopolio en cadena con un impuesto específico en la etapa final. La proposición 2, por otro lado, presenta el efecto de la integración sobre las cantidad y el beneficio.

Proposición 1. En presencia de un impuesto específico en la etapa final y en ausencia de evasión, la relación entre el beneficio del minorista y del productor $\left(\lambda^{h}\right)$ dependerá de la curvatura de la función de demanda. Si la curva demanda es lineal $\lambda^{h}=1 / 2$. Si es estrictamente convexa $\lambda^{h}>1 / 2$, mientras que si es estrictamente cóncava $\lambda^{h}<1 / 2$.

La relación entre el beneficio del minorista y del productor [ecuaciones (3.5) y (3.6)] es:

$$
\begin{gathered}
\lambda^{h}=\frac{\Pi^{h v}}{\Pi^{h p}}=\frac{p\left(q^{h}\right)-\tau-p_{w}^{h}}{p_{w}^{h}\left(q^{h}\right)-c}=\frac{p^{\prime}\left(q^{h}\right) q^{h}}{\left[2 p^{\prime}\left(q^{h}\right)+p^{\prime \prime}\left(q^{h}\right) q^{h}\right] q^{h}} \\
\lambda^{h}=\frac{1}{2+\eta}
\end{gathered}
$$

Donde $\eta=p^{\prime \prime}\left(q^{h}\right) q^{h} / p^{\prime}\left(q^{h}\right)$ es la elastidad-cantidad de la pendiente de la curva de demanda. Si la curva de demanda es lineal $\left[p^{\prime \prime}\left(q^{h}\right)=0\right]$ entonces $\lambda^{h}=1 / 2$, (el beneficio del minorista es la 
mitad del correspondiente al productor), mientras que si la curva de demanda es estrictamente convexa $\lambda^{h}>1 / 2$ y si es estrictamente cóncava $\lambda^{h}<1 / 2$. Q.E.D.

Si bien la ecuación (3.10) es exactamente igual a la relación entre el beneficio del minorista y del productor cuando no hay impuestos, $\eta$ depende en general de $q$ y por lo tanto la relación $\lambda$ no es necesariamente la misma que en ausencia de impuestos. ${ }^{9}$ El efecto del impuesto específico en la relación entre el beneficio vendedor y el del productor dependerá de la forma en la que varía $\eta$ respecto a $q$, ya que bajo monopolio $\partial q / \partial \tau<0$. Si $\partial \eta / \partial q<0$, debe esperarse que la relación $\lambda$ sea menor luego de aplicar los impuestos que antes de aplicarlos. En este caso, el impuesto afecta más que proporcionalmente al beneficio del minorista. Si $\partial \eta / \partial q>0$ se presenta la relación inversa ${ }^{10}$

Proposición 2. En presencia de un impuesto específico en la etapa final, y en ausencia de evasión, la cantidad de equilibrio es mayor bajo integración que con equilibrio descentralizado, mientras que el beneficio del monopolista integrado es mayor al beneficio de toda la cadena bajo equilibrio descentralizado.

La única diferencia entre (3.2) y (3.8) es que el monopolista integrado tiene como costo marginal $c$, pero el minorista $p_{w}^{h}$, donde $c<p_{w}^{h}$. Como $R^{\prime}\left(q^{h}\right)-\tau$ es una función monótona decreciente, esto implica que $\bar{q}^{h m}>\bar{q}^{h}$ (donde la barra se utiliza para designar el valor de equilibrio de la variable en cuestión). El beneficio del monopolista integrado [ecuación (3.9)] será mayor al beneficio de toda la cadena bajo equilibrio descentralizado (ecuación 3.7), ya que evaluado en $\bar{q}^{h}$, el ingreso marginal del minorista es mayor a $c$, por lo cual un nivel mayor de producto implica mayor beneficio. Q.E.D.

Las proposiciones 1 y 2 reflejan que la regla de distribución del beneficio y el efecto de doble margen del monopolio en cadena se mantienen cuando se aplica un impuesto específico que no es evadido en la etapa final.

\footnotetext{
${ }^{9}$ Dos situaciones en las cuales $\lambda^{h}$ es la misma bajo los dos escenarios son cuando la función de demanda es lineal y cuando tiene una elasticidad-cantidad de la pendiente constante (un ejemplo de este último caso sería una función inversa de demanda dada por $p(q)=a-b q^{c}$, donde $a, b$ y $c$ son constantes). En ambos casos el impuesto en la etapa minorista disminuye en forma proporcional el beneficio del minorista y el del productor, no afectando por lo tanto la distribución del beneficio entre ambas firmas.

${ }^{10}$ Este resultado es independiente del signo de $\eta$.
} 


\subsubsection{Monopolio doble y evasión}

Al modelo presentado en la sección anterior, se incorpora ahora la posibilidad de evasión del impuesto. La decisión de evasión se refleja en la declaración al fisco por parte de la firma de ventas iguales a $q-e$, siendo $e$ el monto ocultado. Tal actividad tiene un costo directo para la firma, expresado en la función $g(e)$, donde $g^{\prime}(e)>0$ y $g^{\prime \prime}(e)>0$. La administración tributaria audita una porción fija $\phi$ del total de declaraciones juradas y aplica una penalidad $(f-1)$ sobre el monto del impuesto ocultado, donde $f>1$.

El vendedor debe elegir el nivel óptimo de $q$ y $e$ que maximicen su beneficio esperado: ${ }^{11}$

$$
\operatorname{Max}_{q, e} \Pi^{e v}=q^{e}\left[p\left(q^{e}\right)-p_{w}^{e}-\tau\right]+\tau e(1-\phi f)-g(e)
$$

Donde el supraíndice $e$ hace referencia al modelo en presencia de evasión. Las condiciones de primer orden del vendedor respecto de e y $q$ son, respectivamente:

$$
\begin{aligned}
g^{\prime}(e) & \leq \tau(1-\phi f) \\
R^{\prime}\left(q^{e}\right)-\tau & \leq p_{w}^{e}
\end{aligned}
$$

Notar que la condición (3.13) es idéntica a (3.3) y que en la condición (3.12) no interviene el nivel de producción. Esto refleja que se cumple la separabilidad entre las decisiones de producción y de evasión.

El problema del productor consiste es elegir su nivel de producción de equilibrio, tomando como dadas las ecuaciones (3.12) y (3.13), maximizando sus beneficios:

$$
\begin{aligned}
\operatorname{Max}_{q} \Pi^{e p} & =\left[p_{w}^{e}\left(q^{e}\right)-c\right] q^{e} \\
\operatorname{Max}_{q} \Pi^{e p} & =\left[R^{\prime}\left(q^{e}\right)-\tau-c\right] q^{e}
\end{aligned}
$$

Su condición de primer orden es:

$$
c=p_{w}^{e}\left(q^{e}\right)+\left[2 p^{\prime}\left(q^{e}\right)+p^{\prime \prime}\left(q^{e}\right) q^{e}\right] q^{e}
$$

\footnotetext{
${ }^{11} \mathrm{El}$ siguiente problema de maximización es esencialmente similar al de la sección 2.3.1 del Capítulo 2.
} 
Esta expresión es idéntica (3.4). Al no tener impacto la evasión en las cantidades de equilibrio, tampoco genera externalidades en la cadena por modificaciones en las cantidades. Los beneficios del vendedor, del productor y de toda la cadena serán, respectivamente:

$$
\begin{aligned}
\Pi^{e v} & =q^{e}\left[p\left(q^{e}\right)-p_{w}^{e}-\tau\right]+\tau e(1-\phi f)-g(e) \\
\Pi^{e p} & =\left[p_{w}^{e}(q)-c\right] q^{e} \\
\Pi^{e} & =\Pi^{e v}+\Pi^{e p}=q^{e}\left[p\left(q^{e}\right)-c-\tau\right]+\tau e(1-\phi f)-g(e)
\end{aligned}
$$

Por otro lado, el equilibrio de un monopolista integrado que puede evadir impuestos (y enfrenta la misma función de costos de la evasión, probabilidad de auditorías y penalidades que el minorista bajo no integración) surge de maximizar la misma función de utilidad expresada en (3.11), con $c$ en lugar de $p_{w}^{e}$ [donde $c<p_{w}^{e}$, expresión (3.14)].

Las siguientes proposiciones (3 y 4) son análogas a las proposiciones de la sección anterior pero bajo la presencia de evasión.

Proposición 3. Bajo equilibrio descentralizado, en presencia de evasión la relación entre el beneficio del minorista y el del productor $\left(\lambda^{e}\right)$ dependerá de la curvatura de la función de demanda. Si la curva demanda es lineal o convexa $\lambda^{e}>1 / 2$, mientras que si es estrictamente cóncava $\lambda^{e} \gtrless 1 / 2$.

La relación entre el beneficio del minorista y el del productor en presencia de evasión [ecuaciones (3.15) y (3.16)] es:

$$
\lambda^{e}=\frac{p\left(q^{e}\right) q^{e}-q^{e} \tau+e \tau(1-\phi f)-g(e)-p_{w}^{e} q^{e}}{\left[p_{w}^{e}-c\right] q^{e}}
$$

Utilizando la expresión (3.13) en el numerador y (3.14) en el denominador, y definiendo la tasa de evasión $\beta=e / q$, (3.17) puede expresarse como:

$$
\lambda^{e}=-\beta \frac{\tau(1-\phi f)-g(e) / e}{\left[2 p^{\prime}\left(q^{e}\right)+p^{\prime \prime}\left(q^{e}\right) q^{e}\right] q^{e}}+\frac{1}{2+\eta}
$$

El primer término del lado derecho de (3.18) es siempre positivo, mientras que $\eta$ es mayor, igual o menor a cero según la demanda sea concava, lineal o convexa. Q.E.D. 
Como resultado, se tienen las siguientes situaciones posibles:

\begin{tabular}{|c|c|}
\cline { 2 - 2 } \multicolumn{1}{c|}{} & $\lambda^{e}$ \\
\hline$p^{\prime \prime}(q)=0$ & $>1 / 2$ \\
\hline$p^{\prime \prime}(q)>0$ & $>1 / 2$ \\
\hline$p^{\prime \prime}(q)<0$ & $\lessgtr 1 / 2$ \\
\hline
\end{tabular}

Proposición 4. En presencia de evasión, la cantidad de equilibrio integrado es mayor y el nivel de evasión es el mismo al de equilibrio descentralizado. Por otro lado, el beneficio del monopolista integrado es mayor al beneficio de toda la cadena bajo equilibrio descentralizado.

Calculando el diferencial total de (3.12) y de (3.13) y reemplazando $p_{w}$ por $c$, se tiene:

$$
\begin{aligned}
\frac{\partial q^{e}}{\partial c} & =\frac{1}{R^{\prime \prime}\left(q^{e}\right)}<0 \\
\frac{\partial e}{\partial c} & =0
\end{aligned}
$$

Dado que $c<p_{w}^{e}$ esto implica que $\bar{q}^{e}<\bar{q}^{e m}$ y $\bar{e}^{m}=\bar{e} \quad$ (donde $\bar{q}^{e m}$ y $\bar{e}^{m}$ son los valores de equilibrio del monopolista integrado).

El beneficio del monopolista integrado es débilmente mayor al beneficio del equilibrio no integrado por un argumento de preferencia revelada. El monopolista integrado no tiene restricción para elegir las mismas cantidades (en este caso, de producción y evasión) que las elegidas por el vendedor bajo equilibrio descentralizado, con lo cual el equilibrio implica como mínimo tal nivel de beneficios. Q.E.D.

\subsubsection{Evasión versus honestidad}

En este apartado se comparan los resultados en las variables dependientes para los casos de honestidad y de evasión.

Proposición 5: Bajo equilibrio descentralizado, la cantidad de equilibrio, el precio del insumo y el beneficio del productor son los mismos con evasión que bajo honestidad, mientras que el beneficio del vendedor y el de toda la cadena será mayor con evasión. La relación entre el beneficio del vendedor y el del productor es siempre mayor con evasión $\left(\lambda^{e}>\lambda^{h}\right)$. 
La cantidad de equilibrio es similar en ambos casos debido al principio de separabilidad: la decisión respecto a la evasión no afecta la curva de ingreso marginal del minorista, que es a la vez la curva de demanda que enfrenta el productor. Esto implica también que en la determinación del precio del insumo tampoco interviene la evasión. El beneficio del productor tampoco se verá afectado por la presencia de evasión dado que la cantidad producida, el precio del insumo y el costo marginal no varían. El beneficio del minorista es mayor en presencia de evasión, lo cual genera cambios en el beneficio de toda la cadena. La diferencia entre el beneficio del vendedor $\left(\Delta^{v}\right)$ y de toda la cadena $(\Delta)$ con y sin evasión es:

$$
\Delta=\Delta^{v}=\Pi^{e v}-\Pi^{h v}=\tau e(1-\phi f)-g(e)>0
$$

El lado derecho de la expresión (3.21) es positivo debido a (3.12) y a que $g(e) / e$ es siempre menor a $g^{\prime}(e)$.

Si el beneficio del minorista es mayor cuando hay evasión, pero el del productor se mantiene sin cambios, lógicamente la relación entre ambos es también mayor. Q.E.D.

En la Tabla 3.1 se resume la comparación entre las proposiciones 1 y 3 :

Tabla 3.1. Comparación entre Proposiciones 1 y 3

\begin{tabular}{|c|c|c|}
\cline { 2 - 3 } \multicolumn{1}{c|}{} & $\lambda^{h}$ & $\lambda^{e}$ \\
\hline$p^{\prime \prime}(q)=0$ & $=1 / 2$ & $>1 / 2$ \\
\hline$p^{\prime \prime}(q)>0$ & $>1 / 2$ & $>1 / 2$ \\
\hline$p^{\prime \prime}(q)<0$ & $<1 / 2$ & $\lessgtr 1 / 2$ \\
\hline
\end{tabular}

En conclusión, en este esquema en el cual existe separabilidad y en equilibrio no integrado, el productor no tiene forma de apropiarse de los beneficios que tiene la actividad de ocultamiento para el vendedor.

Proposición 6. En presencia de evasión, la cantidad de equilibrio integrado es la misma que bajo honestidad. Sin embargo, el beneficio del monopolista integrado es mayor bajo evasión.

Si se compara el equilibrio bajo integración sin evasión y con evasión se tiene que, nuevamente, el nivel de producción será el mismo, aunque el beneficio será mayor cuando esté presente 
la evasión. Al ser independiente la decisión de evasión respecto de la cantidad producida, el nivel de evasión es idéntico en este caso al correspondiente al de equilibrio no integrado (donde las cantidades son menores). Por lo tanto, la diferencia en el beneficio del monopolista integrado con y sin evasión, será igual a la expresada en (3.21). Q.E.D.

Proposición 7. En presencia de evasión, la ganancia de la integración para toda la cadena es la misma al caso de honestidad. La ganancia de la integración para el productor es mayor bajo evasión.

En la literatura sobre control vertical se considera que la ganancia de la integración (sin considerar cambios en el excedente del consumidor, ni en la recaudación) es la diferencia entre el beneficio de toda la cadena y el beneficio del monopolista integrado. Dado que el beneficio de la evasión es el mismo en equilibrio descentralizado que bajo integración y teniendo en cuenta que la decisión de evasión no afecta las cantidades de producción de equilibrio, la ganancia de la integración bajo evasión se debe exclusivamente al incremento en las cantidades.

Como el beneficio de la evasión bajo equilibrio descentralizado es apropiado en forma exclusiva por el vendedor, la diferencia entre el beneficio del productor y el del monopolista integrado es mayor en presencia de evasión. El productor tiene un mayor incentivo a integrase cuando existe la posibilidad de evasión de un impuesto en la etapa final. Q.E.D.

\subsubsection{Tarifas en dos partes}

Cuando no existe evasión, un esquema de tarifas en dos partes es condición suficiente para eliminar la externalidad y alcanzar el mismo beneficio de toda la cadena que bajo equilibrio integrado (sección 3.2.). En esta sección se analiza si se mantiene tal resultado cuando hay evasión de un impuesto específico sobre las ventas finales. A tal fin, se asume que el productor está en condiciones de aplicar una estructura de precios no lineal para la venta del insumo. En particular, se asume una estructura de precios del tipo:

$$
T\left(q^{r}\right)=p_{w}^{r} q^{r}+A
$$

Donde $T\left(q^{r}\right)$ es la tarifa, la cual depende en forma no proporcional de las cantidades $\left(q^{r}\right)$ y 
$A$ es un monto fijo determinado por el productor. ${ }^{12}$ A fin de determinar el nivel óptimo de $A$ y de $p_{w}$, se analiza el problema de maximización del productor, que es el siguiente:

$$
\operatorname{Max}_{A, p_{w}} \Pi^{r p}=T\left(q^{r}\right)-c q^{r}
$$

Donde:

$$
\begin{gathered}
\frac{d \Pi^{r p}}{d A}=\left(p_{w}-c\right) \frac{d q^{r}}{d A}+1 \\
\frac{d \Pi^{r p}}{d p_{w}^{r}}=q^{r}+p_{w}^{r} \frac{d q^{r}}{d p_{w}}-c \frac{d q^{r}}{d p_{w}}+\frac{d A^{*}}{d p_{w}}
\end{gathered}
$$

La siguiente proposición analiza el efecto de una tarifa en dos partes en este modelo de monopolio en cadena, donde existe un impuesto específico que puede ser evadido en la etapa final.

Proposición 8. En presencia de evasión, un esquema de tarifas en dos partes es condición suficiente para alcanzar el nivel de equilibrio de un monopolio integrado. El productor puede apropiarse de todo el beneficio de la cadena, incluyendo la porción del beneficio del minorista originado en la evasión.

Por otro lado, el minorista maximiza:

$$
\operatorname{Max}_{q, e} \Pi^{r v}=p\left(q^{r}\right) q^{r}-\tau q^{r}+e^{r} \tau(1-\phi f)-g\left(e^{r}\right)-T\left(q^{r}\right)
$$

$\mathrm{Al}$ ser las condiciones de primer orden que surgen de (3.25) independientes de $A$, las que serán por lo tanto similares a (3.12) y (3.13) esto implica que $\frac{d q}{d A}=0$. Por lo tanto, en virtud de (3.23), $\frac{d \Pi^{r p}}{d A}=1$. Si bien el beneficio del productor aumenta sin límites cuando crece $A$, existe una restricción de participación para el vendedor que se define como:

$$
\Pi^{r v} \geqq 0
$$

\footnotetext{
${ }^{12}$ El supraíndice $r$ alude a las variables del modelo de tarifa en dos partes. Este esquema de precios no lineales fue analizado formalmente por primera vez por Oi (1971). Un tratamiento exhaustivo se encuentra en Schmalensee (1981).
} 
O sea que el valor óptimo $A^{*}$ será igual al beneficio que obtendría el vendedor bajo el esquema tradicional de precios proporcionales y evasión [ecuación (3.15)]:

$$
A^{*}=q^{r}\left[p\left(q^{r}\right)-p_{w}^{r}-\tau\right]+\tau e^{r}(1-\phi f)-g\left(e^{r}\right)
$$

Ahora bien, de la condición (3.27) se tiene que $\frac{d A^{*}}{d p_{w}}=-q^{r}$. Por lo tanto, igualar a cero la condición (3.24) implica que:

$$
\begin{aligned}
q^{r}+p_{w}^{r} \frac{d q^{r}}{d p_{w}^{r}}-c \frac{d q^{r}}{d p_{w}^{r}}-q^{r} & =0 \\
c & =p_{w}^{r}
\end{aligned}
$$

De este modo, el valor óptimo del componente variable de la tarifa es igual al costo marginal, mientras que el valor del cargo fijo surgirá de aplicar el costo marginal en lugar de $p_{w}$ en la ecuación (3.27). Consecuentemente, el nivel de producción y de evasión serán los mismos al caso de integración. ${ }^{13} \mathrm{El}$ beneficio del vendedor será claramente igual a cero, mientras que el del productor será igual a:

$$
\Pi^{r p}=q^{r}\left[p\left(q^{r}\right)-\tau-c\right]+\tau e^{r}(1-\phi f)-g\left(e^{r}\right)-c q^{r}
$$

Q.E.D.

\subsection{Modelo sin separabilidad}

Los resultados principales de la sección anterior son consecuencia de la condición de separabilidad que presenta el modelo de evasión de un impuesto específico utilizado. Los factores que determinan la separabilidad son la probabilidad de auditoría fija, neutralidad al riesgo del monopolista y los costos directos de la evasión que son proporcionales a la base imponible del impuesto. En esta sección, se presenta un modelo sin separabilidad como consecuencia que la probabilidad de auditoría es variable.

\footnotetext{
${ }^{13}$ El beneficio esperado del vendedor será cero. Si efectivamente es auditado, tendrá pérdidas y si no lo es tendrá ganancias extraordinarias. El beneficio del productor por otro lado, siempre será positivo y tiene un valor certero.
} 
Varios autores han incluido en los modelos de evasión una función de probabilidad de auditoria, en lugar de un parámetro. Para el caso de impuestos indirectos, los primeros trabajos de Marrelli (1984) y de Virmani (1989) incluyeron tal esquema. En el caso de Marrelli (1984) la probabilidad de auditoría depende del monto declarado por el contribuyente. Por el otro lado, Virmani (1989) plantea una función de auditoría donde la probabilidad dependerá del tamaño de la firma. Si bien este es un dato no conocido por la administración tributaria, Virmani (1989) plantea que en un impuesto donde se está gravando una actividad productiva el gobierno tiene a su disposición información respecto a variables que están relacionadas en forma monotónica con el nivel de producción y usará en forma intensiva tal información para definir a que contribuyentes auditar. ${ }^{14}$

Aquí se utilizará una función similar a la de Marrelli (1984), donde la probabilidad de auditoría dependerá de la base imponible declarada $d=q-e$. Además, se asumirá que $\phi^{\prime}(d)<0$ y que $\phi^{\prime \prime}(d)=0$. El signo de la derivada primera surge al considerar que, en general, las funciones de auditorías decrecientes dominan a las crecientes respecto a la base imponible declarada. La derivada segunda se asume igua a cero a fin de simplificar la presentación y alcanzar resultados más ambigüos.El análisis se focalizará en las Proposiciones 4 a la 7 , que son aquellas que presentan diferencias de tipo cualitativo con el caso de separabilidad. Para facilitar la lectura, se mantiene la numeración de la sección anterior.

Proposición 4B. La cantidad de equilibrio y el nivel de evasión es mayor para un monopolista integrado que bajo un equilibrio no integrado. El beneficio del monopolista integrado es mayor al beneficio de toda la cadena bajo equilibrio descentralizado.

El problema de maximización del vendedor es ahora:

$$
\Pi^{v}=q\left[p(q)-p_{w}-\tau\right]+\tau e[1-\phi(d) f]-g(e)
$$

\footnotetext{
${ }^{14}$ Otros autores que utilizan como argumentos de la probabilidad de auditoría el nivel de producción o capacidad productiva son Macho-Stadler y Pérez-Castrillo (2002, 2004), Marhuenda, Vasin y Vasina (2002) y Lee (1998).
} 
Las condiciones de primer orden del vendedor respecto $e$ y qson:

$$
\begin{aligned}
\tau\left[1-\left(\phi-e \phi^{\prime}\right) f\right] & =g^{\prime}(e) \\
R^{\prime}(q)-\tau-\tau e \phi^{\prime} f & =p_{w}
\end{aligned}
$$

Calculando el diferencial total de (3.30) y de (3.31) y reemplazando $p_{w}$ por $c$ se obtienen los siguientes resultados de estática comparativa: ${ }^{15}$

$$
\begin{aligned}
& \frac{\partial q}{\partial c}=\frac{\tau \phi^{\prime} f-g^{\prime \prime}(e)}{R^{\prime \prime}(q)\left[\tau \phi^{\prime} f-g^{\prime \prime}(e)\right]-\left(\phi^{\prime} \tau f\right)^{2}}<0 \\
& \frac{\partial e}{\partial c}=\frac{\phi^{\prime} \tau f}{R^{\prime \prime}(q)\left[\tau \phi^{\prime} f-g^{\prime \prime}(e)\right]-\left(\phi^{\prime} \tau f\right)^{2}}<0
\end{aligned}
$$

Como $c<p_{w}$ esto implica que $q<q^{m}$ y que $e<e^{m}$. (donde $q^{m}$ y $e^{m}$ son los valores de equilibrio del monopolista integrado). Respecto al nivel de beneficio, se aplica el mismo argumento de preferencia revelada que para la Proposición 4. Q.E.D.

Proposición 5B: Bajo equilibrio descentralizado, al comparar los valores de equilibrio en presencia de evasión respecto al caso de honestidad surge que el beneficio del vendedor será mayor aunque las cantidades, el precio del insumo, el beneficio del productor y el beneficio de toda la cadena podrán ser mayor o menor. Si la demanda es lineal, en presencia de evasión la cantidad de equilibrio es mayor, el precio del insumo es mayor, el beneficio del productor es mayor y el beneficio de toda la cadena es mayor.

El beneficio del vendedor será mayor en presencia de evasión por el principio de preferencia revelada. La condiciones de primer orden del vendedor, bajo honestidad y evasión son

\footnotetext{
${ }^{15}$ Es necesario asumir que se cumplen las condiciones de segundo orden del problema de maximización del vendedor.
} 
respectivamente:

$$
\begin{aligned}
R^{\prime}\left(q^{h}\right)-\tau & =p_{w}^{h} \\
\tau\left[1-\left(\phi-e \phi^{\prime}\right) f\right] & =g^{\prime}(e) \\
R^{\prime}\left(q^{e}\right)-\tau-\tau e \phi^{\prime} f & =p_{w}^{e}
\end{aligned}
$$

Las condiciones de primer orden del productor bajo honestidad y evasión son, respectivamente [utilizando (3.34) y (3.36)]:

$$
\begin{aligned}
& c=p_{w}^{h}+\left[2 p^{\prime}\left(q^{h}\right)+p^{\prime \prime}\left(q^{h}\right) q^{h}\right] q^{h} \\
& c=p_{w}^{s}+\left[2 p^{\prime}\left(q^{e}\right)+p^{\prime \prime}\left(p_{w}^{e}\right) q^{e}\right] q^{e}
\end{aligned}
$$

Igualando las expresiones (3.34) y (3.36), se tiene que:

$$
R^{\prime}\left(q^{e}\right)-R^{\prime}\left(q^{h}\right)=p_{w}^{e}-p_{w}^{h}+\tau e \phi^{\prime} f
$$

Si la función de demanda es lineal, la igualdad entre (3.37) y (3.38) implica que:

$$
2 p^{\prime}(q)\left(q^{h}-q^{e}\right)=p_{w}^{e}-p_{w}^{h}
$$

Asumiendo que $q^{h}>q^{e}$, la expresión (3.40) implica que $p_{w}^{h}>p_{w}^{e}$. Ahora bien, ambas desigualdades al incorporarlas a la expresión (3.39) serán válidas si y sólo si $\phi^{\prime}(q)>0$, lo cual ya ha sido descartado. Por lo tanto, $q^{h}<q^{e}$ y $p_{w}^{e}>p_{w}^{h}$. La diferencia entre el beneficio del productor con y sin evasión es:

$$
\Delta^{p}=\Pi^{p e}-\Pi^{p h}=p_{w}^{e} q^{e}-p_{w}^{h} q^{h}-c q^{e}+c q^{h}>0
$$

El beneficio de toda la cadena será necesariamente mayor en presencia de evasión ya que tanto el beneficio del vendedor y del productor son mayores ante tal circunstancia. Q.E.D.

Proposición 6B. En presencia de evasión, el beneficio del monopolista integrado será mayor y las cantidades de equilibrio también serán mayores. 
El beneficio del monopolista integrado que puede evadir, por el principio de preferencia revelada. Las condiciones de primer orden del monopolista integrado bajo honestidad y evasión son, respectivamente:

$$
\begin{aligned}
R^{\prime}\left(q^{h m}\right)-\tau & =c \\
R^{\prime}\left(q^{e m}\right)-\tau-\tau e \phi^{\prime} f & =c \\
\tau\left[1-\left(\phi-e \phi^{\prime}\right) f\right] & =g^{\prime}(e)
\end{aligned}
$$

Igualando (3.41) y (3.42) se tiene:

$$
\begin{aligned}
R^{\prime}\left(q^{h m}\right)-\tau & =R^{\prime}\left(q^{e m}\right)-\tau-\tau e \phi^{\prime} f \\
R^{\prime}\left(q^{h m}\right)-R^{\prime}\left(q^{e m}\right) & =-\tau e \phi^{\prime} f
\end{aligned}
$$

Esto implica que $q^{e m}>q^{h m}$.Q.E.D.

Proposición 7B. En presencia de evasión, la ganancia de la integración para toda la cadena así como la ganancia del productor puede ser mayor o menor al caso de honestidad.

Esta proposición surge de comparar los resultados respecto al beneficio con y sin evasión, tanto para el productor como integrado (proposiciones 5B y 6B).Q.E.D.

\subsection{Simulación numérica}

En esta sección se presenta una simulación numérica de los modelos de este capítulo a fin de ilustrar los resultados principales. ${ }^{16}$ La especificación funcional es la siguiente:

Función de Demanda: $p(q)=A-B q^{x}$

\footnotetext{
${ }^{16}$ Las simulaciones fueron realizadas con el Mathematica 5.0., estando los programas disponibles previa solicitud. Todos los Gráficos se presentan en el Apéndice.
} 
Función de costos: $C(q)=c q$

Función de costos directos de evasión: $G(e)=E \frac{e^{\gamma+1}}{\gamma}$

Función de probabilidad de auditoría (modelo sin separabilidad): $\phi(q-e)=V-Z(q-e)$

Donde $A, B, c, E, \gamma, x>0$.

En la Tabla 3.2 se presentan los valores de los parámetros de base. Algunos de ellos podrán varían a fin de mejor ilustrar cada una de las proposiciones, lo cual se señala en cada caso. Por otro lado, los gráficos se construyen obteniendo los niveles de equilibrio de las variables independientes para distintos valores de $x, \phi, t$ y $\tau$, según cual sea el interés

Tabla 3.2. Simulación Numérica. Parámetros

\begin{tabular}{|r|r|r|r|r|r|r|r|r|r|r|}
\hline$\phi$ & $f$ & $c$ & $\gamma$ & $E$ & $A$ & $B$ & $t$ & $x$ & $V$ & $Z$ \\
\hline 0,01 & 1,5 & 1,2 & 1 & 1 & 5 & 1 & 0,2 & 1 & 0,65 & $0,60 / 5$ \\
\hline
\end{tabular}

El Gráfico 3.1 ilustra la Proposición 1: muestra $\lambda$ (en el Gráfico es L), el beneficio del productor y del vendedor sin impuestos (bp y bv respectivamente) y con impuestos ( $\mathrm{bp}_{t} \mathrm{y} \mathrm{bv}_{t}$ ) para valores de $x$ entre 0,8 y 1.8 (o sea, demanda convexa, lineal o cóncava). Debido a la forma funcional de la demanda, la disminución en el beneficio del productor y del vendedor por la presencia del impuesto es proporcional, con lo cual $\lambda$ es igual con impuestos y sin impuestos. Notar que cuando $x>1$ (demanda estrictamente cóncava), $\lambda<1 / 2$ y viceversa. Para $x=1$, $\lambda=1 / 2$.

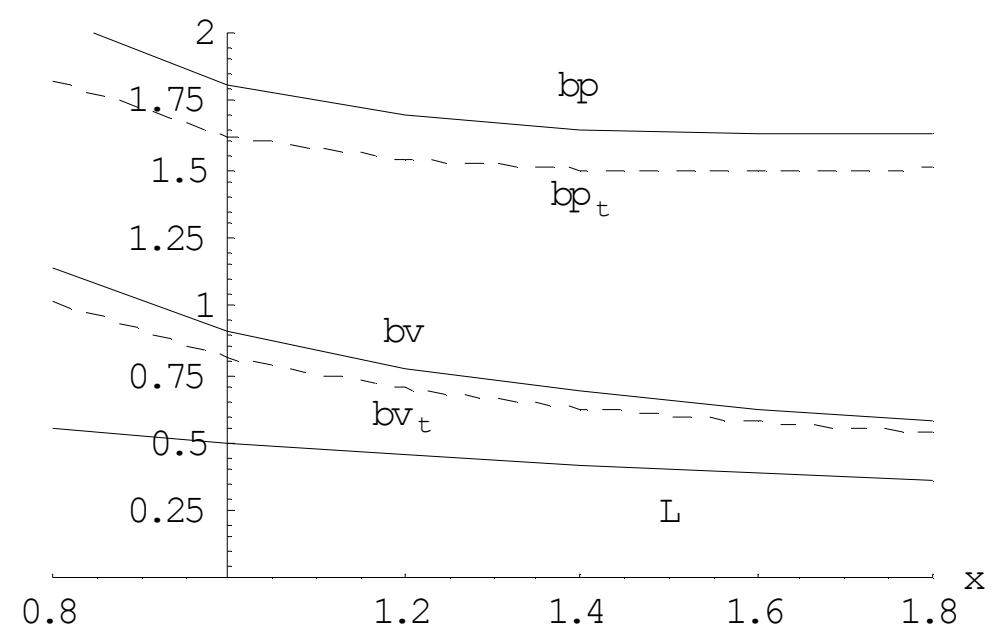

Gráfico 3.1. Proposición 1 
Los Gráficos 3.2 y 3.3 ilustran la Proposición 2 para $x=1$. El Gráfico 3.2 presenta la diferencia entre las cantidades de un monopolista integrado y de un equilibrio descentralizado sin impuestos $(\mathrm{qm}-\mathrm{q})$ y con impuestos $\left(\mathrm{qm}_{t}-\mathrm{q}_{t}\right)$, para distintos valores del impuesto específico (t). ${ }^{17}$ El Gráfico 3.3 presenta un ejercicio similar, pero en este caso comparando el beneficio del monopolista integrado con el beneficio de toda la candena sin impuestos (bm - b) y con impuestos $\left(\mathrm{bm}_{t}-\mathrm{b}_{t}\right)$. En la medida que el impuesto es mayor, la diferencia entre los valores de equilibrio integrado y no integrado tiende a desaparecer. De hecho, la máxima diferencia se da para $t=0$, y la mínima para un nivel de impuesto que lleva a las cantidades de equilibrio igual a cero, en el ejemplo, en un nivel de $t \simeq 3,8$. Desde el punto de vista del productor, entonces, el impuesto hace reducir el efecto del doble margen, mientras mayor es el impuesto la externalidad negativa será menor. Por supuesto esto no implica mayor eficiencia, ya que el propio impuesto tiene su efecto en el bienestar.

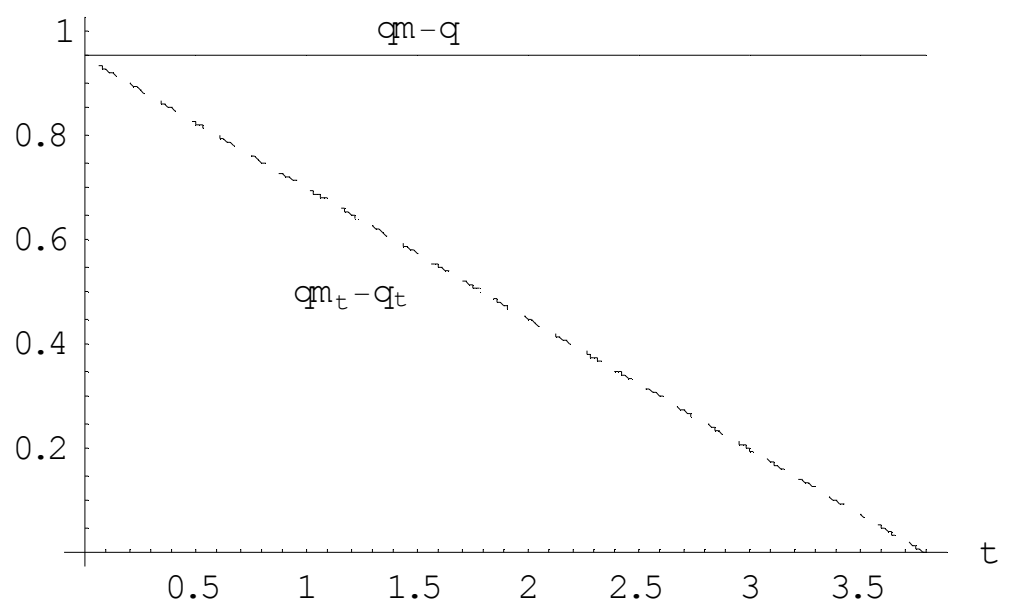

Gráfico 3.2. Proposición 2 (cantidades)

\footnotetext{
${ }^{17}$ La forma recta de la línea punteada surge de que la demanda es lineal, en su defecto tal línea podría ser cóncava o convexa.
} 


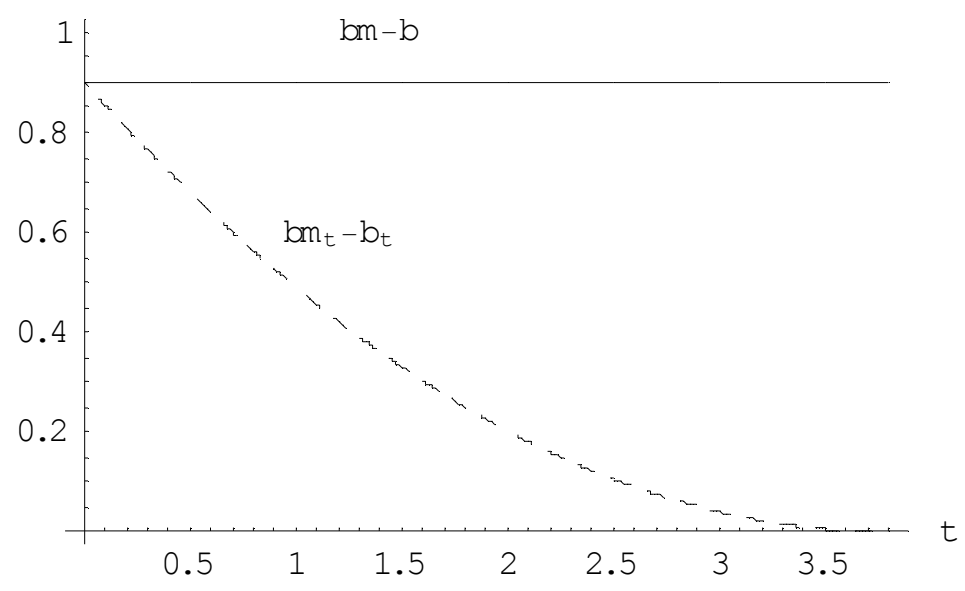

Gráfico 3.3. Proposición 2 (beneficio)

La línea punteada del Gráfico 3.4 expresa el resultado de la proposición 3, esto es, la relación entre el beneficio del minorista y del productor cuando hay evasión $\left(\lambda^{e}\right.$, en el gráfico es $\left.\mathrm{L}_{e}\right)$, para distintos valores de $x .{ }^{18}$ Se incorpora la misma relación para el caso de honestidad en la línea entera $\left(\lambda^{h}\right.$, en el gráfico es $\left.\mathrm{L}_{h}\right)$, con lo cual se observa con claridad también el resultado de la proposición 5: $\lambda^{h}<\lambda^{e}$. Notar que cuando la demanda es lineal $(x=1) \quad \lambda^{e}=0,5 \quad$ y $\lambda^{e}>0,5$.

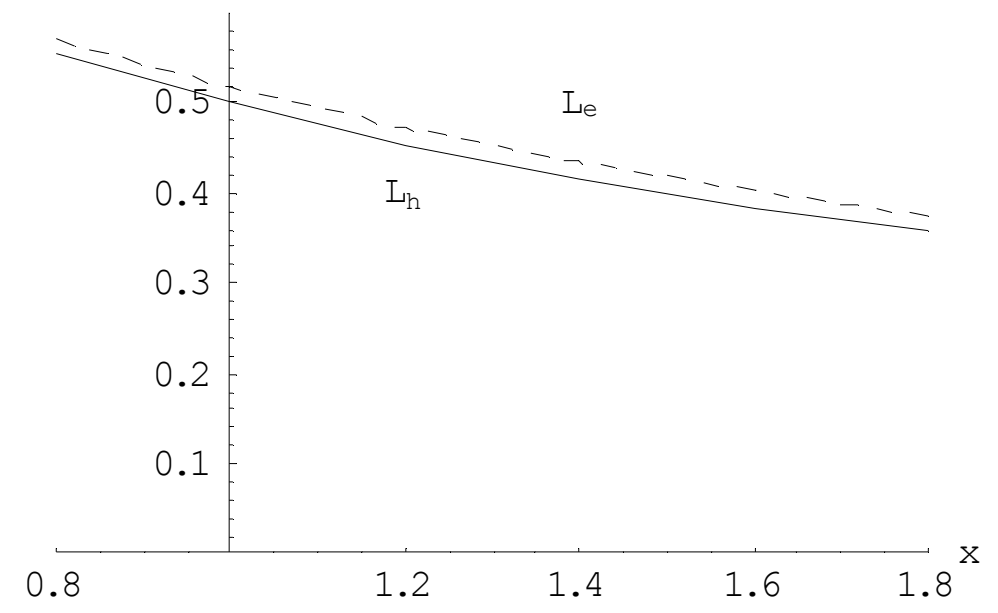

Gráfico 3.4. Proposición 4 (I)

\footnotetext{
${ }^{18}$ Para: $f=1,1 ; \phi=0,001 ; t=0,25$.
} 
El Gráfico 3.5 expresa los resultados de la proposición 4: la relación entre las cantidades y el beneficio, con y sin integración bajo evasión impositiva. La línea recta es la diferencia, en presencia de evasión impositiva, entre el beneficio del monopolista integrado y el beneficio de toda la cadena en equilibrio no integrado $\left(\mathrm{bm}_{e}-\mathrm{b}_{e}\right)$, mientras que la línea punteada es la diferencia entre las cantidades $\left(\mathrm{qm}_{e}-\mathrm{q}_{e}\right)$. El Gráfico 3.5 es esencialmente similar a los Gráficos 3.2 y 3.3 (los valores de lo parámetros también son los mismos), donde se hace la misma comparación pero bajo honestidad. Recordemos que la decisión de evasión no tiene impacto en las cantidades. Además, como el nivel de evasión es similar para el monopolista integrado que para el vendedor minorista, la relación entre el nivel de beneficio es la misma con o sin evasión. Esto indica con claridad que si existe una menor externalidad en este modelo se debe a la presencia de impuestos, y no debido a la evasión impositiva.

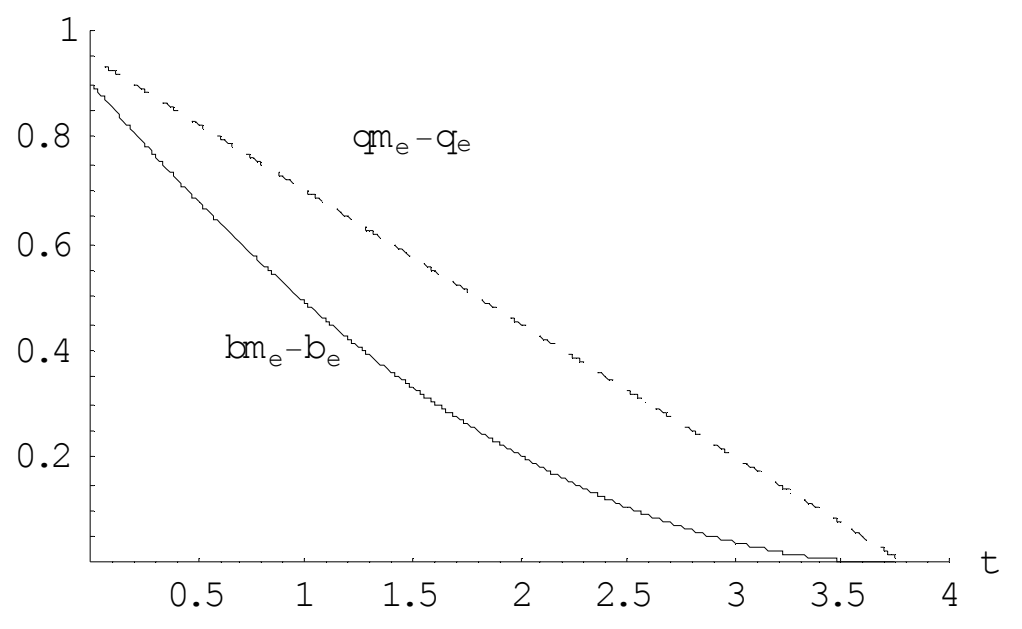

Gráfico 3.5. Proposición 4 (II)

La relación presentada en el Gráfico 3.4 surge del comportamiento del beneficio del productor y del vendedor cuando hay evasión, respecto al caso de no evasión. Tal comportamiento se presenta en al Gráfico 3.6 (y está formalizado en la proposición 5), que ilustra como varía el beneficio del vendedor $\left(\mathrm{bv}_{e}\right)$ y del productor $\left(\mathrm{bp}_{e}\right)$ en presencia de evasión, respecto a una variación en la probabilidad de auditoría (r) y por lo tanto de la evasión de equilibrio. ${ }^{19}$ Como se observa, el beneficio del productor (linea punuteada) no se ve afectado por el nivel de evasión,

\footnotetext{
${ }^{19}$ Para: $t=2$. Los dos gráficos siguientes mantienen estos parámetros (3.7 y 3.8$)$
} 
pero el beneficio del minorista será menor de acuerdo a mayor sea la probabilidad de auditoría (y menor la evasión). En el nivel donde la probabilidad de auditoría es máxima $(\bar{e}=0)$, el beneficio del minorista es la mitad del beneficio del productor (extremo derecho de ambas líneas), o sea que en este caso $\lambda^{h}=\lambda^{e}=1 / 2$. Mientras es mayor la evasión, tal relación aumentará.

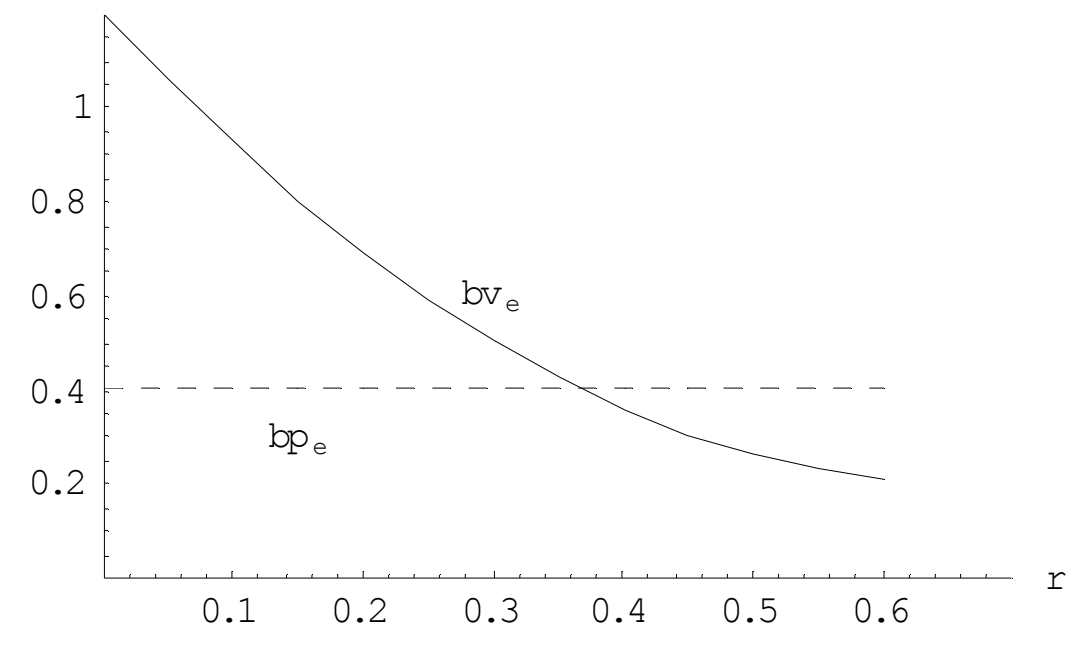

Gráfico 3.6. Proposición 5.

En el Gráfico 3.7 se muestra el beneficio de un monopolista integrado, para distintas probabilidades de auditoría (y niveles de evasión de equilibrio) en el modelo con evasión ( bme $_{e}$, línea entera) y sin evasión (bm, línea punteada). Como se observa, siempre el beneficio con evasión es mayor al beneficio sin evasión, salvo cuando $\bar{e}=0$ (que en este caso se alcanza para $\phi \simeq 0,60$ ). Por último, en el Gráfico 3.8 se presenta la ganancia de la integración para toda la cadena (línea punteada) y para el productor (línea entera) para distintos niveles de probabilidad de auditoría. Se observa que la ganancia de toda la cadena es la misma a la que se obtiene sin evasión, aunque la del productor es siempre mayor. 


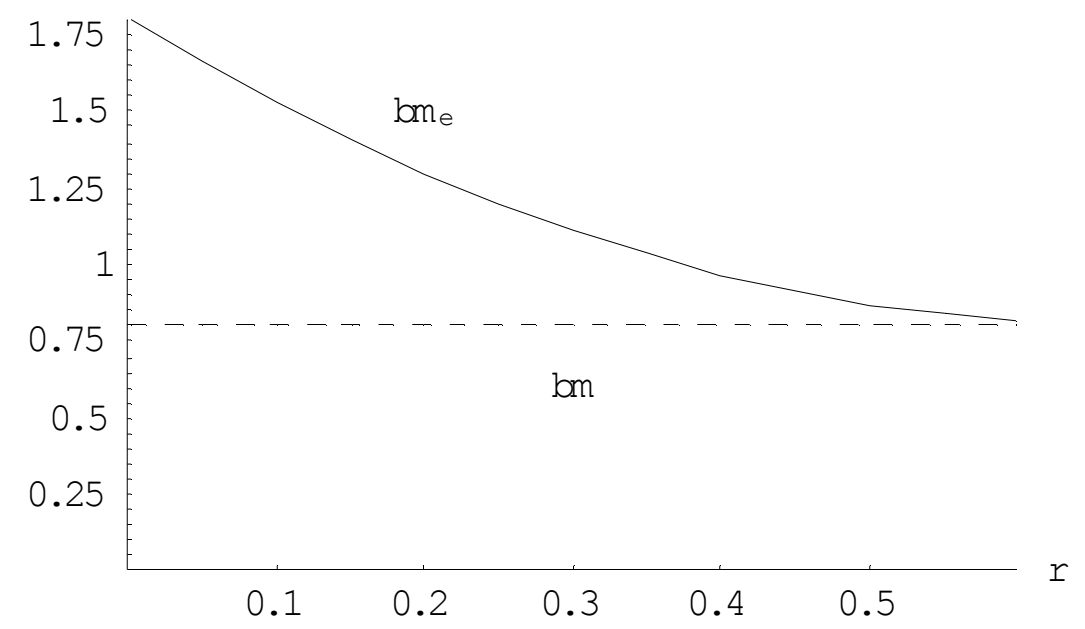

Gráfico 3.7. Proposición 6

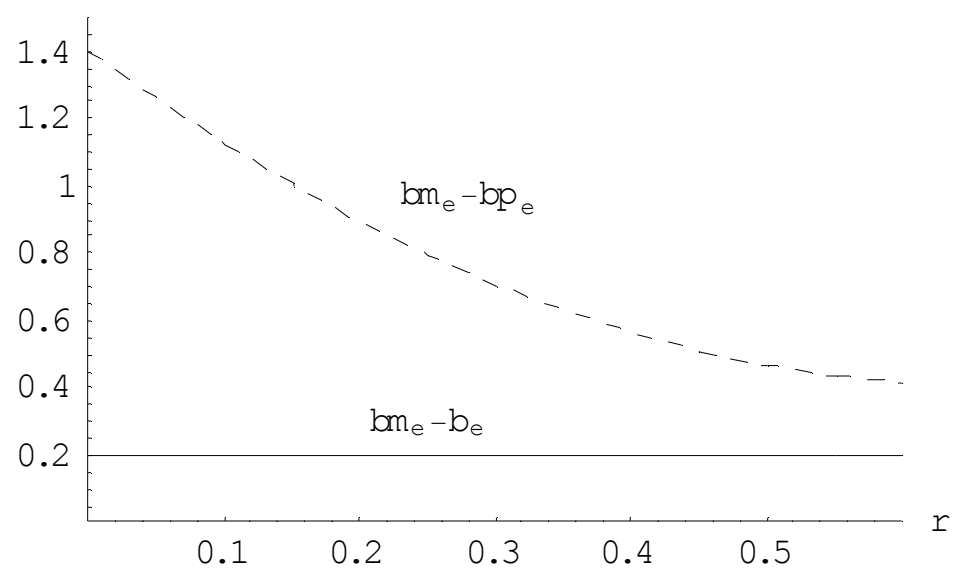

Gráfico 3.8. Proposición 7.

Respecto a los resultados del modelo sin separabilidad, se presenta en el Gráfico 3.9 la proposición 4B, esto es, el nivel de producción, la evasión y el beneficio con evasión, con equilibrio descentralizado e integrado. Se observa que con integración, tanto la cantidad como la evasión y el nivel de beneficio es mayor. 


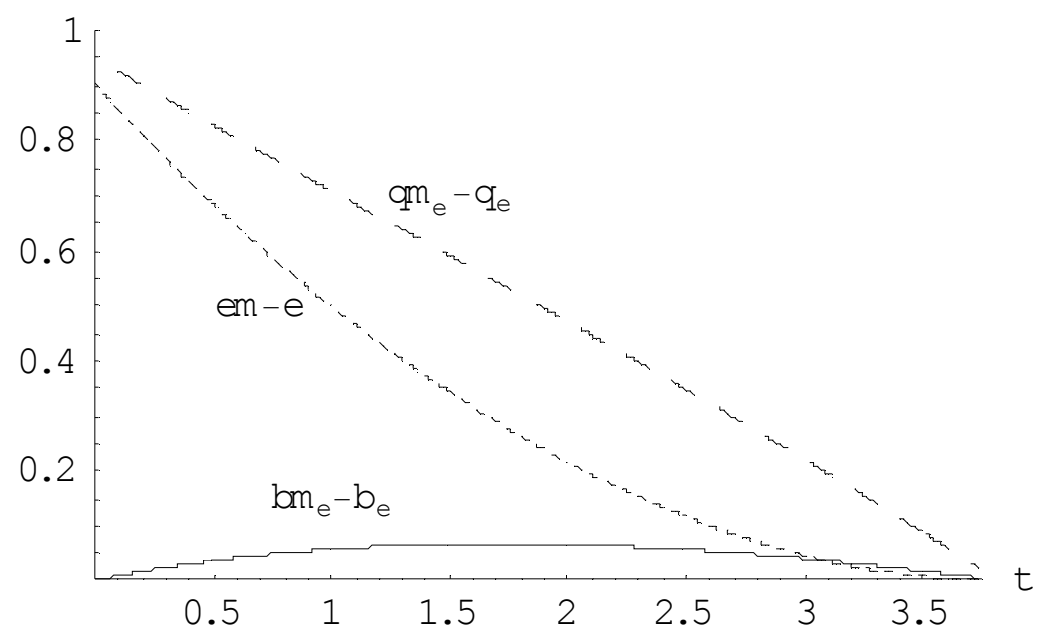

Gráfico 3.9. Proposición 4B. Sin Separabilidad

\subsection{Conclusiones}

Si bien la evasión fiscal es un fenómeno persistente y muy difundido hay diversos aspectos de la misma que permanecen casi sin ser analizados en términos teóricos. Uno de ellos, es la consecuencia de la evasión dentro de una estructura de monopolio en cadena.

En la literatura sobre control vertical, una de las principales preguntas es cual es el efecto de las herramientas de restricción vertical, para lo cual es necesario conocer también su motivación. Dentro de la enorme diversidad de las herramientas que existen y que se han estudiado en términos analíticos, en este capítulo nos concentramos en el esquema más simple de doble monopolio donde el equilibrio descentralizado produce externalidades negativas en toda la cadena.

Si bien este modelo es muy simple, como hemos visto, permite obtener conclusiones interesantes al agregar un impuesto indirecto en la etapa final, que puede ser evadido. Demostramos que si el impuesto es específico y hay separabilidad entre la decisión de producción y la de evasión, la ganancia para toda la cadena proveniente de la integración con evasión es la misma a la de sin evasión. La ganancia para el productor, por el contrario, es siempre mayor cuando hay evasión.

Una tarifa en dos partes resuelve la externalidad generada por el monopolio en cadena, ya que bajo tal esquema el nivel de beneficio que obtiene toda la cadena es el mismo al del equilibrio integrado. Lo notable en este último caso es que la tarifa en dos partes, le permitiría 
al productor apropiarse del beneficio que surge de la actividad de evasión de impuestos, incluso sin asumir riesgos. Algunos resultados varían sensiblemente si el impuesto es ad valorem, y no existe separabilidad entre las decisiones de producción y de evasión. 


\subsection{Apéndice}

\subsubsection{Monopolio y competencia en la etapa final}

Existe un impuesto ad valorem a las ventas en un mercado competitivo con empresas neutrales al riesgo. La empresa puede subdeclarar el nivel de actividad, con el objetivo de pagar menos impuestos. Bajo los supuestos usuales, el minorista maximiza:

$$
\operatorname{Max}_{e, q} \Pi=q(p)\left[p(1-t)-p_{w}\right]+p t e(1-\phi f)-g(e)
$$

Condición de primer orden respecto a $q(p)$ :

$$
\begin{aligned}
\Pi_{q} & =p-p_{w}-p t \leqq 0 \\
p & \leq \frac{p_{w}}{1-t}
\end{aligned}
$$

Condición de primer orden respecto a $e$ :

$$
\begin{gathered}
\Pi_{e}=p t(1-\phi f)-g^{\prime} \leq 0 \\
g^{\prime} \leq p t(1-\phi f)
\end{gathered}
$$

En este modelo, las cantidades de equilibrio son independientes del nivel de la evasión. Existe separabilidad. En este caso, las cantidades individuales están indeterminadas, no así el equilibrio de mercado.

Proposición 1A. Los impuestos a las ventas finales y la posibilidad de evasión de los mismos no generan externalidades dentro de una estructura vertical, ni afectan la distribución de los beneficios entre el productor y los minoristas.

El problema del productor es elegir su nivel de producción de equilibrio, pero tomando como 
dadas las ecuaciones anteriores:

$$
\begin{aligned}
\operatorname{Max}_{q} \Pi^{p} & =\left(p_{w}-c\right) q \\
\operatorname{Max}_{q} \Pi^{p} & =[p(1-t)-c] q
\end{aligned}
$$

Su CPO será:

$$
\frac{\partial \Pi^{p}}{\partial q}=R^{\prime}(q)(1-t)-c \leq 0
$$

Esta es la misma condición del caso bajo integración, no hay doble margen debido a que existe competencia en el nivel minorista, y no hay externalidad debido a la separabilidad.

Beneficio de toda la cadena con evasión

$$
\begin{aligned}
& \Pi^{v}=0 \\
& \Pi^{p}=[p(1-t)-c] q
\end{aligned}
$$

La evasión no tiene impacto alguno en el beneficio de la integración. Q.E.D 


\subsection{Referencias bibliográficas}

Bresnahan, T.F. y P.C. Reiss (1985). "Dealer and manufacturer margins". Rand Joumal of Economics, vol 16, No 2.

Dahlman, C.J. (1979). "The Problem of Externality". Journal of Law and Economics, vol 22, pp 141-162.

Dobson, P. y M. Waterson (1996). "Vertical Restraints and Competition Policy". Office of Fair Trading. Research Paper No. 12.

Gal-Or, E. (1991). "Vertical Restraints with Incomplete Information". Journal of Industrial Economics, vol 39, No 5.

Marrelli, M. (1984). "On Indirect Tax Evasion". Journal of Public Economics, vol 25, pp 181-196.

Mathewson, G. F. y R.A. Winter (1984). "An Economic Theory of Vertical Restraints". RAND Journal of Economics, vol 15, pp 27-38.

Mishan, E.J. (1971). "The Postwar Literature on Externalities: An Interpretative Essay". Journal of Economic Literature, vol 9, pp 1-28.

Oi, W. (1971). "A Disneyland Dilemma: Two-Part Tariffs for a Mickey Mouse Monopoly". Quarterly Journal of Economics, vol 85, pp 77-96.

Rey, P. y J. Stiglitz (1988). "Vertical Restraints and Producers' Competition". NBER Working Paper No 2601.

Rey, P. y J. Tirole (1986). "The Logic of Vertical Restraints". American Economic Review, vol 76, No 5, pp 921-939.

Rey, P. y T. Verge (2005). "The Economics of Vertical Restraints". Conferencia sobre Advances of the Economics of Competition Law, Roma.

Schmalensee, R. (1981). "Monopolistic Two-Part Pricing Arrangements". Bell Journal of Economics, vol 11, pp 445-466.

Spengler, J.J. (1950). "Vertical Integration and Antitrust Policy". Journal of Political Economy, vol 58, No 4, pp 347-352. 
Tan, G. (2001). "The Economic Theory of Vertical Restraints". Reporte preparado para el Competition Bureau, Canada.

Telser, L.G. (1960). "Why Should Manufacturers Want Fair Trade?". Journal of Law and Economics, vol 3, pp 86-105

Vickers, J. y M. Waterson (1991). "Vertical Relationships: An Introduction". Journal of Industrial Economics, vol 39, No 5.

Virmani, A. (1989). "Indirect Tax Evasion and Production Efficiency". Journal of Public Economics, vol 39, pp 223-237. 


\section{Capítulo 4}

\section{Elusión de Impuestos Indirectos. El Caso del Impuesto sobre los Ingresos Brutos}

\subsection{Introducción}

En este capítulo se analiza, desde un punto de vista teórico, la elusión de un impuesto indirecto utilizando como referencia el Impuesto sobre los Ingresos Brutos tal cual está legislado en la Provincia de Buenos Aires. Las preguntas principales a analizar son dos: i) cómo se puede eludir en términos genéricos el Impuesto sobre los Ingresos Brutos, y ii) cuáles deberían ser los lineamientos de una reforma tributaria tendientes a reducir las posibilidades de elusión. Para poner la discusión en su debido contexto, el Apéndice A incluye una breve revisión histórica acerca de los origenes del impuesto.

El Impuesto a los Ingresos Brutos (en adelante IIBB) es la principal fuente de recaudación propia de las Provincias en la República Argentina, alcanzando en el año 2008 el $72 \%$ del total de los recursos tributarios provinciales. ${ }^{1}$ El IIBB forma parte modelo de finanzas públicas que

\footnotetext{
${ }^{1}$ Para el año 2008, en nueve provincias el IIBB representa más del $80 \%$ de los recursos propios, mientras que en las provincias más grandes, la participación supera el 70\%. A nivel país, el $72 \%$ de la recaudación tributaria de las provincias está explicada por el IIBB (fuente: sitio web de la Dirección Nacional de Coordinación Fiscal con las Provincias).
} 
ha adoptado el país. Existe en todas las provincias argentinas con un nivel de uniformidad notable (en casi todas las provincias la definición del hecho imponible y la base imponinble son idénticas), ya tiene casi 60 años y goza de buena salud, al menos en términos recaudatorios. Si bien se han planteado algunas alternativas de reemplazo del impuesto, las mismas no eran necesariamente viables, y definitivamente tampoco fueron exitosas. Sin embargo, la investigación económica acerca de este impuesto ha sido escasa. ${ }^{2}$

La elusión fiscal respecto a impuestos indirectos es un tema no abordado formalmente por la literatura económica. Los estudios más generales de Stiglitz (1985), Cowell (1990) y Slemrod (1998) se refieren exclusivamente a impuestos directos. ${ }^{3}$ En este trabajo se utilizará como referencia metodológica a Stiglitz (1985) y Cowell (1990) y se intenta aplicar sus análisis al caso del IIBB.

Se argumenta en este capítulo que un elemento central en las posibilidades de elusión del IIBB es la diferencia de alícuotas entre sectores económicos, regiones y contribuyentes. Cuando existen posibilidades de transferencia de ingresos entre sectores económicos, regiones o contribuyentes, tal diferencia de alícuotas generan incentivos a eludir el impuesto.

Unificar las alícuotas a través de los sectores económicos, si bien reduce el incentivo de transferencia de ingresos, agrava el problema vinculado con la imposición en varias etapas y las posibilidades de elusión que se generan eliminando etapas de producción y comercialización.

La diferencia de alícuotas entre regiones también es una fuente de elusión, pero es un problema más complejo de resolver, ya que implica coordinación interjurisdiccional.

Un elemento a considerar respecto a la diferencia de alícuotas entre contribuyentes es la significativa concurrencia de bases imponibles con el nivel nacional. Las exenciones subjetivas son similares a las de la Ley de Ganancias e incluso de IVA y, por lo tanto, será limitado el alcance que puedan tener las medidas tomadas por un fisco subnacional.

En la siguiente sección se presenta en forma resumida la literatura teórica sobre elusión fiscal. En el sección 3 se describe en términos generales el Impuesto sobre los Ingresos Brutos tal cual está legislado en la Provincia de Buenos Aires. Luego se presenta un modelo estilizado de elusión

\footnotetext{
${ }^{2}$ Algunas excepciones son Di Gresia (2003) y Rezk (2001), aunque en ninguno de estos casos el objetivo es determinar el impacto económico del impuesto, sino más bien su elasticidad recaudatoria en un caso y los efectos en el bienestar de su reemplazo por otro impuesto directo, en el otro.

${ }^{3}$ En el caso de Slemrod (1998) se incluye en el tratamento el comportamiento de la oferta laboral, cuestión bastante diferente a las decisiones de producción de un empresario.
} 
fiscal de impuestos indirectos para, ya en la sección 5, analizar en detalle las posibilidades de elusion del IIBB. Los comentarios finales se presentan en la sección 6.

\subsection{Antecedentes}

En la visión tradicional, atribuida por Slemrod y Yitzhaki (2000) a un juez norteamericano de principios del siglo XX, Oliver Wendell Holmes, se divide la respuesta a la imposición por parte de los contribuyentes en aquella que utiliza las herramientas legales vigentes (elusión) y la que queda del otro lado de la línea trazada por el "plexo normativo" (evasión). La misma definición adoptan los principales estudiosos del tema. ${ }^{4}$ A los fines de un impuesto indirecto, aquí se adopta como definición de elusión a las conductas llevadas a cabo por parte de las empresas dentro del marco legal vigente que logran reducir la carga impositiva sin modificar las decisiones de producción de bienes y servicios.

La literatura sobre elusión fiscal no es muy abundante. Stiglitz (1985) fue el primero en presentar una teoría general de la elusión focalizada exclusivamente al impuesto a las ganancias personales (individual income tax). Demuestra que bajo los supuestos de información perfecta y mercado de capitales perfectos, los agentes económicos están en condiciones de eludir el $100 \%$ del impuesto, aunque reconoce a la vez que en la realidad el impuesto a las ganancias personales es pagado por la mayoría de las contribuyentes, lo cual atribuye principalmente a imperfecciones del mercado de capitales. A partir del trabajo de Stiglitz (1985), varios autores ampliaron en diversas direcciones el estudio de la elusión. Parte de esta literatura se dedicó a analizar diversas propuestas de reforma impositiva, en términos de si podrían favorecer o perjudicar las posibilidades de elusión señaladas por Stiglitz (1985). ${ }^{5}$ Si bien ninguno de estos trabajos estudian un impuesto a los ingresos brutos, existen varios análisis que son totalmente aplicables a este impuesto.

Por otro lado, Cowell (1990) presenta un modelo en el cual estudia la decisión del contribuyente que enfrenta las siguientes posibilidades respecto del impuesto a los ingresos: i)

\footnotetext{
${ }^{4}$ Ver Cowell (1990, 1995), Alm (1999), Franzoni (1999), Slemrod y Yithhaki (2000), Sandmo (2005) y Kaplow (2006).

${ }^{5}$ McLure (1993), Grubert y Newlon (1995), Murray (1997) y Gale (1999) analizan un impuesto federal al consumo. Ginsburg (1995) estudia un impuesto a los ingresos de las empresas mientras que Feld (1995) y Calegari (1998) analizan la propuesta del impuesto general a los ingresos con tasa plana.
} 
cumplimiento tributario, ii) evasión fiscal, y iii) elusión fiscal. En el modelo presentado, tanto la evasión como la elusión tienen un costo, y a partir de la forma que tenga la función de costos de ambas alternativas, de las tasas impositivas marginales, y de la aversión al riesgo, el resultado puede implicar soluciones de estrategias mixtas (en el cual el contribuyente toma las tres conductas posibles respecto de al menos una porción de su ingreso) o de esquina. El mismo estudio presenta los problemas de asimetría de información que implica la evasión fiscal, a diferencia de la elusión, que es una conducta abierta y conocida por la administración tributaria. Considerando la asimetría de información, Cowell (1990) muestra que el resultado más factible es la polarización (esto es, evasión o elusión total). En general, también se concluye que los contribuyentes de mayores ingresos y aversos al riesgo optarán por eludir el impuesto, mientras que los de bajos ingresos optarán por evadirlo.

\subsection{Descripción del Impuesto sobre los Ingresos Brutos}

El IIBB fue creado en la Provincia de Buenos Aires con la sanción del Código Fiscal en el año 1948. ${ }^{6}$ Tal iniciativa fue seguida por el resto de las jurisdicciones y ya en el año 1954 todas las provincias habian aprobado un impuesto similar. Existe bastante uniformidad en la definición y alcance del impuesto entre las diversas jurisdicciones, en parte porque todos tienen un origen comun (el Código Fiscal de la Provincia de Buenos Aires del año 1948) y quizás también debido a que las fuerzas tendientes a la armonizacion fueron mayores a las de la competencia entre los fiscos. ${ }^{7}$

Tal como está legislado en la Provincia de Buenos Aires, el hecho imponible del impuesto es el ejercicio habitual y a título oneroso -lucrativo o no- dentro de la Provincia, del comercio, industria, profesión, o de otra actividad cualquiera sea la naturaleza del sujeto que la preste y el lugar donde se realice ${ }^{8}$ Esta definición es amplia e incluso cuida de no excluir ningún tipo de actividad realizada a título oneroso.

\footnotetext{
${ }^{6}$ En Fonrouge y Navarrini (1982) y Bulit Goñi (1996) pueden encontrarse los antecedentes mundiales, su historia en Argentina y sus características principales.

${ }^{7}$ En el Apéndice A se describe con mayor detalle las circunstancias que siguieron la creación del IIBB y la armonización del mismo entre todas las jurisdicción.

${ }^{8}$ Los elementos centrales del Impuesto están definidos por el Código Fiscal de la Provincia de Buenos Aires. Ley 10.397 y sus modificatorias (texto ordenado 2004). Libro II. Título II.
} 
Respecto de la base imponible, el Código Fiscal estalece que el gravamen se determina sobre la base de los ingresos brutos devengados durante el período fiscal por el ejercicio de la actividad gravada. Por ingreso bruto se entiende el monto total (sea en valores monetarios, especies o servicios) devengado por el desarrollo de la actividad gravada.

Las tasas impositivas se establecen año a año en la Ley Impositiva y distan mucho de ser uniformes entre actividades económicas. ${ }^{9}$ Las alícuotas se agrupan por sector económico y, dentro de una cadena de producción y comercialización, son crecientes mientras más cerca esté la operación de una venta final. La Ley Impositiva presenta un rango de alícuotas del 0,1\% al $12 \%$, con 17 alicuotas que se asignan a las 438 actividades económicas distintas mencionadas en la misma Ley. ${ }^{10}$

La obligación de cada empresa es discriminar su base imponible en función de cada una de las actividades que realiza, y aplicar la alícuota correspondiente en cada caso. De este modo, aquellas empresas que desarrollan más de una actividad pagarán una tasa impositiva promedio distinta de las 17 establecidas en la legislación. El promedio surgirá de la ponderación de cada una de las alícuotas en función del tamaño de la base imponible para esa actividad.

La legislación establece exenciones que pueden ser clasificadas en subjetivas, objetivas o mixtas. Las primeras están atadas al sujeto (contribuyente en particular o alguna característica del mismo), mientras que las segundas al objeto (la actividad realizada por el contribuyente). En el caso de una exención mixta, éstas se aplican a los ingresos de determinados contribuyentes obtenidos por el ejercicio de ciertas actividades.

Las principales exenciones objetivas fueron establecidas por el Pacto Fiscal del año 1993 y abarcan las siguientes actividades:

a) Producción primaria.

b) Prestaciones financieras realizadas por las entidades comprendidas en el régimen de la Ley 21.526 .

c) Compañías de capitalización y ahorro y de emisión de valores hipotecarios, las Admin-

\footnotetext{
${ }^{9}$ En todo este capítulo, se utilizan como referencia las alícuotas establecidas en la Ley 13.787, aplicables al año 2008. Tales alícuotas se modifican año a año.

${ }^{10}$ Se establece un $1 \%$ para producción primaria, $1,5 \%$ para producción de bienes, $3 \%$ para comercio y $3,5 \%$ para servicios. Sin embargo, más allá de este tratamiento general, muchas actividades especificas tienen un tratamiento diverso: desde exenciones (que equivale a una alícuota del $0 \%$ ) a alícuotas de hasta el $12 \%$ para "servicios de espectáculos artísticos y de diversión".
} 
istradoras de Fondos comunes de Inversión y de Fondos de Jubilaciones y Pensiones y Compañías de Seguros.

d) Compraventa de divisas.

e) Producción de bienes (industria manufacturera).

f) Prestaciones de servicios de electricidad, agua y gas, excepto para las que se efectúan en domicilios destinados a vivienda o casa de recreo o veraneo.

g) Construcción de inmuebles.

Tanto la producción primaria como la construcción de inmuebles fueron luego gravadas, pero el resto de las actividades continuan exentas.

El Código Fiscal, por otro lado, establecen las exenciones subjetivas, que son:

- El Estado Nacional, Provincias y Municipios, sus entes autárquicos y descentralizados.

- Las asociaciones, sociedades civiles, entidades o comisiones de beneficencia, de bien público, asistencia social, de educación e instrucción, científicas, artísticas, culturales y deportivas, instituciones religiosas y asociaciones obreras, siempre que los ingresos obtenidos sean destinados exclusivamente al objeto previsto en sus estatutos y no se distribuya suma alguna de su producido entre asociados o socios. ${ }^{11}$

- Las asociaciones mutualistas, respecto de los ingresos que provengan de la realización de prestaciones mutuales a sus asociados (con excepción de los seguros).

- Los establecimientos educacionales privados incorporados a los planes de enseñanza oficial y reconocidos como tales por las respectivas jurisdicciones.

- Las cooperativas y empresas de servicios eléctricos, cooperativas, integradas por las municipalidades y/o vecinos, que realicen servicios públicos dentro del partido al que pertenecen, cooperativas de trabajo.

- Las emisoras de radiotelefonía y de televisión, inclusive las emisoras de televisión por cable, codificadas, satelitales, de circuitos cerrados y toda otra forma que haga que sus emisiones puedan ser captadas únicamente por sus abonados.

- Los Consorcios o Cooperativas de Exportación.

- Las Bolsas de Comercio autorizadas a cotizar títulos valores y los Mercados de Valores.

\footnotetext{
${ }^{11}$ Este beneficio no alcanza a los ingresos obtenidos cuando desarrollen actividades comerciales y/o industriales y tales ingresos superen, anualmente, el monto que establezca la Ley Impositiva.
} 
A los efectos de evitar la múltiple imposición existe un Convenio Multilateral rubricado por todas las provincias, que establece la forma de distribución de la base imponible para aquellas empresas que actúan en más de una jurisdicción. ${ }^{12}$ Según el Convenio Multilateral, las empresas deben calcular la base imponible nacional (las ventas en todo el territorio Argentino), luego distribuir tal base en función de las normas del propio Convenio y por último aplicar la alícuota que corresponde a cada jurisdicción. Este ejercicio se debe realizar para cada actividad distinta que pueda desarrollar una empresa. La distribución de la base imponible nacional puede seguir dos criterios: el régimen general y los regímenes especiales. Los principales regímenes especiales abarcan la construcción, entidades financieras y de seguro, transporte, y profesiones liberales. El resto de las actividades seguirán el régimen general

El regimen de distribución general establece que la base imponible nacional debe asignarse un $50 \%$ en función de los gastos efectivamente soportados en cada jurisdicción y un $50 \%$ en función de los ingresos brutos provenientes de cada jurisdicción. ${ }^{13}$ Se entiende que un gasto es efectivamente soportado en una jurisdicción, si tiene una relación directa con la actividad que en la misma se desarrolle, aún cuando la erogación se efectúe en otra. Así, los sueldos, jornales y otras remuneraciones se consideran soportados por la jurisdicción en que se prestan los servicios a que dichos gastos se refieren.

De este modo, las normas del Convenio Multilateral son relevantes en el análisis económico del impuesto, ya que introduce los gastos realizados por el contribuyente en el cálculo del impuesto a pagar en cada jurisdicción. ${ }^{14}$

\footnotetext{
${ }^{12}$ La existencia del Convenio Multilateral también expresa un esfuerzo de armonización bastante exitoso. El primer antecedente fue el convenio bilateral entre la Provincia de Buenos Aires y la Municipalidad de la Ciudad de Buenos Aires firmado en el año 1953, a muy pocos años del establecimiento del impuesto en ambas jurisdicciones. El Convenio actualmente vigente fue aprobado en el año 1977.

${ }^{13}$ No se computan como gastos: a) el costo de la materia prima adquirida a terceros destinados a la elaboración en las actividades industriales, ni el costo de las mercaderías en las actividades comerciales, b) el costo de las obras o servicios que se contraten para su comercialización, c) los gastos de propaganda y publicidad, d) los tributos nacionales, provinciales y municipales (impuestos, tasas, contribuciones, recargos cambiarios, derechos, etcétera), e) los intereses, f) los honorarios y sueldos a directores, síndicos y socios de sociedades, en los importes que excedan del uno por ciento $(1 \%)$ de la utilidad del balance comercial.

${ }^{14}$ No se analiza en este capítulo el tratamiento especial dado a los contribuyentes pequeños.
} 


\subsection{Modelo básico de elusión}

Como punto de partida, se presenta un modelo muy simple de elusión fiscal de un impuesto específico por parte de un productor en competencia perfecta. La empresa no puede evadir impuestos, pero si eludirlos si declara parte de su actividad bajo determinada modalidad que le permite pagar una tasa impositiva menor. La actividad de elusión tiene un costo directo.

La firma maximizará la siguiente función de beneficios:

$$
\begin{aligned}
\operatorname{Max}_{q, v} \Pi & =R(q)-C(q)-(q-v) \tau+e \tau_{v}-\Gamma(v) \\
\text { s.a. } & : \quad v \leq q ; \quad \tau_{v} \leq \tau
\end{aligned}
$$

donde:

$q$ : Producción.

$p:$ Precio de equilibrio de mercado.

$\tau:$ Impuesto específico a las ventas.

$v$ : Ventas declaradas bajo la modalidad de elusión.

$\tau_{v}:$ Impuesto específico que pagan las cantidades eludidas $(v)$.

$R(q)=p q:$ Ventas totales

$C(q):$ Costos totales.

$\Gamma(v)$ : Función de costos directos de la elusión (estrictamente convexa).

La ecuación (4.1) puede expresarse como:

$$
\begin{aligned}
\operatorname{Max}_{q, v} \Pi & =R(q)-C(q)-q \tau+\left[\tau_{d} v-\Gamma(e)\right] \\
\text { s.a. } & : \quad v \leq q ; \quad \tau_{d} \leq \tau
\end{aligned}
$$

donde:

$\tau_{d}=\tau-\tau_{v}:$ Diferencia entre la tasa impositiva de la actividad desarrollada por la empresa y la que pagan los ingresos que la eluden. 
Las condiciones de primer orden son:

$$
\begin{aligned}
p-C^{\prime}(q) & \leq \tau \\
\tau_{d} & \leq \Gamma^{\prime}(v)
\end{aligned}
$$

Las ecuaciones (4.2) y (4.3) determinan los niveles óptimos de producción $\left(q^{*}\right)$ y de elusión $\left(v^{*}\right)$. En el caso aquí presentado, es interesante notar que la elusión no modifica las cantidades producidas ni los precios. Simplemente hay un menor costo impositivo para la empresa de vender la misma cantidad de equilibrio $\left(q^{*}\right)$. El menor costo impositivo implica una menor recaudación del Estado, aunque esto no genera en forma directa mayores recursos para el productor, ya que la elusión tiene un costo medido por $\Gamma\left(v^{*}\right)$. Este costo representa una pérdida de eficiencia generada por elusión fiscal.

Como se observa de la ecuación (4.3) el nivel de la elusión dependerá de las diferencias de alícuotas y del costo directo asociado. Tales variables, a la vez, serán determinadas por las alternativas prácticas de elusión que surgen del diseño de la política impositiva. En la próxima sección se evalúa esta cuestión analizando al Impuesto sobre los Ingresos Brutos.

\subsection{Elusión fiscal del IIBB}

En virtud del diseño actual del Impuesto sobre los Ingresos Brutos, la elusión aparece como una posibilidad a través de distintas acciones que se describen a continuación. Para cada caso se elaboran ejemplos simulados que permiten apreciar cómo podría impactar la elusión fiscal en la reducción de la carga impositiva y en el incremento de los beneficios después de impuestos. Tales ejemplos se describen en el texto y se presentan en detalle en el Apéndice B.

\subsubsection{Transferencia de base imponible a actividades menos gravadas}

Al existir distintas alícuotas, con una diversidad importante (del 0 al 12\%), la transferencia de ingresos de una actividad a otra puede generar un beneficio relevante para la firma. Dos formas de realizar esto sin modificar las decisiones de producción, o modificándolas sólo marginalmente son las ventas en bloque y la transformación de bienes de cambio en bienes de uso. 
Respecto a este último mecanismo, nótese que existe la posibilidad de disminuir la base imponible cambiando la categoría de bienes a la venta desde bienes de cambio a bienes de uso, cuyas ventas no están gravadas. Sin embargo, esto puede ser utilizado en forma marginal por las empresas, para muy pocos bienes que permiten ambas clasificaciones, como ser inmuebles, muebles de oficina, vehículos, etc. A fin de que tal recategorización sea legalmente válida la empresa debe utilizar el bien antes de venderlo. La evidencia circunstancial sugiere que tal mecánica sería utilizada en determinadas operaciones de alto valor (por ejemplo, inmuebles de alto costo) en donde el ahorro impositivo compensa los costos asociados que implica el uso de esta mecánica.

Respecto a las ventas en bloque, se entiende por tal conducta a la política de fijar un precio único para dos o más bienes relacionados que se venden en forma conjunta. La literatura sobre ventas en bloque es amplia y refleja un comportamiento usual de las empresas multiproducto maximizadoras de beneficios, que tienen diversas ventajas de tal estrategia. La literatura agrupa los motivos de tal comportamiento en tres: i) ahorros en los costos de producción, transacción e información, ii) complementariedad en el consumo y iii) discriminación de precios. ${ }^{15}$ Esto último sucede debido a que mediante la ventas en bloque el vendedor puede ordenar consumidores con precios de reserva diferentes y de ese modo extraer un excedente del consumidor mayor.

Sin embargo, aún cuando alguna de estas tres motivaciones estén ausentes, el beneficio de la venta en bloque podría provenir de una ventaja impositiva, si la tasa que enfrenta la venta en bloque es diferente de la correspondiente a la venta de los bienes por separado. En este sentido, existiría una cuarta motivación denominada "ventaja impositiva" que se daría cuando el monopolista vende determinado producto en forma conjunta con otro producto con el objeto de obtener un menor costo impositivo, esto es eludir un impuesto. ${ }^{16}$ El caso inverso también es totalmente factible: a través de la política impositiva es posible castigar la venta en bloque y por lo tanto, incentivar la venta separada.

En términos generales, lo que el vendedor está buscando es transferir sus ingresos desde una

\footnotetext{
${ }^{15}$ Ver Adams y Yellen (1976). La literatura iniciada con el trabajo de Stigler (1963) sobre ventas en bloque es frondosa. Para una revisión reciente ver Kobayashi (2005).

${ }^{16} \mathrm{Si}$ bien no se tiene conocimiento de trabajos que analicen esta motivación, la posibilidad la menciona Coloma (2005): "La discriminación de precios, sin embargo, no es la única causa por la cual puede resultar racional que un vendedor ofrezca varios bienes en bloque (...). También puede deberse a razones de tipo impositivo, si -como sucede en algunos países- resulta posible eludir ciertos impuestos sobre determinados bienes si se los empaqueta conjuntamente con otros bienes no gravados" (pg. 275).
} 
actividad gravada a una no gravada o gravada con una alícuota menor. Hay muchos ejemplos observables en la vida diaria que indican que las empresas usan en forma intensiva esta estrategia para reducir la carga impositiva. A continuación se describen cuatro casos.

\section{Caso 1. Ventas de revistas con CD-Rom}

La venta de CD-Rom con juegos interactivos para PC en la Argentina se realizan en buena parte desde hace un tiempo en kioscos de diarios y revistas. La comercialización de estos bienes se realiza mediante la venta de una revista que incluye un CD-Rom de "regalo". La motivación de esta estrategia podría deberse del diferente tratamiento impositivo que tienen estos dos bienes: las revistas están exentas, no así los CD-Rom. De este modo, la empresa convierte ingresos de una actividad gravada (venta de CD-Rom) en ingresos de una actividad exenta (venta de revistas). Debe notarse que esta operación de elusión tiene un costo directo para la empresa, que es el costo de la revista. En la Tabla 4.1a del Apéndice B se presenta un ejemplo de una empresa distribuidora de CD-Rom que tiene tres opciones: vender en forma separada, vender las revistas y por un precio adicional el CD-Rom, o vender directamente ambos bienes en forma conjunta. En este último caso, lo que se vende es la revista, mientras que el CD-Rom viene de regalo. Esta última opción, le permite eludir el $100 \%$ de la carga impositiva, aunque la mejora en el beneficio es un poco menor a tal valor monetario (el de la carga impositiva) ya que tiene como costo adicional a las revistas.

\section{Caso 2. Restaurantes con pistas de baile}

Desde hace varios años, muchos lugares de baile incorporaron un restaurant en el mismo establecimiento ("Resto-Bar"). La alícuota impositiva correspondiente a los ingresos del restaurant es muy diferente a la aplicable a los establecimientos bailables (3,5\% versus $12 \%$ ). Así, si la empresa cobra una consumición mínima en el restaurant y no cobra entrada a la pista de baile a los clientes del restaurant, podrá bajar su carga impositiva.

\section{Caso 3. Cuotas sociales de clubes}

Las Asociaciones Civiles pagan impuestos por sus ingresos comerciales (superando el mínimo establecido en la Ley Impositiva), pero no por las cuotas sociales (gozan de una exención "mixta"). Por lo tanto, todos los servicios dados a los socios puede ser incluidos en el costo de la cuota social y no cobrar adicionales, ya que esto último se tratarían como ingresos comerciales 
y estarían gravados (por ejemplo, el uso de instalaciones en particular, como pileta, cancha de tenis, colonia de vacaciones, etc.). El alcance de esta posibilidad de elusión dependerá de la combinación de ingresos entre socios y no socios, y entre servicios de acceso común y otros por los cuales se puede cobrar entrada. En la Tabla 4.2a del Apéndice B se presenta el caso de un club social y deportivo que tiene dos opciones respecto del uso de las canchas de tenis: cobrarlas en forma separada o cobrarlas sólo a los no socios, mientras que para los socios el uso estará incluido en el cobro de la cuota social. Asumiendo que la mayoría de los usuarios de la cancha son socios, esto le que permite reducir el $90 \%$ de la carga impositiva, el $10 \%$ restante corresponde a ingresos que provienen del uso por parte de no socios de espacios restringidos.

\section{Caso 4. Venta de bienes en cuotas}

Un caso particular de ventas en bloque se da con el costo financiero de las operaciones de venta en cuotas. En estos casos, se están comerciando dos bienes: el principal y el servicio financiero. Ya que ambos son difíciles de separar, será una decisión del empresario qué parte de los ingresos totales proviene de la venta y qué parte de los intereses asociados al financiamiento. Esta decisión dependerá, entre otros factores, del tratamiento impositivo de cada uno de esos ingresos. En el IIBB los servicios financieros pagan la misma tasa que la actividad principal, salvo para empresas que desarrollen la actividad financiera. De este modo, aquellas empresas que además de la actividad comercial estén habilitadas para realizar actividades financieras, tendrán un beneficio impositivo (siempre y cuando la actividad financiada tenga una alícuota mayor a la de servicios financieros).

Desde un punto de vista analítico, se ha demostrado que la venta en bloque sirve como un mecanismo eficiente de discriminación de precios y también se han analizado sus consecuencias normativas. Adams y Yellen (1976) demuestran que cuando un monopolista utiliza la venta en bloque como mecanismo de discrimininación de precios se pueden producir dos ineficiencias respecto a un óptimo de Pareto: de asignación de recursos y de distribución. La primera surge cuando, a través de las ventas en bloque, se sobreproduce (subproduce) un bien; esto es, se venden bienes a un costo marginal mayor al precio de reserva de algun comprador (posibles compradores con precio de reserva mayor al costo marginal del bien no lo compran). La segunda surgen cuando a través de una transacción entre dos compradores es posible mejorar el bienestar 
de ambos.

La solución de política pública debe considerar que de prohibirse la venta en bloque es posible que la situación empeore, ya que la fijación de precios de monopolio en ambos mercados puede generar que la pérdida de eficiencia producida por el monopolio sea mayor a la de la venta en bloque. La recomendación de Adams y Yellen (1976) es promover la competencia en los mercados de cada uno de los bienes.

A continuación se analiza la venta en bloque con impuestos específicos mediante un modelo de un monopolista multiproducto que enfrenta diversas alícuotas cuando vende los bienes separados o en bloque. En este contexto, dos preguntas son relevantes. En primer lugar, cuál es el impacto de un impuesto indirecto específico respecto a la decisión del monopolista de vender en bloque. En segundo lugar, cuales son las consecuencias normativas de la venta en bloque en presencia de un impuesto específico.

La venta en bloque implica la aplicación de poder de mercado y por lo tanto sólo es factible en un contexto distinto al de competencia perfecta. Esto implica tomar con suma precuación las comparaciones entre un monopolista que puede realizar ventas en bloque, para eludir impuestos, y el equilibrio de competencia perfecta. En tales casos, hay dos fuentes de ineficiencia (el monopolio y la "venta en bloque por ventaja impositiva") respecto de un equilibrio de competencia perfecta, lass cuales deben ser adecuadamente discriminadas.

\section{a. El modelo}

Se asume un monopolista que vende dos productos relacionados: $x_{1}$ y $x_{2}$, los cuales pueden venderse en forma separada o a través de una canasta $\left(x_{12}\right)$ a los precios $p_{1}, p_{2}$ y $p_{12}$ respectivamente. Los supuestos centrales son los siguientes:

a) El costo marginal de producir cada bien es constante $\left(\begin{array}{lll}c_{1} & \text { y } & c_{2}\end{array}\right)$, mientras que el costo marginal de proveer en forma conjunta ambos bienes es la suma de los costos marginales de cada bien $\left(c_{12}=c_{1}+c_{2}\right) \cdot{ }^{17}$

b) La utilidad marginal de la segunda unidad de cada bien es cero (demandas unitarias).

c) El precio de reserva para el paquete es igual a la suma de los precios de reserva de cada

\footnotetext{
${ }^{17}$ De este modo se anula la motivación de ventas en bloque por motivos de eficiencia (menores costos).
} 
bien $\left(r_{12}=r_{1}+r_{2}\right){ }^{18}$

d) No es posible la discriminación de primer grado, ni tampoco la reventa de bienes entre compradores.

e) No es posible evitar que los compradores armen la canasta por su cuenta (o sea que compren una unidad de cada bien), lo que implica que son triviales las soluciones donde $p_{12} \geq$ $p_{1}+p_{2}$.

Existe un impuesto específico donde la tasa que se aplica a la venta en bloque no es necesariamente igual a la suma de las tasas de cada uno de los bienes: $t_{12} \lessgtr t_{1}+t_{2}$. El monopolista debe decidir alguna de las siguientes estrategias, las cuales tienen distintas consecuencias impositivas:

a) Ventas Separadas (VS): determinar los precios que individualmente maximizan el beneficio en cada mercado $\left(\begin{array}{lll}p_{1}^{*} & \text { y } & p_{2}^{*}\end{array}\right)$.

b) Ventas en Bloque (VB): ofrecer los bienes únicamente en forma conjunta, al precio maximizador $p_{12}^{*}$.

c) Ventas en Bloque Mixtas (VBM): combinar ambas estrategias y ofrecer los bienes separados y en bloque simultáneamente, a los precios maximizadores $\left(p_{1}^{* *}, p_{2}^{* *}\right.$ y $\left.p_{12}^{* *}\right)$.

\section{b. Análisis positivo}

Si $t_{12}=t_{1}+t_{2}$ el análisis no agrega ninguna complejidad a lo presentado por Adams y Yellen, ya que ellos suponen que $c_{12}=c_{1}+c_{2}$. En este caso, se tiene que $c_{12}+t_{12}=c_{1}+c_{2}+t_{1}+t_{2}$. Adams y Yellen demuestran que cada una de las estrategias podrían ser maximizadoras de beneficios, dependiendo de la distribución de los precios de reserva y la estructura de costos. Toman como caso testigo la discriminación perfecta, donde se dan tres condiciones:

C1. Extracción completa: ningun individuo tiene excedente del consumidor.

C2. Exclusión: ningun individuo consume un bien si el costo de ese bien excede el precio de reserva del mismo.

C3. Inclusión: todo individuo que tenga un precio de reserva mayor al costo consume el bien.

Adams y Yellen demuestran que VS no viola nunca C2, pero viola C1 y C3 en la medida en que la distribución de precios de reserva implique que el monopolista enfrenta una demanda

\footnotetext{
${ }^{18} \mathrm{O}$ sea, las demandas de ambos bienes bienes son independientes, lo que excluye la complementariedad en el consumo.
} 
(del bien compuesto) con pendiente negativa. Si la demanda conjunta es muy elástica, pero no las individuales, VB puede evitar no cumplir con C1 y C3. Este sería el caso, por ejemplo, si los precios de reserva se distribuyen como una línea recta con pendiente -1 (la suma de los precios de reserva de ambos bienes es la misma para cada consumidor). Sin embargo, las VB no cumplen necesariamente con $\mathrm{C} 2$. El beneficio de VB contra VS será mayor si y solo si los mayores beneficios obtenidos por C1 y C3 no son superados por los menores beneficios que se alcanzan por no cumplir con C2. VBM será preferido a VB siempre que C2 no se cumpla con VB.

La conclusión de este análisis es que cada una de las tres estrategias de fijación de precios tiene ventajas y desventajas respecto a las otras dos, que dependerán de los costos y de la distribución de los precios de reserva. .

Otro caso posible es que $t_{12}<t_{1}+t_{2}$ A fin de analizar en detalle esta situación, se presentan tres casos que incorporan impuestos específicos en el contexto del modelo presentado por Adams y Yellen.

\section{Ejemplo 1. Dos consumidores y dos bienes}

Se asumen dos bienes ( 1 y 2 ) y dos consumidores ( $a$ y $b$ ) con las siguientes tasas impositivas, costos y precios de reserva presentados en la Tabla 4.1.

Tabla 4.1. Ventas en Bloque. Parámetros (Ejemplo 1)

\begin{tabular}{|c|c|}
\hline$t_{1}=10 ; \quad t_{2}=2 ; \quad t_{12}=2$ \\
\hline$c_{1}=3 \quad ; \quad c_{2}=5 ; \quad c_{12}=8$ \\
\hline$\left(r a_{1}, r a_{2}\right)=(55,45) ; \quad\left(r b_{1}, r b_{2}\right)=(40,60)$ \\
\hline
\end{tabular}

donde $r a_{1}$ es el precio de reserva para el consumidor $a$ del bien 1, y así sucesivamente. El monopolista elige los siguientes precios, para el caso de Ventas Separadas y Ventas en Bloque, a fin de maximizar su beneficio que se presentan en la Tabla 4.2. ${ }^{19}$

\footnotetext{
${ }^{19}$ Los valores de equilibrio en esta sección fueron obtenidos mediante un modelo de optimización construido en Microsoft Excel, estando el mismo disponible previa solicitud.
} 
Tabla 4.2. Ventas en Bloque. Valores de Equilibrio (Ejemplo 1)

\begin{tabular}{|l|c|c|}
\cline { 2 - 3 } \multicolumn{1}{c|}{} & VS & VB \\
\hline \multirow{2}{*}{ Precios de equilibrio } & $p_{1}^{*}=40$ & \\
\cline { 2 - 3 } & $p_{2}^{*}=45$ & \\
\cline { 2 - 3 } & & $p_{12}^{*}=100$ \\
\hline Beneficio productor & 130 & 180 \\
\hline Recaudación (Impuestos Pagados) & 24 & 4 \\
\hline Excedente del consumidor & 30 & 0 \\
\hline
\end{tabular}

Con lo cual las VB son preferidas para el monopolista a las VS (le generan un mayor beneficio). El mecanismo de VB, además de permitirle al productor apropiarse de un mayor excedente del consumidor (de hecho con la Venta en Bloque el excedente del consumidor es cero), también sirve para eludir impuestos, ya que paga significativamente menos con la VB que con la VS. En los siguientes gráficos se aprecia la apropiación del excedente del consumidor que implica la VB.

En el Gráfico 4.1 se presenta el equilibrio no integrado. Los dos puntos representan las combinaciones de precios de reserva para cada consumidor. A los precios de equilibrio (después de impuestos, iguales a $p_{1}=40$ y $p_{2}=45$ ) ambos consumidores compran ambos bienes y obtienen un excedente. El consumidor $a$ obtiene su excedente de parte del bien 1 (para el cual tiene un precio de reserva de 55 mientras que el precio pagado es de 40 ), mientras que el consumidor $b$ lo obtiene del consumo del bien 2 (con precio de reserva 60 y un precio de equilibrio de 45$)$. 


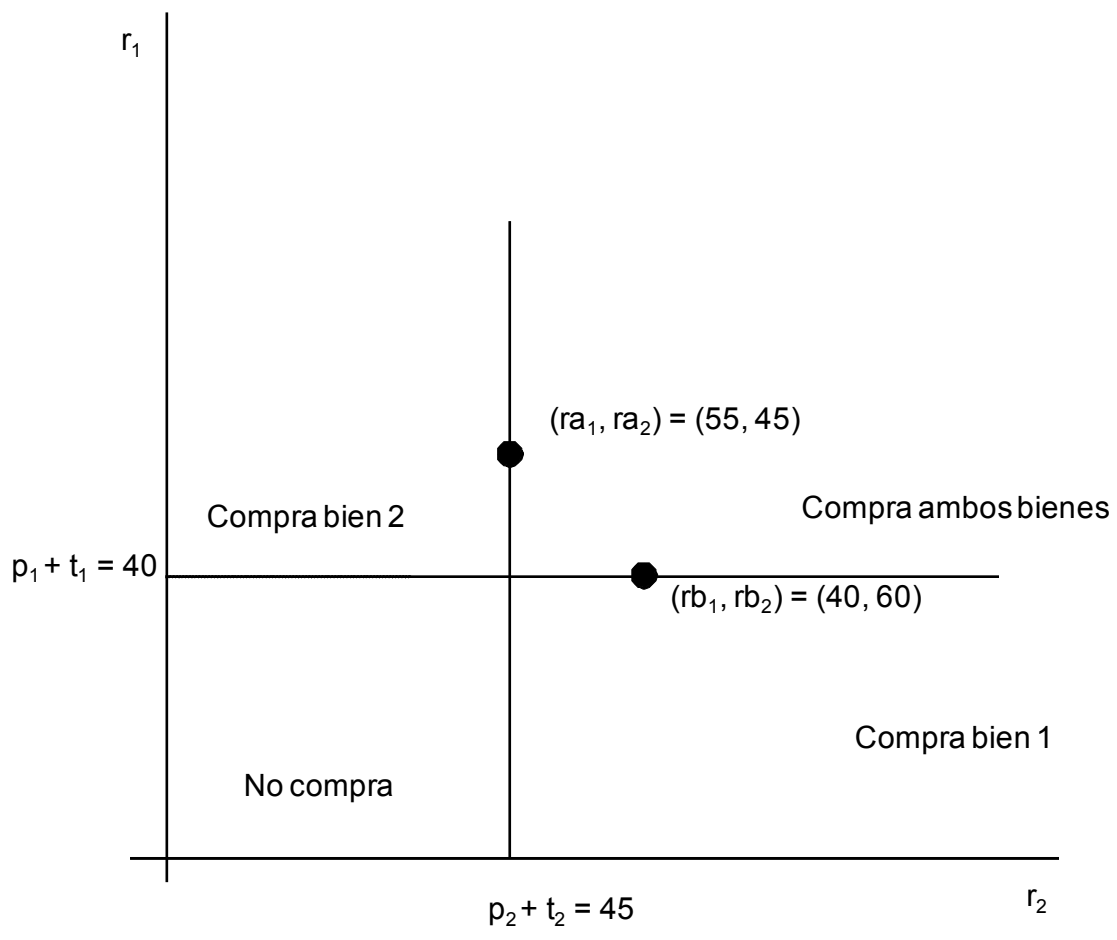

Gráfico 4.1. Venta Separada (Ejemplo 1).

En el Gráfico 2 se presenta la situación con equilibrio integrado. En este caso, el precio para la canasta después de impuestos es de 100. Como la suma de los precios de reserva para ambos consumidores es 100, compran la canasta y pierden el excedente del consumidor. 


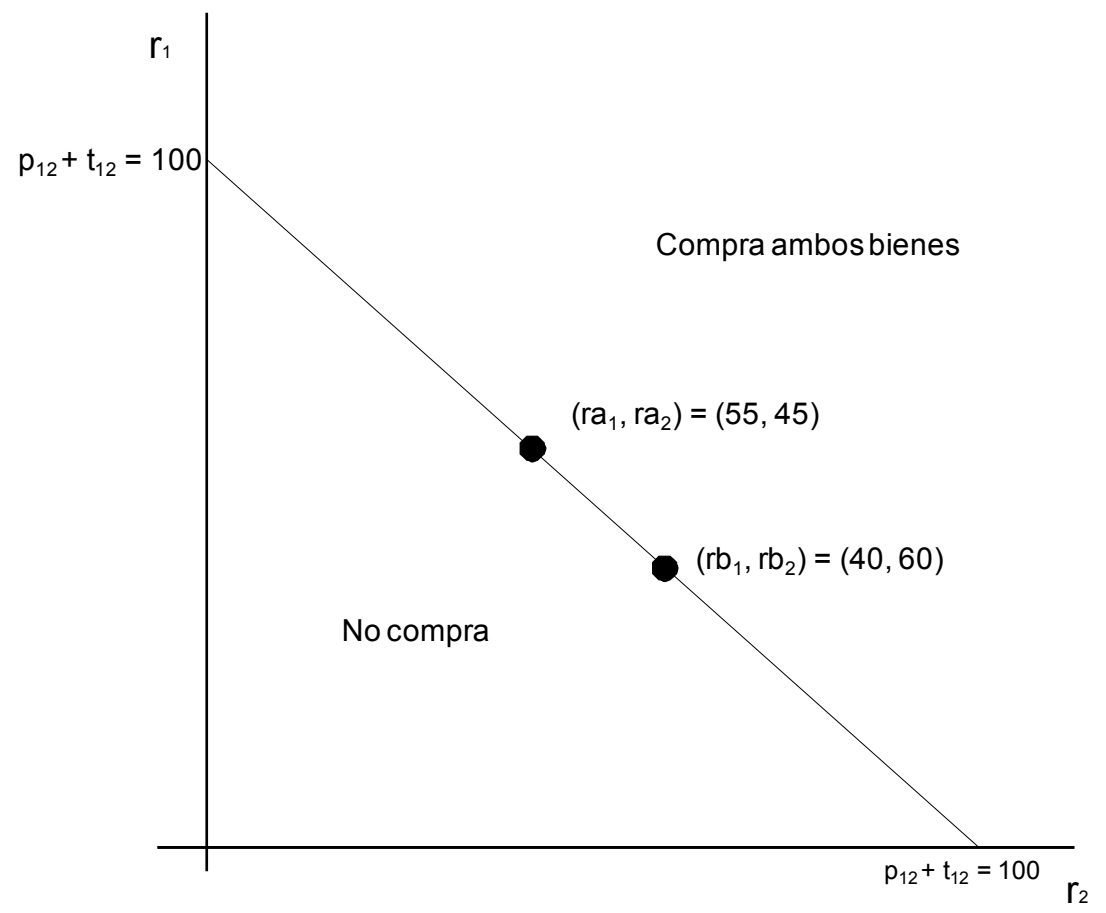

Gráfico 4.2. Venta en Bloque (Ejemplo 1).

\section{Ejemplo 2. Cuatro consumidores con dos bienes}

Para ilustrar la conveniencia de la VBM, se presenta un caso en el cual se tiene a cuatro consumidores $a, b, c$ y $d$. En la Tabla 4.3 se presentan los valroes de los parámetros (tasas impositivas, costos y precios de referencia).

Tabla 4.3. Ventas en Bloque. Parámetros (Ejemplo 2)

\begin{tabular}{|c|c|}
\hline$t_{1}=5 \quad ; \quad t_{2}=10 ; \quad t_{12}=5$ \\
\hline$c_{1}=15 \quad ; \quad c_{2}=20 ; \quad c_{12}=35$ \\
\hline$\left(r a_{1}, r a_{2}\right)=(90,10) \quad ; \quad\left(r b_{1}, r b_{2}\right)=(55,45)$ \\
\hline$\left(r c_{1}, r c_{2}\right)=(40,60) \quad ; \quad\left(r d_{1}, r d_{2}\right)=(10,90)$ \\
\hline
\end{tabular}

Los precios que maximizan el beneficio en los tres escenarios se presentan en la Tabla 4.4. 
Tabla 4.4. Ventas en Bloque. Valores de Equilibrio (Ejemplo 2)

\begin{tabular}{|l|c|c|c|}
\cline { 2 - 4 } \multicolumn{1}{c|}{} & VS & VB & VBM \\
\hline \multirow{2}{*}{ Precios de equilibrio } & $p_{1}^{*}=55$ & & $p_{1}^{* *}=90$ \\
\cline { 2 - 4 } & $p_{2}^{*}=60$ & & $p_{2}^{* *}=90$ \\
\cline { 2 - 4 } & & $p_{12}^{*}=100$ & $p_{12}^{* *}=100$ \\
\hline Beneficio del productor & 130 & 240 & 250 \\
\hline Recaudación (Impuestos Pagados) & 30 & 20 & 25 \\
\hline
\end{tabular}

Los Gráficos 4.3, 4.4 y 4.5 ilustran el ejemplo 2. El Gráfico 4.3 muestra el equilibrio para VS, en cuyo escenario los consumidores b y a consumen sólamente el bien 1, mientras que los consumidores $\mathbf{c}$ y $\mathbf{d}$. consumen sólamente el bien 2. Los consumidores a y d, mantienen un excedente del consumidor.

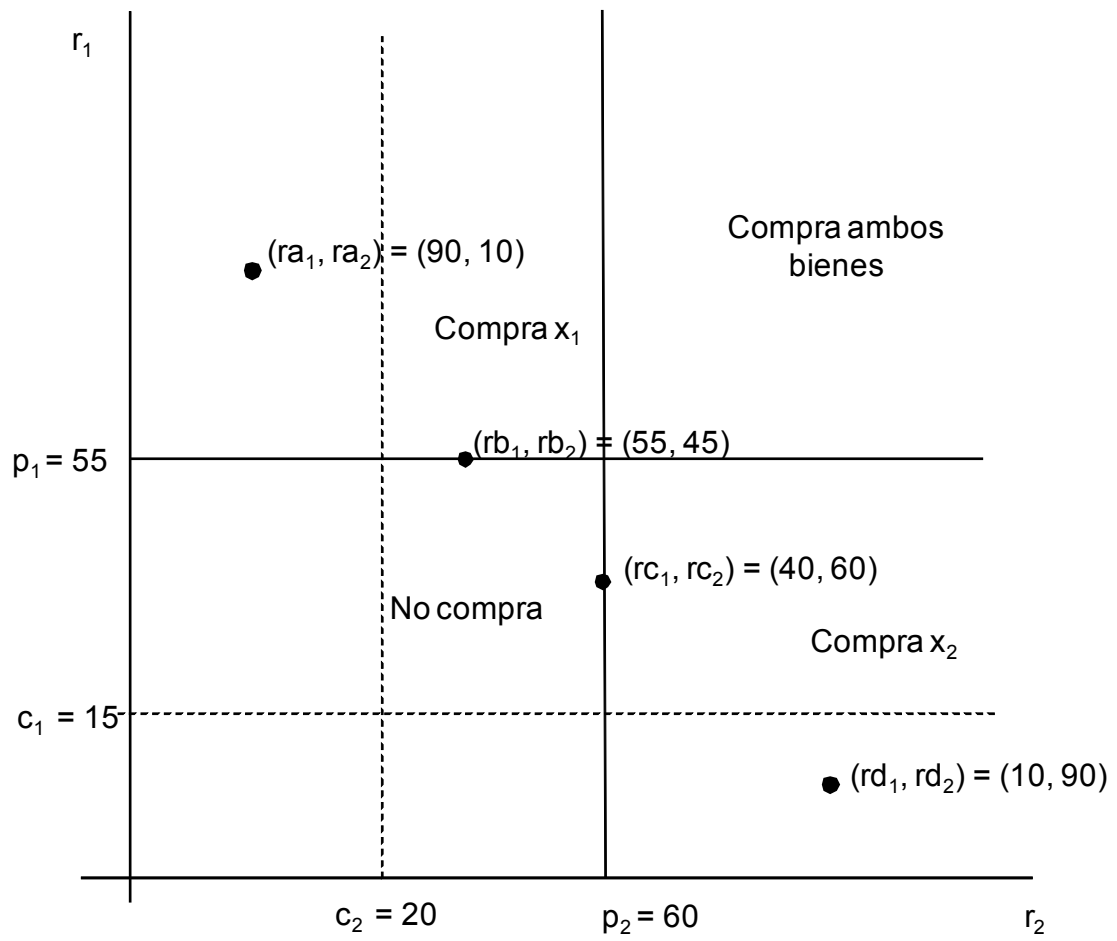

Gráfico 4.3. Venta Separada (Ejemplo 2)

El Gráfico 4.4 muestra el equilibrio con VB. Como se puede observar, en tal caso no se cumple con la condición C2: el consumidor a consume el bien 2 y el consumidor $\mathbf{d}$ el bien 1, 
si bien su precio de reserva es menor al costo de producción. Por este motivo es preferible la VBM, que se ilustra con el Gráfico 4.5. Notar que en este caso la VBM le permite mejorar la apropiación del excedente del consumidor, mientras paga menos impuestos.

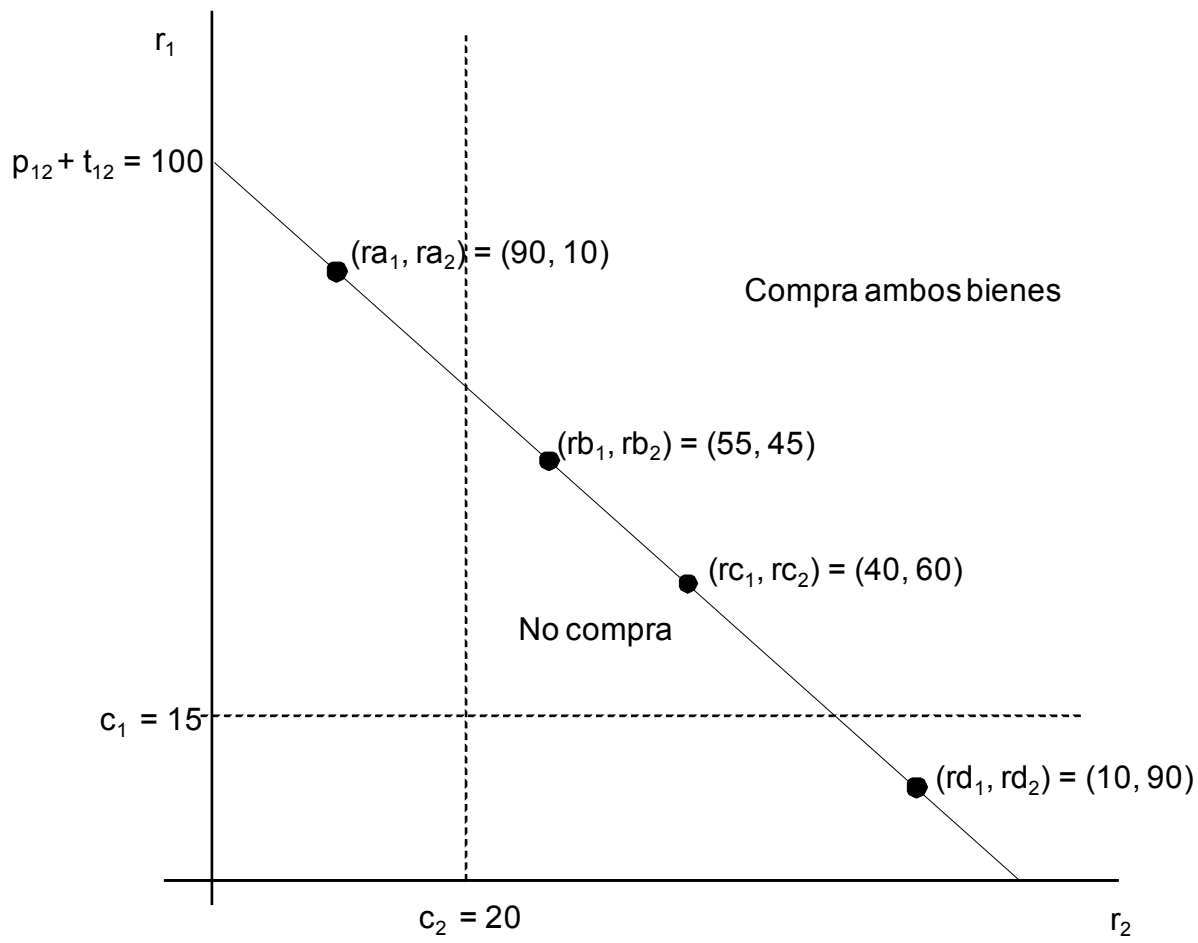

Gráfico 4.4. Venta en Bloque (Ejemplo 2) 


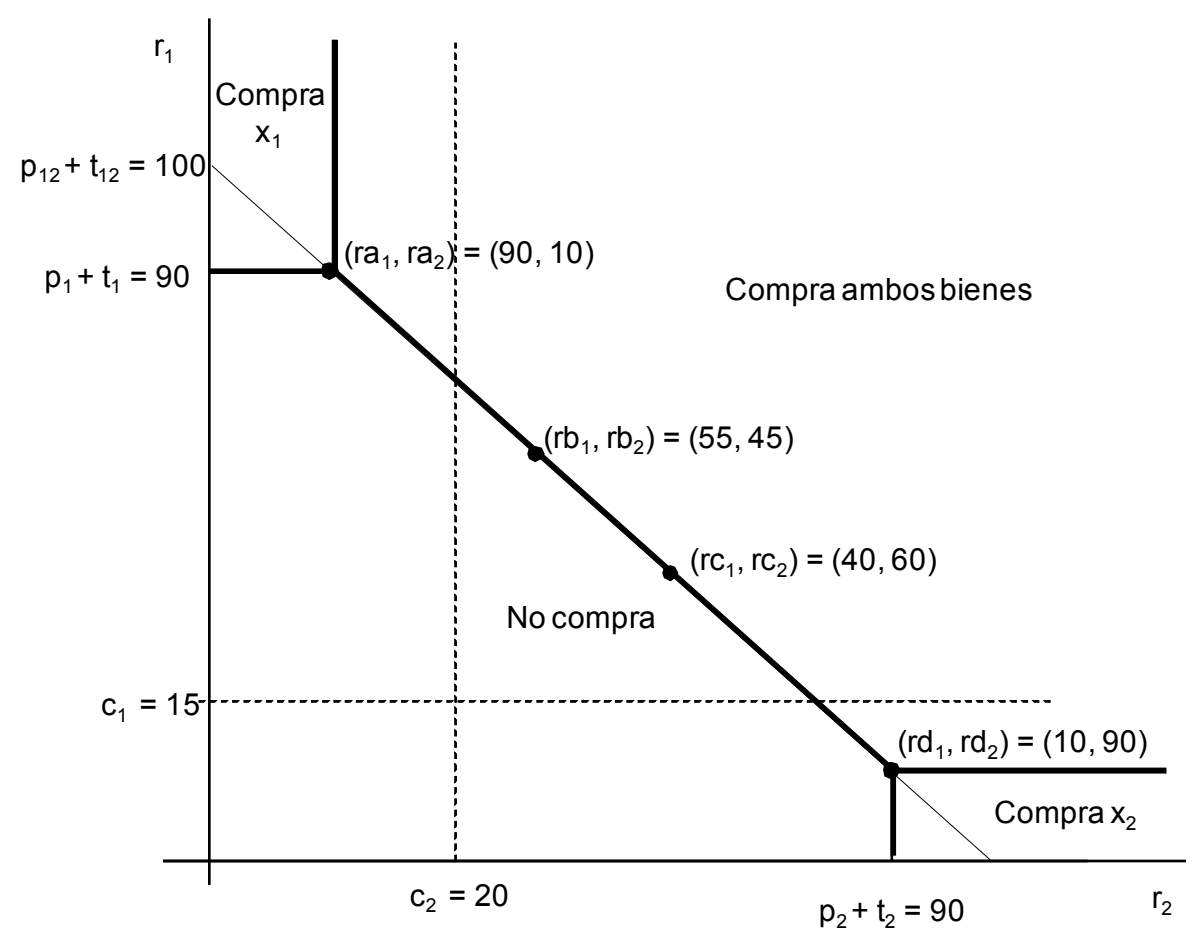

Gráfico 4.5. Venta en Bloque Mixta (Ejemplo 2)

\section{Ejemplo 3. Venta en Bloque "Impositiva"}

En los ejemplos hasta aquí analizados, la venta en bloque es beneficiosa tanto por la distribución de los precios de reserva como por las tasas impositivas. De hecho, con los mismos precios de reserva y costos, pero sin impuestos, el ordenamiento de las tres opciones es exactamente igual. Sin embargo, en el siguiente ejemplo se muestra un caso en el cual si bien en ausencia de impuestos es preferible la venta separada, al considerar los impuestos el monopolista opta por la venta en bloque. Las condiciones son ahora:

Tabla 4.5. Ventas en Bloque Impositiva. Parámetros (Ejemplo 3)

\begin{tabular}{|r|}
\hline$t_{1}=10 ; \quad t_{2}=2 ; \quad t_{12}=2$ \\
\hline$c_{1}=2 ; \quad c_{2}=4 ; \quad c_{12}=6$ \\
\hline$\left(r a_{1}, r a_{2}\right)=(45,45) \quad ; \quad\left(r b_{1}, r b_{2}\right)=(50,50)$ \\
\hline$\left(r c_{1}, r c_{2}\right)=(25,35) \quad ; \quad\left(r d_{1}, r d_{2}\right)=(50,5)$ \\
\hline
\end{tabular}

Las condiciones de equilibrio se presentan en la Tabla 4.6. 
Tabla 4.6. Ventas en Bloque Impositiva. Valores de Equilibrio (Ejemplo 3)

\begin{tabular}{|l|c|c|c|}
\cline { 2 - 4 } \multicolumn{1}{c|}{} & VS & VB & VBM \\
\hline \multirow{2}{*}{ Precios de equilibrio } & $p_{1}^{*}=45$ & & $p_{1}^{* *}=50$ \\
\cline { 2 - 4 } & $p_{2}^{*}=35$ & & $p_{2}^{* *}=50$ \\
\cline { 2 - 4 } & & $p_{12}^{*}=55$ & $p_{12}^{* *}=90$ \\
\hline Beneficio del productor sin impuestos & 222 & 196 & 217 \\
\hline Beneficio del productor con impuestos & 186 & 188 & 202 \\
\hline
\end{tabular}

En este caso, entonces, la política impositiva está promoviendo la venta en bloque. Sin considerar la política impositiva, es óptimo para el monopolista la venta separada (obteniendo un beneficio de 222), pero debido al diferente tratamiento impositivo que tiene la venta en bloque que la venta independiente de cada bien, al considerar los impuestos el productor tiene un mayor beneficio con venta en bloque (202). Si bien la venta en bloque no tiene ventajas por el lado de discriminación de precios, debido a que algunos precios de reserva tienen correlación positiva, la ventaja impositiva compensa la pérdida de beneficio para el monopolista generada por la venta en bloque.

En los Gráficos 4.6, 4.7 y 4.8 se ilustra el ejemplo descripto. En Gráfico 4.6 presenta el equilibrio con VS, el Gráfico 4.7 con VB y el Gráfico 4.8 con VBM. 


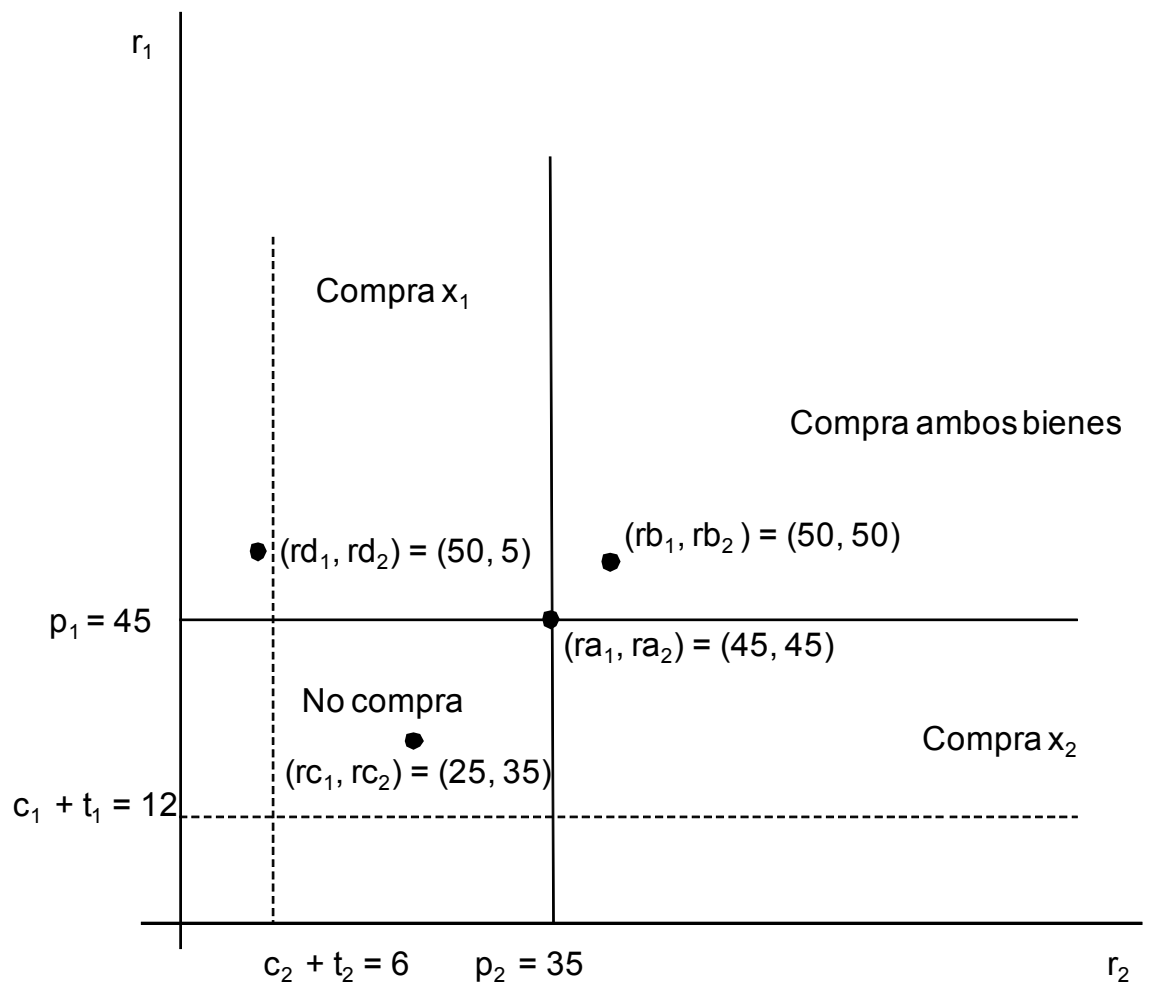

Gráfico 4.6. Venta Separada (Ejemplo 3).

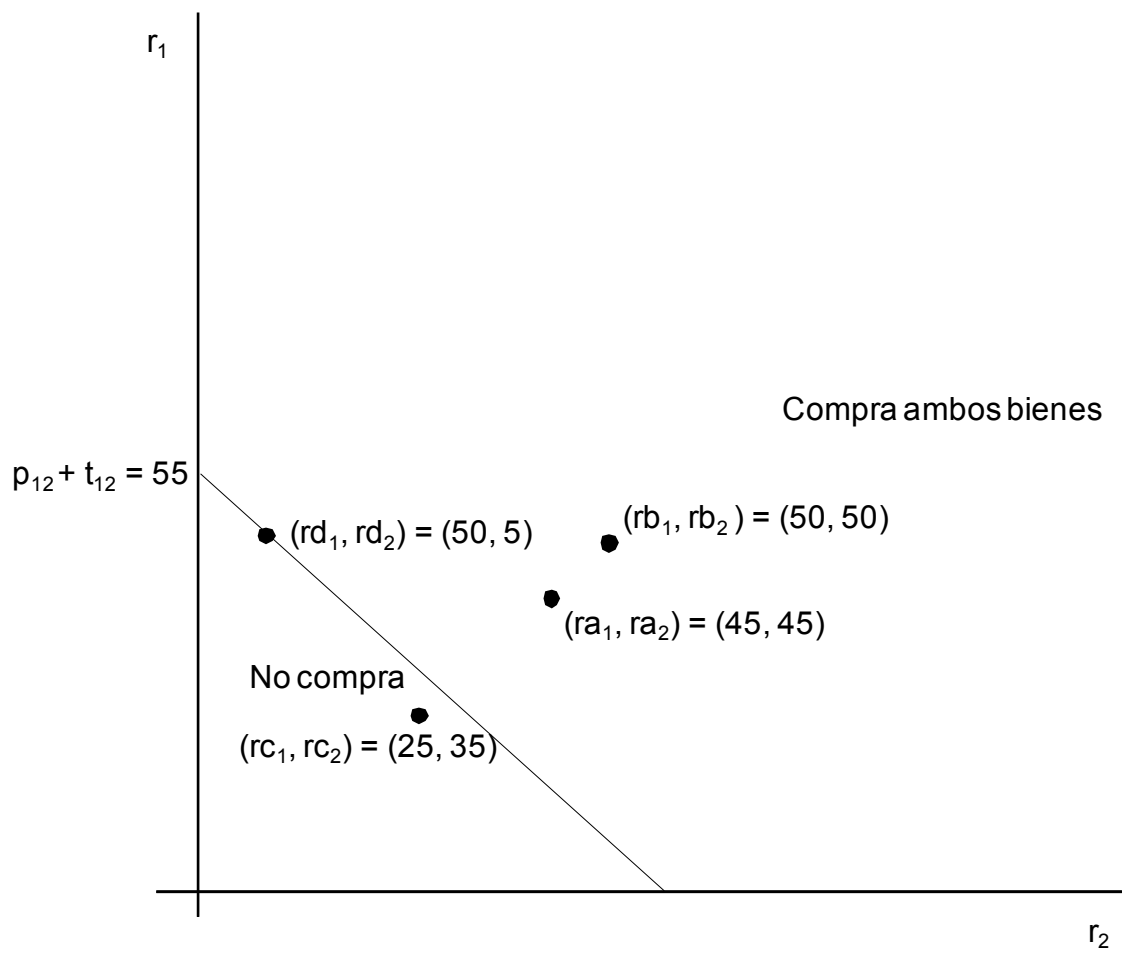

Gráfico 4.7. Venta en Bloque (Ejemplo 3) 


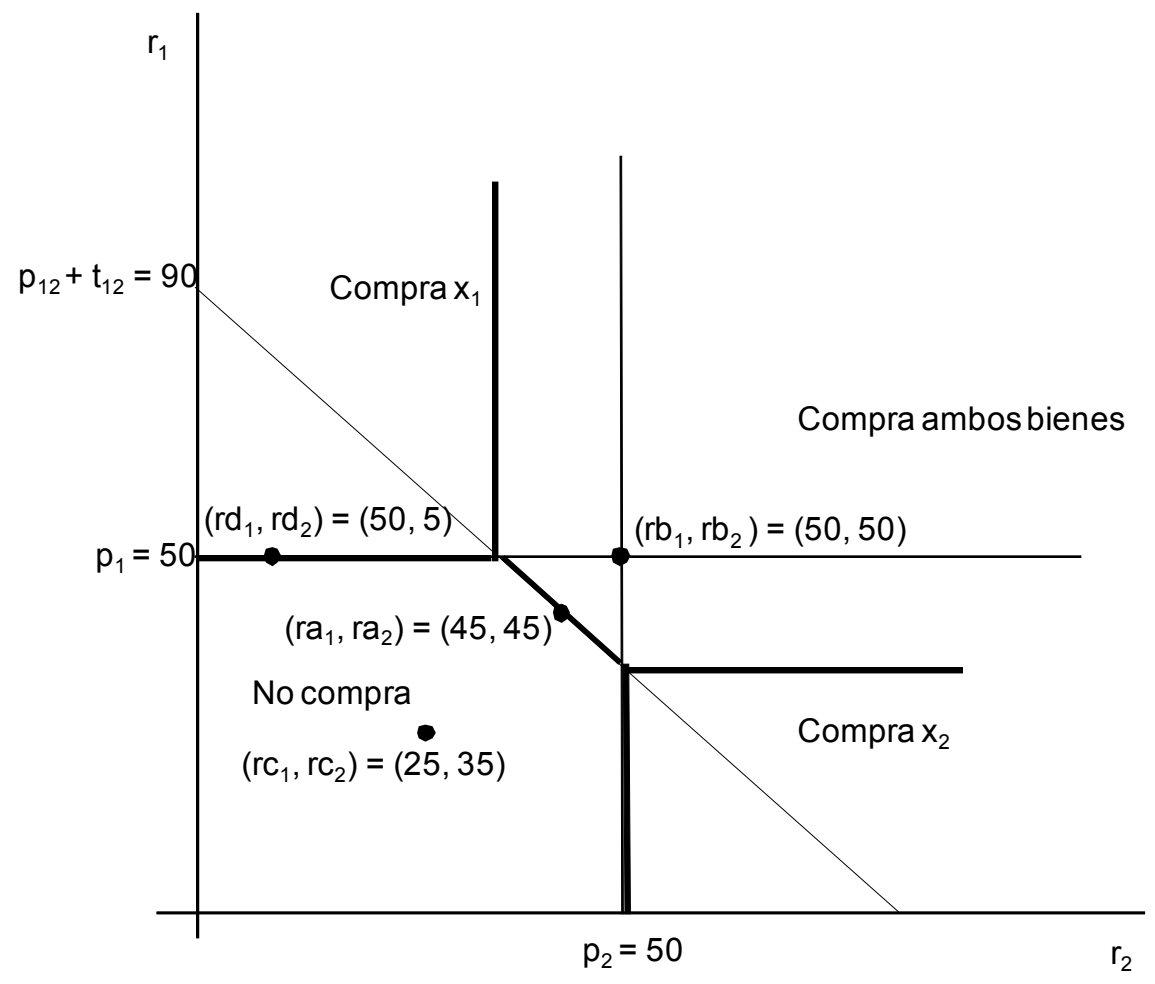

Gráfico 4.8. Venta en Bloque Mixto (Ejemplo 3)

En el caso donde $t_{12}>t_{1}+t_{2}$ tenemos la situación inversa. Cualquier situación en la cual la VB o la VBM sea preferible, puede ser revertida con un $t_{12}$ lo suficientemente alto. ${ }^{20} \mathrm{Si}$ antes de considerar los impuestos la VS era preferida entonces la política tributaria no tendrá ningún efecto.

En conclusión, la política impositiva, siempre que $t_{12}$ sea distinto de $t_{1}+t_{2}$, puede afectar la decisión respecto a si realizar ventas en bloque. A continuación se analizan las consecuencias normativas de esta situación.

\section{c. Análisis normativo}

Adams y Yellen demuestran que la VB puede generar ineficientas respecto a un óptimo de Pareto. Una forma de evaluar estas consecuencias normativas de la decisión del monopolista es mediante el cálculo del bienestar general bajo diversos escenarios, comparando cada uno de

\footnotetext{
${ }^{20}$ En el Ejemplo 1, la VB deja de ser preferida cuando $t_{12} \geqq 28$
} 
ellos con la situación eficiente de competencia perfecta. En los ejemplos hasta aquí presentados, hay tres fuentes de ineficiencia potenciales respecto a un óptimo de Pareto:

1. Monopolio multiproducto con precios uniformes y ventas separadas.

2. Monopolio multiproducto con la posibilidad de vender sus bienes en forma conjunta o separada.

\section{Impuestos.}

Tanto el monopolio como los impuestos generan disminución en el bienestar general. Pero la VB puede aumentar, reducir o dejar sin cambios el bienestar general. La pregunta es si a través de la política impositiva es posible al arbitrar entre las opciones de VB y VS y de ese modo mejorar el bienestar general. Esta situación hipotética sería claramente diferente al caso clásico de monopolio, donde los impuestos pueden mejorar la distribución del excedente del productor pero en ningun caso mejorar el bienestar general.

Para que se de esta situación, el beneficio del monopolista (excedente del productor) en la elección entre VB y VS debería ir en dirección contraria al bienestar general. Esta situación es perfectamente posible, tanto en una dirección como en la otra, tal cual se demuestra a continuación con dos ejemplos lo que se analiza en los siguientes ejemplos.

\section{Ejemplo 4. Política Impositiva Castiga la VS}

En primer lugar, se presenta en la Tabla 4.7. el Ejemplo 4 donde la Venta Separada es preferida por el monopolista, aunque produce pérdidas en el bienestar. Ante tal situación, una política impositiva que castigue la VS mejoraría el bienestar general.

Tabla 4.7. Política Impositiva Castiga VS (Ejemplo 4)

\begin{tabular}{|r|}
\hline$t_{1}=10 \quad ; \quad t_{2}=2 \quad ; \quad t_{12}=2$ \\
\hline$c_{1}=2 ; \quad c_{2}=4 ; \quad c_{12}=6$ \\
\hline$\left(r a_{1}, r a_{2}\right)=(45,45) \quad ; \quad\left(r b_{1}, r b_{2}\right)=(50,50)$ \\
\hline$\left(r c_{1}, r c_{2}\right)=(25,35) \quad ; \quad\left(r d_{1}, r d_{2}\right)=(50,5)$ \\
\hline
\end{tabular}

El ordenamiento de las preferencias antes y después de los impuestos se presentan en la Tabla 4.8 . 
Tabla 4.8. Política Impositiva y Ordenamiento de las Preferencias (Ejemplo 4)

\begin{tabular}{|l|c|c|c|c|c|c|}
\cline { 2 - 8 } \multicolumn{1}{c|}{} & \multicolumn{3}{c|}{ Sin Impuesto } & \multicolumn{3}{c|}{ Con Impuesto } \\
\cline { 2 - 8 } \multicolumn{1}{c|}{} & VS & VB & VBM & VS & VB & VBM \\
\hline Excedente del Consumidor & $\mathbf{1 0}$ & 0 & 30 & 10 & 0 & $\mathbf{3 0}$ \\
\hline Excedente del Productor & $\mathbf{1 5 5}$ & 130 & 150 & 121 & 126 & $\mathbf{1 3 4}$ \\
\hline Recaudación & $\mathbf{0}$ & 0 & 0 & 34 & 4 & $\mathbf{1 6}$ \\
\hline Bienestar General & $\mathbf{1 6 5}$ & 130 & 180 & 165 & 130 & $\mathbf{1 8 0}$ \\
\hline Bienestar General Bajo Competencia Perfecta & $\mathbf{1 9 0}$ & - & - & 180 & - & - \\
\hline Perdida en el bienestar & $\mathbf{2 5}$ & 60 & 10 & 15 & 50 & $\mathbf{0}$ \\
\hline
\end{tabular}

En este ejemplo, mediante la venta en bloque inducida por la política impositiva es posible compensar en forma total la pérdida de bienestar generada por el monopolio. Ante la presencia de los impuestos, el bienestar total bajo monopolio coincide al de competencia perfecta. ${ }^{21}$

\section{Ejemplo 5. Política Impositiva Castiga la VB}

En el Ejemplo 5 se presenta el caso inverso: la VS genera un mayor bienestar general respecto al caso de VB, la cual es preferida por el monopolista (Tabla 4.9). En este caso, una política impositiva que desincentive la VB mejora el bienestar general, tal cual ser observa en la Tabla 4.10.

Tabla 4.9. Política Impositiva Castiga VB (Ejemplo 5)

\begin{tabular}{|r|c|}
\hline$t_{1}=0 \quad ; \quad t_{2}=0 \quad ; \quad t_{12}=20$ \\
\hline$c_{1}=25 \quad ; \quad c_{2}=25 \quad ; \quad c_{12}=50$ \\
\hline$\left(r a_{1}, r a_{2}\right)=(15,45) \quad ; \quad\left(r b_{1}, r b_{2}\right)=(15,45)$ \\
\hline$\left(r c_{1}, r c_{2}\right)=(45,40) \quad ; \quad\left(r d_{1}, r d_{2}\right)=(35,45)$ \\
\hline
\end{tabular}

\footnotetext{
${ }^{21}$ Notar que ante demandas unitarias, en la medida en que no se modifiquen las cantidades vendidas, el monopolio no genera pérdida de eficiencia. En este ejemplo se da tal situación. Después de impuestos, el bienestar general es el mismo bajo competencia que bajo monopolio.
} 
Tabla 4.10. Política Impositiva y Ordenamiento de las Preferencias (Ejemplo 5)

\begin{tabular}{|l|c|c|c|c|}
\cline { 2 - 5 } \multicolumn{1}{c|}{} & \multicolumn{2}{c|}{ Sin Impuesto } & \multicolumn{2}{c|}{ Con Impuesto } \\
\cline { 2 - 5 } \multicolumn{1}{c|}{} & VS & VB & VS & VB \\
\hline Excedente del Consumidor & 25 & 0 & 25 & 5 \\
\hline Excedente del Productor & 80 & $\mathbf{9 5}$ & $\mathbf{8 0}$ & 20 \\
\hline Recaudación & 0 & 0 & 0 & 40 \\
\hline Bienestar General & $\mathbf{1 0 5}$ & 95 & $\mathbf{1 0 5}$ & 65 \\
\hline Bienestar Bajo Competencia Perfecta & 105 & - & 105 & - \\
\hline Perdida en el bienestar & 0 & 10 & 0 & 40 \\
\hline
\end{tabular}

En conclusión, la política impositiva puede servir para alinear los beneficios privados (los del productor) con los beneficios sociales (excedente del productor, excedente del consumidor y recaudación impositiva) en aquellos casos en los cuales los mismos no están alineados.

\section{d. Conclusiones venta en bloque}

Es claro que el comportamiento del monopolista respecto a la venta en bloque puede ser una estrategia exitosa para reducir su carga impositiva en forma legal (elusión fiscal):

1) Bajo el caso $t_{12}=t_{1}+t_{2}$ la política impositiva no agrega ningun elemento adicional a la decisión del monopolista respecto de la venta en bloque.

2) Bajo el caso $t_{12}<t_{1}+t_{2}$, se produce un incentivo a la venta en bloque que puede implicar que la misma sea preferible para el empresario, aún cuando tendría un mayor beneficio con la venta separada sin considerar el impuesto. En éste último caso, la motivación excluyente de la venta en bloque es la elusión de la carga fiscal.

3) Bajo el caso $t_{12}>t_{1}+t_{2}$, podría darse que la VS sea preferida a la VB aún cuando la situación sea la inversa sin considerar la política impositiva.

4) En los ejemplos presentados, cuando la decisión óptima del monopolista no está alineada con el máximo bienestar social, es posible mejorar el mismo a través de la política impositiva. Es más, a través de los impuestos es posible compensar la pérdida de bienestar generada por el monopolio y volver a la situación de competencia perfecta, dada la existencia de impuesto. 


\subsubsection{Disminución de base imponible por reducción de etapas}

Es posible reducir la carga tributaria de determinada operación disminuyendo las etapas de producción y comercialización, en cada una de las cuales se generan hechos imponibles por las características propias del impuesto. Tal disminución se pueden dar a través de dos mecanismos que se analizan a continuación: las ventas en comisión y la integración vertical.

\section{a. Ventas en comisión}

Cuando un impuesto grava las ventas intermedias, las firmas pueden usar esquemas para ligar al comprador con el vendedor y de ese modo pagar un impuesto menor. Desde el punto de vista de la empresa intermediaria, pagará el impuesto únicamente sobre la comisión y no sobre el precio de venta. Sin embargo, si se analiza la operación en su conjunto el ahorro impositivo real es sólo respecto al impuesto sobre la primer venta, menos el impuesto sobre la comisión. En el Gráfico 4.9 se presenta esta situación en la cual hay un proveedor, un intermediario y un comprador.

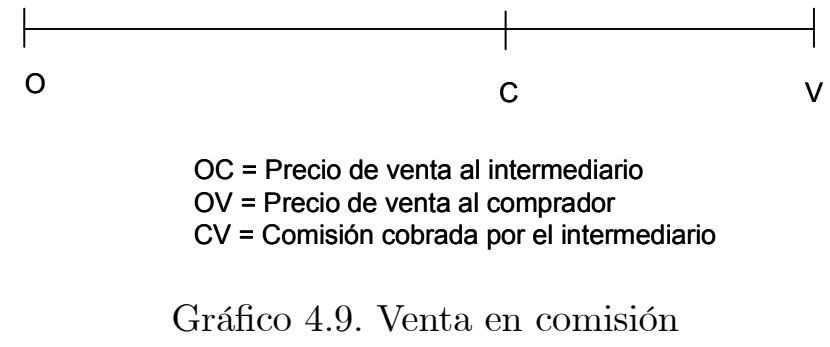

Si la operación se realiza como compra-venta, el proveedor paga el impuesto sobre el precio de venta al intermediario (OC), quien paga el impuesto sobre el precio de venta al comprador (OV). Si, por el contrario, la operación se realiza como consignación, la primera operación de compra venta (entre el proveedor y el intermediario) no existe y se paga de la siguiente forma: el proveedor paga el impuesto sobre el precio de venta al comprador (OV), y el intemediario paga el impuesto sobre la comisión cobrada al proveedor (la diferencia entre el precio de venta al comprador y los ingresos efectivamente percibidos por el proveedor, CV). Suponiendo alícuotas uniformes para cada una de las operaciones (que no es siempre el caso) será beneficioso utilizar 
esta mecánica en la medida en que CV sea menor a OC. Esto es, siempre existirá ahorro si la comisión es inferior al $50 \%$ del precio de venta final del producto.

Reconociendo esta situación, la legislación fija una tasa para los ingresos por comisión significativamente mayor (6\%) que para los ingresos por compra venta (en general, $3 \%$ ). Aún así, existe un incentivo para realizar las operaciones en comisión. Con estas alícuotas, existe ahorro fiscal siempre y cuando la comisión sea menor al $25 \%$ del precio final de venta.

Esta es una operación muy usual en supermercados mayoristas, los cuales a fin de disminuir el efecto cascada venden al comercio minorista "a cuenta y orden" del fabricante. Los mismo sucede con la venta de electrodomésticos, donde el comercio vende a cuenta y orden del importador o del fabricante. ${ }^{22} \mathrm{El}$ hecho de que la venta en comisión no se presente tan seguido en otros sectores puede ser un reflejo de que las comisiones son altas o de que existen otros costos asociados a esta mecánica.

En la Tabla 4.3a del Apéndice B, se presenta el caso de un supermercado mayorista que tiene la opción de compra venta o venta en consignación. Se asume que en ambos casos el precio final es similar, así como la demanda que enfrenta (el consumidor no tiene preferencias respecto a quien le factura la mercadería). La alícuota para las ventas en consignación es el doble que la de compra venta. Siendo el costo de la mercadería un $90 \%$ del precio final, la venta en consignación implica la reducción del impuesto a pagar en un $37 \%$, y el incremento en el beneficio después de impuestos es del $131 \%$ (notar que en este ejemplo, como es usual en la venta mayorista, el margen es pequeño y por lo tanto lo es el beneficio respecto a los ingresos brutos).

\section{b. Integración vertical}

Una de las implicancias del IIBB es que genera una menor carga tributaria para empresas que están integradas verticalmente, ya que las operaciones de compra venta entre empresas están gravadas. La estructura de alícuotas intenta reducir este inventivo a la integración vertical, aplicando alicuotas menores para las actividades de producción y mayores para el comercio minorista. Bajo un entorno competitivo, la integración vertical implica un ahorro fiscal que

\footnotetext{
${ }^{22}$ Dentro de la actividad industrial, una operatoria diferente pero que genera el mismo efecto es la manufactura por mandato de un tercero ("fasón"). En este caso, la materia prima no es propiedad del industrial, por lo cual el destinatario de la mercadería recibe dos facturas, una por la materia prima y la otra por la elaboración.
} 
será directamente proporcional a la participación del costo de los insumos que se producirán en forma propia en el precio final del producto. Si hay monopolio en una de las etapas, pero competencia en el resto, la integración genera el mismo beneficio.

Una situación distinta se da si existe un monopolio en cadena. En estos casos, la integración produce un beneficio per se vinculado con la eliminación del doble margen. Este beneficio se sumará al que se obtenga eludiendo el impuesto sobre los insumos. ${ }^{23}$

A fin de analizar este caso formalmente, en esta sección se presenta el caso más simple de doble monopolio sin impuestos y luego se lo compara con un modelo en presencia de impuestos sobre los insumos y el producto final. De este modo, es posible evaluar el efecto de un impuesto sobre toda la cadena sobre los beneficios de la integración.

i. El modelo sin impuestos. Se aume un doble monopolio con un insumo que se transforma en producto en una relación 1 a 1, con lo cual el esquema se asimila a la relación de un mayorista y un minorista que venden el mismo bien, o a la de un productor y un minorista (en adelante, se utilizan estos términos). El minorista enfrenta una curva inversa de demanda dos veces diferenciable $p(q)$, con $p^{\prime}(q)<0$ y tiene como costo marginal constante $\left(p_{w}\right)$, el precio cobrado por el productor por unidad de insumo. Se asume que el minorista no tiene costo adicional al precio del insumo y que tampoco existe acumulación de stock ni desperdicio, con lo cual todos los bienes comprados por el minorista son vendidos a los consumidores finales. Por lo tanto, la curva de ingreso marginal del minorista es también la función de demanda que enfrenta el productor. El productor debe seleccionar el nivel de $p_{w}$ que maximice su beneficio, dada la función de demanda que enfrenta (que es la curva de ingrso marginal del minorista) y su costo marginal constante $(c)$. Una vez definido el valor de $p_{w}$, el minorista fijará $p$.

La condición de primer orden del minorista, es:

$$
p^{\prime}(q) q+p(q)=p_{w}
$$

\footnotetext{
${ }^{23}$ Este elemento fue advertido por Spengler (1950) en el primer análisis sobre los efectos económicos de la integración bajo monopolio en cadena: "La integración vertical puede ser la respuesta que produce ahorro al consumidor a diversos impuestos transaccionales y a arreglos de precios monopolistas (...). Ya que la integración vertical permite evitar transferencias que, al implicar una modificación en la propiedad, están sujetas a regulación de la transacción (...). En este sentido, la experiencia de economías que han utilizado impuestos sobre el giro del negocio [turnover taxes] son de algún interés" (traducción propia, p. 571). Notar la equivalencia entre impuesto sobre el giro del negocio y el IIBB.
} 
La condición de primer orden del productor es::

$$
p^{\prime \prime}(q) q^{2}+2 p^{\prime}(q) q+p^{\prime}(q) q+p(q)=c
$$

Reemplazando (4.4) en (4.5), la condición del productor queda:

$$
c=p^{\prime \prime}(q) q^{2}+2 p^{\prime}(q) q+p_{w}
$$

De esta última expresión, se deduce que $p_{w}>c$, ya que el cumplimiento de la condición de segundo orden del problema de maximización expresado en (4.4) implica que:

$$
p^{\prime \prime}(q) q^{2}+2 p^{\prime}(q) q<0
$$

Para los valores de equilibrio de $q, p$ y $p_{w}$, el beneficio de toda la cadena (П) -la suma del beneficio del productor $\left(\Pi_{p}\right)$ y del vendedor $\left(\Pi_{v}\right)$ - es igual a:

$$
\Pi=\Pi_{p}+\Pi_{v}=\left(p-p_{w}\right) q+\left(p_{w}-c\right) q=(p-c) q
$$

Si ambos monopolistas deciden integarse y existe por lo tanto un único productor-vendedor, la condición de primer orden será:

$$
p^{\prime}\left(q^{m}\right) q^{m}+p\left(q^{m}\right)=c
$$

Esto implica que $p>p^{m}$, y $q^{m}>q$, dado que $p_{w}>c$. El beneficio del productor-vendedor es:

$$
\Pi^{m}=\left(p^{m}-c\right) q^{m}
$$

Claramente $\Pi^{m}>\Pi$, ya que $\Pi^{m}$ es máximo para la función de demanda y los costos vigentes. Como $p>p^{m}$, también el excedente del consumidor es mayor bajo integración. Los Gráficos 4.10 y 4.11 ilustran los equilibrios no integrados e integrados respectivamente para el caso de función inversa de demanda $\mathrm{p}(\mathrm{q})$, donde IM es el ingreso marginal del minorista, e $\mathrm{IM}_{w}$ es el ingreso marginal del productor. 


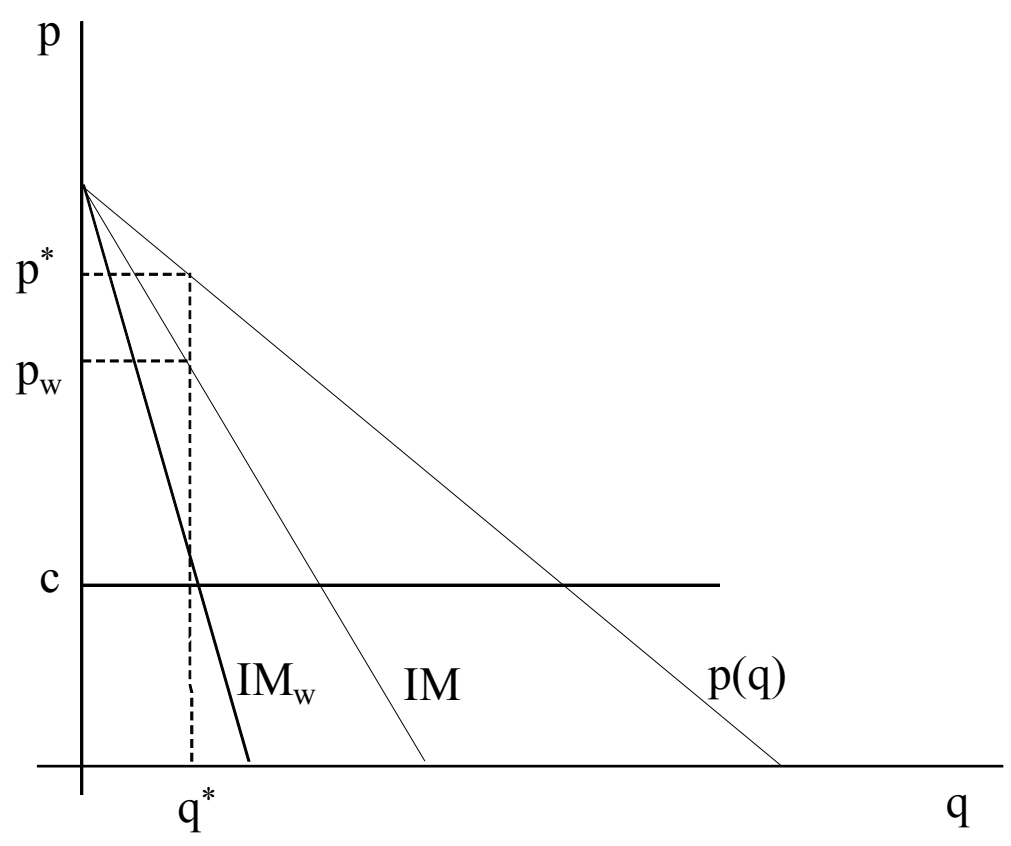

Gráfico 4.10. Monopolio en Cadena

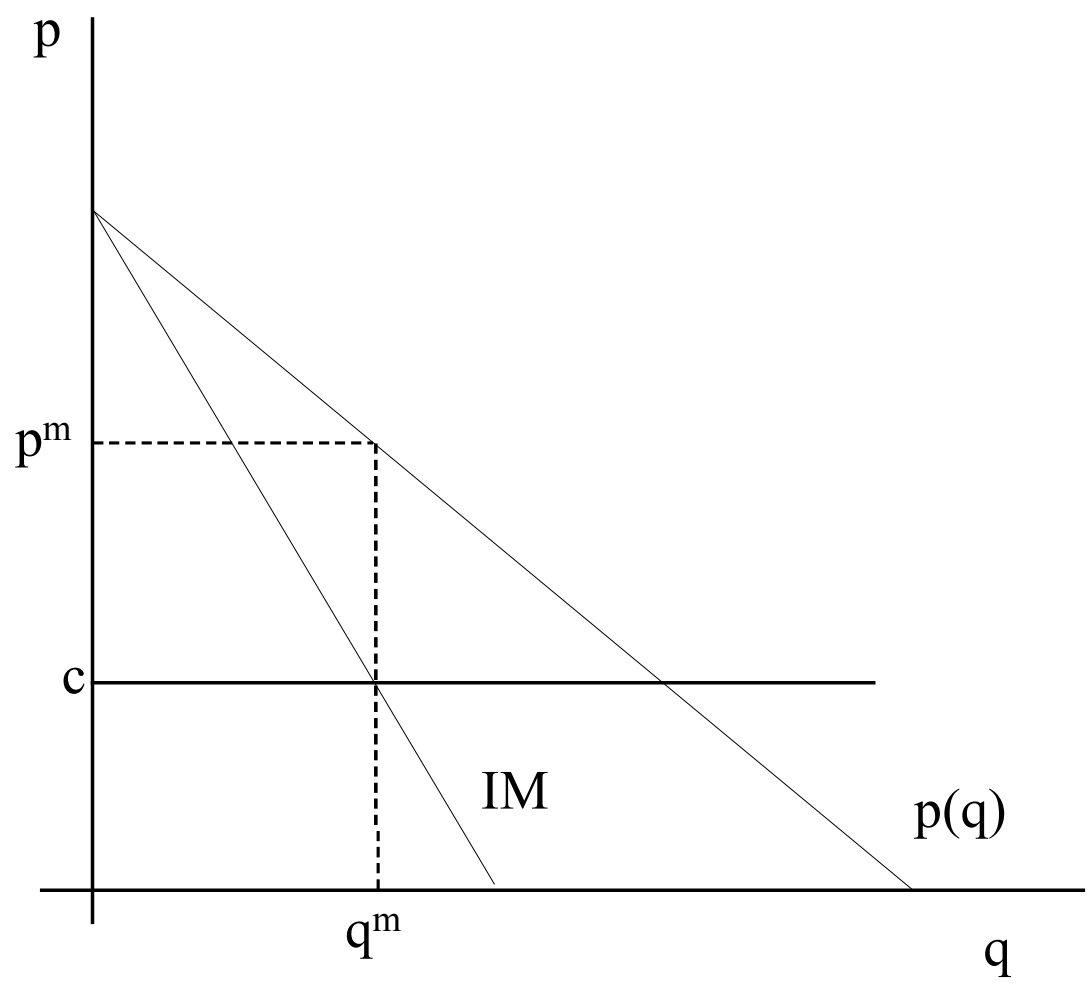

Gráfico 4.11. Integración Vertical 
Las principales conclusiones de este modelo simple son:

1. Cuando existen dos monopolios en cadena el punto de equilibrio implica un nivel de producción menor al que se alcanzaría si actuaran como un único monopolio.

2. El beneficio de toda la cadena (o sea, el beneficio del minorista más el del productor) es menor al que obtendrían como un monopolio integrado.

3. Una fusión entre ambos productores mejoraría el bienestar de los consumidores y aumentaría el beneficio del monopolista. En la literatura sobre organización industrial, el efecto de la integración ante un caso de doble monopolio se lo denomina eliminación del doble margen. $^{24}$

ii. Impuestos sobre toda la cadena. A los efectos de estudiar la incidencia impositiva en este esquema, se incorporan al modelo presentado impuestos ad valorem sobre cada una de las etapas. Sea $t$ el impuesto sobre las ventas minoristas y $t_{w}$ el correspondiente a las ventas mayoristas, donde $0<t<1,0<t_{w}<1$ y $t \neq t_{w}$. Bajo equilibrio descentralizado, el equilibrio del minorista implica:

$$
\left[p^{\prime}(q) q+p(q)\right](1-t)=p_{w}
$$

De la condición de primer orden del productor surge:

$$
\left[p^{\prime \prime}(q) q^{2}+2 p^{\prime}(q) q\right]\left(1-t_{w}\right)+\left[p^{\prime}(q) q+p(q)\right]\left(1-t_{w}\right)=\frac{c}{1-t}
$$

Para los valores de equilibrio de $q, p_{w}$ y $p$, el beneficio toda la cadena será:

$$
\begin{aligned}
\Pi_{p} & =\left(p_{w}-c-p_{w} t_{w}\right) q \\
\Pi_{v} & =\left(p-p_{w}-p t\right) q \\
\Pi & =\Pi_{p}+\Pi_{v}=\left(p-p_{w} t_{w}-c-p t\right) q
\end{aligned}
$$

\footnotetext{
${ }^{24}$ Notar que es posible alcanzar el resultado de integración $\left(p^{m}, q^{m}\right)$ manteniendo una estructura no integrada en la cual el productor aplica una tarifa en dos partes del tipo $T(q)=p_{w} q+A$, donde $p_{w}=c$ y $A=\Pi^{m}$. El minorista maximiza $(p-c) q(p)$ y luego el mayorista puede extraer el beneficio extraordinario haciendo $A=\Pi^{m}=\left(p^{m}-c\right) q^{m}$. Ante esta situación, el minorista pierde el beneficio monopólico, el cual es apropiado en su totalidad por el productor.
} 
Un monopolista integrado sufrirá una carga tributaria menor, ya que no paga ningún impuesto sobre los insumos $\left(t_{w}\right)$. Esto implica un beneficio adicional a eliminación del doble margen. Esto se observa analíticamente notando que la condición de primer orden de un monopolista integrado será:

$$
\begin{aligned}
{\left[p^{\prime}\left(q^{m}\right) q^{m}+p\left(q^{m}\right)\right](1-t) } & =c \\
p^{\prime}\left(q^{m}\right) q^{m}+p\left(q^{m}\right) & =\frac{c}{1-t}
\end{aligned}
$$

Comparando las ecuaciones (4.6) y (4.8) puede notarse que, independientemente de los valores de $t$ y $t_{w}, p>p^{m}$ y $q^{m}>q$. En este caso, el beneficio es:

$$
\Pi^{m}=\left(p^{m}-c-p^{m} t\right) q^{m}
$$

Comparando (4.7) con (4.9) surge que el beneficio de un monopolista integrado es mayor al correspondiente al equilibrio no integrado por dos motivos. Por un lado, en la expresión del equilibrio no integrado aparece una pérdida adicional correspondiente a la carga impositiva sobre los insumos $\left(p_{w} t_{w} q\right)$, que se elimina solo si $t_{w}=0$. Debe notarse que el beneficio de la integración dependerá no solo del valor de $t_{w}$ sino también de $p_{w}$. Mientras más se acerque $p_{w}$ a $p$ el beneficio de la integración será mayor. Por otro lado, la integración implica la eliminación del doble margen y por lo tanto un mayor nivel de producción. El excedente del consumidor también será mayor (ya que $p>p^{m}$ ). En lo Gráficos 4.12 y 4.13 se presenta el equilibrio no integrado e integrado. ${ }^{25}$

\footnotetext{
${ }^{25}$ El nivel de producción bajo integración se alcanzará, sin necesidad de integrarse, si el productor fija como esquema de precios a: $T(q)=p_{w} q+A$. Donde $p_{w}=c\left(1+t_{w}\right)$, y $A=\Pi^{f}$. El minorista maximizará $\left(p-c-c t_{w}-p t\right) q$, con lo cual el precio y cantidad de equilibrio es igual a $\left(p^{f}\right.$ y $\left.q^{f}\right)$. Luego, el mayorista le puede extraer el beneficio extraordinario haciendo $A=\Pi^{f}=\left(p^{f}-c-c t_{w}-p^{f} t\right) q^{f}$. Notar que el beneficio del productor en este caso será $\Pi^{f}=\left(p^{f}-c-c t_{w}-p^{f} t\right) q^{f}$. Como es fácil ver $\Pi^{f}=\Pi^{m}$ si y solo si $t_{w}=0$. Por otro lado, está claro que $\Pi^{m}>\Pi^{f}>\Pi^{p}$. El productor se ve beneficiado con este esquema de precios en dos partes sobre los insumos, aunque no tiene el mismo nivel de beneficio que tuviese bajo integración (como es en el modelo básico sin impuestos).
} 


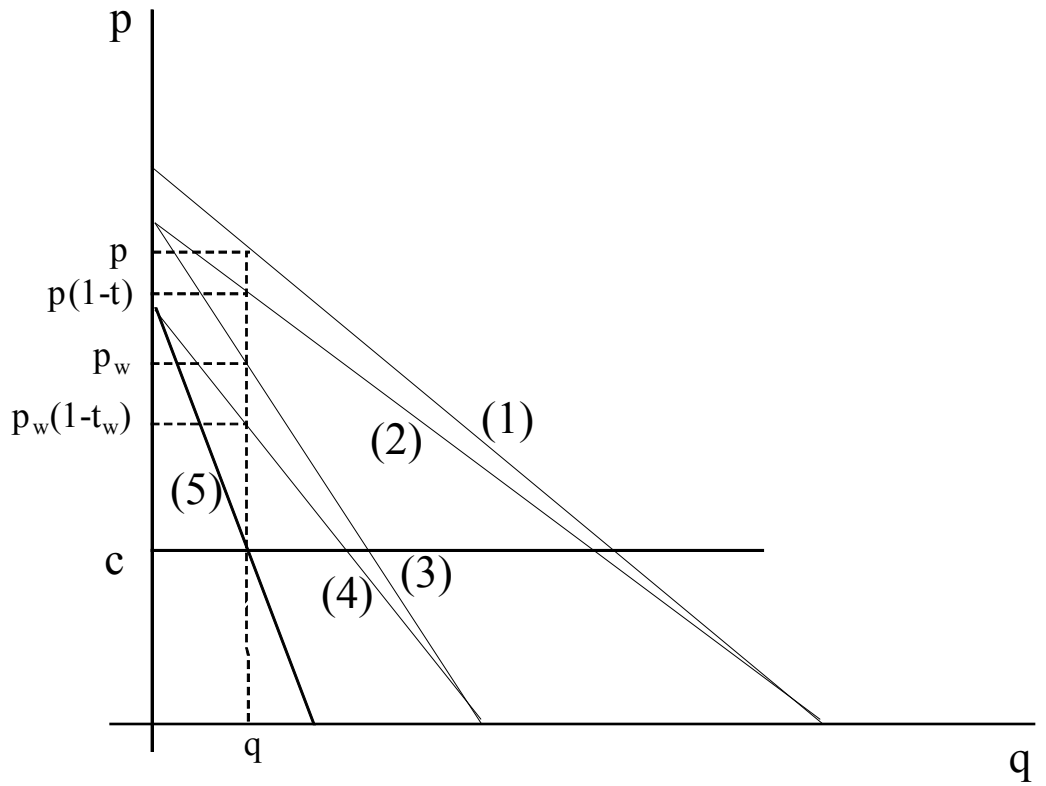

Gráfico 4.12. Monopolio en cadena

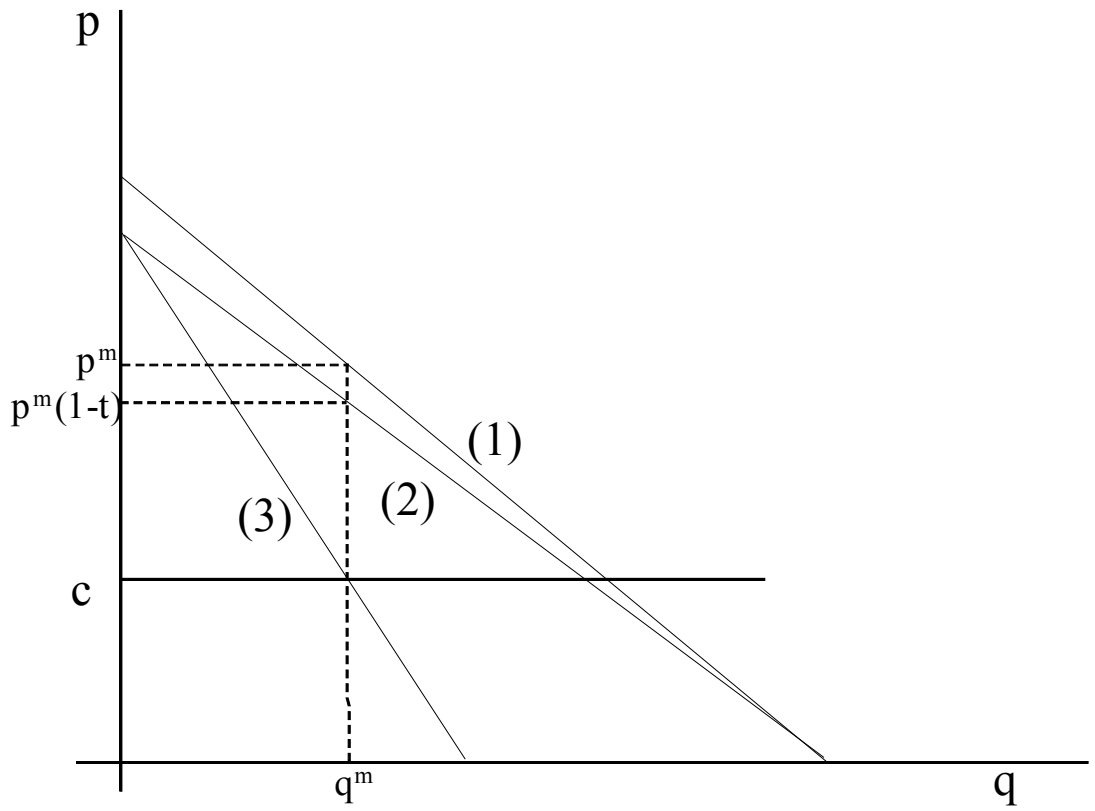

Gráfico 4.13. Monopolio Integrado

Donde las líneas numeradas representan lo siguiente:

(1): Curvas inversa de demanda $p(q)$

(2): Curvas inversa de demanda después del impuesto sobre el bien final $p(q)(1-t)$

(3): Ingreso marginal del minorista/Ingreso marginal del monopolio integrado: $I M(q)$ 
(4): Curva inversa de demanda del mayorista después del impuesto sobre el insumo:

$$
\operatorname{IM}(q)\left(1-t_{w}\right)
$$

(5): Ingreso marginal del mayorista $I M_{w}(q)$.

En los gráficos se observa claramente que las cantidades del monopolio integrado son mayores a las correspondientes a un equilibrio no integrado.

\subsubsection{Transferencia de base imponible a contribuyentes menos gravados}

Las exenciones subjetivas implican un tratamiento impositivo distinto a la misma actividad en función de las características del contribuyente. Los contribuyentes exentos pueden realizar actividades a título oneroso sin pagar el impuesto, y tales actividades estarían gravadas en otro caso. A continuación se describen tres casos típicos.

\section{Caso 1. Televisión Abierta y Producción de Espectáculos}

Todas las actividades realizadas por los canales de TV abierta no están alcanzadas por el IIBB, por más que no sea una actividad vinculada con la TV (como ser un espectáculo teatral), ya que el sujeto está exento. Si cierta productora decide realizar un espectáculo teatral, podría convertir esos ingresos en comisiones o entradas pagadas a un canal de TV (por ejemplo, por intercambio de publicidad) y de ese modo tal espectáculo resultará exento de IIBB (los espectáculos artísticos pagan una tasa del $12 \%$, que es la más alta de la Ley Impositiva).

\section{Caso 2. Asociaciones Civiles y División de la Base Imponible}

Las Asociaciones Civiles, Mutuales y Fundaciones no pagan IIBB por actividades vinculadas a su objeto social. Tampoco pagan cuando realizan actividades comerciales o industriales, siempre y cuando los ingresos anuales no superen los 180.000 pesos anuales. Sobre el excedente, pagarán la misma alícuota que una sociedad comercial. Esta modalidad de imposición genera alícuotas marginales crecientes respecto del total de la base imponible. ${ }^{26}$ Esto implica que los esfuerzos para dividir la base imponible (práctica denominada en la jerga contable "enanismo

\footnotetext{
${ }^{26}$ Este es un caso exactamente similar al del impuesto Hall y Rabushka, que implicaba una alícuota fija del $19 \%$ por los ingresos que superen los 9.500 dolares anuales. Ver Calegari (1998) acerca de las posibilidades de elusión de ese impuesto.
} 
fiscal") generan un beneficio impositivo. Una Asociación Civil que realiza una actividad comercial, una vez superados los $\$ 180.000$ anuales, puede crear una segunda Asociación Civil gemela, funcionar en el mismo establecimiento comercial y así alcanzar una exención por $\$ 360.000$ anuales. Si bien crear y operar una Asociación Civil gemela tendrá algún costo, el incentivo es directo y permite ahorrar el $100 \%$ del impuesto, ya que no hay límite a la mecánica. El ahorro neto será la totalidad del impuesto menos el costo de operar las asociaciones civiles paralelas.

\section{Caso 3. Asociaciones Civiles y Actividades de Bien Público}

Otro incentivo generado por la exención subjetiva de las Asociaciones Civiles y Fundaciones, es el de orientar los ingresos de determinadas actividades comerciales a través de fundaciones. El caso más usual se presenta en el área de servicios de salud, donde clínicas y sanatorios privados pagan IIBB, aunque si sus ingresos son canalizados a través de una Fundación están exentos. En este caso, no se aplica el límite de $\$ 180.000$ anuales ya que la provisión de servicios de salud no se considera una actividad comercial, sino ingresos vinculados con el objeto de bien público de la Fundación. El único problema de este mecanismo es que impide la distribución de beneficios, al menos respecto a la porción de ingresos que se traslada a la Fundación, aunque tal dificultad no sería mayor para el caso de empresas con margen pequeño.

En la Tabla 4.4a del Apéndice B se presenta un ejemplo de un clínica privada que puede transferir hasta el $90 \%$ de sus ingresos a una Fundación. Se asume que tal maniobra no modifica

la demanda ni los precios finales y que la operatoria comercial a través de la Fundación tiene sólamente un costo fijo (el costo variable como porcentaje de la facturación es el mismo que tendría la Clínica). El uso de la Fundación le permite reducir la carga tributaria en un $90 \%$ (o sea, exactamente en la proporción que se trasladan ingresos a la Fundación) mientras que el beneficio crece en un $135 \%$. Como los beneficios son menores a la diferencia entre ingresos y costos de la Clínica Privada, aun después de haber realizado la transferencia de ingresos, éstos pueden ser distribuidos.

\subsubsection{Transferencia de base imponible a regiones con menores tasas}

Las normas del Convenio Multilateral implican varias alternativas de elusión para las empresas. Las alícuotas son diversas y algunas actividades están exentas en una jurisdicción y gravadas en otras (por ejemplo los servicios profesionales). Además, el tratamiento de los gas- 
tos implica modificar la carga tributaria sin mover la actividad desde el punto de vista de los ingresos (precios, sucursales, clientela). A continuación se describen tres alternativas al respecto.

\section{a. Realizar gastos en jurisdicciones de menor carga fiscal}

Si el gasto se realiza en una jurisdicción con menor carga, el coeficiente de distribución de la base imponible estará sesgado hacia esa jurisdicción y por lo tanto el contribuyente pagará una alícuota promedio menor. Es decir, que sin modificar los puntos de venta, la empresa puede modificar su carga impositiva mudando los centros de costos de la empresa (por ejemplo, la sede administrativa). Esta modalidad puede ser igualmente beneficiosa para grandes o pequeños contribuyentes. En el Apéndice B se desarrollan dos casos que ilustran esta modalidad, los cuales se describen a continuación.

\section{Caso 1. Hipermercado Nacional.}

En la Tabla 4.5a del Apéndice B se presenta el caso de un hipermercado nacional cuya actividad está gravada en el Provincia con una alícuota del $4 \%$, la cual es superior a la del resto de las jurisdicciones. Se asume que tiene gastos computables que representan el $20 \%$ del total de sus ingresos (recordar que no se pueden computar el costo de la mercaderías pero sí los salarios y demás costos asociados a la operación del comercio). De este total se asume que el $50 \%$ está asociado a la localización (sueldo de empleados de la sucursal), mientras que la otra mitad no lo está (gastos de sede central y publicidad nacional), con lo cual la empresa tiene la posibilidad de mover tales centros de costos hacia jurisdicciones de menor carga fiscal. Se comparan dos situaciones. En el corto plazo, la empresa tiene el $80 \%$ de los gastos en la jurisdicción con mayor venta (la Provincia de Buenos Aires). En el largo plazo la relación es inversa, el $80 \%$ de los costos no asociados a la localización han sido mudados a una jurisdicción de menor carga fiscal. Si bien la diferencia impositiva no es muy grande (se asumen tasas de $4 \%$ para la Provincia de Buenos Aires y $3 \%$ para el resto), la maniobra le permite al hipermercado reducir en un $4 \%$ el costo impositivo y un aumento del $2,4 \%$ en los beneficios después de impuestos. Si bien no parece un porcentaje alto, la escala de la actividad de un hipermercado permite un ahorro fiscal significativo. ${ }^{27}$

\footnotetext{
${ }^{27}$ Los principales hipermercados en la Argentina tienen ventas que superan los $\$ 2000$ millones al año, con lo cual el ahorro del $4 \%$ de la carga impositiva puede representar mas de $\$ 3$ millones al año.
} 


\section{Caso 2. Profesional Independiente.}

En la Tabla 4.6a del Apéndice B se desarrolla otro ejemplo referido a un contribuyente individual: un profesional independiente cuya actividad está gravada en la Provincia pero exenta en la Ciudad Autónoma. Si bien tiene clientes tanto en la Provincia como en la Ciudad, en el corto plazo tiene su oficina en la Provincia (donde están radicados la mayor parte de sus clientes). Modificar su domicilio comercial, en este caso, implicaría una reducción de su carga fiscal en casi un $50 \%$ por el hecho de que, aun sin modificar la localización de sus ingresos (la Provincia de Buenos Aires), ahora sus gastos radican en una jurisdicción en la cual su actividad está exenta.

\section{b. Activos intangibles}

El impuesto a pagar por ingresos generados por activos intangibles variará según la localización del activo. En algunas situciones, la localización del activo es indiferente desde el punto de vista comercial. Por lo tanto, tal decisión será llevada a cabo puramente por motivos fiscales. Se localizará el activo en aquella jurisdicción donde la carga fiscal es menor.

\section{c. Importación de servicios}

La importación de servicios implica la posibilidad de eludir el Impuesto sobre los Ingresos Brutos. ${ }^{28}$ En particular, las empresas tendrán un beneficio al consumir servicios brindados a distancia por parte de prestadores radicados en jurisdicciones con menor carga fiscal. Un caso muy significativo debido a la cantidad de contribuyentes involucrados es el de los servicios profesionales. Tales servicios, que en muchos casos implica el desarrollo de actividades a distancia, están exentos en la Ciudad Autónoma de Buenos Aires pero gravados en la Provincia de Buenos Aires. Claramente, los contribuyentes de la Provincia de Buenos Aires encontrarán conveniente contratar servicios a profesionales radicados en la Ciudad Buenos Aires. De este modo, estarán eludiendo el Impuesto sobre los Ingresos Brutos que, en caso contrario, sería adicionado a la facturación del profesional.

\footnotetext{
${ }^{28}$ Situación similar a la señalada por varios autores respecto a un posible impuesto federal a las ventas en EE.UU. Por ejemplo, ver Murray (1997).
} 


\subsubsection{Comentario final sobre las posibilidades de elusión}

La alternativa de elusión mencionada por Stiglitz (1986) consistente en posponer el hecho imponible para el caso del IBB no tiene relevancia ya que tal impuesto actúa en base a lo devengado y no lo percibido. Las alternativas aquí descriptas respecto a la transferencia de ingresos entre contribuyentes y entre fuentes de ingreso son asimilables a los casos 2 y 3 de Stiglitz. Ambas formas de elusión desaparecerán con una sola alícuota y con la eliminación de las exenciones subjetivas. La alternativa respecto a la transferencia de ingreso entre jurisdicciones presenta una situación no alcanzada por el análisis de Stiglitz, ya que es propia de un impuesto subnacional. Este caso desaparecería con alícuotas uniformes entre jurisdicciones, aunque esto requiere una decisión acordada entre los fiscos difícil de llevar a cabo.

La alícuota única es muy cuestionada en los impuestos directos ya que los mismos intentan dar progresividad al sistema impositivo, lo que implica diversidad de alícuotas según el tamaño del cotnribuyente. En el caso de un impuesto indirecto, como IIBB, no es tan clara tal dificulad de la alícuota única. Por otro lado, en el caso del IIBB la aplicación de una alícuota única incrementaría el incentivo a la elusión fiscal mediante la integración vertical. Esto genera, claramente, un desafío a la hora de diseñar la estructura de alícuotas de impuesto de este tipo. ${ }^{29}$

Stiglitz también demuestra que el diseño del impuesto sobre los ingresos personales permitiría eludir el $100 \%$ de la carga impositiva. Sin embargo, la evidencia señala que este impuesto es pagado por gran parte de los contribuyentes y esto implica evaluar cuales son los supuestos del análisis que no se presentan. Aplicando un razonamiento similar al IIBB, y sobre la base de evidencia circunstancial, aparece como pregunta relevante el análisis de las razones por las cuales las alternativas de elusión aquí descriptas no son explotadas con la intensidad que su beneficio económico indica. En el caso analizado por Stiglitz esta contradicción se explicaría, según el autor, por la ausencia de mercados de capitales competitivos e información perfecta.

Sin embargo, en el caso del IIBB, al ser éste aplicado a los ingresos devengados y no a lo percibidos, tales supuestos no son tan relevantes. De este modo, se debe buscar otra explicación a la contradicción señalada. Si bien esta es una cuestión claramente empírica, lo cual excede los alcances de este capítulo, un elemento a tener en cuesta es la concurrencia de bases imponibles

\footnotetext{
${ }^{29}$ Esta dificultad está ausente en el Impuesto al Valor Agragado, el cual permite aplicar alícuotas únicas sin distorsionar las etapas de producción y comercialización.
} 
con otros fiscos provinciales y con el fisco nacional, tema que se analiza a continuación.

\subsubsection{Concurrencia de Base Imponible}

En la Argentina, como en la mayoría de los países con una organización federal, tanto la Nación como las Provincias tienen competencias tributarias originadas en la Constitución Nacional y de hecho hay pocas limitaciones a la concurrencia de base imponible (esto es impuestos nacionales y provinciales que gravan las mismas actividades). El análisis económico tiene que considerar esta situación, ya que las decisiones del empresario serán tomadas en función de todos los impuestos que afectan a su actividad, sean nacionales o provinciales. Esto genera externalidades entre los diversos niveles de gobierno, ya que modificaciones en una herramienta de política para combatir la evasión fiscal en un nivel afectarán el cumplimiento tributario en ambos niveles. Una cuestión relevante en este contexto es el grado de coordinación entre los fiscos. ${ }^{30}$

Esta situación estará presente en el caso del IIBB si las decisiones del empresario vinculadas a la elusión del impuesto tiene efectos es la carga tributaria de impuestos nacionales. En Argentina, las empresas deben pagar los siguientes impuestos nacionales: ${ }^{31}$

1. Impuestos sobre los ingresos, beneficios y ganancias de capital

2. Impuestos sobre bienes y servicios

2.1. Impuesto al Valor Agregado (IVA)

\subsection{Impuestos Internos}

3. Aportes y contribuciones a la seguridad social

4. Impuestos sobre la propiedad

5. Impuestos sobre el comercio y las transacciones internacionales

El comercio y las transacciones internacionales no están gravadas por el Impuesto sobre los Ingresos Brutos. La propiedad es claramente otra base imponible muy distinta y los aportes y contribuciones a la seguridad social, si bien actúan sobre los costos de las empresas constituyen una base imponible sustancialmente distinta a los ingresos brutos. Por último, los impuestos internos afectan a sectores particulares y tienen en general objetivos de política diferentes a los

\footnotetext{
${ }^{30}$ El tema es tratado en extenso en Esteller-Moré (2004).

${ }^{31}$ Ministerio de Economía (2005).
} 
puramente fiscales (como puede ser el medio ambiente).

Por lo tanto, sólo el IVA y el Impuesto sobre los ingresos, beneficios y ganancias de capital tienen una base imponible vinculada a la base imponible del IIBB.

Cuando se analiza el cumplimiento tributario de estos impuestos respecto al IIBB la principal diferencia radica en que aquellos permiten deducciones, sea a nivel de costos (Ganancias) como de crédito fiscal (IVA). Entonces, las decisiones del cumplimiento tributario afectan tanto a las decisiones de insumos como a las de producción. Esto es, las empresas pueden decidir subdeclarar ventas, pero también sobredeclarar compras. ${ }^{32}$ En el caso del IIBB, sobredeclarar compras no tiene ningun impacto, y las decisiones que impactan sobre el cumplimiento son exclusivamente las que afectan el nivel de ingresos declarado. ${ }^{33,34}$ El IVA y Ganancias no tienen tasas únicas y muchos sectores están exentos, tanto en forma subjetiva como objetiva. Esto implica posibilidades de elusión similares a las del IIBB.

A continuación, se analiza el impacto en el IVA y en Ganancias de los cuatro comportamientos identificados en la sección anterior que permiten eludir el IIBB.

Respecto de la transferencia de ingresos, muchas de las actividades exentas de IIBB también lo están en IVA. El ejemplo de revistas vendidas en forma conjunta con un CD-Rom es uno de los casos, ya que los diarios y revistas están exentos de IVA, al igual que en IIBB. Por otro lado, IVA no tiene tantas tasas diferenciales como en IIBB, con lo cual aparecen una importante cantidad de opciones que tiene el empresario para eludir IIBB sin afectar sus declaraciones juradas de los impuestos nacionales.

La elusión mediante la disminución en las etapas de producción y comercialización es una práctica exclusiva del Impuesto a los Ingresos Brutos por sus propias características. Las operaciones a cuenta y orden o en consignación no generan beneficio respecto del IVA o del Impuesto a las Ganancias.

\footnotetext{
${ }^{32}$ Por supuesto, que las compras de unos son ventas de otros: este control cruzado es el secreto del IVA que lo hace tan popular en el diseño de sistemas impositivos, tanto en países en desarrollo como en países desarrollados.

${ }^{33}$ Una excepción es el tratamiento de los gastos para la distribución de base imponible entre jurisdicciones. En este caso, sin embargo, no es relevante el nivel de los gastos, sino la localización de los mismos.

${ }^{34}$ Notar que en el IIBB las tasas van creciendo en la cadena de producción y comercialización, mientras que el IVA, si bien tiene una tasa más uniforme, impacta en forma más importante al inicio de la cadena donde el valor agregado es mayor. Es decir, el impacto del IVA es inverso al de IIBB. Esto implica cierta divergencia en el interés fiscal que podría comprometer el grado de coordinación necesaria para maximizar el impacto de las acciones de fiscalización.
} 
La transferencia de ingresos a contribuyentes menos gravados surge como posibilidad de elusión, en general, por las exensiones subjetivas. En muchos casos, tales exenciones son similares para IVA, Ganancias e IIBB, motivo por el cual la mecánicas desciptas al respecto tendrán un efecto relevante en los impuestos nacionales.

$\mathrm{Al}$ ser impuestos nacionales que tienen exactamente el mismo tratamiento en todas las jurisdicciones, la transferencia de ingresos entre jurisdicciones no afecta la base imponible de los impuestos nacionales. ${ }^{35}$

Debido a que las tasas impositivas son, en general, mucho más altas en IVA que en IIBB, sería razonable pensar que las decisiones de elusión del IVA dominarán a las que se tomen respecto del IIBB, en la medida en que el tratamiento sea simétrico.

\subsection{Comentarios finales}

Si bien la elusión es una práctiva no oculta, como lo es la evasión, su estudio resulta complejo. La principal dificultad del análisis radica en que, si bien se pueden observar conductas que claramente tienen un beneficio impositivo, las mismas también pueden otros beneficios, de tipo comercial o productivo. En consecuencia, para poder verificar la existencia de la elusión fiscal y el alcance de la misma, es necesario discriminar la motivación de la empresa.

Si bien aquí no se realiza tal análisis empírico, la descripción del impuesto y el análisis de las posibilidades de elusión realizadas en este documento permiten alcanzar, con las precauciones del caso, algunas conclusiones interesantes.

El propio funcionamiento del impuesto y sus consecuencias económicas genera un incentivo a la integración vertical. Tal incentivo, en un escenario con poder de mercado en más de una etapa, se agrega a los beneficios de la integración vertical ante tales mercados, debido a la eliminación del doble margen. La magnitud del incentivo dependerá de la tasa impositiva que se aplique sobre los insumos, de la participación del costo de los insumos gravados en el precio final (a mayor valor agregado, menor el incentivo) y de los costos directos de la integración. Como alternativa intermedia entre la integración y el pago en cascada del impuesto, aparece la

\footnotetext{
${ }^{35}$ Una excepción a esta regla son las excenciones de impuestos nacionales para determinadas regiones. Por ejemplo, las leyes de promoción industrial que permiten a empresas nacionales eludir parcialmente IVA y Ganancias mediante la producción en determinadas regiones.
} 
posibilidad de realizar operaciones a comisión, y no de compra venta, si bien tal situación puede darse para actividades puramente comerciales, y no productivas o de servicios. La eliminación de esta posibilidad de elusión se alcanzaría gravando exclusivamente las ventas al consumidor final.

Aparecen como elemento central dentro de las posibilidades de elusión del impuesto las alícuotas diferenciales entre actividades y las exenciones, ya sean subjetivas u objetivas. Se suman al costo en elusión fiscal vinculado con las alícuotas diferenciales por rubro de actividad, al problema tradicional de modificar los precios relativos de los bienes, afectando el bienestar económico. $^{36}$ Eliminar exenciones y unificar las alícuotas parece tener sentido, aunque esto último agravaría el problema vinculado con imposición en varias etapas y las posibilidades de elusión que se generan respecto a eliminar algunas de las etapas. Una alternativa de mínima sería mantener una estructura de alícuotas crecientes (en la medida en que uno se acerque a la venta final), pero uniforme en cada etapa.

La diferencia de alícuotas entre regiones y las posibilidades de elusión que esto genera a través de las normas del Convenio Multilateral, representan problemas complejos de resolver. Es claro que esto implica una coordinación interjurisdiccional, ya que una provincia por si misma no puede resolver el problema. La literatura acerca de competencia versus harmonización fiscal pueden dar mayor luz respecto a este punto. No obstante ello, es destacable que el diseño actual del sistema impositivo así como el grado de harmonización existente han surgidos de iniciativas nacionales más que de esfuerzos de coordinación provincial.

Respecto de la diferencia de alícuotas entre contribuyentes, un elemento importante relacionado al mismo es la concurrencia de bases imponibles con el nivel nacional, la cual es significativa. Las exenciones subjetivas son en muchos casos similares a las de la Ley de Ganancias y del IVA y, por lo tanto, el efecto de las medidas tomadas por un fisco subnacional será limitado.

Las diferencias de alícuotas en todo sentido son una fuente de elusión (y también de evasión) de cualquier impuesto indirecto. Es interesante destacar que desde un punto de vista del bienestar, el impuesto eficiente no es necesariamente un impuesto con alícuota plana, como surge de la literatura sobre imposición óptima sobre bienes. Sin embargo, aun asumiendo que las alícuotas

\footnotetext{
${ }^{36}$ La regla de Ramsey establece que las alícuotas óptimas respecto al bienestar económico no son necesariamente uniformes. Sin embargo, el argumento del texto se mantiene ya que las alícuotas diferenciales de la Ley Impositiva no están vinculadas con argumentos de imposición óptima.
} 
diferenciales surgen de un criterio de eficiencia económica, podría suceder que los beneficios desde el punto de vista del bienestar de las mismas sean más que compensados con las pérdidas ocasionadas por la elusión y la evasión.

Es interesante destacar la relación entre las políticas públicas orientadas a reducir la elusión y la evasión. En términos generales, las herramientas de combate a la evasión están en manos de la administración tributaria, mientras que las posibilidades de elusión surgen como consecuencia de la política tributaria. Además, las medidas que apuntan a una menor evasión (mayor fiscalización y penalidades más altas) pueden implicar más elusión, ya que los contribuyentes estarían dispuestos a asumir un costo mayor vinculado con la elusión, si el costo de la evasión está en aumento. Sin embargo, es muy probable que simplificar la política tributaria a fin de reducir la elusión también reduzca la evasión. Muchas exenciones y tratamientos diferenciales, que son un problema desde el punto de vista de la elusión, también tienen el efecto de aumentar la evasión. Las empresas tienen más opciones de evadir, sin trastocar necesariamente sus registros contables (declarando una actividad por otra) y la administración tributaria debe dedicar más recursos para auditar sistemas impositivos complejos. Ambas fuerzas implican mayor evasión. Por lo tanto, simplificar la ley impositiva, por ejemplo mediante la unificación de alícuotas, tendería a reducir tanto la elusión como la evasión. 


\subsection{Apéndice A. Breve historia del Impuesto sobre los Ingresos Brutos}

\subsubsection{Introducción}

El objetivo en este Apéndice es presentar una perspectiva histórica respecto al Impuesto sobre los Ingresos Brutos de la Provincia de Buenos Aires (IIBB). A partir de esta visión histórica, hay varias cuestiones referidas al análisis del impuesto que adquieren una dimensión diferente. Conocer cuales eran los objetivos de la creación del IIBB, así como las instituciones previamente existentes tomadas en cuenta en su momento, ayudan a comprender las características que hoy tiene el impuesto.

Además, tal perspectiva es útil al analizar los efectos del impuesto, al conocer si los mismos fueron buscados o no. También sirve para responder una pregunta relevante: si los objetivos de política que se buscaron con la creación del IIBB siguen estando vigentes. Es bastante común encontrar, sobretodo para instituciones económicas de menor relevancia, que las mismas siguen existiendo sea por imperio de la costumbre o porque pequeños intereses sectoriales las defienden, aún cuando el objetivo que perseguían ya no está.

La aprobación del Código Fiscal de la Provincia de Buenos Aires en el año 1948 que establece la vigencia, a partir del año 1949, del Impuesto a las Actividades Lucrativas (IAL), es considerado habitualmente el nacimiento formal del IIBB, por las fuertes similitudes entre ambos impuestos. Luego de esa aprobación, el IAL se extiende rápidamente al resto de las jurisdicciones. Sin embargo, es necesario retroceder un poco más para alzancar una mayor respectiva del IIBB: de hecho, la propia aprobación del Código Fiscal del año 1948 tuvo sus condicionantes y antecedentes de interés. Por este motivo, en este breve repaso histórico, se comienza con los antecentes coloniales y republicanos del impuesto, lo cual obliga repasar instituciones fiscales previas a la creación del Estado de Buenos Aires en el año 1852. Previo a esa fecha, la revisión pierde alguna precisión no sólo por la escasez de fuentes sino también por el hecho de que las referencias se realizan respecto a los impuestos sobre la compraventa de mercancías que se cobraban en la región geográfica donde hoy está la Provincia de Buenos Aires, más allá de que la propia provincia no existía como Estado autónomo. 


\subsubsection{La colonia}

La colonia, en tanto extención del Reino de España, tanía básicamente las mismas instituciones fiscales que la metrópoli, las cuales consistían en una gran cantidad de reglamentos, cédulas reales, ordenanzas y leyes que establecían las más diversas contribuciones, muchas de las cuales recaían en el intercambio de mercancías, y de difícil recaudación y control. La mayoría de tales contribuciones tenían origen real, aunque algunas de ellas eran de origen eclesiástico. A estas contribuciones, se les agregaban las referidas al comercio entre la Metrópoli y la Periferia, las cuales más adelante adquirirían una importancia central como ingresos aduaneros. Entre las contribuciones más relevantes que gravaban el intercambio de mercancías se encuentran el derecho de Alcabalas, las Sisas, el Diezmo, las Licencias y el Estanco. ${ }^{37}$

El derecho de Alcabalas, o directamente Alcabala, era de uso generalizado por parte de la Corona de Castilla desde el siglo XIV y es considerado habitualmente un claro antecedente del IIBB. ${ }^{38}$ En los países anglosajones, las mercancías se gravaban más comunmente por medio de Sisas, que consistían en impuestos específicos sobre determinandos bienes de alto valor (y baja elasticidad), como la sal y las especies. Eran relativamente fáciles de administrar y tenían buena capacidad recaudatoria. Al recaer sobre bienes caros. Inclusive, en su aplicación había un componente de equidad, ya que algunos de esos bienes se consideraban suntuosos. Esto generaba mayor legitimidad popular, todo lo opuesto a la Alcabala, el cual dio origen a unas cuantas rebeliones populares, tanto en la Metrópoli como en la Colonia.

La Alcabala era un impuesto general que recaía, en palabras de Adam Smith "sobre las ventas de cualquier especie de propiedad tanto mueble como inmueble, y sus derechos se devengan cada vez que se verifica una nueva venta". ${ }^{39}$ En aquella época se consideraba que los impuestos sobre las mercancías recaían sobre el productor, comerciante o intermediario, es decir, no estaba muy desarrollado el concepto de traslación e incidencia de una determinada carga impositiva. Debido a ello, la principal justificación de un impuesto de este tipo era la equidad tributaria. Había sido común hasta entonces gravar la producción, la importación de mercancías, y también las ventas finales, pero un principio de igualdad consideraba entonces necesario también gravar

\footnotetext{
${ }^{37}$ Ver Alberdi (1854) y Benegas Lynch (2000). En 1630 se estableció la primer caja real en Buenos Aires, aunque recién en la década de 1740 la recaudación comienza a despegar [Miguez (2008)].

${ }^{38}$ Di Gresia (2003), p. 2.

${ }^{39}$ Smith (1776), Tomo III. p. 205
} 
los que "intervienen entre el tráfico entre el introductor, el fabricante y los consumidores" ${ }^{40}$

Cuando la Corona de Castilla establece por primera vez el impuesto la alícuota original era del $5 \%$, quedándose la Corona con una "veintena parte de cuanto se vendiese y comerciase en el Reino" (p. 204), pero tal alícuota fue aumentando hasta un $10 \%$. Además, durante el Siglo XVII se fueron agregando cuatro "cientos" con asignación específica, llegando a alcanzar por lo tanto un máximo del $14 \%$. En el virreinato aparece en el siglo XVII con una tasa del $4 \%$ y llegó al $6 \%$ a partir del año 1776.

El problema de la Alcabala era que implicaba el control, por parte de algún agente recaudador (en general se vendía en remate la recaudación de este tipo de contribuciones), de todas y cada una de las operaciones de compra venta, lo cual incluía controles en los caminos, en todas las tiendas, y en cada caso la verificación de los precios y cantidades. Esto llegó a generar barreras fuertes al comercio y a la exportación de mercancías, limitando el crecimiento de la industria al tamaño del mercado local. El Marqués de Uztariz, uno de los más inminentes políticos y economistas de España durante el reinado de Felipe V, llegó a asignarle a la Alcabala la "ruina de la industria de España". ${ }^{41}$ Más allá de que la industria de España haya tenido otros motivos que contribuyeron a su decadencia, muchos también consideraban que lo realmente gravoso eran las permanentes necesidades de recursos de la Corona y que el impuesto era eficiente en ese sentido.

Otro impuesto de bastante importancia recaudatoria y de una base muy general era el diezmo, destinado al sostén de la Iglesia Católica y de los hospitales. Consistía en el $10 \%$ de la producción agrícola y ganadera, y tiene un claro origen eclesiástico (de hecho aparece mencionado en el Antiguo Testamento).

Completaban los impuestos vinculados a las mercancías, las licencias y el estanco. Las licencias eran pagadas por las pulperías y tiendas de Buenos Aires y si bien tenían una importancia muy menor, y podrían considerarse una contribución de funcionamiento bastante diferente a un impuesto indirecto, es interesante mencionar que permanecieron como institución durante los siglos venideros y por momentos toca la propia evolución del Impuesto sobre los Ingresos

\footnotetext{
${ }^{40}$ Smith (1776). p. 204.

${ }^{41}$ Paredes, en 1863, dice "No conocemos un hombre de estado eminente ni estranjero ni español que se haya ocupado de la materia, que no señale a las alcabalas como una de las principales causas de la decadencia de España" (p. 16). La referencia a Uztariz está tomada de una nota del traductor de la obra de Smith (1776), p. 204.
} 
Brutos, en la forma de patentes comerciales. ${ }^{42}$ El estanco estaba vinculado con el monopolio de tabaco, sal, trigo, naipes, pimienta y algunos otros productos. En otros países estos bienes se gravaban a través de las sisas, pero en el Reino de España existía un monopolio estatal que cuando era otorgado a particulares, implicaban el ingreso del estanco al fisco.

Desde esta época, los impuestos tuvieron finalidades no exclusivamente fiscales, lo cual será un continuo inclusive luego de la Revolución de Mayo. Por ejemplo, algunas contribuciones directas tenían exenciones de hasta diez años para aquellos indios que se convertían al cristianismo. ${ }^{43}$ En la época de Rosas, algunos Estatutos Provinciales (por ejemplo el de la Provincia de San Luis) imponía contribuciones dobles a los "enemigos de la causa", o sea a los unitarios. ${ }^{44}$ Respecto a estos excesos, la aprobación de la Constitución Nacional del año 1853 limita el uso discresional de cualquier impuesto, consagrando principios de "equidad tributaria", al establecer que la igualdad es el principio de la imposición. Así, el artículo 16 dispone en forma explícita que "la igualdad es la base del impuesto y de las cargas públicas".

Otro elemento central de la epoca colonial son los monopolios y la prohibición de comerciar que imponía la Corona. Esto impedía por una parte cobrar ingresos significativos, en la medida en que el comercio era muy reducido o directamente nulo, y a la vez permitía establecer fuertes contribuciones vinculadas a determinados monopolios. Recién hacia el final de la época colonial (en el año 1809) cuando se abre la posibilidad de comerciar con el Imperio Británico, comienzan a adquirir importancia los ingresos aduaneros, que durante gran parte del siglo XIX serán la principal fuente de ingresos públicos.

En resumen, dos impuestos a la produción y comercio de mercancías estaban en el centro del sistema fiscal de la Colonia, la Alcabala y el Diezmo. Ambos eran de base muy general, gravando todo tipo de producción y comercialización de bienes y, quizás por ese motivo, fueron rápidamente eliminados por el gobierno de la Revolución. Tal eliminación fue luego criticada por Juan Bautista Alberdi, quien alzaría una defensa leve pero firme al establecer:

"De estos impuestos suprimidos en la República Argentina, la alcabala, el diezmo

\footnotetext{
${ }^{42}$ Por ejemplo, en el año 1974, cuando se crea el IVA y decide eliminarse el Impuestos a las Actividades Lucrativas (nombre original del IIBB), se crea en la Provincia un Impuesto a las Patentes Comerciales, exactamente con la misma base imponible y hecho imponible que el Impuesto sobre los Ingresos Brutos.

${ }^{43}$ Benegas Lynch et all (2000), p. 7.

${ }^{44}$ Rosa (1958).
} 
y el estanco, conservados en Chile, no han estorbado a este país acrecentar su Erario y su industria con doble éxito que los nuestros. No pretendo que sean buenos estos impuestos, sino que en Chile no han sido obstáculo al progreso del país". ${ }^{45}$

\subsubsection{Revolución y los gobiernos de Rodriguez y de Rosas}

Luego de la Revolución de Mayo, las finanzas se continuaron manejando mediante las instituciones heredades de la Corona Española y por diversas herramientas legales de muy distinto tenor y poco efectivas, ya que seguían el ritmo del proceso de organización de la República y de los diversos Estados Provinciales. Como afirma Burguin (1946) respecto a estos años, pp. 76-77:

"Para atender sus necesidades normales la provincia se confirmaba momentaneamente con el sistema financiero que había heredado del gobierno virreinal. Y para hacer frente a las exigencias extraordinarias derivadas de la guerra, adoptó medidas especiales que a veces completaban, pero más a menudo contradecían, los principios y las prácticas de la antigua administración. El resultado fue la formación de un complejo sistema de impuestos y ordenanzas administrativas, que en un medio económico y político que cambiaba se fue haciendo rápidamente cada vez más ineficaz."

Recién durante los años posteriores al proceso de organización iniciado en el año 1821 se implementa una reforma integral del sistema fiscal de la Provincia, que incluyó sumprimir los principales impuestos de origen colonial, particularmente el derecho de alcabala, así como el diezmo (primero reformado y luego eliminado definitivamente), y el resto de las contribuciones impuestas al comercio que hemos mencionado.

Los ingresos a partir de ese momento se concentran fundamentalmente en los derechos de aduana, y completan como las principales fuentes de ingresos al incipiente fisco, diversos impuestos creados durante los años 1821 a 1823, siendo los más relevantes los papeles sellados (que ya existían durante la Colonia), la contribución directa y las patentes.

\footnotetext{
${ }^{45}$ Alberdi (1854), p. 163.
} 
Los sellados consistían en papeles especiales sobre los cuales obligatoriamente debían escribirse determinados documentos o contratos, lo cuales eran adquiridos en oficinas públicas. ${ }^{46}$

La contribución directa se creó por primera vez en el año 1812 para financiar algunos gastos de la campaña militar, pero fue finalmente legislada en el año 1822. Gravaban el total de bienes que tenía cada habitante, valuados por el propio contribuyente, a partir de la siguiente escala:

"Los comerciantes y mercaderes pagarían por su capital en giro, a razón de 8 pesos al año por cada mil; los fabricantes pagarían por el capital empleado en sus establecimientos, 6 por mil; los hacendados, 4 pesos por cada mil al año; y los labradores y los dueños de capitales empleados en cualquier otro objeto pagarían al año 2 pesos por mil". ${ }^{47}$

La diferencia sustancial de la contribución directa con los impuestos anteriores y posteriores vinculados a la actividad económica, es que era un impuesto al capital, sin relación con los ingresos o ventas. Curiosamente, seguía una lógica similar en la determinación de alícuotas al IIBB tal cual fue creado en el año 1948 (y que hoy se mantiene en forma sustancial): las actividades comerciales pagaban una alícuota mayor que las de producción industrial, mientras que la producción agropecuaria pagaban las menores alícuotas.

Los enormes problemas que creaba la contribución directa, principalmente respecto a la valuación de los bienes alcanzados, serán parcialmente resueltos cuando se elimina de su base de cálculo aquellos capitales que no son bienes raíces, y se unifica la alícuota, pasando a partir de ese momento (año 1854) a ser un impuesto sobre los inmuebles.

Las Patentes consistían en un impuesto de suma fija requerido para poder circular (carruajes) y para ejercer determinadas actividades comerciales. Consistían en un certificado adquirido una vez al año (según la escala provista por la legislación año a año para cada tipo de comercio) que debía ser exhibido por los establecimientos comerciales dentro de los tres primeros meses del año. Como dice Dino Jarach

"la institución de las patentes se remontan a la época medieval, en que el soberano otorgaba una carta-patente, o sea, una autorización para ejercer determinada

\footnotetext{
${ }^{46} \mathrm{El}$ cargo recaía sobre los papeles que llevaran el escudo provincial [Burguin (1946), p. 244]

${ }^{47}$ Benegas Lynch et all (2000). p 17.
} 
actividad, como la de comercio e de la industria, o un oficio, y hasta el corso armado de los mares". ${ }^{48}$

En el caso de la República Argentina, el antecedente de la patente fueron las licencias a las pulperías y tiendas de Buenos Aires. Luego de sancionada la Constitución Nacional, el concepto de patente comercial queda desvirtuada, ya que se consagra el principio de libertad de comercio, quedando solo el nombre, aunque lo relevante pasa a ser el gravámen, y no la patente (que pasaría a ser sólo el comprobante de pago). De este modo, a partir del año 1854, la Patente pasa a ser un impuesto vinculado con la capacidad contributiva y que no estaba relacionado con una contraprestación específica por parte del estado.

Sin embargo, como todo impuesto de suma fija era fácil de determinar y recaudar pero difícil su legislación. Implicaba establecer para cada tipo de establecimiento comercial e industrial un determinado monto de la patente, en algunos casos con dos o tres categorías para cada tipología. Además, si determinado ramo no estaba listado en la ley que establecía la suma fija a pagar, ese comercio eludía totalmente su pago. Gradualmente se fueron incorporando más ramas de actividad, inluyendo en el año 1844 el impuesto a las profesiones y oficios, fijando distintos valores según la localización geográficas (pagaban más los que comercios que estaban en el centro de Buenos Aires). Esta situación de complejidad creciente intentará ser corregida a principios del Siglo XX con la cración de impuestos más generales sobre la actividad agropecuaria, industrial o comercial.

Esta conformación de las finanzas públicas fue similar hasta el momento de creación del Estado de Buenos Aires, esto es durante toda la década del 30 y del 40'. Las principales modificaciones impuestas por el Gobierno de Rosas estaban orientadas a mejorar la administración de los impuestos, fortalecer las herramientas de cobranza (estableciendo multas e intereses para pagos fuera de términos, por ejemplo) y también aumentando las alícuotas, sobretodo respecto a los aranceles. La estructura de ingresos, salvo en los años con bloqueo externo, tuvo un comportamiento similar a los de la década del 20', donde más del $80 \%$ consistían en ingresos aduaneros. $^{49}$

\footnotetext{
${ }^{48}$ Jarach (1958) p. 356.

${ }^{49}$ Burgin (1946) presenta en forma detallada la composición de los ingresos fiscales de la Provincia de Buenos Aires, entre los años 1822 hasta 1850. Ver Cuadros $N^{\circ} 7,29$ y 34.
} 
Tanto la Contribución Directa como las Patentes pueden considerarse un antecedente lejano del Impuesto sobre los Ingresos Brutos, en la medida en que estaban vinculados, en forma más o menos directa, al ejercicio de una actividad económica y su determinación en algunos casos seguía el monto de los ingresos o el capital circulante que haya tenido el comercio en un determinado año.

Cabe destacar que si bien los impuestos creados en los años 1821-1823 eran de base muy amplia, todos partían de declaraciones juradas donde los contribuyentes detallaban los bienes con que contaban y los valuaban. En el caso de la Contribución Directa, este era un supuesto crítico y durante muchos años existió desazón en los gobernantes respecto a la enorme subvaluación aplicadas en la declaración de los capitales gravados. Durante estos años, no existía una registro de la propiedad que constituyese un padrón de los bienes inmuebles, ni mucho menos un catastro territorial que valuaba los mismos. Además del problema de subvaluación, los impuestos no eran realmente fiscalizados ni controlados y podía pasar que en determinadas distritos de la provincia durante años (por ejemplo, desde el año 1840 al 1844) no existiesen ingresos por Contribución Directa. Por otro lado, en estos años existieron fuertes devaluaciones del papel moneda, el cual era aceptado en su valor nominal para el pago de los impuestos, aunque los precios seguían la moneda metálica. Además, la mayoría de los impuestos internos (no así los aranceles) estaban establecidos a valor nominal en la legislación (eran específicos, no ad valorem). Ambos factores afectaron fuertemente la recaudación efectiva de estos impuestos.

Respecto a la contribución directa, Alberdi resume genialmente la dificultades de implementar un impuesto de base declarativo:

"Basada sobre el capital, y valorado éste por la declaración del capitalista, resultó lo que era de esperarse, nadie habló la verdad al fisco en la declaración de su capital. Negociante que en un solo año había pagado seiscientos mil pesos de derechos de aduana, se declaró sin ningún capital propio a fin de pagar un cuatro en vez de un ocho por mil. La casa más pudiente de comercio del país declaró tener por todo capital veinte mil pesos papel. Hubo millonarios que hacían el negocio de banca, que declararon diez mil pesos de capital, y otros nada. Faltaba la base de que habla Say para esta clase de impuesto, que es la buena fe del contribuyente: base con que no se debe contar en tiempos y países sin espíritu público. Dejar 
la declaración del contribuyente, y echar mano de la pesquisa de sus documentos y libros y del testimonio del vecindario, es envenenar la contribución y suscitar enemigos y resistencias a la autoridad naciente. Por eso Rosas, para apoyarse en el pueblo, prefirió sellar papel moneda antes que alzar la contribución directa a su valor real primitivo. Entretanto Rivadavia, menos contraído a buscar popularidad para conservar el poder, aumentó con la contribución directa las causas del descontento que arruinaron el ascendiente de su partido." 50

\subsubsection{Organización nacional y creación del Estado de Buenos Aires}

El inicio de la existencia de la Provincia de Buenos Aires, en su configuración institucional actual, conviene datarlo con la aprobación de la Constitución del Estado de Buenos Aires, el 12 de abril de 1854. Luego de creada y constituida la Honorable Legislatura del Estado de Buenos Aires es posible observar mediante las leyes aprobadas la conformación formal de las finanzas del Estado. La Constitución del año 1854 establece claramente que es responsabilidad de la Camara de Representantes "La iniciativa en la creación de impuestos ó contribuciones", mientras que es la Asamblea General la que debe "fijar cada año los gastos generales del Estado con arreglo á los presupuestos de ellos y al plan de recursos que deberá presentar el gobierno; establecer los impuestos y contribuciones necesarias para cubrir aquéllos; suprimir, modificar y aumentar los existentes." (art. 49 a 52).

La única modificación sustancial de esos años fue en la Constribución Directa: en el año 1853 se suprimió toda imposición a capitales que no estén represetados por bienes raices. A partir de este momento, la contribución directa deja de gravar capitales comerciales y se comienza a asemejar a un impuesto inmobiliario. La alícuota general consistía en el 2 por mil por año del valor de las propiedades, tanto urbanas como rurales.

Los principales impuestos que cobraba la Provincia de Buenos Aires en 1854 eran los Derechos Aduaneros, Sellados, Patentes y la Contribución Directa. La importancia relativa de cada uno de ellos era muy diferente, en el presupuesto del año 1855 se preveía recaudar 41 millones de pesos por derechos de Aduana, dos millones por Contribución Directa y cinco millones por Sellados y Patentes. Esta proporción se venía manteniendo durante la década del 30 y del 40,

\footnotetext{
${ }^{50}$ Alberdi (1858). p 166.
} 
con la excepción de los años del bloqueo del comercio exterior que implicaron fuertes bajas de los derechos de aduana.

Durante el resto del siglo XIX fueron apareciendo nuevos impuestos vinculados principalmente con servicios públicos que comenzaban a ser ofrecidos en cada municipio y que se financiaban con estos impuestos con destino específico. Estos impuestos son los que hoy se denominan tasas municipales, y su primer antecedente legislado por la Provincia de Buenos Aires fue el Impuesto de Serenos (1854), cuyo objetivo era financiar la custodia de serenos en zonas urbanas. Debían ser pagados en forma mensual por los frentistas en aquellas manzanas efectivamente custodiadas y era recaudado y administrado por la propia comisión de serenos. La ley de creación del Impuesto de Serenos es la $N^{\circ} 13$ de la Honorable Legislatura de la Provincia de Buenos Aires y la primera de tipo netamente impositiva (si dejamos de lado los derechos de importación establecidos por la Ley $\left.\mathrm{N}^{\circ} 6\right)$.

En el año 1854 se aprueba la ley de creación de la municipalidad de Buenos Aires y se establece cuales impuestos serán de jurisdicción provincial y cuales municipales, comenzado el proceso de descentralización de aquellas tasas vinculadas directamente con un servicio público (caso alumbrado). El artículo 54 de la mencionada ley establece como ingresos de la ciudad a "todas las rentas que paga la ciudad y el distrito municipal al Erario público; escluyendo solamente la del papel sellado, patentes, correos, aduanas y contribución directa".

Sin embargo, algunos impuestos fueron creados por la Provincia pero rápidamente municipalizados, como el Alumbrado (1859), Barrido (1874) y Limpieza (1879), que son el origen del "ABL" que hoy cobran los Municipios en la Provincia. Mucho más adelante, se crearon los Impuestos de aguas corrientes, cloacas y desagües (principios del siglo XX). Un impuesto de esa época, tambien municipalizado, fue el Impuesto de Abasto (1858) que gravaba el consumo de ganado en las zonas urbanas.

Este esquema de finanzas públicas se mantuvo sin mayores cambios hasta que los recursos aduaneros fueron perdidos por el Estado de Buenos Aires, y el mismo se incorpora en forma plena a la República Argentina en 1862 (luego de perdida la batalla de Cepeda y firmado el Pacto de San José de Flores). Luego de ese año, los "derechos de aduana" no forman parte de los ingresos de la Provincia de Buenos Aires, aunque no fueron reemplazados en forma inmediata por otra fuente de ingreso. 
A partir de este momento, y por varias décadas, la organización de las finanzas públicas se basa en un principio bajo el cual los impuestos a la exportación y a la importanción son exclusivos de la Nación (impuestos externos) mientras que el resto de los impuestos, que comenzaron a denominarse "impuestos internos", en general sobre los consumos, la producción de bienes o los capitales, los cobraban las provincias. ${ }^{51}$ Que el esquema se haya mantenido sin modificaciones sustanciales no quita que existiese fuerte insatisfacción con el mismo. Por ejemplo, en el informe del gobierno saliente ante la Asamblea Legislativa, en el año 1874, se vierten los siguientes conceptos respecto a los ingresos públicos de la Provincia:

"Todo lo que tenemos en esta materia es defectuoso, injusto y muchas veces absurdo. Capitales enormes escapan a todo impuesto y sobre otros pesan contribuciones exageradas; en algunos casos no se respeta debidamente el principio de la proporcionalidad, en otros no se le tiene en cuenta absolutamente. La ley de Contribución Directa, tradicional en nuestro réjimen financiero, es de todo punto defectuosa para la avaluación y percepción del impuesto en la campaña. La ley de patentes, no obstante sus categorías y gradaciones, está muy lejos de gravar proporcionalmente el capital o la renta" ${ }^{52}$.

\subsubsection{Reformas fiscales como consecuencia de crisis económicas: 1890 y 1935}

Este esquema sufre una modificación sustancial como consecuencia de la crisis del año 1890, cuando luego de una baja sustancial de los ingresos aduaneros (consecuencia de la depreciación de la moneda), la Nación decide crear en el año 1891 impuestos internos nacionales sobre la venta de alcoholes, cerveza, y otros bienes. Como ya existían en la Provincia de Buenos Aires desde el año 1879 impuestos al consumo de bebidas alcohólicas, naipes y tabaco, se inicia el debate sobre la concurrencia de base imponible entre impuestos provinciales y nacionales. Tal discusión continúa y se profundiza con la creación por parte del Estado Nacional del Impuesto a los Réditos en el año 1932 y el Impuesto a las Ventas en 1935.

Por otro lado, a comienzos de siglo aparecen impuestos provinciales con bases imponibles más amplias que intentaban generar un financiamiento acorde a un gobierno provincial que venía

\footnotetext{
${ }^{51}$ Ver Bulit Goñi (1986), p. 21.

${ }^{52}$ Ministerio de Economía, p. 163.
} 
asumiendo mayores servicios públicos. Otro objetivo importante era la simplificación y reemplazo de las Patentes, que continuaban convirtiendose en un impuesto de cada vez más escasa y dificultosa recaudación. Estos impuestos estaban vinculados con la actividad agropecuaria, comercial e industrial y con el consumo de bienes considerados suntuarios. Entre estos impuestos, que hoy deberían considerarse también antecedentes mediatos del Impuesto sobre los Ingresos Brutos, están el Impuesto a la Producción Agropecuaria (1903), el Impuesto al Comercio e Industria (1911) y el Impuesto a la Cerveza (1909).

El Impuesto al Comercio e Industria intentaba reemplazar la Patente pero con una base imponible distinta: ahora es el "volumen del negocio" del año anterior (representado en general por el monto de las ventas, aunque en algunos casos eran el monto de las comisiones). Sin embargo, durante muchos años, hasta la creación del Impuesto a las Actividades Lucrativas (en 1948), coexistieron las Patentes (aunque sólo para algunas actividades, y con diversas de bases imponibles), con los impuestos mas generales de Comercio e Industria y Producción. Las profesiones, artes y oficios, así como determinados servicios bancarios y de seguros (y toda otra actividad no incluida en el Impuesto al Comercio e Industria) pagaban Patentes, y el resto pagaba Comercio e Industria. Las bases imponibles eran muy diferentes, no solo entre ambos impuestos sino también dentro de cada impuesto, para diversas actividades. Por ejemplo, los Bancos pagaban una patente anual que se calculaba sobre las base de las utilidades del año anterior (muy similar el impuesto a los réditos, que se implementaría en el año 1932), otros comercios sobre las comisiones, las ventas (ingresos brutos), determinados actos (profesionales) o directamente una suma fija.

En el año 1935 y como consecuencia de la creación del Impuesto a las Ventas nacional, e inaugurando el esquema de "Ley Convenio", se propicia un régimen de unificación de los impuestos internos nacionales y provinciales: la Nación coparticiparía a las provincias la recaudación de Internos, y las provincias derogarían sus propios impuestos internos y se comprometieron a no establecer impuestos análogos a los de la Nación que sean coparticipables. Más allá de esta declaración de voluntades, esta ley convenio no implicó modificaciones inmediatas en los impuestos provinciales. 


\subsubsection{El Impuesto a las Actividades Lucrativas}

En el año 1948 se produce una reforma muy importante en las finanzas de la Provincia de Buenos Aires con la creación del Impuesto a las Actividades Lucrativas. Dino Jarach (1958), autor de la reforma, señala que la misma fue "el fruto de una evolución de instituciones jurídicas preexistentes en el derecho posuitivo argentino" (p. 354), como ser las antiguas patentes comerciales y especialmente pasando por el impuesto al comercio y a la industria aplicado en la Provincia de Buenos Aires sobre el volumen de los negocios desde el año 1911.

Giuliani Fonrouge y Navarrine (1974), por otro lado, consideran que el origen del Impuesto debe remontarse a todas aquellos gobiernos de diverso tenor que hayan aplicado algo similar (impuestos sobre el volumen de los negocios) en la historia universal. Así ubican antecedentes en Grecia, en Bizancio y en la Roma imperial, y más modernamente en Alemania, Francia e Italia. Destacan la importancia de la Alcabala en el reino de España, pero también en las ciudades alemanas y de Italia. Es interesante el paralelismo que hace Giuliani Fonrouge y Navarrine (1974) de la evolución de determinadas instituciones fiscales en Europa con sus similares en Argentina. Destacan que durante la Primer Guerra y debido a las necesidades de financiamientos de la misma, en varios países Europeos se comenzó a aplicar un impuesto similar, por ejemplo, en Alemania (1916), Francia (1917), Italia (1919) y Bélgica (1921). Sin embargo, estos impuestos comienzan a perder terreno por la aplicación del régimen comunitario derivado del Tratado de Roma. Así, respecto a esta evolución se afirma

"en 1968 se decidió Alemania por reemplazarlo por el IVA, que lo sustituyó en todos los países, excepto en la Argentina, en donde, al contrario, se ha sumando a aquél como medio de obtener recursos, aunque sea a costa del sacrificio de los contribuyentes y el desarrollo de una sorda resistencia". ${ }^{53}$

En 1948 se acomete la tarea de crear un impuesto que reemplace la Patente y Comercio e Industria, con un sólo hecho imponible y una base imponible unitaria, creándose el Impuesto sobre las Actividades Lucrativas, que existió en la Provincia de Buenos Aires en forma ininterrumpida desde el año 1948 hasta el año 1975. Con el Código Fiscal del año 1948 se crea este impuesto que es rápidamente adoptado por el resto de las jurisdicciones subnacionales.

\footnotetext{
${ }^{53}$ Giuliani Fonrouge y Navarrine (1974), p.14.
} 
Esencialmente, es el IIBB tal cual hoy existe, con algunas diferencias menores, si bien en la redacción original la parte referida al IAL del Código Fiscal tenía 13 artículos y hoy el capítulo de IIBB tiene 56. La base imponible y el hecho imponible son similares, aunque el impuesto cuando se crea era un impuesto anual (sin anticipos) que se calcula en función de los ingresos brutos obtenidos en el año anterior, mientras que hoy tiene anticipos mensuales. Lo relevante es la definición de hecho imponible y de base imponible, que son sustancialmente similares en el Impuesto a las Actividades Lucrativas del año 1948 y el Impuesto sobre los Ingresos Brutos hoy vigente.

Una característica saliente del flamente Impuesto a las Actividades Lucrativas se refiere a la diversidad de alícuotas. Según Dino Jarach (1958), el principal fundamento de esta diversidad es la siguiente: "Se puede afirmar que las tasas del impuesto van en aumento a medida que los ingresos brutos se acercan más a las utilidades netas". (p. 383).

Lo que sucedía es que se consideraba superior un impuesto a los réditos, pero no aplicable. En primer lugar, ya existía un impuesto a los réditos nacional, y además la discusión sobre la territorialidad (fundamental en un impuesto provincial) se consideraba demasiado compleja para un impuesto a los réditos provincial, y de hecho lo es inclusive para un impuesto calculado sobre los ingresos brutos. Se intentó, como alternativa, que el impuesto a las actividades lucrativas tenga una incidencia proporcional al monto de los réditos: de este modo mientras la utilidad era una proporción mayor de los ingresos brutos, las alícuotas eran mayores. De este modo, los servicios pagan mayores alícuotas, y el comercio minorista más que el comercio mayorista.

Un segundo elemento que se consideró para aplicar alícuotas diferenciales fue:

"Aliviar la presión tributaria sobre actividades referentes a artículos de primera necesidad o de abastecimiento crítico, a fin de evitar su encarecimiento; o bien a someter a pesados gravámenes ciertas actividades socialmente poco deseables o que motivan una particular actividad de contralor policial" (p. 383).

El IAL al reemplazar el Impuesto al Comercio e Industria así como las Patentes Comerciales, termina con una importante diversidad de alícuotas.

La mecánica utilizada en la Ley impositiva del año 1949 (la ley N 5345, primer ley que establece las alícuotas del Impuesto a las Actividades Lucrativas) fue establecer una alícuota 
general del 4 por mil, y luego establecer rebajas (de hasta el $30 \%$, sin incluir las excenciones) y recargos que van del 100 al $1500 \%$ de la alícuota general (esta última alícuota, $6 \%$ se aplicaba a prestamistas con o sin garantía hipotecaria o prendaria).

En los años posteriores, el impuesto tuvo pocas modificaciones, entre las cuales se destacan las siguientes (Bulit Goñi, p 33):

a) La noción de ingreso recibido fue reemplazada por la de ingreso percibido o devengado. Luego se tomó como criterio el devengado.

b) Por influencia de la inflación, se abandonó el sistema de liquidar el tributo sobre los ingresos brutos del año anterior, pasando a tomar en cambio períodos más próximos, el mes anterior o el bimestre.

c) En el hecho imponible se modificó la finalidad o propósito de lucro por el de onerosidad.

d) La estructura tarifaria, que al principio se manejó con una sola alícuota general y una amplia gama de recargos y rebajas, pasó luego a tres alícuotas centrales (1 para actividades primarias, 1,5 para industria, 3,5 para el comercio), con un conjunto de alícuotas de rebaja o recargo, menos que antes, sólo para supuestos de bases imponibles especiales.

e) Mayor significancia económica: al principio la alícuota general era del 0,4 pasando luego a ser 1, 1,5 etc, hasta el 3,5. La participación en la recaudación provincial creció sustancialmente.

En definitiva, con la creación del IAL se completa la arquitectura básica de los ingresos públicos de la Provincia de Buenos Aires, generando un impuesto vinculado con una base amplia y elástica que permite generar una viabilidad fiscal de largo plazo a un estado con demandas siempre crecientes. Tanto fue así, que el impuesto se mantiene hoy (a los 60 años de su creación), con caractesíticas muy similares. ${ }^{54}$

\footnotetext{
${ }^{54}$ Para tener una idea más precisa de la continudad que implica hoy el IIBB respecto al IAL nótese que en el momento de creación de éste último la base imponible era "el monto total de los ingresos brutos anuales, obtenidos el año anterior en el ejercicio de las actividades lucrativas gravadas."(ley 5.248 art. 95). En el Codigo Fiscal vigente, la descripción de la base imponible es "el gravamen se determinará sobre la base de los ingresos brutos devengados durante el período fiscal por el ejercicio de la actividad gravada"(ley 10.397 art. 161).
} 


\subsubsection{El Impuesto sobre los Ingresos Brutos}

Duranta la década del 70' hay varias modificaciones en las finanzas públicas en la país, bastante tumultuosas que afectaron el impuesto. En el año 1974, mediante la ley convenio 20.633 se decide crear el Impuesto al Valor Agregado, coparticipable, el cual debía reemplazar tanto el Impuesto nacional a las Ventas y el Impuesto provincial a las Actividades Lucrativas. ${ }^{55}$ Claro que luego de sancionada la ley de creación del IVA y derogado el Impuesto a las Ventas, se crea a nivel subnacional el Impuesto a las Patentes Comerciales, denominado "Derecho de Patente para el Ejercicio de Actividades con Fines de Lucro". Al decir de Bulit Goñi (1986), este impuesto "mantenía un hecho imponible similar al de su tan inconfesable como indisimulable antecesor" (p. 35). El principal fundamento de tal decisión fue que el IVA no había rendido a las provincias lo que se esperaba.

Luego, el 3 de diciembre de 1975 se firma un Acta de Concertación de la Política Fiscal que da lugar a las leyes 21.251 y 21.252, donde renace el impuesto primero como Impuesto a las Actividades Lucrativas con Fines de Lucro y luego (en el año 1977) con la denominación actual de Impuesto sobre los Ingresos Brutos (designación primero utilizada por Chubut y que luego se fue generalizando). ${ }^{56}$ Aún así, hay una clara continuidad, como afirma La Rosa (1977):

"Antes, después y ahora no han variado demasiado su estructura jurídica, sus presupuestos económicos y son las mismas urgencias financieras" (p. 2).

Facilitado por el régimen de facto, en el año 1979 y para regir en 1980, se impartieron pautas desde la Secretaría de Estado de Hacienda de la Nación, consistentes en una regulación completa y terminada para ser incorporada textualmente a cada una de las legislaciones locales positivas. De esta forma, desaparecieron las diversidad locales y, al inicio del período democrático, nos encontramos con el mismo impuesto vigente en todas las provincias de la Argentina, incluso con la misma reglamentación.

Como parte de las profundas reformas económicas acometidas durante la década de los 90’ y justificados por el gobierno en la estabilidad monetaria, el recupero de la tributación en la financiación de los gastos públicos y las necesidades de armonización vinculadas por el Mercorsur, se

\footnotetext{
${ }^{55}$ La Rosa (1977), p. 2-5

${ }^{56}$ Respecto al nombre, ahora su denominación sigue a la base imponible, y no al hecho imponible, que es en general lo preferible [Bulit Goñi (1986)].
} 
celebra en agosto de 1993 el Pacto Federal para el Empleo, la Producción y el Crecimiento. A través de este Pacto Federal se establecen varios cambios en el tributo siendo el más relevante la eximición de manera parcial y progresiva de determinadas actividades (producción primaria, entidades financieras y afines, compraventa de divisas, actividades industriales excepto sus ventas a consumidores finales, prestación de ciertos servicios, construcción de inmuebles).

El mismo Pacto Federal establece que el IIBB se sustituirá "por un impuesto general al consumo que tienda a garantizar la neutralidad tributaria y la competitividad de la economía", pero esta parte del Pacto nunca se implementó.

\subsubsection{Comentarios finales}

Esta revisión histórica, si bien breve y a trazos generales, permite observar que la Provincia de Buenos Aires tiene básicamente las mismas instituciones fiscales desde el período de organización iniciado luego de la Revolución de Mayo. Así como las organizaciones públicas a cargo de la recaudación datan de aquella época (la Dirección de Rentas se crea en el año 1821), la escructura tributaria es bastante similar: en aquellos años fundacionales se cobraba la Contribución Directa, Patentes, Sellados y Aduana, aunque los ingresos aduaneros fueron la parte más relevante, cerca del $80 \%$ del total de ingresos, aunque algunos años llegó al $90 \%$. Hoy se cobra Inmobiliario, Patente, Sellos e IIBB y este último representa cerca del $75 \%$ de los ingresos, con lo cual reemplaza en la planilla de recaudación lo que en el período posterior a la organización del estado constitutían los ingresos aduaneros. 


\subsection{Apéndice B. Ejemplos sobre el beneficio de la elusión}

Tabla 4.1a

Fijación de Precios Canasta. Distribuidora de Juegos Interactivos

La empresa puede utilizar tres estrategias de venta, las cuales se analizan por separado:
a. Corto plazo
Vende los CD Rom y las Revistas por separado
b. Mediano plazo
Vende las Revistas y por un adicional, el comprador se
b. Largo plazo lleva un CD Rom "de regalo"
Vende las revistas con un CD Rom "de regalo"

\begin{tabular}{|c|c|c|c|c|c|c|}
\hline \multirow[b]{2}{*}{ 1. Alicuota } & \multicolumn{2}{|c|}{ Venta CD Rom } & \multicolumn{2}{|c|}{ Venta de Revistas } & \multicolumn{2}{|c|}{ Total } \\
\hline & & $3 \%$ & & $0 \%$ & & \\
\hline 2. Costo unitario & $\$$ & 5 & $\$$ & 1,5 & & \\
\hline 3. Precios & & & & & & \\
\hline a. Corto plazo & $\$$ & 18,00 & $\$$ & 5,00 & & \\
\hline b. Mediano plazo & $\$$ & 18,00 & $\$$ & 5,00 & & \\
\hline c. Largo plazo & $\$$ & - & $\$$ & 20,00 & & \\
\hline $\begin{array}{l}\text { 3. Unidades vendidas } \\
\text { a. Corto plazo } \\
\text { b. Mediano plazo } \\
\text { c. Largo plazo }\end{array}$ & & $\begin{array}{l}400 \\
200 \\
400\end{array}$ & & $\begin{array}{r}50 \\
250 \\
400\end{array}$ & & \\
\hline $\begin{array}{l}\text { 4. Impuesto a pagar } \\
\text { a. Corto plazo } \\
\text { b. Mediano plazo } \\
\text { c. Largo plazo }\end{array}$ & & $\begin{array}{l}216 \\
108 \\
-\end{array}$ & & $\begin{array}{l}- \\
- \\
-\end{array}$ & $\begin{array}{l}\$ \\
\$\end{array}$ & $\begin{array}{l}216 \\
108 \\
-\end{array}$ \\
\hline $\begin{array}{l}\text { 8. Beneficio despues del } \\
\text { impuesto }\end{array}$ & & & & & & \\
\hline a. Corto plazo & $\$$ & 4.984 & $\$$ & 175 & $\$$ & 5.159 \\
\hline b. Mediano plazo & $\$$ & 2.492 & $\$$ & 875 & $\$$ & 3.367 \\
\hline c. Largo plazo & $\$$ & -2.000 & $\$$ & 7.400 & $\$$ & 5.400 \\
\hline $\begin{array}{l}\text { 9. Ahorro elusión } \\
\text { b. Mediano plazo } \\
\text { c. Largo plazo }\end{array}$ & & & & & $\begin{array}{l}\$ \\
\$\end{array}$ & $\begin{array}{r}-1.792 \\
241\end{array}$ \\
\hline $\begin{array}{l}\% \text { Beneficios (LP) } \\
\% \text { Carga impositiva (LP) }\end{array}$ & & & & & & $\begin{array}{r}5 \% \\
100 \%\end{array}$ \\
\hline
\end{tabular}




\section{Tabla 4.2a}

Fijación de Precios Canasta. Club Social y Deportivo

El club puede utilizar dos estrategias de venta, las cuales se analizan por separado:

a. Corto plazo: La cuota social no incluye el derecho de uso de las canchas de tenis, por lo cual los socios y no socios deben pagar cada vez que la usen.

b. Largo plazo: Incoporar el uso de la cancha en la cuota social, cobran el uso de la cancha solo a los no socios.

1. Alicuota

2. Costo total

3. Precios

a. Corto plazo

b. Largo plazo

3. Unidades vendidas
a. Corto plazo

b. Largo plazo

4. Impuesto a pagar
a. Corto plazo

b. Largo plazo

8. Beneficio despues del impuesto

a. Corto plazo

c. Largo plazo

9. Ahorro elusión b. Largo plazo $\%$ Beneficios (LP) $\%$ Carga impositiva (LP)

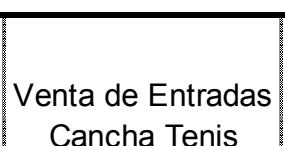

Cancha Tenis

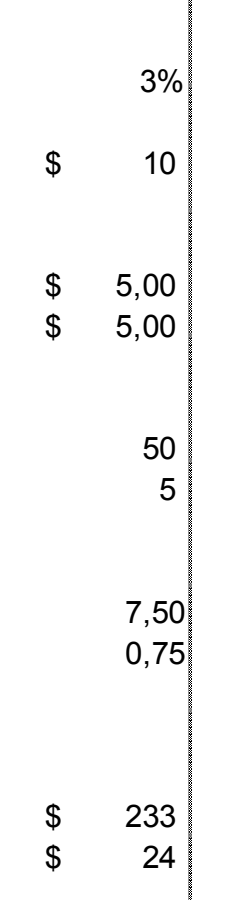

Cuota Social Total

$\$ \quad 10,0$

$\$ \quad 0,50$

$\$ 1,00$

100

250

$0 \%$

(a) 
Tabla 4.3a

Venta en Comisión. Supermercado Mayorista

La empresa puede utilizar dos estrategias de venta, las cuales se analizan por separado. Se evalúa el costo impositivo total de la operación en cada caso, o sea, lo que pagan todas las partes.
a. Corto plazo
b. Largo plazo

Compra la mercadería al proveedor y la vende al consumidor final.

Recibe la mercadería "en consignación" y la vende a cuenta y orden del proveedor. Paga el impuesto solo por la comisión.

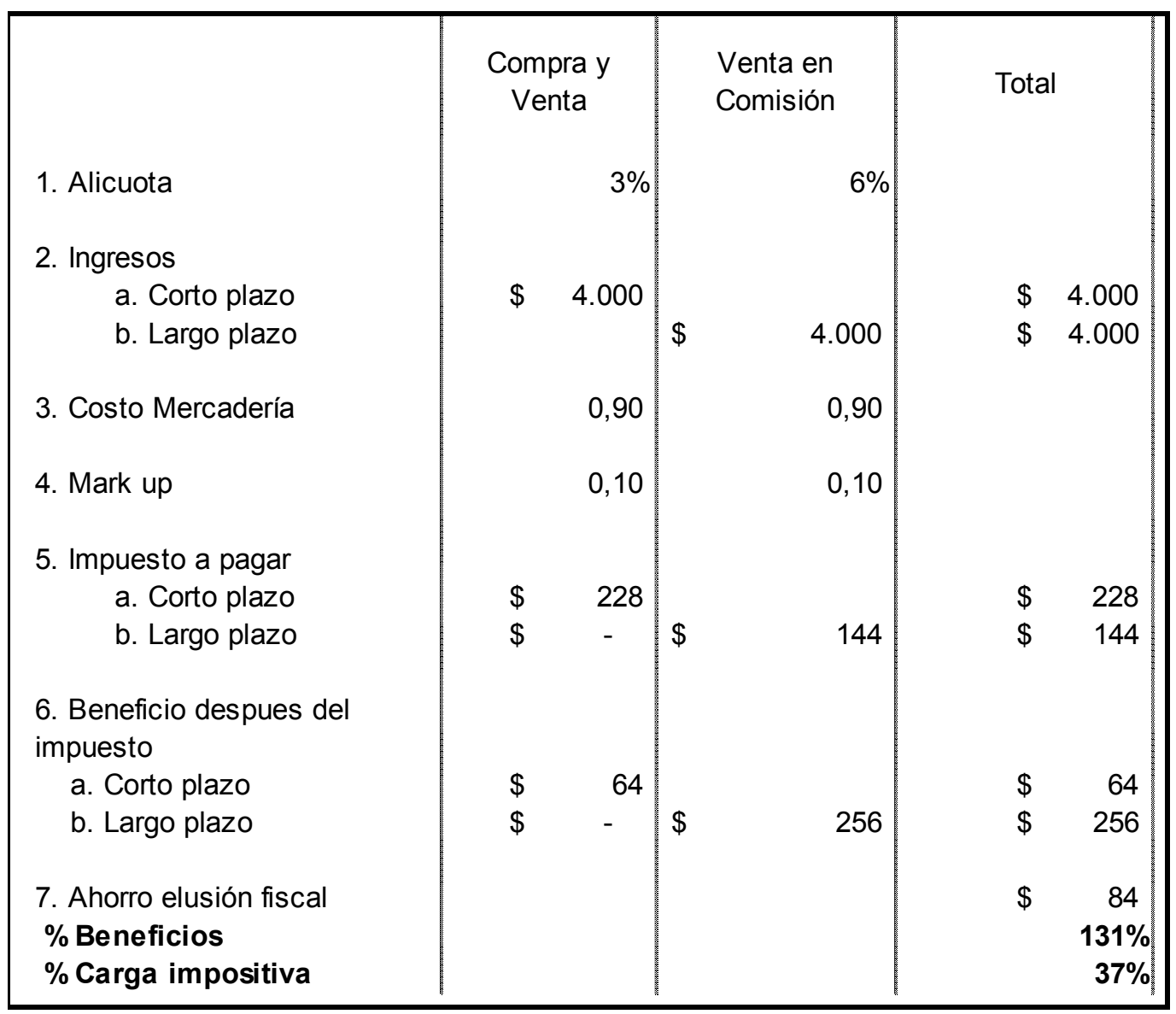


Tabla 4.4a

Transferencia de Ingresos. Clinica Privada

El Hospital decide, en el largo plazo, crear una Fundación a fin de derivar los ingresos a una organización exenta en el IIBB. La creación y operación de la Fundación tiene un costo fijo (anual) de \$5. A fin de permitir distribuir beneficios, una parte de los ingresos de la clínica se continuan ingresando a través de la clínica (el 10\%).
a. Corto plazo
Todos los ingresos los factura la Clínica.
b. Largo plazo
El $90 \%$ de los ingresos lo factura la Fundación y el $10 \%$ la Clínica.

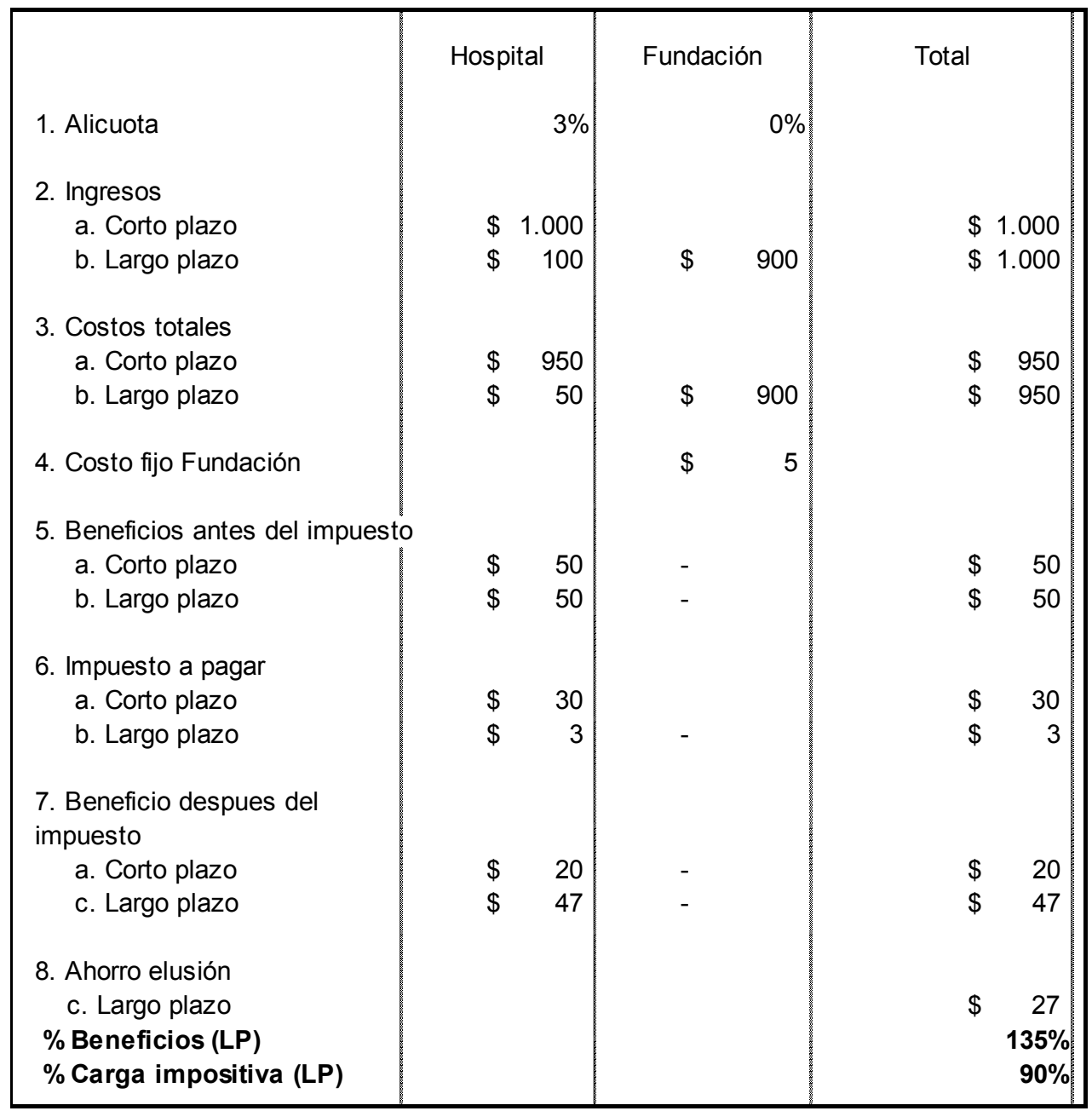


Tabla 4.5a

Mudanza Centro de Costos. Hipermercado Nacional

Debido a la diferencia de alícuotas vigentes para la actividad entre la Provincia de Buenos Aires y otras jurisdicciones, el Hipermercado decide transferir centros de costos a localidades con menores alícuotas.
a. Corto plazo
$80 \%$ gastos computables no asociados con
b. Mediano plazo localización en la zona donde mas ventas tiene.
b. Largo plazo $50 \%$ en cada zona
$80 \%$ de los gastos en zonas menos gravadas

\begin{tabular}{|c|c|c|c|c|c|c|}
\hline & & PBA & & & & Total \\
\hline 1. Alicuota & & $4 \%$ & & $3 \%$ & & \\
\hline 2. Ingresos & $\$$ & 70.000 & $\$$ & 50.000 & $\$$ & 120.000 \\
\hline 3. Costos & & 0,90 & & 0,90 & & \\
\hline \multicolumn{7}{|l|}{ 4. Gastos computables } \\
\hline $\begin{array}{l}\text { - Asociados localizacion } \\
\text { - Ivu asuu. Ivualıauıuı } \\
\text { Distribución }\end{array}$ & $\$$ & 7.000 & $\$$ & 5.000 & $\begin{array}{l}\$ \\
\$\end{array}$ & $\begin{array}{l}12.000 \\
1<. \text { vuv }\end{array}$ \\
\hline a. Corto plazo & $\$$ & 9.600 & $\$$ & 2.400 & $\$$ & 12.000 \\
\hline b. Mediano plazo & $\$$ & 4.000 & $\$$ & 4.000 & $\$$ & 8.000 \\
\hline c. Largo plazo & $\$$ & 2.400 & $\$$ & 9.600 & $\$$ & 12.000 \\
\hline \multicolumn{7}{|l|}{ Coeficientes } \\
\hline $\begin{array}{l}\text { Coeficiente ingresos } \\
\text { Coeficiente gastos }\end{array}$ & & 0,5833 & & 0,4167 & & \\
\hline a. Corto plazo & & 0,6917 & & 0,3083 & & \\
\hline b. Mediano plazo & & 0,4583 & & 0,3750 & & \\
\hline $\begin{array}{l}\text { c. Largo plazo } \\
\text { Coeficiente unificado }\end{array}$ & & 0,3917 & & 0,6083 & & \\
\hline a. Corto plazo & & 0,6375 & & 0,3625 & & \\
\hline b. Mediano plazo & & 0,5208 & & 0,3958 & & \\
\hline c. Largo plazo & & 0,4875 & & 0,5125 & & \\
\hline \multicolumn{7}{|l|}{ 4. Impuesto a pagar } \\
\hline a. Corto plazo & $\$$ & 3.060 & $\$$ & 1.305 & $\$$ & 4.365 \\
\hline b. Mediano plazo & $\$$ & 2.500 & $\$$ & 1.425 & $\$$ & 3.925 \\
\hline c. Largo plazo & $\$$ & 2.340 & $\$$ & 1.845 & $\$$ & 4.185 \\
\hline \multicolumn{7}{|l|}{$\begin{array}{l}\text { 5. Beneficio despues del } \\
\text { impuesto }\end{array}$} \\
\hline a. Corto plazo & $\$$ & 3.940 & $\$$ & 3.695 & $\$$ & 7.635 \\
\hline b. Mediano plazo & $\$$ & 4.500 & $\$$ & 3.575 & $\$$ & 8.075 \\
\hline c. Largo plazo & $\$$ & 4.660 & $\$$ & 3.155 & $\$$ & 7.815 \\
\hline \multicolumn{7}{|l|}{ 6. Ahorro elusión } \\
\hline b. Mediano plazo & & & & & $\$$ & 440 \\
\hline c. Largo plazo & & & & & $\$$ & 180 \\
\hline$\%$ Beneficios (LP) & & & & & & $2,4 \%$ \\
\hline$\%$ Carga impositiva (LP) & & & & & & $4,1 \%$ \\
\hline
\end{tabular}


Tabla 4.6a

Mudanza Centro de Costos. Profesional Independiente (CPN)

Debido a que la actividad está gravada en la Provincia de Buenos Aires pero exenta en la Ciudad Autónoma, el profesional decide establecer su oficina en la Ciudad, aunque su servicio lo sigue realizando principalemente en la PBA.
a. Corto plazo
$100 \%$ gastos en PBA
b. Mediano plazo
$50 \%$ en cada zona
c. Largo plazo
$100 \%$ gastos computables no asociados con localización en otra jurisdicción.

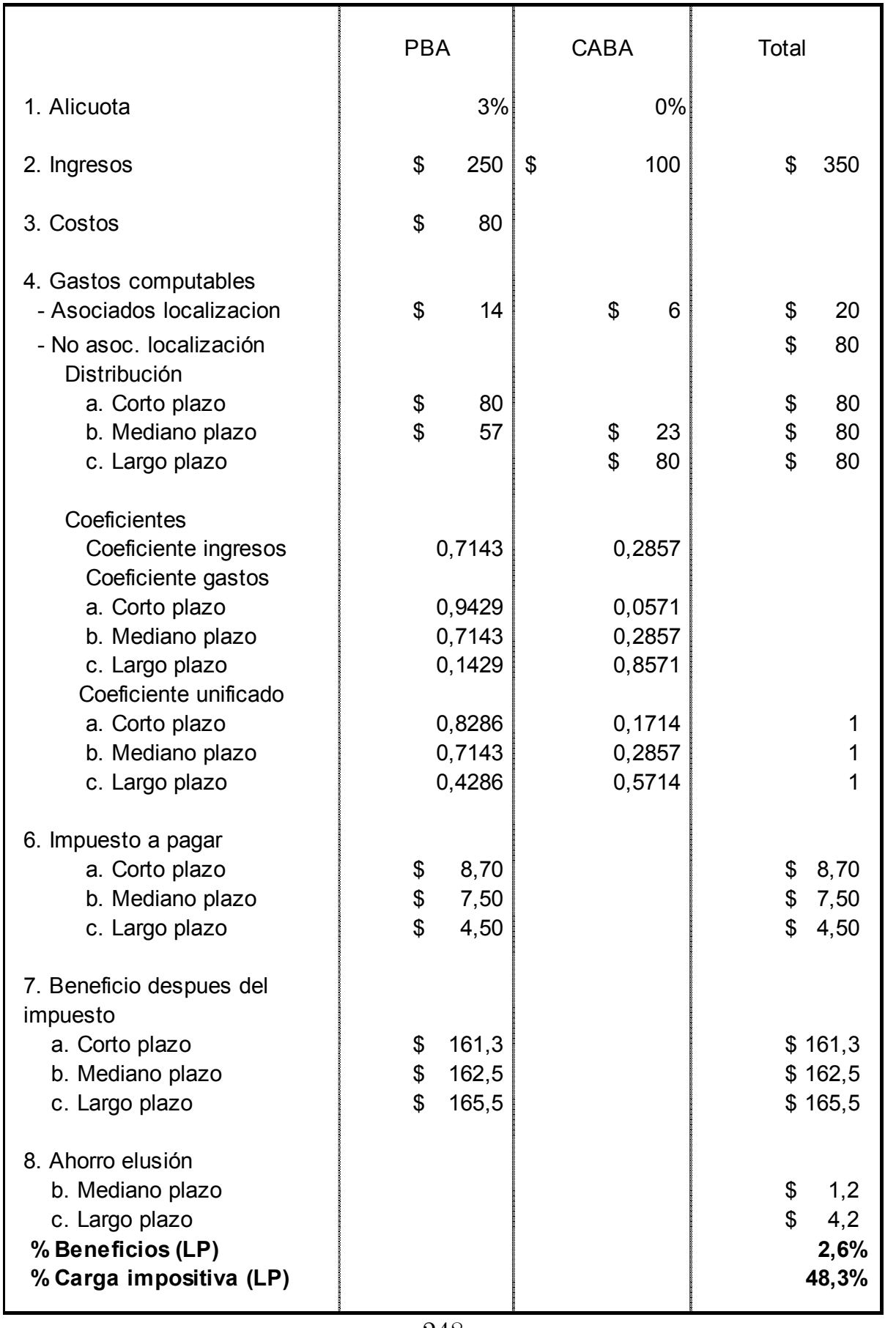




\subsection{Referencias bibliográficas}

Adams, W. J., y J.L. Yellen (1976). "Commodity Bundling and the Burden of Monopoly". Quarterly Journal of Economics, vol 90, pp 475-498.

Agell, J. y M. Persons (1998) "Tax arbitrage and labor suply". Seminar Paper No 647. Institute for International Economic Studies.

Alberdi, J. B. (1854). Sistema Economico y Rentistico de la Confederacion Argentina Según su Constitucion de 1853.

Althabe, M. (1983). El Impuesto sobre los Ingresos Brutos. Buenos Aires: Editorial LA LEY.

Benegas Lynch, A y Dania, R (2000). "Sistemas Tributarios. Un Análisis en Torno al Caso Argentino". Revista Libertas 33. Instituto Universitario ESEADE.

Bulit Goñi, E. (1986). Impuesto sobre los Ingresos Brutos. Buenos Aires: Depalma.

Burgin, M. (1946). Aspectos Económicos del Federalismo Argentino. Buenos Aires: Ediciones Solar.

Calegari, M. (1998). "Flat Taxes and Effective Tax Planning". National Tax Journal, vol 51, pp 689-713.

Coloma, G. (2005). Economía de la Organización Industrial. Buenos Aires: Temas Grupo Editorial.

Cowell, F.A. (1990). "Tax Sheltering and the Cost of Evasion". Oxford Economic Papers, vol 42, pp 231-243.

Cowell, F.A. (1995). Engañar al Estado. Un Análisis Económico de la Evasión. Madrid: Alianza Editorial.

Di Gresia, L. (2003). "Impuesto a los Ingresos Brutos: Análisis Comparativo de su Evolución y Perspectivas". Documento de Federalismo Fiscal Nro. 7. Departamento de Economía, Facultad de Ciencias Económicas. Universidad Nacional de La Plata. 
Erickson, M., Goolsbee, A. y E. Maydew (2003). "How prevalent is tax arbitrage? Evidence from the Market for Municipal Bonds". National Tax Journal, vol 56, pp 259-270.

Esteller-Moré, A. (2004). "Tax Evasion in Interrelated Taxes". Universitat de Barcelona and Institut d'Economia de Barcelona (IEB), Document de treball No 2004/2.

Feld, A. (1995). "Living with the Flat Tax". National Tax Journal, vol 48, pp 603-17.

Gale, W. G. (1999). "The Required Tax Rate in a National Retail Sales Tax". National Tax Journal, vol 52, pp 443-458.

Ginsburg, M. D. (1995). "Life Under a Personal Consumption Tax: Some thoughts on Working, Saving, and Consuming in Nunn-Domenici's World". National Tax Journal, vol 48, pp 585-602.

Guiliani Fonrouge,. S.M. y Navarrine, S.C. (1982). Impuesto de los Ingresos Brutos. Buenos Aires: Ediciones Depalma.

Gordon, R.H. y S.B. Nielsen (1996). "Tax Avoidance and Value-Added vs. Income Taxation in an Open Economy". NBER Working Paper No 5527.

Grubert, H, y T.S. Newlon (1995). "The international Implications of Consumption Tax Proposals". National Tax Journal, vol 48, pp 619-47.

Jarach, D. (1958). Curso superior de derecho tributario. Buenos Aires: Liceo Profesional Cima.

Kobayashi, B.H. (2005). "Not Ready For Prime Time? A Survey of the Economic Literature on Bundling". Law and Economics Working Paper Series No 05-35, George Mason Unviversity School of Law.

La Rosa, R. (1977). Impuesto a los Ingresos Brutos - Actividades Lucrativas. Buenos Aires: Ediciones Nueva Técnica S.R.L. y Compañía Editora Los Cardales S.A.

McLure, C.E. Jr. (1993). "Economic, Administrative, and Political Factores in Choosing a General Consumtion Tax". National Tax Journal, vol 46, pp 345-58.

Míguez, E. (2008). Historia económica de la Argentina: de la Conquista a la crisis de 1930. Buenos Aires: Ed. Sudamericana. 
Ministerio de Economía (2005). "Tributos Vigentes en la República Argentina a Nivel Nacional".

Murray, M. (1997). "Would Tax Evasion and Tax Avoidance Undermine a Nacional Retail Sales Tax?". National Tax Journal, vol 50, pp 167-82.

Paredes, A. (1863). Representación de los Hacendados del Distrito del Apan al Señor prefecto del Mismo sobre la Alcabala del Pulque y Modo de Exigirla. Google Books.

Rezk, E. (2001). "Efectos sobre el Bienestar de la Tributación Directa sobre el Consumo: Una Aplicación al caso Subnacional Argentino". Sexto Seminario Internacional sobre Federalismo Fiscal. Buenos Aires, Argentina.

Rosa, J.M. (1958). Del Municipio Indiano a la Provincia Argentina 1850-1852. Formación Social y Política de las Provincias Argentinas.

Slemrod, J. (1998). "A General Model of the Behavioral Response to Taxation". NBER Working Paper No 6582.

Slemrod, J. y S. Yitzhaki S. (2000). "Tax Avoidance, Evasion, and Administration". NBER Working Paper No 7476.

Smith, A. (1776). La Riqueza de las Naciones. Buenos Aires: Ediciones Orbis S.A (ed 1983).

Spengler, J.J. (1950). "Vertical Integration and Antitrust Policy". The Journal of Political Economy, vol 58, pp 347-352.

Stigler, G. (1963). "United States v. Loew's Inc.: A note on block booking”. Supreme Court Review, vol 152, pp 152-157.

Stiglitz, J. (1985). "The General Theory of Tax Avoidance". NBER Working Paper No 1868.

Waud, R.N. (1986). "Tax Aversion, Deficits and the Tax Rate-Tax Revenue Relationship". NBER Working Paper No 1533. 